Dr. LUIS F. LELOIR

\title{
Suprarrenales y Metabolismo de los
}

\section{Hidratos de Carbono}


UNIVERSIDAD NACIONAL DE BUENOS AIRES

FACULTAD DE CIENCIAS MEDICAS

\title{
INSTITUTO DE INVESTIGACIONE \\ SUPRARRENALES \\ $\mathrm{Y}$ \\ METABOLISMO \\ DE LOS \\ HIDRATOS DE CARBONO}

\author{
TESIS DE DOCTORADO EN MEDICINA \\ POR
}

\section{LUIS F. LELOIR}

Prof. Dr. BERNARDO A. HOUSSAY

FUNDACION INSTITUTO LELOIR

BIBLIOTECA

DR. CARLOS E. CARDINI

ST TES $1934 \mathrm{~L}$

INV 001106 
Teris

A mi Madre 
Al Dr. Bernardo A. Houssay

Profesor de Fisiologia

Director del Instituto de Fisiología

19:2

Al Dr. Carlos Bonorino Udaondo

Profesor de Semiología y Clinica Propedéutica 


\section{INDICE GENERAL DE MATERIAS}

Introducción

\section{CAPITULO I}

\section{La glucemia en la insuficiencia suprarrenal}

La glucemia en la insuficiencia suprarrenal total ............ 15

Perro. (Investigaciones personales.) ................ 16

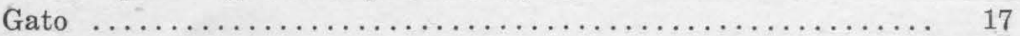

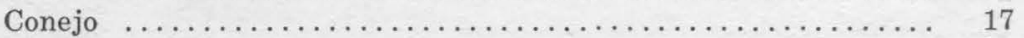

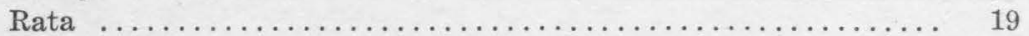

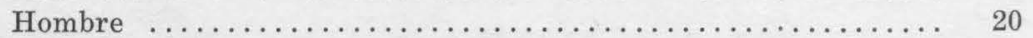

La glucemia en los animales privados de médula suprarrenal ..... 21

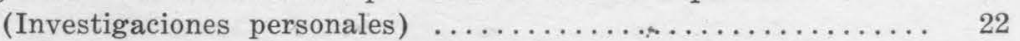

La glucemia en los animales con suprarrenales desnervadas ...... 23

(Investigaciones personales) $\ldots \ldots \ldots \ldots \ldots \ldots \ldots \ldots \ldots \ldots \ldots 23$

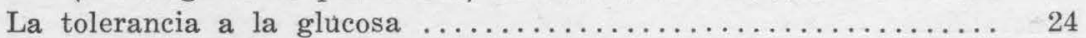

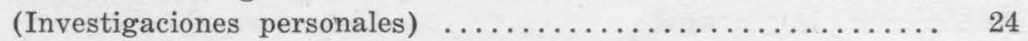

Acción de la glucosa en la insuficiencia suprarrenal ........... 25

\section{CAPITULO II}

\section{Variaciones del glucógeno hepático, muscular y de otros componentes musculares}

La cantidad de glucógeno del hígado y músculos en reposo ...... 27

Perro (Investigaciones personales) $\ldots \ldots \ldots \ldots \ldots \ldots \ldots \ldots \ldots .27$

Gato ......................................... 29

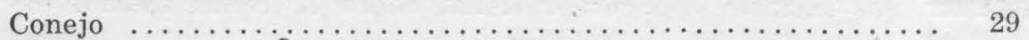

Rata .................................... 29

La formación de glucógeno por inyección de azúcares. (Investiga-

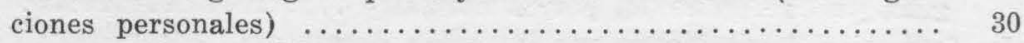

La recomposición del glucógeno muscular después de la fatiga .. 31

El ácido láctico del músculo ........................ 32

Las fracciones fosforadas del músculo .................. 33

\section{CAPITULO III}

\section{Acción de la adrenalina}

Acción hiperglucemiante de la adrenalina $\ldots \ldots \ldots \ldots \ldots \ldots \ldots \ldots . \ldots \ldots$

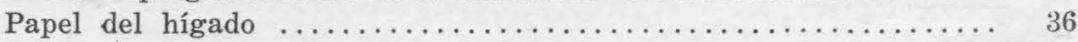

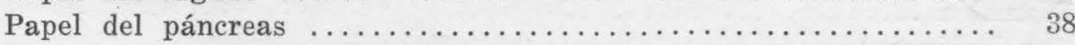




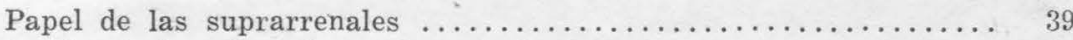

Acción de la adrenalina sobre el glucógeno muscular ......... 40

Acción de la adrenalina sobre el glucógeno hepático ........... 42

Acción de la adrenalina sobre el ácido láctico ............... 43

Influencia de la adrenalina sobre el consumo de azúcar ........ 44

Acción de la adrenalina sobre la diferencia de glucemia arterio-

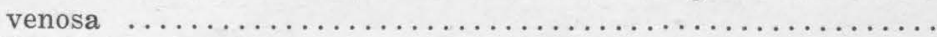

Acción de la adrenalina sobre consumo de oxígeno y cociente res-

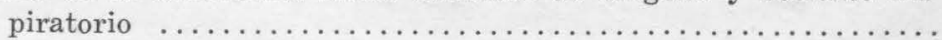

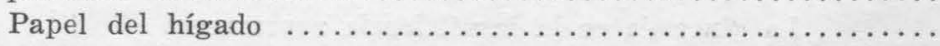

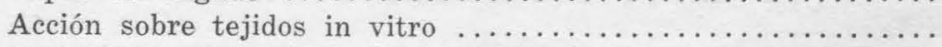

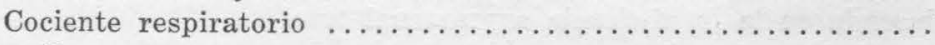

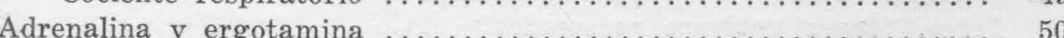

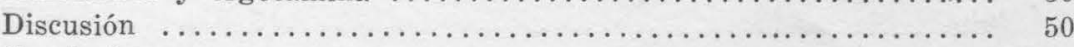

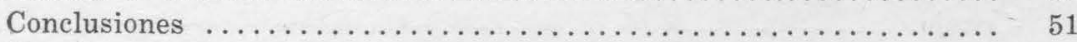

\section{CAPITULO IV}

\section{Acción del extracto córticosuprarrenal}

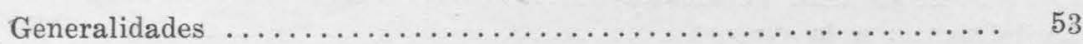

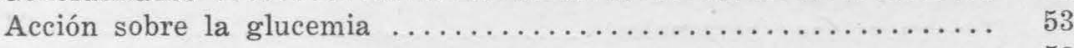

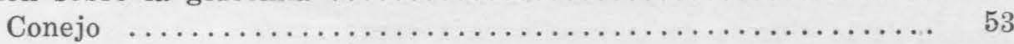

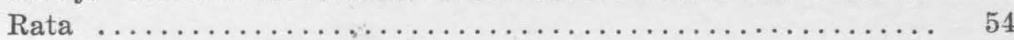

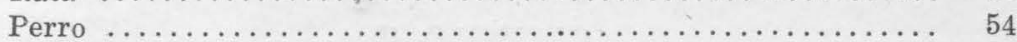

Acción sobre el glucógeno muscular y hepático en ratas ......... 55

La recomposición del glucógeno muscular después de la fatiga... 58

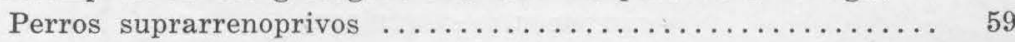

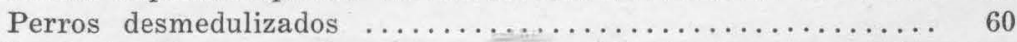

Acción de la glucosa en la recomposición del glucógeno muscular

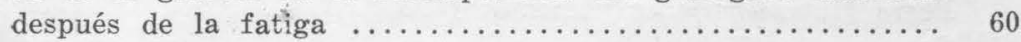

Acción del extracto córticosuprarrenal sobre la recomposición de glucógeno después de la fatiga $\ldots \ldots \ldots \ldots \ldots \ldots \ldots \ldots \ldots \ldots \ldots \ldots \ldots \ldots \ldots \ldots \ldots \ldots \ldots \ldots$

Acción del extracto córticosuprarrenal sobre la reconstitución del

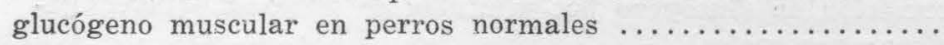

La formación de glucógeno por inyección de glucosa $\ldots \ldots \ldots \ldots$

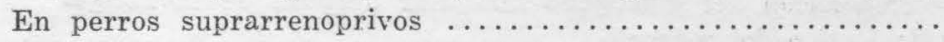
En perros suprarrenoprivos inyectados con extracto...$\ldots \ldots$ En perros suprarrenoprivos inyectados con insulina ..........

Influencia del extracto córticosuprarrenal en los perros pancreato-

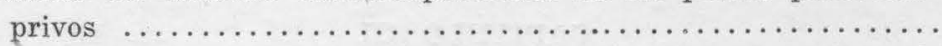

Influencia del extracto córticosuprarrenal sobre la tolerancia a la

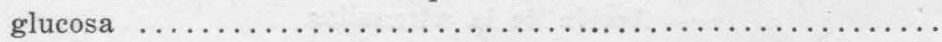

Acción del extracto córticosuprarrenal en un perro parcialmente

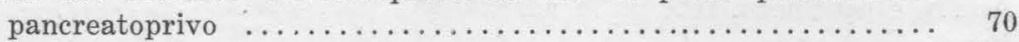

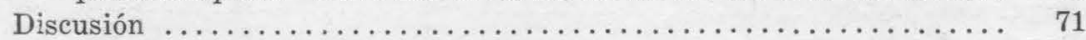

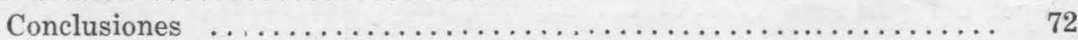




\section{CAPITULO V}

Papel de las suprarrenales en la producción de diversas hiperglucemias y glucosurias

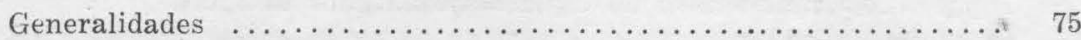

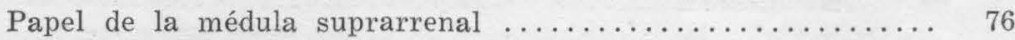

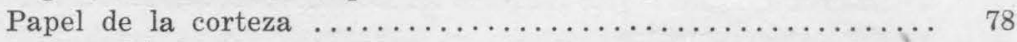

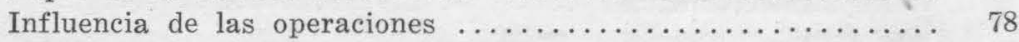

Hiperglucemias y glucosurias provocadas por influencias fisiológicas $\quad 79$

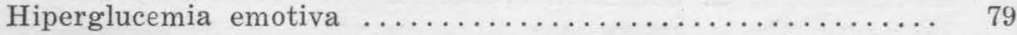

Hiperglucemia por contención $\ldots \ldots \ldots \ldots \ldots \ldots \ldots \ldots \ldots \ldots . \quad 80$

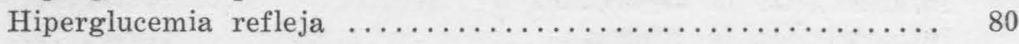

Hiperglucemia por excitación del esplácnico $\ldots \ldots \ldots \ldots \ldots . .61$

Hiperglucemia asfíctica $\ldots \ldots \ldots \ldots \ldots \ldots \ldots \ldots \ldots \ldots \ldots \ldots \ldots \ldots \ldots \ldots \ldots$

Choque anafiláctico y peptona $\ldots \ldots \ldots \ldots \ldots \ldots \ldots \ldots \ldots \ldots . \ldots \ldots$

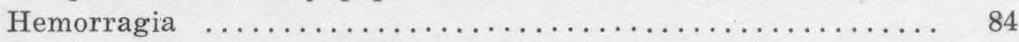

Hiperglucemia por picadura del IV ventrículo ........... 85

Hiperglucemia producida por el frío ............... 87

Hiperglucemias y glucosurias provocadas por diversos agentes fár-

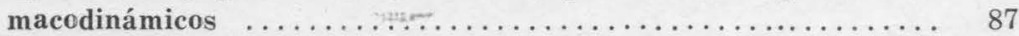

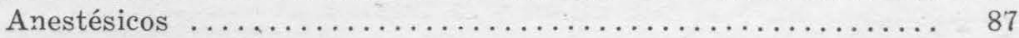

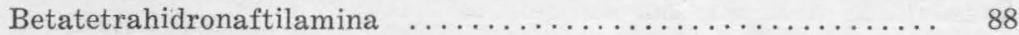

Betadimetilteluronio ........................... 88

Cloretona .................................. 88

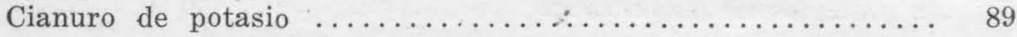

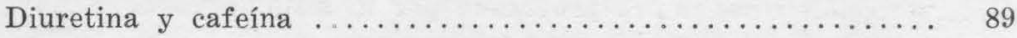

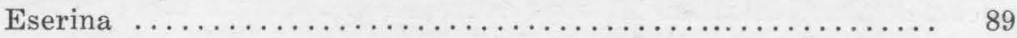

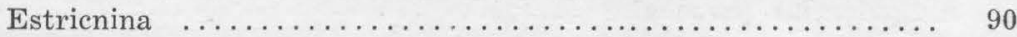

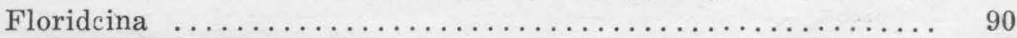

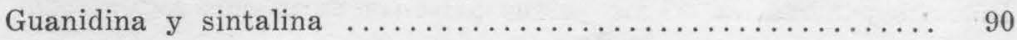

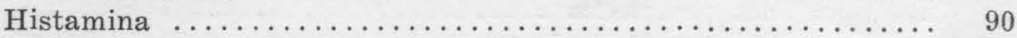

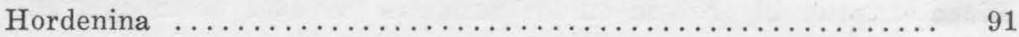

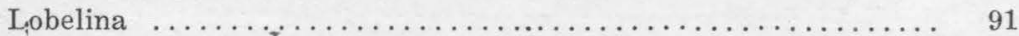

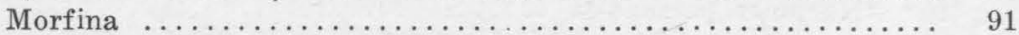

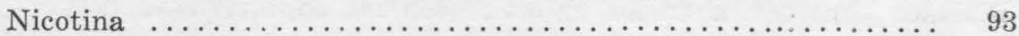

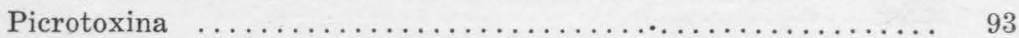

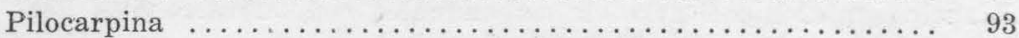

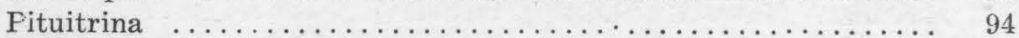

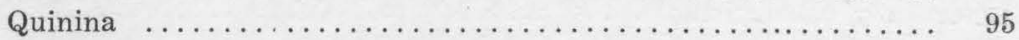

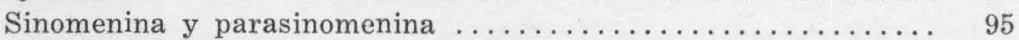

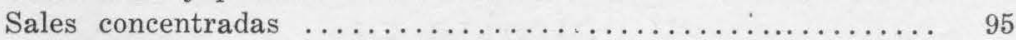

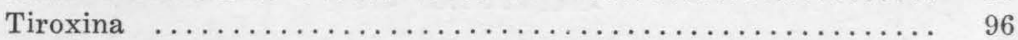

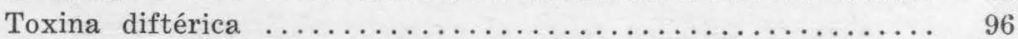

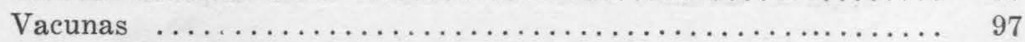

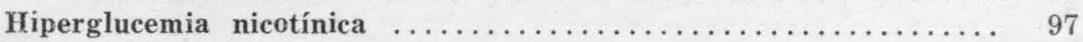

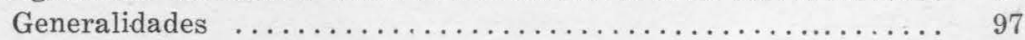

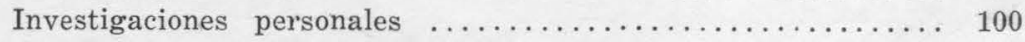


Hiperglucemia nicotínica en esplacnicotomizados y suprarreno-

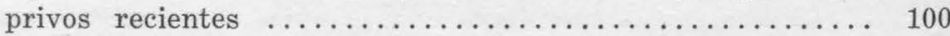

Suprarrenoprivos ......................... 102

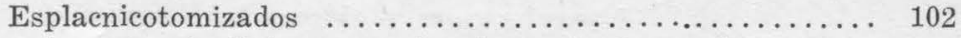

Hiperglucemia nicotínica en esplacnicotomizados antiguos y en

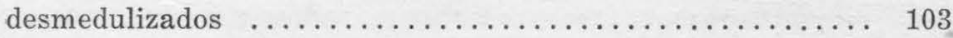

Desmedulizados ............................. 103

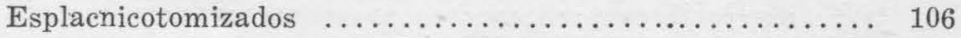

Anastomosis suprarrenoyugular $\ldots \ldots \ldots \ldots \ldots \ldots \ldots \ldots \ldots \ldots$

Mecanismo de la inhibición operatoria ............... 108

Influencia de la anestesia ....................... 109

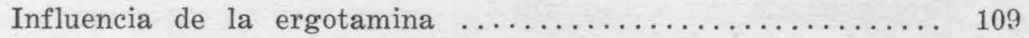

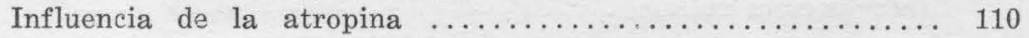

Discusión ................................. 111

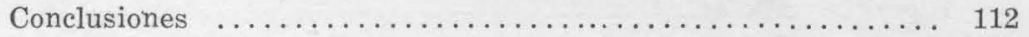

\section{CAPITULO VI}

\section{Suprarrenales y diabetes}

Antagonismo entre la adrenalina y la insulina $\ldots \ldots \ldots \ldots \ldots \ldots . . \ldots 13$

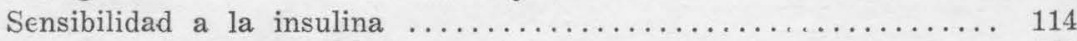

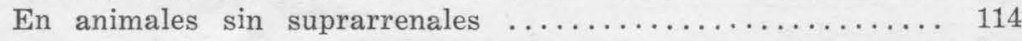

En animales con suprarrenales desnervadas $\ldots \ldots \ldots \ldots \ldots \ldots, 114$

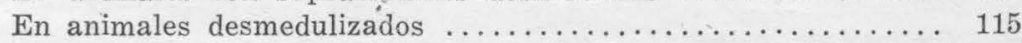

Hipersecreción adrenalínica provocada por la insulina ......... 115

Diebates pancreática en los suprarrenopricos .............. 117

Experiencias personales ......................... 119

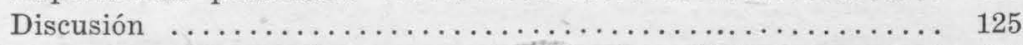

Diabetes pancreática en los perros privados de médula suprarrenal 125

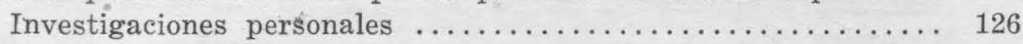

Diabetes anterohipofisaria en los animales privados de médula su-

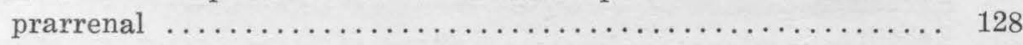

Investigaciones personales $\ldots \ldots \ldots \ldots \ldots \ldots \ldots \ldots \ldots \ldots \ldots \ldots$

Diabetes pancreática en los animales con las suprarrenales desner-

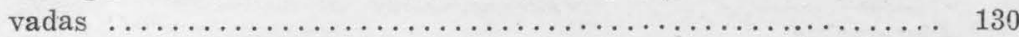

Diabetes anterohipofisaria en los animales con suprarrenales desnervadas. (Investigaciones personales) $\ldots \ldots \ldots \ldots \ldots \ldots \ldots, 131$

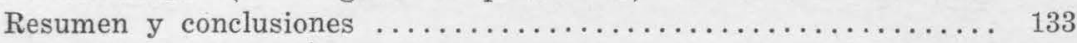

CAPITULO VII

Algunos estudios sobre el extracto córticosuprarrenal

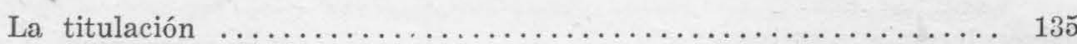

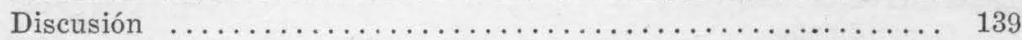

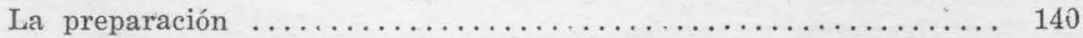


Tentativa de descubrir su presencia en la sangre de la vena supra-

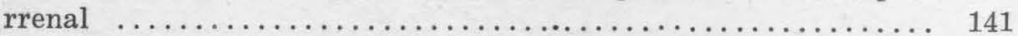

Acción sobre las glándulas endócrinas .................. 142

Técnica y animales empleados $\ldots \ldots \ldots \ldots \ldots \ldots \ldots \ldots \ldots \ldots . \ldots \ldots$

Resumen ............................... 148

Resumen y conclusiones $\ldots \ldots \ldots \ldots \ldots \ldots \ldots \ldots \ldots \ldots \ldots \ldots \ldots \ldots$

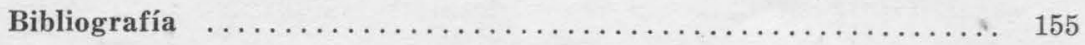




\section{IN T RODUCCION}

El papel de las suprarrenales, como factor regulador del metabolismo de los hidratos de carbono, ha sido objeto de numerosos estudios. Primeramente se fijó la atención sobre la parte medular. Después que Blum descubrió la acción glucosúrica de los extractos suprarrenales, que más tarde pudo atribuirse a la presencia de adrenalina, se llegó a considerar, con Zuelzer, que la glucemia se mantenía normal gracias a las influencias antagónicas del páncreas y de las suprarrenales.

Pero cuando Houssay y Lewis y, después, Stewart y Rogoff demostraron que la extirpación completa del tejido medular suprarrenal era compatible con la vida, la corteza pasó a ocupar el primer plano.

Otro de los descubrimientos más importantes consistió en el aislamiento de la hormona cortical por Swingle y Pfiffner, y Hartman y colaboradores. Con este nuevo elemento de estudio se han intensificado las investigaciones sobre la relación entre corteza suprarrenal y metabolismo hidrocarbonado, llegando Britton y Silvette a afirmar que estas glándulas juegan en dicho metabolismo un papel tan importante como el hígado o el páncreas.

Hemos estudiado el papel no sólo de la médula sino también el de la corteza, comprobando que ambas tienen su papel en el metabolismo hidrocarbonado. La médula interviene en ciertas reacciones hiperglucémicas, ya sea como parte del sistema simpático - adrenal, ya actuando independientemente de éste cuando es excitada por ciertos agentes farmacológicos (nicotina, p. ej.). La corteza, por otra parte, interviene en el mantenimiento de la glucemia; pero su importancia mayor se manifiesta en la formación y resíntesis del glucógeno.

Para nuestras investigaciones hemos contado con la sabia dirección y la valiosa ayuda del profesor Houssay, así como con la eficaz colaboración del personal del Instituto de Fisiología, a quienes testimoniamos nuestra más sincera gratitud. 


\section{CAPITULO I}

\section{LA GLUCEMIA EN LA INSUFICIENCIA SUPRARRENAL}

La glucemia en la insuficiencia suprarrenal total, p. 15 - Perro (Investigaciones personales), p. 16 - Gato, p. 17 - Conejo, p. 17 Rata, p. 19 - Hombre, p. 20 - La glucemia en los animales privados de médula suprarrenal (Investig. personales), p. 21 - La glucemia en los animales con suprarrenales desnervados (Investig. personales), p. 23 - La tolerancia a la glucosa en la insuficiencia suprarrenal. (Investig. person.), p. 24 - Acción de la glucosa en la insuficiencia suprarrenal, p. 25.

\section{LA GLUCEMIA EN LA INSUFICIENCIA SUPRARRENAL TOTAL}

Hay un acuerdo casi completo entre todos los investigadores en lo que se refiere-a la manera de comportarse la glucemia en los estados de insuficiencia suprarrenal. Han observado todos que la glucemia desciende o tiene tendencia a descender. Las divergencias aparecen cuando se trata de precisar el valor y el momento en que aparece esta caída; pues, mientras unos ven en ella el síntoma fundamental y característico del hiposurrenalismo, otros creen que se trata sólo de un fenómeno accesorio y que aparece sólo a veces y únicamente en los momentos finales.

Descubierta la acción hiperglucemiante de la adrenalina, se pensó que el trastorno en cuestión obedecía a la falta de esta substancia; pero se ha comprobado que la extirpación de toda la substancia medular no modificaba en nada el nivel glucémico, y entonces se atribuyó la hipoglucemia a la insuficiencia cortical.

Entre las numerosísimas investigaciones experimentales que se han realizado debemos distinguir aquellas que se refieren al papel de la corteza y las que se refieren al de la médula. Por consiguiente, consideraremos el comportamiento de la glucemia: primero después de la extirpación de la glándula íntegra, y luego después de la extirpación de la substancia medular solamente.

La extirpación de las suprarrenales tiene en las distintas especies de animales de laboratorio consecuencias algo dife- 
rentes: mientras en el gato y el perro lleva a la muerte en breve plazo (3-6 días), las ratas, que están dotadas de gran cantidad de glándulas accesorias, sobreviven casi todas a la extirpación capsular, y la insuficiencia es en ellas sólo pasajera y poco marcada. Un lugar intermediario vendría a ocupar el conejo, que sobrevive en un 20 a $25 \%$ de los casos.

Dada esta diferencia para cada especie de animales, referiremos por separado los resultados obtenidos en cada una.

Perro. - En los primeros trabajos, las supervivencias eran, en general, cortas. Porges (1908-9-10) comprobó que, después de la extirpación de las suprarrenales, se producía una disminución progresiva de la glucemia, que podía llegar a menos de la mitad de la cifra normal (hasta $0.32 \mathrm{o} / \mathrm{oo}$ ).

Bierry y Malloizel (1908), en cinco casos de ablación bilateral, observaron un descenso rápido de la glucemia, que comenzó ya a la hora y pudo alcanzar, a las $2-3$ horas, al quinto o a la mitad del tenor inicial.

Gautrelet y Thomas (1908), Bornstein y Holm (1923), Bornstein y Horneman (1923), señalan un descenso progresivo de la glucemia después de la decapsulación; pero sus perros vivieron pocas horas. Según los mismos autores, la hipoglucemia se debe a la hiperpnea, pudiéndosela producir en animales normales por intensa ventilación artificial. Desgraciadamente, la escasa supervivencia de sus perros resta valor a sus conclusiones.

Las experiencias que citamos a continuación fueron realizadas en animales de supervivencia más larga, y tienen, por lo tanto, un valor más apreciable en cuanto permiten descartar la influencia del shock operatorio.

Lewis y Magenta (1924) encuentran glucemias normales a las 2 - 3 horas; a las 4 horas, Houssay y Lewis hallan valores normales en 8 casos, e inferiores a 0.60 por mil en cuatro.

Lewis (1924) observa que la glucemia sube 1 - 2 horas después de la operación; que se normaliza hacia las 5 - 8 horas, pero ya con tendencia al descenso. Pocas horas antes de la muerte, hay cifras muy bajas: $0.67-0.47$, y aún $0.20-0.30$ por mil en los últimos momentos. Más o menos lo mismo observó Pico Estrada (1926). 
Banting y Gairns (1926) insisten sobre la importancia del shock operatorio en la génesis de la hipoglucemia, pero también observan una marcada caída premortal en animales que viven 100 a 200 horas. Ellos están de acuerdo con Stewart y Rogoff (1926) en que la glucemia se modifica poco hasta los momentos finales, en los cuales baja, aunque no en todos los casos.

Houssay piensa que la hipoglucemia es un factor importante de agravación, pero no la causa de la muerte, pues los animales mueren con los síntomas habituales de insuficiencia suprarrenal, aunque se haya normalizado la glucemia por inyección glucosa. También Swingle (1927) cree que la hipoglucemia puede intervenir en la determinación de la muerte.

Las cifras normales halladas por Sato, Kaiwa y Wada (1931), y otros, obedecen a que han hecho sus observaciones pocas horas después de la operación, antes de que se hubiese desarrollado una acentuada-insuficiencia suprarrenal.

Investigaciones personales. - Hemos reunido numerosos datos de glucemias de perros, suprarrenoprivos. Pocos de ellos fueron seguidos hasta los momentos finales, porque fueron sacrificados para otros experimentas. Sin embargo, algunos presentaban ya ciertos síntomas de insuficiencia suprarrenal. Los resultados están indicados en el cuadro $1^{\circ}$.

Gato. - Barlow y Ellis (1924) estudiaron la glucemia de los gatos suprarrenalectomizados y hallaron una hiperglucemia que duraba dos a tres horas después de la operación, y luego hipoglucemia que comenzó a las 15 - 24 horas y que se acentuó progresivamente hasta la muerte.

Swingle (1927) observó que la glucemia cae lentamente desde las 20 horas después de la operación hasta la muerte. La hipoglucemia sería la causa que provoca la astenia, pues ambos síntomas varían paralelamente, pero no sería la causa de la muerte, puesto que ésta no se evita con la inyección de glucosa. Corroboran estas experiencias las de Hartman y sus colaboradores (1927) y las de Britton y Silvette (1932).

Conejo. - En esta especie, debido a la presencia de glándulas accesorias que se hipertrofian en los que sobreviven, no aparece una insuficiencia suprarrenal marcada, y, por lo tanto, ella no se presta muy bien para estas investigaciones. 
- Cuadro I

Glucemia de perros suprarrenoprivos (glueemia en gr. o/oo) (Mérodo de Hagedorn y Jensen)

\begin{tabular}{|c|c|c|c|c|c|}
\hline $\begin{array}{l}\text { Námero } \\
\text { del perro }\end{array}$ & Antes & 1-4 horas & 4-8 horas & 24 horas & 48 horas \\
\hline $\begin{array}{r}1 \\
2 \\
5 \\
6 \\
7 \\
32 \\
35 \\
37 \\
48 \\
55 \\
56 \\
58 \\
66 \\
67 \\
68 \\
69 \\
70 \\
102 \\
104 \\
108 \\
109 \\
113 \\
127 \\
128\end{array}$ & $\begin{array}{l}1.02 \\
1.10 \\
1.24 \\
1.17 \\
0.93 \\
1.17 \\
0.89 \\
1.08\end{array}$ & $\begin{array}{l}1.27 \\
0.99 \\
1.10\end{array}$ & $\begin{array}{l}1.28 \\
1.03 \\
0.99 \\
0.74 \\
\\
\\
\\
0.94 \\
1.03\end{array}$ & $\begin{array}{l}1.24 \\
0.65 \\
1.00 \\
0.91 \\
0.94 \\
0.98 \\
1.03 \\
\\
0.89 \\
0.96 \\
0.74\end{array}$ & $\begin{array}{l}0.95 \\
\\
1.30 \\
0.68 \\
0.97 \\
0.56 \\
\\
0.82 \\
1.10 \\
0.93 \\
0.62 \\
0.62\end{array}$ \\
\hline
\end{tabular}

T. M.

1.03

0.90

0.87

Frank e Isaac (1911) observaron que la hipoglucemia no es la regla. En 4 casos comprobaron existencia de glucemia normal hasta las 69 horas.

La hipoglucemia observada por Bornstein y Holm (1923) puede atribuirse al shock y no a la insuficiencia suprarrenal.

Kisch (1924) observó hiperglucemia durante las 3 horas que siguieron a la ablación de la segunda suprarrenal, y, a partir de las 5 horas, una caída progresiva que alcanzó a durar hasta 40 horas (en un caso llegó a 0.30 por mil en un conejo que se repuso). Después de ésto, los sobrevivientes tuvieron glucemias normales. La hipoglucemia observada pareció deberse a la falta de función suprarrenal y no al traumatismo operatorio, pues faltó en los testigos operados. 
Sundberg (1925) también observó, tras una fugaz hiperglucemia post-operatoria, hipoglucemia durante un día y después, vuelta a la normal. También Mima (1927) observó hipoglucemia.

Mucho más numerosas son las observaciones en que se han hallado glucemias normales: Stewart y Rogoff (1917-18), Catan, Houssay y Mazzocco (1920), Artundo (1926), Sataké (1926), Hirayama (1926), etc.

Ohguri (1931) ha estudiado la glucemia en conejos a los cuales extirpó, además đe las dos suprarrenales, las glándulas accesorias abdominales y del epidídimo, y ha encontrado glucemias bajas en los que representaban síntomas de gravedad. En los aparentemente sanos, la glucemia era normal. La caída premortal la observó en casi todos.

Por consiguiente, los conejos sin glándulas accesorias se comportan de una manera muy parecida a la de los perros.

Rata. - Es importante tener en cuenta que la suprarrenalectomía en la rata puede dar resultados muy variables.

Según la experiencia de numerosos autores, las ratas suprarrenoprivas mueren, en su gran mayoría, poco después de la operación. En cambio, en este Instituto, donde se ha operado gran cantidad de ratas, Lewis (1920), Lewis y Torino (1926), Marval (1926), Artundo (1926)), Crivellari (1926), Houssay y Marenzi (1931), Lascano González (1920), etc., se ha llegado a conclusiones completamente opuestas. La causa de esta discrepancia no nos es conocida. Sin embargo, se puede descartar la distinta técnica operatoria como causa de mayor o menor supervivencia; pues hemos observado que, en lotes de ratas criadas fuera del Instituto, ha habido mucho mayor mortalidad, habiendo empleado exactamente el mismo procedimiento de suprarrenalectomía. Es posible que intervenga en ello algún factor alimenticio.

El comportamiento variable de los animales después de la operación se manifiesta también en lo que se refiere a la glucemia. Kuriyama (1918) estudia la glucemia en los días que siguen a la suprarrenalectomía y encuentra valores normales aunque algo inferiores que en los testigos. También han hallado glucemias normales Catan, Houssay y Mazzocco (1920), entre los dos y veintiseis días. Sin embargo, en los primeros 
días hallaron, aunque sólo en algunas, un ligero descenso. Artundo (1926) encuentra un ligerísimo descenso a los 3 días (0.813 comparado con 0.862 que dieron los testigos que sufrieron la misma operación, pero sin la extirpación de las suprarrenales) con elevación progresiva $(0.822)$ a los 8 días y vuelta a la normal a las dos semanas.

La hipoglucemia ha sido observada además por Cori y Cori (1927), (Suprarrenoprivas en ayunas: 0.53 a 0.79 ; testigos: 0.99), Wyman y Walker (1929) y por Lumley Hills y Nice (1930 - término medio: normaleŝ, 1.45 ; suprarrenoprivas, 1.27).

Hombre. - Han sido muy estudiadas las variaciones de la glucemia en los distintos tipos de insûficiencia suprarrenal. En la enfermedad de Addison, fué Porges (1909 - 10) el primero que llamó la atención sobre el descenso de la glucemia. De sus tres casos, uno llegó a bajar hasta 0.32 por mil. Esta observación ha recibido desde entonces numerosas confirmaciones; pero también son numerosos los casos en los cuales se han encontrado cifras normales o cercanas al límite inferior de la normalidad.

El problema ha sido bien estudiado por Marañón (1929), quien, después de haber observado 104 casos de enfermedad de Addison, declara que la hipoglucemia es más constante en ella que en cualquier otra enfermedad y que es tanto más marcada cuanto más grave es el caso y más avanzado está el proceso.

En cambio, según Giménez Díaz y Mansera (1928), sólo habría hipoglucemia en una minoría de los casos.

Hemos colocado en un cuadro algunas de las numerosísimas observaciones que se han efectuado. (Cuadro $2^{\circ}$ ).

En estas observaciones se puede notar que la glucemia ha sido inferior a 0.80 en el $56,2 \%$; entre 0.80 y 1.20 en el $34,3 \%$; y mayor de 1.20 en el $9.3 \%$ de los casos.

Por supuesto que todos estos dosajes de glucemia no han sįdo efectuados con el mismo método. Muchos de ellos lo han sido con el antiguo método de Folin y Wu, que da cifras más altas que otros más exactos. Sin embargo, estos datos nos ayudan a formarnos una idea del fenómeno. 
CUADRO $2^{\circ}$

Glucemia en la enfermedad de Addison

\begin{tabular}{|c|c|c|}
\hline 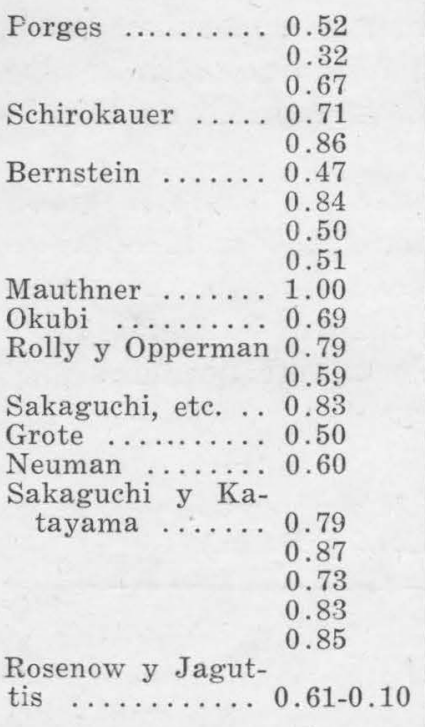 & 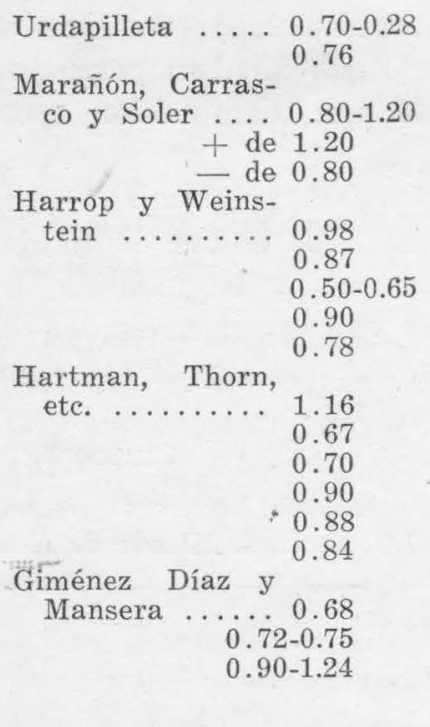 & $\begin{array}{l}(8 \text { casos }) \\
(2 \text { casos }) \\
(11 \text { casos })\end{array}$ \\
\hline
\end{tabular}

Se ha observado, por otra parte, que la glucemia baja en los momentos en que la enfermedad se agrava (Marañón). Además, muchas de las crisis de debilidad y comatosas, comunes en estos enfermos, son debidas a la hipoglucemia y mejoran rápidamente con la inyección de dextrosa (Harrop y Weinstein, 1925). Sin embargo, la caída de la glucemia no es la única causa de estos episodios graves de los addisonianos; pero es un factor importante de agravación y que debe tenerse en cuenta.

\section{LA GLUCEMIA EN LOS ANIMALES PRIVADOS DE LA MÉDULA SUPRARRENAL}

Houssay y Lewis (1923) han comprobado glucemias normales en 4 perros, a los que habían extirpado, en dos tiempos, la médula suprarrenal izquierda y toda la glándula derecha Los mismos resultados obtuvieron Lewis y Magenta (1924) y Zwemer, Smith y Shirley (1930). 
En cambio, Houssay y Molinelli (1926, exper. inédito), en 11 perros operados de un mes antes, encontraron valores un poco bajos en ayunas, (Término medio: 0.74 por mil). Pero es probable que más tarde se normalizarían, como lo vieron Houssay y Lewis (1923) en perros con más supervivencia.

Böggild (1923 - 25), en perros con tejido cromafínico disminuído, halló una disminución apenas perceptible de la glucemia.

Investigaciones personales. - Hemos estudiado la glucemia en perros a los cuales se había extirpado la médula suprarrenal izquierda y la glándula derecha íntegra. Nuestras observaciones van consignadas en el Cuadro $3^{\circ}$, donde salvo en un caso se encuentran cifras completamente normales.

\section{CUADRO $3^{\circ}$}

Glucemia de los perros sin médula suprarrenal. (Grs. por mil. Método de Hagedorn y Jensen)

\begin{tabular}{|c|c|c|c|c|c|c|c|c|c|}
\hline $\mathrm{N}^{9}$ & 1 (1) & Glucemia & a los & 23 & días & de la & operación & $\ldots \ldots \ldots \ldots$ & 0.97 \\
\hline & & " & $"$ & 37 & $"$ & $"$ & , & $\ldots \ldots \ldots \ldots$ & 0.81 \\
\hline \multirow{2}{*}{$N^{o}$} & 5 & $"$ & $"$ & 45 & $"$ & " & $"$ & …… & 0.85 \\
\hline & $b$ & $"$ & $"$ & $\begin{array}{r}5 \\
12\end{array}$ & $"$ & $"$ & " & $\ldots \ldots \ldots \ldots$ & $\begin{array}{l}0.89 \\
1.08\end{array}$ \\
\hline \multirow[t]{2}{*}{$\mathrm{N}^{9}$} & 6 & ", & ", & 5 & $"$ & ", & $"$ & … & 0.90 \\
\hline & & $"$ & $"$ & 12 & $"$ & $"$ & $"$ & .......... & 1.01 \\
\hline \multirow[t]{2}{*}{$N^{0}$} & 17 & $"$ & $"$ & 19 & $"$ & " & " & $\ldots \ldots \ldots \ldots$ & 0.87 \\
\hline & & $"$ & $"$ & $\begin{array}{l}37 \\
97\end{array}$ & $"$ & " & $"$ & $\ldots \ldots \ldots$ & $\begin{array}{l}1.02 \\
1.21\end{array}$ \\
\hline \multirow[t]{2}{*}{$\mathrm{N}^{i}$} & 31 & $"$ & " & 9 & " & $"$ & $"$ & $\ldots \ldots \ldots \ldots$ & 0.84 \\
\hline & & " & ", & 60 & " & $"$ & $n$ & $\ldots \ldots \ldots \ldots$ & 1.07 \\
\hline \multirow[t]{2}{*}{$N^{\circ}$} & 93 & " & $"$ & 42 & " & $"$ & $"$ & …...... & 1.05 \\
\hline & & $"$ & ," & $\begin{array}{l}79 \\
87\end{array}$ & $"$ & $"$ & $"$ & $\cdots \cdots$ & $\begin{array}{l}0.97 \\
0.91\end{array}$ \\
\hline \multirow[t]{2}{*}{$N^{0}$} & 99 & " & " & 20 & $"$ & ", & $"$ & $\ldots \ldots \ldots$ & 0.96 \\
\hline & & " & $"$ & 58 & $"$ & " & " & $\ldots \ldots \ldots \ldots$ & 0.94 \\
\hline \multirow[t]{2}{*}{$\mathrm{N}^{0}$} & 111 & $"$ & " & 66 & $"$ & ", & $"$ & …… & 0.60 \\
\hline & & $"$ & $"$ & 25 & $"$ & $"$ & $"$ & 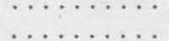 & $\begin{array}{l}0.88 \\
0.80\end{array}$ \\
\hline \multirow[t]{2}{*}{$\mathrm{N}^{o}$} & 116 & " & $"$ & 17 & $"$ & ", & $"$ & $\ldots \ldots \ldots \ldots$ & 1.03 \\
\hline & & , & ", & 25 & $"$ & $"$ & ", & $\ldots \ldots \ldots \ldots$ & 0.78 \\
\hline
\end{tabular}

- Puede concluirse, por lo tanto, que la falta de médula suprarrenal no modifica el nivel glucémico. Solamente en las

(1) Los perros 1,5 y 6 corresponden a experimentos inéditos de Houssay y Molinelli. En 9 de estos perros desmedulizados, la presión arterial descendió 1 a 3 cms. en los primeros 20 a 30 días de la vperación. (Lo mismo observó Biasotti, 1927). El número de pulsaciones no varió en la mayoría de los casos. Expuestos al frío, estos perros mostraron mayor tendencia al descenso de la temperatura que los normales. 
dos o tres primeras semanas, pueden hallarse cifras un poco bajas; pero esto podría ser causado por insuficiencia cortical consecutiva a la operación. Sin embargo, esto no significa que la médula no intervenga en la regulación de la glucemia, puesto que, como veremos más adelante, ella toma parte en numerosas reacciones hiperglucemiantes y en la recuperación de la hipoglucemia insulínica.

\section{LA GLUCEMIA EN LOS ANIMALES CON SUPRARRENALES DESNERVADAS}

La influencia de la desnervación. suprarrenal sobre la glucemia ha sido estudiada por varios investigadores.

Stewart y Rogoff (1922) encuentran glucemias normales en perros y gatos con súprarrenales desnervadas o desmedulizadas y desnervadas. Ciminata (1926) también halla glucemias normales en 4 perros con las suprarrenales desnervadas. Baranow (1928), sacando la suprarrenal derecha y desnervando la izquierda, no encuentra variación de la glucemia.

Unicamente Griffith (1923) observó, en gatos con suprarrenal única y desnervada, una ǵlucemia más baja que la normal.

Investigaciones personales. - Los perros estudiados habían sufrido la sección de los esplácnicos mayores y, además, la extirpación de la cadena simpática lumbar con el objeto de asegurar de esta manera la completa desnervación de las suprarrenales. La media de las glucemias de ocho perros, a las 3 - 5 horas después đe la operación, fué de 0.98 por mil.

Los resultados de las determinaciones efectuadas días después se detallan en el Cuadro $4^{\circ}$.

CUAdro $4^{\circ}$

Glucemias de los perros esplácnicotomizados

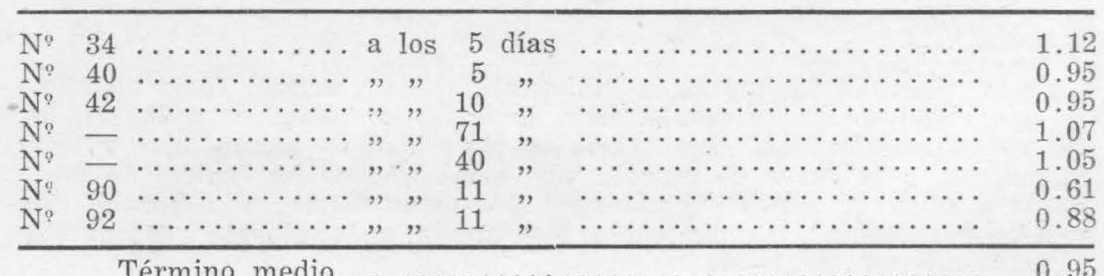

Término medio $\ldots \ldots \ldots \ldots \ldots \ldots \ldots \ldots \ldots \ldots \ldots \ldots \ldots \ldots \ldots, 0.95$ 
La cifra media es, pues, completamente normal. Sólo en un caso hubo una glucemia baja (0.61). Tratándose de un caso aislado, no le asignamos valor alguno.

\section{LA TOLERANCIA A LA GLUCOSA EN LA INSUFICIENCIA SUPRARRENAL (1)}

Las curvas glucémicas halladas en los suprarrenoprivos después de inyectar azúcares son variables. Crowe y Wisloki (1914) y Allen (1923) en perros con extirpación parcial, no observan aumento ni disminución de la tolerancia a la levulosa, galactosa o glucosa. En perros con extirpación completa, Banting y Gairns (1926) observan igual curva glucémica que en los normales, y Pico Estrada (1926) encuentra, en 4 perros, curvas más altas, y, en uno, más baja que en los normales. En la rata suprarrenopriva, Schichi - Schiozawa (1926) y Reid (1932) hallan aumento de la tolerancia. En el conejo, Sundberg (1925), y Sakaguchi, Hayashi y Katayama (1919) la encuentran normal, mientras que Hill y Koehler (1932) la hallan disminuída. En los addisonianos se ha encontrado una tolerancia alta para la glucosa (Eppinger, Falta y Rudinger, 1909; Grote, 1916; Mauthner, 1912; Marañón, 1917). Sin embargo, este último autor observa que falta en gran número de casos.

Investigacioneș personales. - Hemos seguido, durante tres horas, las variaciones glucémicas producidas después de inyectar 2 grs. por $\mathrm{kg}$. de glucosa en perros suprarrenoprivos de 48 horas antes, anestesiados con cloralosa.

En comparación con las curvas que presentaron los perros normales, fué bien manifiesta la disminución de tolerancia de los perros suprarrenoprivos: a la hora, hora y media y tres horas, ninguno de los normales tuvo una glucemia tan alta como la más baja de los suprarrenoprivos (gráfico 3, capítu-

(1) Usamos la expresión "tolerancia a la glucosa" como sinónimo de capacidad de hacer desaparecer de la sangre la glucosa inyectada. En realidad, tolerancia significaría la capacidad de metabolizar y fijar la glucosa, y la curva de glucosa sólo sería uno de los índices de ésta. Pero, a falta de mejor expresión, y por estar consagrada por el uso, seguimos empleando la expresión "tolerancia a la glucosa" con el significado primeramente enunciado. 
lo IV). Por lo tanto, en nuestras experiencias el resultado fué bien claro; hecho que no indicaban los experimentos de los demás investigadores. La diferencia obedece seguramente a que éstos han hecho sus experiencias sin esperar que la insuficiencia suprarrenal sea marcada. También podría haber intervehido la influencia de la cloralosa. En el capítulo IV correspondiente a la acción del extracto córtico - suprarrenal, se hallarán las cifras y los detalles de estos experimentos.

\section{ACCIÓN DE LA GLUCOSA EN LA INSUFICIENCIA SUPRARRENAL}

Porges (1908-9) observó que las inyecciones de glucosa mejoraron a sus perros suprarrenoprivos de corta supervivencia. Stewart y Rogoff (1925) han extirpado las suprarrenales, en dos tiempos, a 36 perros, consiguiendo una supervivencia máxima de 15 días en animales no preñados, mientras que inyectándoles líquido de Ringer con glucosa en las venas, dos de ellos vivieron más de 30 días.

Lewis (1924) practicó inyecciones subcutáneas de glucosa (3 a 5 grs. por hora) a perroś suprarrenoprivos, con lo que consiguió mantener la glucemia elevada; a pesar de ello, los síntomas de astenia y debilidad creciente se instalaron como de costumbre o aún más pronto, llevándolos a la muerte. Llamó la atención la brusquedad con que en dos casos cayó al final la glucemia en el corto plazo de una hora.

En estos experimentos como en los de Pico Estrada (1926) la glucosa hípertónica (al $30 \%$ ) por vía venosa, acortó la supervivencia.

Lo mismo que Lewis, Banting y Gairns (1926), elevando la glucemia de un perro decapsulado mediante inyecciones de glucosa, no evitaron su muerte.

Banting y Gairns (1926), Lewis y Turcatti (1933) y nosotros mismos (Cap. IV) hemos visto producirse la muerte por insuficiencia suprarrenal en perros suprarrenopancreatoprivos con cifras glucémicas altas o normales.

Estos experimentos demuestran que la hipoglucemia no es la causa de la muerte de los perros suprarrenoprivos. Por otra parte, estos animales mueren en hiperglucemia morfínica 
con sólo 3 ctgrs. por kg. de clorhidrato de morfina subcutánea (Houssay y Lewis, 1923). En las ratas suprarrenoprivas, la glucosa no mejora la gran sensibilidad a los efectos tóxicos de la morfina. Todos estos hechos nos hacen creer que la falta de glucosa circulante no es el factor esencial de la insuficiencia suprarrenal. 
CAPITULO II

\section{VARIACIONES DEL GLUCOGENO HEPATICO Y MUSCULAR Y DE OTROS COMPONENTES MUSCULARES}

La cantidad de glucógeno del hígado y músculos en reposo, p. 27 - Perro (Investig. person.), p. 27-Gato, p. 29 - Conejo, p. 29-Rata, p. 29. - La formación de glucógeno por inyección de azúcares, (Investig. person.), p. so - La recomposición de glucógeno muscular después de la fatiga, p. 31 - El ácido láctico del músculo, p. 32 Las fracciones fosforadas del músculo, $p .33$.

\section{LA CANTIDAD DE GLUCÓGENO DEL HígADO Y MÚSCULOS EN REPOSO}

En la insuficiencia suprarrenal, la cantidad de glucógeno hepático tiene tendencia a disminuir, $\mathrm{y}$, en forma análoga a lo que acontece con la glucemia, los valores varian según el tiempo transcurrido desde la suprarrenalectomía y la cantidad de tejido cortical accesorio que tiene el animal estudiado.

En cuanto al glucógeno muscular, también se lo ha encontrado disminuído, pero en menor escala que el hepático. Lo mismo sucede con el glucógeno cardíaco.

Hay que tener en cuenta que en las disminuciones de glucógeno puede influir un importante síntoma de la insuficiencia suprarrenal, que es la anorexia. Lógicamente, si el animal no se alimenta, es imposible que tenga sus reservas de glucógeno normales. Sin embargo, la disminución del glucógeno producido por la extirpación de las suprarrenales es mayor que la que provoca el ayuno solamente.

Perro. - Fué en este animal que se hicieron las primeras investigaciones:

Porges, en 1909 -10, comprobó que, después de la suprarrenalectomía, se producía una disminución progresiva del glucógeno hepático que podía llegar a desaparecer.

Este hecho fué confirmado por Kahn y Starkenstein (1911), quienes hacen notar, sin embargo, que cualquier operación grave puede provocar el mismo trastorno. 
Otros (Bornstein y Holm, Bornstein y Horneman, 1923) atribuyen la disminución del glucógeno a la hiperventilación pulmonar, pues también la encuentran en los perros normales con respiración artificial, pero sus supervivencias fueron demasiado breves, y es probable que haya habido shock.

Lewis (1924), en experimentos inéditos, observó siempre una disminución del glucógeno hepático y muscular, sienđo algo menor la de este último.

Banting y Gairns (1926), en perros con larga supervivencia, observaron en 4 de ellos $0,5 \%$ de glucógeno hepático y en uno que sobrevivió 217 horas había 1,2 gr. \%, cantidad que puede considerarse como normal.

Pico Estrada (1926) comprobó que, al morir los perros, había valores muy bajos de glucógeno hepático. Término medio: 0,024 gr. \%. También encontró reducido el glucógeno muscular $(0,112$ gr. \%) y cardíaco $(0,038$ gr. \%). Estas cifras equivalen respectivamente a un centésimo, un cuarto, y un décimo de lo normal.

Viale y colaboradores (1926-27) observaron marcada disminución del glucógeno hepático y mucho menor la del muscular, el cual no desaparece nunca.

En todas las experiencias se ha observado que la disminución del glucógeno aparece junto con los demás síntomas de insuficiencia y que es tanto más acentuada cuanto más marcados son éstos.

Investigaciones personales. - Hemos dosado los glucógenos muscular y hepático en perros suprarrenoprivos de 24 y 48 horas, operados en uno o dos tiempos. El método empleado fué el de Pflüger, dosando el azúcar final por el método de Bertrand. (Cuadro $5^{\circ}$ ).

Las cifras halladas en perros normales, como término medio, del glucógeno de los tres músculos de una pata han sido los siguientes: (mgs. por 100 grs. de músculo), 247, 271, 310, $461,760,311,508,560,613,732,912,389,589,641,666,685$, $575,374,314,403,473,293$. El término medio de estas cifras es: $504 \mathrm{mgs}$. El término medio de glucógeno muscular de los 4 perros suprarrenoprivos de 24 horas es de 399 y de 481 para los suprarrenoprivos de 48 horas. Como se ve, los términos medios son apenas inferiores a los de los perros normales, y las variaciones son bastante grandes. 
CUADRO $5^{\circ}$

Glucógeno en mgrs. por 100 grs. de músculo fresco.

\begin{tabular}{|c|c|c|c|c|c|c|c|c|c|c|c|c|}
\hline N.o & $\begin{array}{l}\text { Peso } \\
\text { kg8. }\end{array}$ & $\begin{array}{l}\text { Tiempo } \\
\text { de } \\
\text { operado } \\
\text { hs. }\end{array}$ & Hígado & $\begin{array}{c}\text { Tibial } \\
\text { ante- } \\
\text { rior }\end{array}$ & $\begin{array}{c}\text { Extensor } \\
\text { común }\end{array}$ & Gemelo & $\begin{array}{c}\text { Térmi- } \\
\text { no } \\
\text { medio }\end{array}$ & $\begin{array}{c}\text { Tibial } \\
\text { ante- } \\
\text { rior }\end{array}$ & $\begin{array}{c}\text { Extensor } \\
\text { común }\end{array}$ & Gemelo & $\begin{array}{c}\text { Térmi- } \\
\text { no } \\
\text { medio }\end{array}$ & Glucemia \\
\hline 1 & 12.1 & 24 & & 375 & 485 & 302 & 387 & 260 & 307 & 399 & 328 & 1.03 \\
\hline 2 & 11.0 & 24 & & 209 & 296 & 367 & 291 & 320 & 327 & 281 & 309 & \\
\hline 3 & 9.0 & 24 & & 615 & 439 & 500 & 518 & 390 & 484 & 469 & 448 & \\
\hline 4 & 14.0 & 48 & & 393 & 380 & 501 & 408 & 509 & 413 & 419 & 447 & 0.95 \\
\hline 5 & 10.2 & 48 & & 298 & 220 & 314 & 277 & 300 & 255 & 301 & 285 & \\
\hline $10 z$ & & 48 & 164 & 579 & 625 & 409 & 537 & & & & , & 0.70 \\
\hline 104 & & $\$ 8$ & 185 & 325 & 706 & 400 & 477 & & & & & 0.87 \\
\hline 106 & 8.1 & 48 & 92 & 471 & 400 & 362 & 411 & & & & & \\
\hline 107 & & 48 & 197 & 435 & 525 & 432 & 464 & & & & & \\
\hline $10 x$ & 11.4 & 48 & 59 & 617 & 556 & 543 & 572 & & & & & 1.10 \\
\hline 109 & 12.8 & 48 & 82 & 452 & 565 & 511 & 509 & & & & & 0.93 \\
\hline 113 & 15.2 & 48 & $\subseteq 5$ & 617 & 807 & 603 & 676 & & & & & 0.56 \\
\hline
\end{tabular}

En contraste con esta -disminución pequeña en las cantidades de glucógeno muscular, el glucógeno hepático estaba fuertemente disminuído en comparación con las cifras que dan los perros normales que son las siguientes: 1877, 2203, 1110, 2183 y 1700.

Gato. - Britton y Silvette (1932) observaron que en los gatos suprarrenoprivos disminuye el glucógeno hepático, llegando casi a desaparecer en algunos. En el glucógeno muscular hallaron también disminución, aunque no tan acentuada.

Conejo. - Después de la disminución inicial postoperatoria se observan cantidądes normales de glucógeno hepático y muscular en todo el período de supervivencia que es de meses o de años (Kahn y Starkenstein, 1911; Stewart y Rogoff, 1917-18; Catan, Houssay y Mazzoceo, 1920; Kisch, 1924).

Rata. - Schwarz (1910), cuyas ratas sobrevivieron pocos días a la suprarrenalectomía, halló en ellas poco o ningún glueógeno hepático. También Kahn y Starkenstein (1911) encontraron valores bajos. En cambio, Stewart y Rogoff (1918) encontraron cantidades normales de glucógeno, y lo mismo halló Kuriyama (1918) en las ratas que se alimentaban suficientemente. En numerosos experimentos, Catan, Houssay y Mazzocco (1920) observaron que entre los 3 y 10 días después 
de la suprarrenalectomía tenían las ratas menor cantidad de glucógeno que los testigos operados, y que después se normalizaban. Más o menos a la misma conclusión llega Artundo (1926) : El glucógeno hepático estaba disminuído a los 3 días; más aún a $\operatorname{los} 8$; aumentado a los 14, y era normal a los 32 días. El glucógeno muscular, elevado a los 3 días, había bajado netamente a los 8 y era normal a los 14 días.

Cori y Cori (1927), en sus experiencias, han encontrado, estando las ratas en ayunas, que el glucógeno hepático faltaba completamente o sólo quedaban vestigios, mientras que los testigos tenían 0,096 a 0,102\%. El glucógeno muscular era normal; el glucógeno total daba 0,141 para las suprarrenoprivas y 0,150 para las testigos.

\section{LA FORMACIÓN DE GLUCÓGENO POR INYECCIÓN DE AZÚCARES.}

Observada la fuerte disminución del glucógeno provocada por la insuficiencia suprarrenal, resultaba interesante averiguar si ella dependía de la falta del material necesario para su formación o la incapacidad de los órganos de efectuar la síntesis del glucógeno. En apoyo de esta última hipótesis hablan las experiencias de Porges (1910), quien encontró, en los perros suprarrenoprivos, menor cantidad de glucógeno aunque estuvieran bien alimentados con hidratos de carbono. Mackenzie (1917) inyectó glucosa a los perros suprarrenoprivos hasta alcanzar una glucemia de $5.6 \mathrm{o} / \mathrm{oo}$, pero sus hígados almacenaron poco o ningún glucógeno, mientras que éste se depositaba en los testigos.

Pico Estrada (1926) observó que el hígado no formaba glucógeno y que el músculo sólo lo hacía en pequeñas proporciones después de inyectar glucosa a los perros decapsulados.

Britton y Sivette (1932), inyectando glucosa a gatos suprarrenoprivos, obtienen menor formación de glucógeno hepatico que en los normales. En el glucógeno muscular no observaron casi diferencia.

En las ratas, que sólo presentan una insuficiencia sủprarrenal pasajera después de la operación, se ha observado la formación de glucógeno a expensas de diversos azúcares (Schwarz, 1910), de glucosa, sacarosa, polisacaridos y proteí- 
nas (Kuriyama, 1918), de sacarosa (Catan, Houssay y Mazzocco, 1920).

Cori y Cori (1927) observaron también que las ratas suprarrenoprivas forman glucógeno hepático y muscular cuando se le administra glucosa, pero no investigaron si éstas lo hacían en la misma proporción que las normales.

Investigaciones personales. - Hemos investigado la formación de glucógeno muscular y hepático en perros suprarrenoprivos desde 48 horas. Bajo anestesia con cloralosa se hacía una toma de los tres músculos de una pata y de una lengüeta de hígado; luego se inyectaban 2 grs. de glucosa por $\mathrm{kg}$. de peso y, después de una hora, se hacía una nueva toma de músculo y de hígado. En 5 perros normales, el aumento en la cantidad de glucógeno muscular fué el siguiente: 508 a 715; 732 a 839; 613 a 864 ; 560 a $620 ; 912$ a 1036 . En cambio, en los suprarrenoprivos desde 48 hs. no se observó aumento en ningún caso; las variaciones de glucógeno fueron: 411 a $393 ; 572$ a $588 ; 509$ a $443 ; 676$ a 563.

Los detalles de estas experiencias los damos en el capítulo correspondiente a la acción de la hormona corticosuprarrenal.

\section{LA RECOMPOSICIÓN DEL GLUCÓGENO MUSCULAR DESPUÉS DE LA FATIGA.}

Se estudió la reconstitución del glucógeno muscular en perros suprarrenoprivos desde 24 y 48 horas. Después de anestesiarlos con clorảosa, se seccionaron ambos ciáticos y se tetanizó durante 15 minutos con reposos de 5 segundos cada minuto. Inmediatamente se hacía una primera toma de tres músculos de una pata para dosar el glucógeno. Después de una hora de reposo, se hacían tomas de músculos en la otra pata.

En los perros normales se observa, inmediatamente después de la fatiga, cifras bajas de glucógeno, pero a la hora se encuentran cantidades normales.

De ocho suprarrenoprivos, desde 24 horas, hubo tres que tuvieron recomposiciones normales, y cinco en los cuales fueron muy bajas. 
En 4 suprarrenoprivos, desde 48 horas, no hubo reconstitución del glucógeno durante la hora de reposo.

La inyección de glucosa por vía endovenosa no provocó mayor diferencia en la formación de glucógeno; en cambio, con extracto corticosuprarrenal se obtuvieron recomposiciones mayores que la de los perros normales. Por lo tanto, es éste un trastorno más precoz y evidente que la disminución del glucógeno en reposo.

Los detalles de estas experiencias los daremos en el capítulo IV al tratar la acción del extracto corticosuprarrenal.

\section{EL ÁCIDO LÁCTICO DEL MÚSCULO}

Siendo el ácido láctico el principal producto de descomposición del glucógeno en el músculo, se ha supuesto que de su estudio podían obtenerse algunos datos relativos a la utilización de dicha substancia en los animales suprarrenoprivos.

Según Houssay y Mazzoco (1927) el ácido láctico del músculo en reposo es algo más abundante en las ratas suprarrenoprivas (185 mgs. \%) que en las normales (169 mgs. \%). Después de tetanizar durante un minuto aumentó a $502 \mathrm{mgs}$ \% en las suprarrenoprivas y sólo a 390 en las testigos.

Después de 5 minutos de reposo bajó a 185 en las suprarrenoprivas y sólo a 221 en las normales. Tanto las suprarrenoprivas como las testigos habían sufrido la operación de 6 a 40 días antes.

Mazzocco (1928), en otra serie de experimentos, confirma que el ácido láctico aumenta más en las suprarrenoprivas después de la tetanización; en cuanto a la desaparición, halla cifras diversas, siendo, en término medio, más lenta en las suprarrenoprivas.

A conclusiones completamente opuestas llegan Arvay y Lengyel (1931), quienes observan que en las ratas suprarrenoprivas la cantidad de ácido láctico del músculo es menor que en las normales (más o menos la mitad), ya sea después del -trabajo, de la tetanización o en la rigidez cadavérica.

También Ochoa y Grande (1933) encuentran menor formación de ácido láctico en el músculo durante la contracción en ranas y cobayos con las suprarrenales cauterizadas. 
Ante estas experiencias contradictorias es imposible formarse un juicio sobre el punto. Parece que en los animales que soportan bien la suprarrenalectomía y que están en buen estado, el ácido láctico muscular queda normal o aumentado (Houssay y Mazzoceo, 1927; Mazzocco, 1928), mientras que en los que presentan insuficiencia suprarrenal manifiesta, baja el glucógeno muscular y el ácido láctico en el reposo y durante el trabajo.

\section{LAS FRACCIONES FOSFORADAS DEL MÚSCULO}

Dada la íntima relación existente entre las distintas fracciones del fósforo del músculo con el consumo de los hidratos de carbono, hemos creído conveniente resumir las investigaciones realizadas sobre la cuestión. Hasta hace algunos años se creyó que el fósforo intervenía para formar un éster, que era el producto intermediario entre el glucógeno y el ácido láctico. Ultimamente ha habido un cambio radical en la manera de interpretar los fenómenos químicos de la contracción muscular. Hoy día, entre las distintas fracciones fosforadas del músculo, se da importancia prepond́erante al fosfágeno o fosfocreatina, cuyo papel fué descubierto por Fiske y Subbarow en 1929. También se asigna importancia a los pirofosfatos (Lohman, 1928). La fosfocreatina al desdoblarse proporcionaría la energía necesaria para la contracción muscular; y el glucógeno, descomponiéndose ulteriormente, cedería energía para la resíntesis de la fosfocreatina. La prueba de que el glucógeno no es indispensable para la contracción muscular la da la intoxicación por el ácido monoiodoacético, en la cual el músculo se contrae con la energía que le proporciona el desdoblamiento de la fosfocreatina sin consumo de glucógeno ni formación de ácido láctico (Lundsgaard).

Consignaremos, pues, por separado las investigaciones hechas antes y después que ocurriera esta renovación en la química de la contracción muscular.

Antiguas investigaciones. - Se refieren todas al lactacidógeno. Se dosaba éste con el método viejo de Embden o sus variantes. Se determinaba el fósforo inorgánico liberado por el músculo durante dỏs horas de autolisis en una solución de 
bicarbonato de sodio. El 70-90\% del fósforo liberado en estas condiciones correspondía no al lactacidógeno sino al ácido pirofosfórico y no tenía ninguna relación con la cantidad de ácido hexosafosfórico del músculo. Por lo tanto, estos dosajes no tienen el significado que se les había atribuído.

Las cifras obtenidas para el músculo normal en reposo eran de 70 a 120 mgs. por 100 grs. en el conejo y 50 a 80 en el gato. Sabemos ahora que sólo menos de $10 \mathrm{mgs}$. corresponden al hexosafosfato.

Kisch (1924) en conejos suprarrenoprivos encuentra cantidades iguales de lactacidógeno que en los normales. Houssay y Mazzocco (1927) en ratas suprarrenoprivas de 6 a 40 días antes encuentran, después de una tetanización de un minuto menos hexosafosfato que en las normales. En perros suprarrenoprivos, Viale, Neuschlosz y Tureatti (1927) encuentran cifras correspondientes a la mitad de lo normal.

Nuevas investigaciones. - Lang (1932) ha dosado el fosfágeno en los músculos de gatos, perros y conejos suprarrenoprivos desde algunas horas antes y lo ha encontrado disminuído hasta un tercio de lo normal. El ester de Embden y los pirofosfatos no variaron. Ochoa y Grande (1932) en cobayos y ranas encuentran también una gran disminución del fosfágeno (54\% de lo normal) y cifras variables para los pirofosfatos, aunque con tendencia al descenso. Estos autores atribuyen a esta disminución de fosfágeno la menor capacidad de trabajo de los músculos. Como han hallado también menor formación de ácido láctico suponen que faltaría la recomposición de la fosfocreatina, es decir, algo parecido a lo que sucede en la intoxicación por el ácido monoiodoacético.

Lundsgaard y Wilson (1933) han dosado el fósforo inorgánico, el fosfágeno, los pirofosfatos y hexofosfatos del músculo en gatos suprarrenoprivos de 5 a 8 días antes, hallando sólo ligeras diferencias con los testigos. No creen estos autores que la debilidad muscular que produce la insuficiencia suprarrenal pueda atribuirse a las modificaciones del fósforo muscular. 


\section{CAPITULO III}

\section{ACCION DE LA ADRENALINA}

Acción hiperglucemiante de la adrenalina, p. 35 - Papel del hígado

(Investig. person.), p. 36 - Papel del páncreas, p. 38 - Papel de las suprarrenales, p. 39 - Acción de la adrenalina sobre el glucógeno muscular, p. 40 - Acción de la adrenalina sobre el glucógeno hepático, p. 42 - Acción de la adrenalina sobre el ácida láctico, p. 43 Influencia de la adrenalina sobre el consumo de azúcar, $p .44$ - Influencia de la adrenalina sobre la diferencia de glucemia arteriovenosa, $p .45$ - Acción de la adrenalina sobre consumo de oxígeno $y$ cociente respiratorio, p. 46 - Adrenalina y ergotamina, p. $50-$ Discusión, p. 51 -Conclusiones, p. 52.

\section{Acción hiperglucemiante de la adrenalina}

Blum en 1901 descubrió que la inyección de extractos de la glándula suprarrenal producía glucosuria en el perro y en el conejo. Al poco tiempo el hecho fué verificado en el gato (Zuelzer 1901) en la rana (Velich, 1901; Loewit, 1910; Gautier, 1904 - 13;-Bang, 1913), en el hombre (Noorden, 1907) y en numerosos otros vertebrados.

Se demostró luego que esta acción se debía esencialmente a la adrenalina (Herter y Richards, 1902, etc.),

La adrenalina produce como modificación principal una hiperglucemia que puede o no ser seguida de glucosuria. Las inyecciones repetidas producen siempre la hiperglucemia, pero suele faltar la glucosuria (Loeper y Crouzon, 1903; Paton, 1903; Underhill y Closson, 1906; Pollak, 1909).

En el hombre la inyección subcutánea de $1 \mathrm{mg}$. de adrenalina eleva generalmente la glucemia más o menos hasta 1,50 gr. por mil a la hora, con normalización hacia la segunda o cuarta hora sin que se observe en general glucosuria.

Las dosis mínimas en mgs. por $\mathrm{Kg}$. y minuto, por vía endovenosa, capaces de elevar la glucemia son de: 0.000025 para el hombre (Cori y Buchwald, 1930); mg. 0.00005 en el conejo (Trendlenburg, 1923; Cori y Cori, y Buchwald, 1930), y mg. 0.0002 en la rata anestesiada con amytal (Cori y Cori, 
1930). Estas dosis son inferiores a las necesarias para provocar una elevación de la presión arterial.

\section{Papel del hígado}

Se considera actualmente que el glucógeno muscular no puede convertirse directamente en glucosa y regular la glucemia; de manera que la única fuente apreciable de producción de azúcar para la sangre sería el hígado. El glucógeno muscular es convertido en ácido láctico por los fermentos musculares; en cambio, en el hígado el glucógeno se transforma en glucosa.

La única manera admitida por la cual el glucógeno muscular puede suministrar azúcar para la sangre, sería pasando por la etapa de ácido láctico que en el hígado se transformaría en glucosa.

Se basan estas suposiciones en el hecho de que en los animales privados de hígado la glucemia baja a pesar de que haya aún reservas de glucógeno muscular. Tampoco se observan en estos animales las hiperglucemias producidas por la adrenalina, anestesia, asfixia, etc. Citamos a continuación las experiencias que apoyán esta hipótesis:

Ya en 1897 Kausch observó la progresiva hipoglucemia que aparecía en los patos hepatectomizados. Este hecho ha sido más tarde confirmado y extendido a los mamíferos (Mann y Magath, 1922).

En cuanto a la hiperglucemia adrenalínica, se ha comprobado que falta en la rana hepatectomizada (Velich, 1911) y lo mismo sucede en los mamíferos (Mann 1925). Jacobson (1920) afirmaba que, en los perros con fístula de Eck, el tejido muscular es capaz de efectuar tanto la glucogenolisis como la glucogenesis. Ohara (1925), en perros con fístula de Eck y en conejos con hígado excluído (por ligadura de aorta y cava inferior), observó todavía hiperglucemia adrenalínica con disminución del glucógeno muscular. Pero estas experiencias no son probantes porque siempre existe posibilidad de que la sangre proveniente del hígado se vierta en la circulación general.

- Bollman, Mann y Magath (1925) observaron que el glucógeno muscular disminuía simultáneamente con el azúcar de la sangre en los perros privados de hígado y que, además, los síntomas hipoglucémicos eran más tardíos en los que tenían 
mayor cantidad de glucógeno muscular. Pero, como aparecía la hipoglucemia con cantidades aún considerables de glucógeno muscular, concluyeron estos autores que este último no podía descomponerse con suficiente rapidez como para mantener normal la glucemia.

Best, Hoet y Marks (1926) han observado que el glucógeno muscular no disminuye durante la hipoglucemia insulínica. Creemos que estas experiencias no apoyan la hipótesis de que el glucógeno muscular no puede transformarse en glucosa, puesto que interviene en este caso la insulina, una de cuyas acciones es favorecer la formación de glucógeno muscular.

Soskin (1927) observa que en los perros hepatoprivos la adrenalina, el éter y la asfixia no son ya capaces de elevar la glucemia.

Además de las experiencias de extirpación del hígado hay otras que también apoyan el papel esencial de este órgano en la producción de las diversăs hiperglucemias.

Después de lesionar al hígado por el fósforo (Frank e Isaac, 1911) o después de la ligadura de sus vasos (Falta y Priestley, 1911), ya no se observa la acción hiperglucemiante de la adrenalina. Collens, Shelling y Byron (1926) comprobaron que, en los perros en que se ligaba la arteria hepática el grado de hiperglucemia producida por la adrenalina variaba en relación inversa al tiempo de aplicación de la ligadura.

Además se ha observado que, privando al hígado de glucógeno, falta la glucosuria adrenalínica (Blum, 1912; Herter y Richards, 1902; Ringer, 1908, etc.) y también la hiperglucemia (Markowitz, 1925): En estas últimas experiencias se comprobó que existía aún glucógeno muscular.

La desnervación del hígado no impide la hiperglucemia adrenalínica (Freund y Schlaginweit, 1914, etc.). Sin embargo, según Lépine (1902) la sección medular en el límite cervicodorsal impediría la hiperglucemia adrenalínica. Pero en este caso se producen trastornos diversos (circulatorios, respiratorios, etc.), que dificultan la interpretación de los resultados.

Por otra parte, Molitor y Pollak (1930) dosando simultáneamente la glucemia en la sangre de la vena cava al salir del hígado y la de la oreja, observaron en conejos y perros que: En las primeras horas, la hiperglucemia iba acompañada de un aumento en la diferencia de la glucemia, aumento debido a la 
mayor cantidad de glucosa en la vena cava. Al mismo tiempo observaron una disminución en la cantidad de glucógeno hepático.

Investigaciones personales. - Con el objeto de descubrir una elevación glucémica, aun cuando fuera muy pequeña en los sapos hepatectomizados, se procedió en la siguiente forma: Bajo anestesia etérea, se extirpó el hígado a dos lotes de sapos. Tres horas después se inyectó $1 \mathrm{mg}$. de adrenalina a los sapos de uno de los dos lotes. Luego se hicieron tomas de sangre de la pata anterior, a los 15 - 20 minutos y a las dos horas para dosar la glucemia según Hagedorn y Jensen. (Cuadro $\left.6^{\circ}\right)$.

\section{CuAdro $6^{\circ}$}

Lote I. - No inyectados (Glucemias por mil)

\begin{tabular}{c|c|c|c}
\hline N. & 0. & $15.20^{\circ}$ & 2 hs. \\
\hline 1 & 0.60 & 0.61 & 0.62 \\
2 & 0.56 & 0.58 & 0.51 \\
3 & 0.43 & 0.47 & 0.47 \\
4 & 0.42 & 0.43 & - \\
5 & 0.51 & 0.52 & 0.43 \\
\hline
\end{tabular}

Lote II. - Inyectados con $1 \mathrm{mg}$. de adrenalina

\begin{tabular}{c|c|c|c}
\hline N.o & $0^{*}$ & $15-20^{\circ}$ & 2 hs. \\
\hline 1 & 0.47 & 0.42 & 0.51 \\
2 & 0.40 & 0.51 & 0.42 \\
3 & 0.36 & 0.56 & - \\
4 & 0.49 & 0.49 & 0.39 \\
5 & 0.43 & 0.54 & - \\
\hline
\end{tabular}

Como puede observarse en este cuadro, no hubo ninguna diferencia significativa en las glucemias de los sapos de los dos lotes.

\section{Papel del páncreas}

Se obtuvo en un tiempo que la hiperglucemia se debía a una inhibición del páncreas o de la acción de su hormona. Herter y Wakeman (1902) señalaron la especial intensidad de los efectos obtenidos aplicando la adrenalina en pincelaciones sobre el páncreas, pero se comprobó lo mismo inyectándola en el 
mayor cantidad de glucosa en la vena cava. Al mismo tiempo observaron una disminución en la cantidad de glucógeno hepático.

Investigaciones personales. - Con el objeto de descubrir una elevación glucémica, aun cuando fuera muy pequeña en los sapos hepatectomizados, se procedió en la siguiente forma: Bajo anestesia etérea, se extirpó el hígado a dos lotes de sapos. Tres horas después se inyectó $1 \mathrm{mg}$. de adrenalina a los sapos de uno de los dos lotes. Luego se hicieron tomas de sangre de la pata anterior, a los $15-20$ minutos y a las dos horas para dosar la glucemia según Hagedorn y Jensen. (Cuadro $\left.6^{\circ}\right)$.

Cuadro $6^{\circ}$

Lote I. - No inyectados (Gluceñias por mil)

\begin{tabular}{c|c|c|c}
\hline N. ${ }^{0}$ & 0. & $15-20^{,}$ & 2 hs. \\
\hline 1 & 0.60 & 0.61 & 0.62 \\
2 & 0.56 & 0.58 & 0.51 \\
3 & 0.43 & 0.47 & 0.47 \\
4 & 0.42 & 0.43 & $-\overline{1}$ \\
5 & 0.51 & 0.52 & 0.43 \\
\hline
\end{tabular}

Lote II. - Inyectados con $1 \mathrm{mg}$. de adrenalina

\begin{tabular}{|c|c|c|c|}
\hline N. & $0^{\text {. }}$ & $15-20$, & 2 hs. \\
\hline $\begin{array}{l}1 \\
2 \\
3 \\
4 \\
5\end{array}-$ & $\begin{array}{l}0.47 \\
0.40 \\
0.36 \\
0.49 \\
0.43\end{array}$ & $\begin{array}{l}0.42 \\
0.51 \\
0.56 \\
0.49 \\
0.54\end{array}$ & $\begin{array}{l}0.51 \\
0.42 \\
- \\
0.39 \\
-\end{array}$ \\
\hline
\end{tabular}

Como puede observarse en este cuadro, no hubo ninguna diferencia significativa en las glucemias de los sapos de los dos lotes.

\section{Papel del páncreas}

Se obtuvo en un tiempo que la hiperglucemia se debía a ¿una inhibición del páncreas o de la acción de su hormona. Herter y Wakeman (1902) señalaron la especial intensidad de los efectos obtenidos aplicando la adrenalina en pincelaciones sobre el páncreas, pero se comprobó lo mismo inyectándola en el 
peritoneo (Kleiner y Meltzer, 1918, etc.). La acción antagónica de la inyección peritoneal de extracto pancreático (Zuelzer, 1.907) no es específica, pues se observa con irritaciones peritonales provocadas por la trementina y el aleuronato (Furth y Schwarz, 1911). Por otra parte, la hiperglucemia adrenalínica se observa también en los animales pancreatoprivos (Velich, 1906; Paton, 1905; Frank e Isaac, 1911; Eppinger, Falta y Rudinger, 1908, etc.), lo que hemos comprobado también nosotros (capítulo VI) en un perro pancreato-suprarrenoprivo.

\section{Papel de las suprarrenales}

La inyección de adrenalina al conejo suprarrenoprivo produce glucosuria (Ka'hn y Starkenstein, 1911), e hiperglucemia como en los normales, a veces precedida de hipoglucemia (Kisch, 1924). En el perro suprarrenoprivo, eleva la glucemia por encima del valor inicial, (Banting y Gairns, 1926), pero no tanto como en los normales; la glucosuria también es menor (Bierry y Malloizel, 1908), o falta (Gautrelet y Thomas, 1909).

En los perros desmedulizados la hiperglucemia producida por $0.2 \mathrm{mgs}$. de adrenalina en inyeçción peritoneal fué más 0 menos igual a la producida en los testigos. (Testigos: 1.01; $1.34 ; 2.32 ; 1.14 ; 0.81 ; 0.52 ; 0.35 ; 0.85$. Desmedulizados: $0.67 ; 0.37 ; 0.92 ; 1.01 ; 0.71 ; 1.00$. Elevación en grs. por mil, Houssay y Molinelli, inédito). En gatos suprarrenoprivos, Britton y Silvette (1931) inyectando 0.02 a $0.08 \mathrm{mgs}$. deadrenalina por $\mathrm{kg}$. de peso, obtuvieron pequeñas elevaciones glucémicas y no en todos los casos. Los resultados negativos de Viale (1931) y Carrasco Formiguera (1933) en perros, obedecieron seguramente al mal estado de sus animales. Conviene recordar aquí que la adrenalina es más tóxica para la rata suprarrenopriva que para la normal (Schwarz, 1910; Kahn y Starkenstein, 1911; Lewis, 1921).

En los addisonianos no observaron glucosuria, en tres casos, Eppinger, Falta y Rudinger (1909), Pollak (1910), Forshbach y Severín (1914); pero observaron hiperglucemia neta. Billigheimer (1921), Rosenow y Jaguttis (1922) observaron hiperglucemia menor que en los sanos con ausencia de hipoglucemia secundaria. En cuanto a la susceptibilidad, los datos son discordantes: En efecto: mientras Rosenow y Jaguttis ob- 
servaron menos síntomas que en los testigos, Grote (1916), con pequeñas dosis, observó palpitaciones, tensión torácica y sudor.

\section{Acción de la adrenalina sobre el glucógeno muscular}

A pesar de los numerosos estudios realizados sobre este punto, no puede decirse que esté definitivamente aclarado, aunque parece desprenderse de la mayoría de las experiencias que la adrenalina tiene en el músculo una acción glucogenolítica.

Ya Gatin Gruzewska (1905) y Agadchanianz (1907) habían observado que el glucógeno muscular disminuía bajo la acción de la adrenalina, pero los métodos que usaron son criticables (Cori y Cori, 1928).

Ohara (1925) encuentra también una disminución del glucógeno una hora después de inyectar 0.04 a $1 \mathrm{mg}$. por $\mathrm{kg}$. de adrenalina en perros con fístula de Eck y en conejos sin hígado.

Cori y Cori (1928) observaron que después de inyectar $0.02 \mathrm{mg}$. de adrenalina por 100 grs. de rata, en ayuno, el glucógeno del hígado aumentaba de 6 a 42 mgs., mientras que en el resto del cuerpo bajaba de 128 a $71 \mathrm{mgs}$. (la glucemia subió de 0.92 a 1.10 ).

Estas experiencias de Cori se pueden considerar como seguras, pues han sido confirmadas por todos los que las han repetido (Zimmerman, 1929, etc.).

Chaikoff y Weber (1928) encontraron también disminución del glucógeno muscular en las ratas, pero no en el perro, usando dosis pequeñas de adrenalina.

Eadie (1929) en gatos anestesiados con isoamiletilbarbiturato (amytal) y con dosis de adrenalina de 0.1 a $1.0 \mathrm{mg}$. por kg.. no encontraron a la hora y media modificación del glucógeno muscular, pero sí disminución del hepático. Firor y Eadie (1930) no hallaron modificación del glucógeno muscular en gatos hepatectomizados. En otro trabajo, Eadie (1930) tampoco encuentra variación del glucógeno en gatos no anestesiados, y como en la rata encuentra las mismas modificaciones que Cori y Cori, concluye que la diferencia es dependiente de la especie de animal.

En conejos, Blatherwick y Sahyun (1929) hallaron 24 horas después de inyectar 1.0 a $1.15 \mathrm{mgs}$. por $\mathrm{kg}$. de adre- 
nalina, un aumento del glucógeno hepático y una tendencia a descender del muscular. Con menos de 0.5 mgs., ningún cambio significativo.

Sahyun y Luck (1929), trabajando también en conejos, hallaron una disminución de ambos glucógenos a la hora y media. El glucógeno hepático se normalizó a la tercera hora, siguió aumentando hasta la hora 18 y luego descendió otra vez. El glucógeno muscular, que disminuyó rápidamente en la primera hora, quedó después más o menos estacionario. Más o menos a las mismas conclusiones llega Goldblatt (1933) para el conejo.

Corkill y Marks (1930), en gatos eviscerados, sin riñón y con el hígado excluído, manteniendo la glucemia por inyección de glucosa, observan que la adrenalina determina una disminución del glucógeno muscular, con pequeño aumento del ácido láctico de la sangre y ninguno de la glucemia. La suma del azúcar quemado (análisis de los gases) y el transformado en ácido láctico fué menor que la cantidad desaparecida; de donde deducen que hubo transformación de azúcar en otra substancia desconocida.

Sacks (1931) en gatos anestesiados con amytal o nembutal, con dosis de 0.1 y $1.0 \mathrm{mg}$. por $\mathrm{kg}$. de adrenalina encuentran las siguientes modificaciones: El glucógeno hepático de los testigos anestesiados no varió hasta la 1 y $1 / 2$ horas, pero se redujo en $1 / 4$, a las 3 horas. En los inyectados con $0.1 \mathrm{mg}$. de adrenalina la cantidad de glucógeno hepático era menor que en los testigos a la 1 y $1 / 2$ hora, casi igual a las $3 \mathrm{hs}$. En el glucógeno muscular, ningún cambio. Con $1.0 \mathrm{mg}$., el glucógeno hepático disminuyó más que con 0.1 y el muscular tuvo tendencia a descender.

Evans, Tsai y Young (1931) en el gato (dosis 0.09 a 1.0 mg. por kg.) encuentran disminución del glucógeno muscular y hepático con aumento de la glucemia y lactados. En la rata hubo aumento del glucógeno hepático y disminución del muscular, salvo cuando estaban anestesiados con amytal.

Bodo, Benaglia y Friedman (1933) en el perro, usando anestesia local y una dosis de adrenalina de 0.15 a $0.30 \mathrm{mg}$. por kg. hallaron a las 5 horas disminución del glucógeno muscular y aumento de los lactados. En el hígado hubo aumento 
del glucógeno en los perros ayunados y disminución en los alimentados.

Major y Mann (1933), después de verificar que la anestesia no causaba disminución de glucógeno muscular, estudiaron el efecto de dosis grandes de adrenalina, 1.0-2.5 mg. por hora, y hallaron franca disminución de glucógeno muscular a las dos horas. Obtuvieron glucógenolisis muscular con dosis hasta de $0.00016 \mathrm{mg}$. por $\mathrm{kg}$. y minuto (esta dosis no modificó la presión arterial ni el volumen del miembro). Con 0.000066 mgs. no hallaron variación en la cantidad de glucógeno.

Por lo tanto, según la mayoría de los investigadores, la adrenalina disminuye la cantidad de glucógeno muscular. No hemos podido determinar cuál es el factor que ha influído en los resultados negativos de otros investigadores.

\section{Acción de la adrenalina sobre el glucógeno hepático}

La primera explicación sobre el mecanismo de la hiperglucemia adrenalínica fué que el hígado arrojaba a la circulación más glucosa de la que podían almacenar o consumir los tejidos. De acuerdo con esta hipótesis, era lógico suponer que bajo la acción de la adrenalina disminuiría la cantidad de glucógeno hepático.

Las primeras experiencias apoyaron este modo de pensar. Según Doyon et Kareff (1904), Wolwonick (1905), Doyon, Morel et Kareff (1905), etc., el glucógeno hepático disminuye o desaparece por la acción de la adrenalina.

En cambio, según otro grupo de investigadores, el glucógeno hepático aumentaría en los animales que en ayuno son tratados por la adrenalina (Loeper y Crouzon, 1903; Pollak, 1909; Kuriyama, 1918).

A pesar de que estos dos últimos trabajos están bien hechos y en un número considerable de animales, se siguió considerando que la adrenalina disminuía la cantidad de glucógeno hepático.

Markowitz (1925) en conejos privados de glucógeno por el ayuno y estricnina, observa que las inyecciones repetidas de adrenalina llevan a la acumulación de glucógeno en el hígado, corazón y músculos. 
Cori y Cori (1928), en ratas en ayuno, hallaron a las 3 horas de inyectar $0.002 \mathrm{mg}$. por $\mathrm{kg}$. de adrenalina que el glucógeno hepático subía de 6 a $42 \mathrm{mgs}$. por 100 grs. (en el resto del cuerpo bajó de 128 a 71). En las que recibieron glucosa 4. horas antes obtuvieron más o menos el mismo resultado.

En el conejo en ayunas, Sahyun y Luck (1929), observaron que la adrenalina provocaba a la hora y media una disminución del glucógeno hepático, que se normalizaba hacia la tercera hora, y desde entonces aumentaba hasta las $18^{\mathrm{a}}$ hora.

Habría, pues, primero una fase negativa con disminución y luego una positiva con aumento del glucógeno hepático.

Según Cori y Cori, en la rata el ciclo sería más rápido: la fase negativa se observa a los 15 minutos y la positiva ya es bien manifiesta a las 3 horas.

Hemos citado al referirnos al glucógeno muscular las experiencias de Eadie (1929), ,Sacks (1931), Evans, Tsai y Young (1931), quienes hallaron disminución del glucógeno hepático. Solamente Bodo, Benaglia y Friedman (1933) han hallado aumento del glucógeno hepático en perros en ayuno (en los alimentados hubo disminución).

Resumiendo, diremos que la adrenalina determina en la rata y el conejo, primero, una disminución y luego un aumento del glucógeno hepático, y que en el perro produce casi siempre disminución.

\section{Acción de la adrenalina sobre el ácido láctico}

La inyección de adrenalina determina un aumento en la cantidad de ácido láctico de la sangre. Esto ha sido comprobado: en el hombre (Tolstoi y colab. 1924; Cori y Buchwald, 1930); en el perro (Campos, Cannon y colab. 1928; Geiger y Schmidt, 1929); en el gato (Corkill y Marks, 1930; Cori, 1930); en el conejo (Cori, 1925; Cori y Cori, 1929; Bischoff y Long, 1930) y en la rata (Cori, Cori y Buchwald, 1930), etc.

En el conejo, $0.2 \mathrm{mg}$. por $\mathrm{kg}$. de adrenalina elevaron en ana hora el ácido láctico de $11 \mathrm{mgs}$. por ciento a $74 \mathrm{mgs}$. con vuelta a la normal a la tercera hora. Este aumento fué paralelo al de la glucemia (Cori y Cori, 1929). En la rata hubo aumento en los primeros 15 minutos. 
Collazo y Puyal (1932) también en el conejo hallaron en término medio: en reposo, $39 \mathrm{mgs}$. \%; $3 / 4$ de hora después de administrar $0.5 \mathrm{mg}$. por $\mathrm{kg}$. de adrenalina, $97 \mathrm{mgs}$; a las dos horas, 74 y a las 3 horas $37 \mathrm{mgs}$. (Hubo también aumento del ácido láctico en la orina de $23 \mathrm{mgs}$ \% a $65 \%$ ).

En el hombre, un mg. de adrenalina elevó la lactacidemia de 14.4 a 27.1 a la media hora; a 21 a las dos horas, con aumento algo más tardío de la glucemia $(0.89 ; 1.15 ; 1.31$; y 1.00) (Collazo y Puyal, 1932). También Leys (1931) halla aumentos francos de un 28 a $224 \%$ (nivel inicial: $15.8 \mathrm{mgs}$.).

Además se ha observado que la adrenalina aumenta la formación de ácido láctico en las ranas puestas en anaerobiosis (Cori y Buchwald, 1930).

En las ranas hepatectomizadas sè observa aumento de ácido láctico en la orina cuando son inyectadas con adrenalina. La perfusión de las extremidades (Preparado de Trendelenburg) con una solución de adrenalina aumenta la formación de ácido láctico (Geiger, 1930).

En el músculo de la rata, Cori (1930) halló aumento del ácido láctico, ligera disminución de fosfatos inorgánicos y ningún cambio de fosfageno.

\section{Influencia de la adrenalina sobre el consumo de azúcar}

Este punto ha sido estudiado de diversas maneras:

Wilenko (1912) observó que mientras que la glucosa, cuando se administraba sola, aumentaba el cociente respiratorio en 12 a $31 \%$, si se acompañaba de adrenalina, el mayor aumento era de $8.8 \%$ y en algunos casos no había variación.

Cori y Cori (1931) lo han hecho comparando la hiperglucemia adrenalínica con la producida por administración de glucosa en cantidad suficiente para provocar un aumento glucémico de igual intensidad y duración.

En las ratas tratadas con adrenalina hubo una hiperglucęmia de 2.0 grs. por mil, que persistió hasta tres horas después de inyectar la adrenalina. Ahora bien: cuando ratas anestesiadas con amytal reciben una inyección endovenosa contínua de $250 \mathrm{mgs}$. de glucosa por 100 grs. y hora, la glucemia se mantiene también alrededor de 2.00 grs. por mil.

Por lo tanto, la cantidad de glucosa que debiera propor- 
cionar el hígado en el caso de la hiperglucemia adrenalínica sería de $750 \mathrm{mgs}$. en tres horas.

Calculan estos autores que el hígado debería tener para esto $20 \%$ de glucógeno y movilizarlo íntegramente. En cambio, la cantidad inicial fué de $2.4 \%$ y hubo aumento en lugar de disminución. Por lo tanto, la cantidad de glucosa requerida no puede ser originada por el glucógeno hepático preformado.

Se dosó al mismo tiempo la eliminación de nitrógeno, y calculando que cada gramo de nitrógeno eliminado correspondía a la formación de 3.65 grs. de glucosa, se dedujo que sólo $11 \mathrm{mgs}$. de glucosa por hora podrían formarse a expensas de las proteínas. Han calculado también los autores la cantidad de glucosa que habría podido formarse a expensas del ácido láctico: serían $80 \mathrm{mgs}$. por hora. Sólo quedarían las grasas como fuente de glucosa; pero no está probado que esta transformación sea posible en el organismo.

Estos mismos autores han hecho cálculos similares en sus experimentos con conejos, y concluyen que la hiperglucemia no puede ser debida solamente a una hiperproducción de glucosa y responde, por lo tanto, a una menor utilización de esta última por los tejidos. Como se ve, estos argumentos están basados en una serie de cálculos que, si bien parecen convincentes, deben estar expuestos a muchos errores.

Las experiencias de Colwell y Bright (1930) indican también que la adrenalina provoca una menor utilización de la glucosa. En gatos anestesiados con amytal se inyectaba glucosa y adrenalina $(0.001 \mathrm{mg}$. por $\mathrm{kg}$. y minuto $)$ en forma continuada; hora tras hora se dosaba el azúcar excretada y se calculaba la oxidada por medio de los gases de la respiración. Después de dos o tres horas, se llegaba a una completa supresión de la oxidación de azúcar, cosa que no sucedía cuando no se inyectaba adrenalina. La larga duración de las experiencias (8 - 14 horas) les dan un valor considerable.

\section{Acción de la adrenalina sobre la diferencia de glucemia arteriovenosa}

Se ha comprobado que, en condiciones normales, la cantidad de glucosa existente en las arterias periféricas es mayor que en las venas. 
Las diferencias halladas son más o menos iguales para las distintas especies de animales y son de unos 5 cgr. por mil (Henriquez y Ege, 1921; Foster, 1923, etc.). La diferencia aumenta hasta $30 \mathrm{mgs}$. después de administrar azúcar, lo que indicaría que más glucosa es detenida en los tejidos. Según Wertheimer (1924) la diferencia sería pequeña o no existiría en los hombres diabéticos o perros pancreatoprivos.

Durante la hiperglucemia adrenalínica, esta diferencia no se modifica en el hombre (Wiechmann, 1924; Cori y Cori, 1929) ni en el conejo (Cori y Cori, 1929). Según Carrasco Formiguera y Bieto (1933) la diferencia arteriovenosa aumentaría solamente cuando la adrenalina es inyectada en la vena porta. La inyección en otras venas provocaría, pues, una hiperglucemia no acompañada de fijación en los tejidos, la que sólo existiría cuando la adrenalina actúa directamente sobre el hígado.

Soskin, Priest y Schutz (1932) han hecho notar que estas mediciones estaban sujetas a errores, pues lo que se mide es la concentración de la glucosa y no la cantidad absoluta que entra y sale de los tejidos, que depende de la concentración de la sangre y de su vélocidad.

Estos autores han dosado la glucosa, el residuo seco total y han medido la circulación venosa. Deducen de estas experiencias que la adrenalina, según la dosis, disminuye o aumenta la circulación periférica y concentra la sangre, mientras que la inyección de glucosa siempre aumenta la circulación y diluye la sangre; que, por lo tanto, las correcciones que habría que introducir en las cifras de glucemias arteriovenosas, por distinta concentración y velocidad de la sangre, serían suficientes para cambiar una aparente retención en pérdida y viceversa. Concluyen que la adrenalina no parece disminuir la retención de azúcar por los tejidos.

\section{Acción de la adrenalina sobre el consumo de oxígeno y cociente respiratorio}

- El estudio de las modificaciones sobre el consumo de oxígeno y sobre el cociente respiratorio, provocadas por la adrenalina, puede informarnos acerca de su influencia sobre la combustión de los hidratos de carbono. 
La adrenalina aumenta el consumo de oxígeno. Esto ha sido comprobado en el hombre y varias especies de animales por un gran número de investigadores (1). Las elevaciones obtenidas son bastante marcadas: En el hombre, una inyección subcutánea de un milígramo de adrenalina eleva el metabolismo en 50 calorías durante unas pocas horas. En el perro, $0.1 \mathrm{mg}$. por $\mathrm{kg}$. (vía subcutánea) aumenta el consumo en un $62 \%$ a los 80 minutos. También en el conejo se obtienen elevaciones de $+50 \%$ con un milígramo de adrenalina.

El aumento puede obtenerse con dosis muy pequeñas: en el hombre la inyección intravenosa, durante 30 minutos de $0.00005 \mathrm{mg}$. por $\mathrm{kg}$. y minuto aumenta la presión arterial, la lactacidemia y el metabolismo basal (Cori y Buchwald, 1930).

En el conejo es suficiente la cantidad de $0.00025 \mathrm{mg}$. por kg. y minuto (Cori y Cori, 1931).

Algunos autores han supuesto que él aumento del metabolismo provocado por la adrenalina se debe al temblor 0 aumento del tono que son a menudo producidos por ella. Hablan en favor de esta hipótesis las experiencias de Hari (1912), quien no obtuvo aumento en perros curarizados, y las de Klein y Weiss (1928) en conejos profundamente anestesiados con uretano. Sin embargo, en éstos el resultado negativo puede deberse a otra acción del curare y del uretano.

Por el contrario, Aub, Bright y Forman (1922) y Hunt y Bright (1926) no hallaron abolición de la acción calorígena de la adrenalina en gatos anestesiados con uretano y amytal.

Ni la sección de la médula cervical en el conejo (Freund y Grafe, 1922), ni la destrucción del cerebro en la rana (Cori y Buchwald, 1930) son capaces de suprimir la acción de la adrenalina sobre el metabolismo basal.

Además, en el erizo invernante, la adrenalina eleva fuertemente el metabolismo, determinando elevación de temperatura y el despertar. La sección de la médula cervical o la extirpación de la región del centro termoregulador no impiden ese efecto (Adler, 1920; Schenk, 1922).

Demuestran todas estas experiencias que la adrenalina no actúa por intermedio del sistema nervioso central.

(1) Ver la bibliografía en el libro de Trendelenburg: Die Hormone, 1929. Julius Springer, Edit. Berlín, y en Cori, C. F.: Mamalian Carbohidrate Metabolism. Physiological Reviews, 1931. 
Papel del hígado. - La extirpación del hígado suprime la hiperglucemia adrenalínica. Se ha estudiado también su efecto sobre la acción calorigénica.

En gatos eviscerados, Corkill y Marks (1930) observaron que la adrenalina era aún capaz de elevar, aunque fugazmente, el consumo de oxígeno. También hallaron aumento Hunt y Bright en perros con los vasos hepáticos ligados. En cambio, Soskin (1927) en cinco perros eviscerados y dos hepatectomizados no obtuvo con la adrenalina ningún efecto sobre el progresivo descenso del metabolismo basal (tampoco sobre el cociente respiratorio). En ranas hepatectomizadas, Cori y Buchwald (1930) obtuvieron con la adrenalina aumentos en el consumo de oxígeno, pero éstos fueron tanto menores cuanto más tiempo pasaba desde la operación, llegando hasta desaparecer.

Acción sobre tejidos in vitro. - A pesar de que algunas experiencias lo niegan, parece que la adrenalina es capaz de aumentar el consumo de oxígeno en músculos de rana aislados (Ahlgren, 1926; Cloedt y van Canneyt, 1924; Abderhalden y Gellhorn, 1926, etc.). La reducción del azul de metileno es también más rápida en los músculos tratados con adrenalina (Adler y Lipschitz, 1922; von Euler, 1927, etc.) .

Hay numerosas experiencias en las cuales no se halló modificación alguna: (Rotchchild, 1930, en músculos de rana; Bornstein 1927, en hematíes de ave, etc.).

El aumento de consumo de oxígeno no es debido a hiperglucemia. - Podría suponerse que la acción de calorígena de la adrenalina se debe a que, al aumentar la glucemia, tendrían los tejidos a su disposición más material para efectuar combustiones; pero ésto queda descartado por las siguientes experiencias de Boothby y Sandiford (1923). Se comparó en hombres el aumento metabólico provocado por la administración de 100 grs. de glucosa y por la inyección subcutánea de ¿0.5 mgs. de adrenalina. La adrenalina aumentó la glucemia en $37 \%$ y el metabolismo en $20 \%$, mientras que la ingestión de glucosa elevó la glucemia en $105 \%$ y el metabolismo sólo en $9 \%$. 
Cociente respiratorio. - Podría esperarse que el cociente respiratorio nos informara sobre la calidad de los materiales quemados en exceso bajo la acción de la adrenalina. Pero, dado que la adrenalina provoca cambios en el ritmo respiratorio y aumento del ácido láctico en la sangre, puede así llevar a una mayor eliminación de anhidrido carbónico con el consiguiente aumento del cociente respiratorio bruto o aparente.

Son numerosísimos los investigadores que han hallado aumentos del cociente respiratorio por la acción de la adrenalina. Juschtschenko, 1909; Lusk y Riche, 1914; Boothby y Sandiford, 1921; Grafe, 1923; Bornstein y Holm, 1922, etc.). Bornstein y Müller (1921) atribuyeron el aumento del cociente respiratorio al aumento de ventilación pulmonar, hipótesis que ha sido apoyada por Erichson (1926). Este último autor observó en el hombre que la elevación del cociente (1.00 a 1.20) llegaba a su máximo en 10 minutos después de inyectar la adrenalina, coincidiendo con la mayor ventilación pulmonar y con la mayor disminución de la tensión de $\mathrm{CO}_{2}$ alveolar, mientras que el aumento de la glucemia recién aparecía a los 50 o 60 minutos. Más o menos los mismos resultados obtuvieron Lyman, Nicholls y Mc Cann (1923).

En las experiencias de Cori y Cori (1931) el dosaje de los gases se hizo durante las tres horas que siguieron a la inyección de adrenalina. En ratas en ayunas con un cociente respiratorio de 0.71 y poco glucógeno hepático, la adrenalina produjo una insignificante elevación de la glucemia, pero su acción calorígena fué tan marcada como en las ratas alimentadas, en las cuales se eleva considerablemente la glucemia. En esas ratas en ayunas, el cociente respiratorio indicó que el exceso de combustión se realizó enteramente sobre las grasas. $\mathrm{Si}$ al inyectar la adrenalina el cociente respiratorio indicaba combustión de hidratos de carbono y grasas, el aumento metabólico se realizó a expensas de estos mismos materiales. Durante la absorción de glucosa desde el tubo digestivo, el aumento de oxidación se produjo sobre las grasas.

En resumen: podemos decir que la adrenalina provoca un aumento del consumo de oxígeno y que su acción parece ejercerse directamente sobre los tejidos. 
El fugaz aumento del cociente respiratorio no puede atribuirse a una mayor combustión de hidratos de carbono. Recordamos a propósito de esto las experiencias de Wilenko y de Colwell y Bright que ya hemos citado al tratar de la influencia de la adrenalina sobre el consumo de azúcar.

$\mathrm{El}$ aumento de consumo de oxígeno provocado por la adrenalina puede tal vez relacionarse con la propiedad de ésta de aumentar la formación de ácido láctico. En efecto: Meyerhoff ha demostrado que, agregando ion lactato a músculos aislados de rana o de mamíferos, se provoca un aumento de la respiración (hasta de $100 \%$ en el músculo de rana). El efecto: se obtiene también con ácido pirúvico. El ácido láctico que desaparece se oxida sólo parcialmente, siendo el resto sintetizado en glúcidos.

\section{Adrenalina y ergotamina}

La ergotamina, y la ergotoxina que tiene idénticas propiedades, provoca una anulación o inversión del efecto hipertensor de la adrenalinạ.

Según Micucilich (1912) y Burn (1923), la ergotamina impide también el efecto hiperglucemiante de la adrenalina.

Sólo se logra impedir la hiperglucemia adrenalínica con grandes dosis de ergotamina. Con menos de $1 \mathrm{mg}$. por $\mathrm{kg}$., de ergotamina, la adrenalina eleva todavía la glucemia como en los animales no tratados (Farrar y Duff, 1928; Youmans y Tremble, 1930).

Se ha intentado, utilizando estas propiedades de la ergotamina, obtener una disociación de los efectos sobre glucógeno muscular y hepático de la adrenalina. Según Nitzescu y Munteanu (1932), la ergotamina (2 - $2.5 \mathrm{mg}$. por $\mathrm{kg}$. en conejos) impediría la hiperglucemia adrenalínica, pero no el aumento del ácido láctico. Este hecho no se deduce claramente de sus protocolos $\mathrm{y}$ ha sido negado posteriormente por Goldblatt (1933), quien, en conejos (1 mg. por kg.) y en gatos (más de $1 \mathrm{mg}$. por kg.) anestesiados con amytal o uretano, observa que la inyección de adrenalina ya no eleva ni la glucemia ni la lactacidemia. 


\section{Discusión}

Es difícil, basándose en el cúmulo de observaciones tan variadas y muchas de ellas contradictorias, formarse una idea clara del mecanismo por el cual la adrenalina provoca un aumento de la glucemia. Sin embargo, hay algunos puntos, que están suficientemente comprobados.

La hiperglucemia no se debe a una inhibición de la secreción insular pancreática, como lo prueba categóricamente el hecho de que la adrenalina tiene acción hiperglucemiante en los animales prancreatoprivos.

El papel del hígado es mucho más importante: nadie ha observado hiperglucemia en los animales totalmente hepatectomizados. Por lo tanto, el glucógeno del hígado sería el único que podría transformarse en glucosa para verterse en la sangre. Sólo cabría la posibilídād de que el hígado proporcionara una substancia que fuera capaz de transformar el glucógeno muscular en glucosa.

El hecho de que la adrenalina disminuye la cantidad de glucógeno muscular, puede aceptarse como definitivo.

En cuanto a la acción sobre el glucógeno hepático, ella es clara en la rata y conejo, en los cuales hay una fase de disminución seguida de una de aumento. En el perro casi siempre se observa una disminución sin que se haya logrado conocer los factores que intervienen para determinar el efecto inverso de la adrenalina.

El ácido láctico aumenta marcadamente bajo la acción de la adrenalina y está probado que el hígado puede transformarlo en glucógeno.

En lo que se refiere a la influencia sobre la utilización de glúcidos, las experiencias no son concluyentes, pero parece que es disminuída por la adrenalina. Las investigaciones sobre la diferencia de glucemia arteriovenosa no merecen mucha confianza, por existir otras causas que la hacen variar: concentración de la sangre, velocidad, etc.

La adrenalina aumenta las combustiones, pero no especialmente a expensas de los glúcidos, como lo prueba el hecho de que el cociente respiratorio sólo se eleva fugazmente y 
coincidiendo con una hiperventilación y disminución de la tensión de $\mathrm{CO}_{2}$ alveolar.

\section{Conclusiones}

La adrenalina determina:

Aumento de la glucemia;

Aumento de la lactacidemia;

Disminución del glucógeno muscular;

Aumento o disminución, según los casos, del glucógeno hepático;

Aumento del consumo de oxígeno con elevación del cociente respiratorio debido probablemente a la hiperventilación pulmonar.

Parece disminuir, por su acción, la utilización de glúcidos.

La glucosa vertida en la sangre parece provenir toda del hígado, y los músculos sólo podrían proporcionarla indirectamente por el ácido láctico que, en el hígado, se transformaría en glucosa. 


\section{CAPITULO IV}

\section{ACCION DEL EXTRACTO CORTICOSUPRARRENAL}

Generalidades, $p .53$ - ACción sOBRE LA GLUCEMIA, p. 53: Conejo, p. 53; Rata, p. 54; Perro, p. 54 - Acción sobre el glucógeno muscular y hepático en ratas, p. 55 - LA RECOMPOSICIÓN DEL GLUCÓGENO MUSCULAR DESPUÉS DE LA FATIGA, p. 58 - Perros suprarrenoprivos, $p .59-$ Perros desmedulizados, $p$. 60 - Acción de la glucosa en la recomposición del glucógeno muscular después de la fatiga, p.60-Acción del extracto corticosuprarrenal sobre la recomposición del glucógeno después de la fatiga, p. 61 - Acción del extracto corticosuprarrenal sobre la reconstitución del glucógeno muscular en perros normales, p. 62 - LA FORMACIÓN DE GLUCÓGENO POR INYECCIÓN DE GLUCOSA, p. 64: En perros suprarrenoprivos, p. 64 - En perros suprarrenoprivos inyectados con extracto, p. 65 - En perros suprarrenoprivos inyectados con insulina, p. 65 - Influencia del extracto corticosuprarrenal en los perros pancreatoprivos, p. 66 - INFLUENCIA DEL EXTRACTO CORTICOSUPRARRENAL SOBRE LA TOLERANCIA A LA GLUCOSA, p. 67 - Acción del extracto cortisuprarrenal en un perro parcialmente pancreatoprivo, $p .70-$ Discusión, $p .71$ - CONCLUSIONES, p. 72.

Generalidades. - Según Britton y Silvette (1932), el extracto corticosuprarrenal produce en las ratas normales un aumento de glucemia $(50-100 \%)$, del glucógeno muscular $(100 \%)$, y especialmente del glucógeno hepático (1 - 5 veces). Igual efecto se observaría en conejos y gatos, en los cuales el glucógeno hepático podría aumentar 3 a 5 veces sobre las cifras normales. Eñ los gatos suprarrenoprivos, en los cuales hallaron descenso de la glucemia y del glucógeno muscular, gran disminución del glucógeno hepático que puede llegar a desaparecer y ligero aumento de la lactacidemia, el extracto provocó la normalización.

\section{ACCIÓN SOBRE LA GLUCEMIA}

Conejo. - Dos conejos en ayunas desde 20 horas antes fueron inyectados con $10 \mathrm{cc}$. de extracto corticosuprarrenal ( 1 ce. igual a 20 grs. de glándula) por vía subcutánea. La sangre se extrajo de la oreja y se dosó la glucemia según Hagedorn y Jensen. (Cuiadro $7^{\circ}$ ). 
CUAdRo $7^{?}$

Conejos inyectados con $10 \mathrm{cc}$. de extracto corticosuprarrenal

\begin{tabular}{l|l|l|l|l|l|l|l}
\hline $\begin{array}{c}\text { Peso: } \\
\text { kgs. }\end{array}$ & Antes & 1 h, & 2 hs, & 3 hs. & 4 hs. & 5 hs. & 6.30 h.. \\
\hline 1.75 & 1.27 & 1.92 & 1.72 & 1.58 & 1.54 & 1.36 & 1.01 \\
2.45 & 1.17 & 1.52 & 1.36 & 1.45 & 1.49 & 1.45 & 0.99 \\
\hline
\end{tabular}

Glucemias en grs. por mil.

Se produjo una elevación neta de la glucemia, especialmente marcada en la primera hora y que se mantuvo durante 5 horas.

Rata. - Seis ratas de 120 - 150 gramos, mantenidas en ayunas durante 24 horas, fueron inyectadas con distintas dosis de extracto cortical. Se les extrajo sangre cortando la cola 0 al final y sólo en algunas por punción cardíaca. (Cuadro $8^{\circ}$ )

CUAdRo $8^{\circ}$

Glucemia de las ratas inyectadas con extracto corticosuprarrenal

\begin{tabular}{|c|c|c|c|c|}
\hline Rata & $\begin{array}{l}\text { Dosis de } \\
\text { extracto }\end{array}$ & 0 & 2 hs. & 5 hs. \\
\hline $\begin{array}{l}\text { OD } \\
\text { OI } \\
2 O \\
\text { MD } \\
\text { MI } \\
2 M\end{array}$ & $\begin{aligned} 1 & \text { cc. } \\
1 & \text { cc. } \\
1 & \text { cc. } \\
3 & \text { cc. } \\
3 & \text { cc. } \\
3 & \text { cc. }\end{aligned}$ & $\begin{array}{l}\overline{0.98} \\
0.76 \\
0.86 \\
0.94 \\
0.68\end{array}$ & $\begin{array}{l}0.94 \\
1.44 \\
1.38 \\
1.76 \\
1.44 \\
1.12\end{array}$ & $\begin{array}{l}1.12 \\
1.26 \\
1.34 \\
1.26 \\
0.98 \\
1.04\end{array}$ \\
\hline
\end{tabular}

Se produjo también en las ratas una hiperglucemia que se mantenía aún en algunas a las 5 horas.

Perro. - Harrop, Swingle y Pfiffner (1931) han inyectado 25 a 100 cc. de extracto por vía venosa a perros normales sin encontrar ninguna modificación de la glucemia. En cambio, Regnier y Simonnet (1932) han observado aumentos glucémicos de $60 \%$ sobre el valor inicial, y, por inyecciones diarias, pretenden haber obtenido estados de hiperglucemia permanente.

En nuestros perros suprarrenoprivos que recibieron extracto (Cuadro $9^{\circ}$ ) en diversas dosis desde la tarde de la 
operación, no se observó una mayor diferencia con la de los no tratados. (Cuadro $1^{\circ}$ ).

\section{Cuadro $9^{\circ}$}

Glucemias de perros suprarrenoprivos inyectados con extracto corticosuprarrenal.

\begin{tabular}{r|c|c|c}
\hline Perro N. ${ }^{0}$ & Antes & 24 hs. & 48 hs. \\
\hline 25 & & 1.30 & \\
46 & & 1.07 & \\
47 & & 0.82 & \\
57 & 1.11 & 1.12 & 0.86 \\
78 & 1.07 & & 0.72 \\
79 & 0.84 & & 0.74 \\
123 & 0.93 & & 0.77 \\
124 & 0.74 & 1.08 & 0.73 \\
126 & & & \\
\hline
\end{tabular}

\section{ACCIÓN SOBRE EL GLUCÓGENO MUSCULAR Y HEPÁTICO EN RATAS.}

A ratas suprarrenoprivas desde seis días antes se inyectó 1 cc. de extracto corticosuprarrenal durante tres días. Se las dejó en ayunas 24 horas. Cuatro horas después de la última inyección y de administrarles $0.5 \mathrm{gr}$. de glucosa por boca, fueron decapitadas. La glucemia se dosó según Hagedorn y Jensen y el glucógeno según Pflüger (1). (Cuadro 10).

\section{CuAdro $10^{\circ}$}

Ratas suprarrenoprivas desde seis días antes, sacrificadas 4 horas después de la última inyección y de administrar $0.5 \mathrm{gr}$. de glucosa (Glucógeno en grs. por 100) per os (ayuno de 24 horas).

Lote I. - Ratas inyectadas durante tres días consecutivas con 1 cc. de extracto corticosuprarrenal.

\begin{tabular}{c|c|c|c|c}
\hline Marca & $\begin{array}{c}\text { Peso } \\
\text { grs. }\end{array}$ & Glucemia & $\begin{array}{c}\text { Glucógeno } \\
\text { hepático }\end{array}$ & $\begin{array}{c}\text { Glucógeno } \\
\text { muscular }\end{array}$ \\
\hline MI & 295 & 1.54 & 2.103 & 0.095 \\
2M & 210 & 1.72 & 1.732 & 0.045 \\
2 O & 195 & 1.61 & 2.943 & 0.082 \\
OI $1 / 2 \mathrm{C}$ & 145 & 2.08 & 3.460 & 0.074 \\
OD $1 / 2 \mathrm{C}$ & 145 & 1.29 & 1.457 & 0.135 \\
\hline \multicolumn{5}{r}{} \\
\hline
\end{tabular}

(1) Los dosajes de glucógeno en las ratas fueron efectuados por el Dr. Mazzocco, a quien quedamos agradecidos. 
Lote II. - Testigos no inyectados. (Un día de ayuno y $0.5 \mathrm{gr}$. de glucosa)

\begin{tabular}{l|c|c|c|c}
\hline Marca & $\begin{array}{c}\text { Peso } \\
\text { grs. }\end{array}$ & Glucemia & $\begin{array}{c}\text { Glucogeno } \\
\text { hepático }\end{array}$ & $\begin{array}{c}\text { Glucégeno } \\
\text { muscular }\end{array}$ \\
\hline MI & 160 & 1.17 & 3.681 & 0.383 \\
2O & 185 & 1.17 & 1.652 & 0.202 \\
OI $1 / 2 \mathrm{C}$ & 165 & 1.29 & 1.441 & 0.229 \\
OI & 235 & 1.24 & 1.380 & 0.231 \\
2M & 160 & 1.22 & 0.521 & 0.153 \\
\hline & T. M. & 1.20 & 1.735 & 0.239 \\
\hline
\end{tabular}

Como puede observarse, hubo en el lote inyectado una elevación de la glucemia, una disminución del glucógeno muscular y un aumento del hepático. Es decir, que obtuvimos el efecto descrito para la adrenalina. En vista de este resultado, decidimos repetir el experimento, pero utilizando un extracto tratado con una solución de bicarbonato de sodio para destruir la adrenalina.

Las ratas, todas machos, fueron operadas 4 días antes y divididas en 5 lotes: Lote $1^{\circ}$, se inyectan durante 4 días consecutivos con $1 \mathrm{cc}$. de extracto corticosuprarrenal (1 cc. igual a 20 grs. de glándula); se sacrifican 4 horas después de la última inyección ( 24 horas de ayuno). Lote $2^{\circ}$, inyectadas con 1 cc. de suero fisiológico en lugar de extracto. Lote 3 , inyectadas con extracto como el lote $1^{\circ}$. pero administrando $0.5 \mathrm{gr}$. de glucosa "per os" 4 horas antes. Lote $4^{\circ}$. igual que el lote $3^{\circ}$ pero inyectadas con suero fisiológico. Lote $5^{\circ}$, operadas, pero sin sacar las suprarrenales.

\section{CUADRO $11^{\circ}$}

Ratas machos operadas 8 días antes.

Lote.I. - Ratas inyectadas durante 4 días consecutivos con 1 cc. de extracto corticosuprarrenal; sacrificadas $4 \mathrm{hs}$. después de la última inyección (24 hs. de ayuno).

\begin{tabular}{l|c|c|c|c}
\hline Marca & $\begin{array}{c}\text { Peso } \\
\text { grs. }\end{array}$ & Glucemia & $\begin{array}{c}\text { Glucógeno } \\
\text { hepático }\end{array}$ & $\begin{array}{c}\text { Glucógeno } \\
\text { muscular }\end{array}$ \\
\hline MI & 170 & 0.63 & 0.048 & 0.187 \\
OI & 175 & 0.66 & 0.029 & 0.125 \\
OD & 355 & 0.67 & 0.024 & 0.090 \\
2O & 160 & 0.60 & 0.055 & 0.153 \\
MD & 155 & 0.67 & 0.017 & 0.094 \\
2M & 180 & 0.62 & 0.021 & 0.111 \\
\hline \multicolumn{5}{r}{} \\
\hline
\end{tabular}


(Cuadro 11\%, continuación).

Lote II. - Ratas inyectadas durante 4 dias consecutivos con $1 \mathrm{cc}$. de solución fisiológica.

\begin{tabular}{c|c|c|c|c}
\hline Marca & $\begin{array}{c}\text { Peso } \\
\text { grs. }\end{array}$ & Glucemia & $\begin{array}{c}\text { Glucógeno } \\
\text { hepático }\end{array}$ & $\begin{array}{c}\text { Glucógeno } \\
\text { muscular }\end{array}$ \\
\hline 20 & 165 & 0.83 & 0.017 & 0.110 \\
OD & 350 & - & 0.039 & 0.146 \\
2M & 180 & - & 0.069 & 0.136 \\
MI & 280 & 0.92 & 0.072 & 0.124 \\
MD & 315 & 0.94 & 0.043 & 0.100 \\
OI & 210 & 0.80 & 0.035 & 0.169 \\
\hline \multicolumn{5}{r}{} \\
\hline
\end{tabular}

Lote III. - Igual que lote I, pero tratados con 0.5 grs. de glucosa "per os" 4 horas antes.

\begin{tabular}{|c|c|c|c|c|}
\hline Marca & $\begin{array}{l}\text { Peso } \\
\text { grs. }\end{array}$ & Glucemia & $\begin{array}{l}\text { Glucógeno } \\
\text { hepático }\end{array}$ & $\begin{array}{l}\text { Glucógeno } \\
\text { muscular }\end{array}$ \\
\hline $\begin{array}{l}20 \\
\mathrm{MD} \\
\mathrm{MI} \\
2 \mathrm{M}\end{array}$ & $\begin{array}{l}260 \\
165 \\
185 \\
175\end{array}$ & $\begin{array}{r}1.33 \\
1.37 \\
1.04\end{array}$ & $\begin{array}{l}0.143 \\
0.229 \\
0.020 \\
0.016\end{array}$ & $\begin{array}{l}0.105 \\
0.137 \\
0.210 \\
0.047\end{array}$ \\
\hline & T. M. & 1.24 & 0.102 & 0.047 \\
\hline
\end{tabular}

Lote IV. - Igual que lote III, pero tratadas con sol. fisiológica en vez de extracto.

\begin{tabular}{|c|c|c|c|c|}
\hline Marca & $\begin{array}{l}\text { Peso } \\
\text { grs. }\end{array}$ & Glucemia & $\begin{array}{l}\text { Glucógeno } \\
\text { hepático }\end{array}$ & $\begin{array}{l}\text { Glucógeno } \\
\text { muscular }\end{array}$ \\
\hline $\begin{array}{c}\text { OD } \\
\text { OI } \\
\text { MD }\end{array}$ & $\begin{array}{l}295 \\
325 \\
210\end{array}$ & $\begin{array}{l}1.19 \\
1.09 \\
1.36\end{array}$ & $\begin{array}{l}0.733 \\
0.616 \\
0.311\end{array}$ & $\begin{array}{l}0.123 \\
0.091 \\
0.689\end{array}$ \\
\hline & T. I & 1.21 & 0.553 & 0.101 \\
\hline
\end{tabular}

Lote V. - Ratas operadas pero sin sacar las suprarrenales.

\begin{tabular}{c|c|c|c|c}
\hline Marca & $\begin{array}{c}\text { Peso } \\
\text { grs. }\end{array}$ & Glucemia & $\begin{array}{c}\text { Glucógeno } \\
\text { hepático }\end{array}$ & $\begin{array}{c}\text { Glueógeno } \\
\text { muscular }\end{array}$ \\
\hline OD & 195 & 0.93 & 0.214 & 0.222 \\
MD & 270 & 0.91 & 0.175 & 0.176 \\
2O & 260 & 0.84 & 0.209 & 0.183 \\
M & 275 & 0.89 & 0.653 & 0.256 \\
2M & 320 & 0.93 & 0.794 & 0.212 \\
MI & 240 & 0.93 & 0.391 & 0.164 \\
1/2C & 200 & 0.73 & 0.460 & 0.200 \\
OI & 275 & 0.84 & 0.553 & 0.231 \\
\hline \multicolumn{5}{r}{} \\
\hline \multicolumn{5}{r}{}
\end{tabular}


Los resultados obtenidos en este experimento son distintos de los del anterior. Entre el lote de ratas inyectadas con extracto ( $\mathrm{N}^{\circ}$ 1) y las inyectadas con solución fisiólogica ( $\left.N^{\circ} 2\right)$ no hay mayor diferencia en los glucógenos hepático y muscular. Sólo llaman la atención las glucemias bajas $(0.62)$ de las inyectadas: hemos creído que pueden haber estado en una fase de hipoglucemia post-hiperglucémica.

En las ratas que recibieron además $1 / 2$ gr. de glucosa por boca (lote III), el glucógeno muscular y la glucemia fueron iguales en las inyectadas y en las no inyectadas (lote IV), pero el glucógeno hepático fué mucho más alto en estas últimas. Ignoramos cuál puede ser la causa de este resultado.

En las ratas operadas sin sacar las suprarrenales (lote V) la cantidad de glucógeno muscular y hepático era mayor que en las suprarrenalectomizadas; hecho que está de acuerdo con las experiencias que hemos relatado en el capítulo II.

Por consiguiente, dada la divergencia de los resultados en los diversos experimentos realizados, no es posible sacar conclusión alguna al respecto.

\section{LA RECOMPOSICION DEL GLUCOGENO MUSCULAR DESPUES DE LA FATIGA. (1)}

Hemos estudiado la recomposición del glucógeno muscular después de una fatiga intensa. Las experiencias se realizaron en perros suprarrenoprivos desde 24 y 48 horas antes, en la siguiente forma: anestesia con cloralosa en cantidad variable, según el estado del animal. Con la dosis corriente para los perros normales ( 0.08 gr. por kg.), se produjo en varios casos la muerte de los suprarrenoprivos, hecho que no nos extraña, pues es conocida su gran sensibilidad a diversos tóxicos. Se practicaba en seguida la sección bien alta de ambos ciáticos con el objeto de paralizar los músculos para impedir las pérdidas de glucógeno por las contracciones y para poder excitar el músculo por el cabo periférico. Luego con , un carrete de inducción, se provocaba en ambas patas la tetanización durante 15 minutos con interrupciones de 5 segundos cada minuto. Inmediatamente se hacía la primera toma de

(1) Estas experiencias fueron realizadas en colaboración con el Dr. R. Dambrosi. 
tres músculos de la pata de un lado (tibial anterior extensor común y gemelo). La disección de estos músculos se hacía durante la tetanización, de modo que las muestras se extraían apenas terminada ésta. Después de una hora de reposo se hacía la toma de músculo en la otra pata (1). Los trozos de músculo se colocaban inmediatamente de extraídos en tubos tarados con $\mathrm{KOH}$ al 60 \% mantenidos en bañomaría.

En los perros normales se encuentran inmediatamente después de la fatiga cifras bajas de glucógeno, pero después de una hora de reposo ya han alcanzado valores normales. La cantidad de glucógeno se normaliza en menos de una hora: según Milroy (1927) bastan 8 minutos; y Debois (1930) en 15 minutos, obtiene una recomposición completa.

CuAdro $12^{\circ}$

Perros normales

\begin{tabular}{|c|c|c|c|c|c|c|c|c|c|}
\hline \multirow{3}{*}{ N. 0} & \multirow{3}{*}{$\begin{array}{c}\text { Peso } \\
\text { kg. }\end{array}$} & \multicolumn{8}{|c|}{ Glucógeno en mgrs. por $100 \mathrm{grs}$. de másculo fresco } \\
\hline & & \multicolumn{4}{|c|}{ En seguida de la fatiga } & \multicolumn{4}{|c|}{ Después de 1 hora de reposo } \\
\hline & & $\begin{array}{c}\text { Tibial } \\
\text { anterior }\end{array}$ & $\begin{array}{l}\text { Extensor } \\
\text { común }\end{array}$ & Gemelo & $\begin{array}{l}\text { Termino } \\
\text { medio }\end{array}$ & $\begin{array}{c}\text { Tibial } \\
\text { anterior }\end{array}$ & $\begin{array}{l}\text { Extensor } \\
\text { comán }\end{array}$ & Gemelo & $\begin{array}{l}\text { Termino } \\
\text { medio }\end{array}$ \\
\hline 1 & 8.5 & 156 & 209 & 85 & 150 & 478 & 550 & 466 & 498 \\
\hline 2 & 10.0 & 286 & 196 & 237 & 240 & 479 & 475 & 481 & 478 \\
\hline 3 & 9.0 & 178 & 204 & 97 & 160 & 509 & 537 & 493 & 513 \\
\hline 4 & 6.2 & 90 & 91 & 103 & 95 & 600 & 540 & 615 & 585 \\
\hline
\end{tabular}

Perros suprarrenoprivos. - De los perros suprarrenoprivos desde 24 horas, hubo tres ( $N^{\circ} 4,5$ y 6 ) que reconstituyeron como los normales. En 4 (No 1, 2, 3 y 7) la cantidad de glucógeno era, a la hora, manifiestamente más baja que en los perros normales. En uno ( $N$ \% 8) el glucógeno no aumentó en la hora de reposo.

En los suprarrenoprivos de 48 horas ( $\mathrm{N}^{\circ} 9,10,11$ y 12) la cantidad de glucógeno apenas aumentó durante la hora de reposo.

Existe, por lo tanto, en los perros suprarrenoprivos, un evidente trastorno en la capacidad de formar glucógeno mus-

(1) Se había comprobado previamente que la cantidad de glucógeno muscular en reposo es casi igual en ambas patas. Las cifras halladas por Dambrosi fueron las siguientes: 575 y 650,374 y 403,314 y 320,403 y 422,473 y 490,293 y 292 (mgs. por 100 grs.). Como se ve, la mayor diferencia entre una pata y la otra fué de 75 mgs. por 100 grs. de músculo. 
cular durante la fatiga, trastorno que se observa ya a las 24 horas de la operación en casi dos tercios de los casos y que no falta en ninguno a las 48 horas.

\section{Cuadro $13^{\circ}$}

Perros suprarrenoprivos.

Las glucemias corresponden al momento de cada extracción muscular.

\begin{tabular}{|c|c|c|c|c|c|c|c|c|c|c|c|c|}
\hline \multirow{3}{*}{ N. 0} & \multirow{3}{*}{$\begin{array}{c}\text { Peso } \\
\text { kg. }\end{array}$} & \multirow{3}{*}{$\begin{array}{c}\text { Tiempo } \\
\text { de } \\
\text { opera- } \\
\text { dos }\end{array}$} & \multicolumn{10}{|c|}{ Glucógeno en mgrs, por $100 \mathrm{grs}$. de músculo fresco } \\
\hline & & & \multicolumn{5}{|c|}{ En seguida de la fatiga } & \multicolumn{5}{|c|}{ Después de 1 hora de reposo } \\
\hline & & & $\begin{array}{l}\text { Tibial } \\
\text { ante- } \\
\text { rior }\end{array}$ & $\begin{array}{c}\text { Exten- } \\
\text { sor } \\
\text { comán }\end{array}$ & Gemelo & $\begin{array}{c}\text { Término } \\
\text { medio }\end{array}$ & $\begin{array}{l}\text { Gluce- } \\
\text { mia }\end{array}$ & $\begin{array}{c}\text { Tibial } \\
\text { ante- } \\
\text { rior }\end{array}$ & $\begin{array}{l}\text { Exten- } \\
\text { sor } \\
\text { común }\end{array}$ & Gemelo & $\begin{array}{c}\text { Término } \\
\text { medio }\end{array}$ & $\begin{array}{c}\text { Gluce- } \\
\text { mia }\end{array}$ \\
\hline 1 & 8.5 & 24 hs. & 72 & 55 & 93 & 73 & 0.65 & 178 & 113 & 166 & 152 & \\
\hline 2 & 9.0 & $84 \gg$ & 173 & 150 & 76 & 133 & 0.94 & 333 & 209 & 311 & 284 & 0.74 \\
\hline 3 & 14.5 & 24 & 73 & 90 & 118 & 94 & 0.76 & 192 & 168 & 200 & 186 & 0.56 \\
\hline 4 & 11.0 & & 116 & 90 & 164 & 123 & 0.98 & 383 & 402 & 425 & 403 & 0.87 \\
\hline 5 & 7.5 & 24 & 129 & 146 & 170 & 148 & 0.89 & 545 & 506 & 470 & 507 & 0.67 \\
\hline 6 & 11.0 & & 212 & 235 & 188 & 212 & 0.81 & 691 & 436 & 507 & 545 & 0.56 \\
\hline 7 & 11.0 & 24 & 109 & 35 & 20 & 55 & - & 113 & 81 & 165 & 126 & - \\
\hline 8 & 11.0 & 24 & 160 & 40 & 92 & 97 & - & 129 & 47 & 111 & 96 & - \\
\hline 9 & 13.2 & 48 & 46 & 60 & 117 & 74 & - & 98 & 43 & 101 & 81 & - \\
\hline 10 & 12.5 & 48 & 70 & 103 & 95 & 89 & - & 210 & 179 & 122 & 170 & - \\
\hline 11 & 15.6 & 48 & 172 & 36 & 80 & 96 & - & 125 & 125 & 100 & 116 & 0.61 \\
\hline 12 & 14.9 & 48 & 48 & 53 & 105 & 69 & 0.79 & 77 & 24 & 139 & 77 & 0.75 \\
\hline
\end{tabular}

Perros desmedulizados. - La médula suprarrenal no influye la recomposición del glucógeno muscular, como lo atestigua la siguiente experiencia (Dambrosi) realizada en un perro privado de la médula de la suprarrenal izquierda y de toda la suprarrenal derecha.

Cuadro $14^{\circ}$

Perro desmedulizado

\begin{tabular}{|c|c|c|c|c|c|c|c|c|c|}
\hline \multirow{3}{*}{$\begin{array}{c}\text { Peso } \\
\text { kg. }\end{array}$} & \multirow{3}{*}{$\begin{array}{l}\text { Días de } \\
\text { operado }\end{array}$} & \multicolumn{8}{|c|}{ Glucógeno en mgrs. por 100 grs. de músculo fresco } \\
\hline & & \multicolumn{4}{|c|}{ En seguida de la fatiga } & \multicolumn{4}{|c|}{ Después de 1 hora de reposo } \\
\hline & & $\begin{array}{c}\text { Tibial } \\
\text { anterior }\end{array}$ & $\begin{array}{c}\text { Extensor } \\
\text { comán }\end{array}$ & Gemelo & $\begin{array}{l}\text { Término } \\
\text { medio }\end{array}$ & $\begin{array}{c}\text { Tibial } \\
\text { anterior }\end{array}$ & $\begin{array}{c}\text { Extensor } \\
\text { común }\end{array}$ & Gemelo & $\begin{array}{c}\text { Termino } \\
\text { medio }\end{array}$ \\
\hline 8.5 & 8 & 198 & 130 & 165 & 164 & 695 & 571 & 640 & 635 \\
\hline
\end{tabular}

ACCIÓN DE LA GLUCOSA EN LA RECOMPosición DEL GLUCóGENO MUSCULAR DESPUÉS DE LA FATIGA. - Estas experiencias fueron realizadas en colaboración con el Dr. Dambrosi. La tetanización y extracción muscular se realizaron con la técnica 
habitual ya descrita. Cinco perros suprarrenoprivos desde 24 y 48 horas fueron inyectados inmediatamente después de la tetanización con un gramo de glucosa por kg. de peso. Damos a continuación los resultados obtenidos. (Cuadro 15).

CUADRO $15^{\text {? }}$

Suprarrenoprivos inyectados con glucosa

\begin{tabular}{|c|c|c|c|c|c|c|c|c|c|c|c|c|}
\hline \multirow{3}{*}{ N. 0} & \multirow{3}{*}{$\begin{array}{c}\text { Peso } \\
\text { kg. }\end{array}$} & \multirow{3}{*}{$\begin{array}{c}\text { Tiempo } \\
\text { de } \\
\text { opera- } \\
\text { dos }\end{array}$} & \multicolumn{10}{|c|}{ Glucógeno en mgrs. por $100 \mathrm{grs}$. de másculo fresco } \\
\hline & & & \multicolumn{5}{|c|}{ En seguida de la fatiga } & \multicolumn{5}{|c|}{ Después de 1 hora de reposo } \\
\hline & & & $\begin{array}{l}\text { Tibial } \\
\text { ante- } \\
\text { rior }\end{array}$ & $\begin{array}{l}\text { Exten- } \\
\text { sor } \\
\text { común }\end{array}$ & Gemelo & $\begin{array}{c}\text { Termi- } \\
\text { no } \\
\text { medio }\end{array}$ & $\begin{array}{l}\text { Gluce- } \\
\text { mia }\end{array}$ & $\begin{array}{l}\text { Tibial } \\
\text { ante- } \\
\text { rior }\end{array}$ & $\begin{array}{c}\text { Exten- } \\
\text { sor } \\
\text { común }\end{array}$ & Gemelo & $\begin{array}{c}\text { Termi- } \\
\text { no } \\
\text { medio }\end{array}$ & $\begin{array}{c}\text { Gluce- } \\
\text { mia }\end{array}$ \\
\hline 1 & 10.0 & $24 \mathrm{hs}$. & 73 & 56 & 42 & 57 & - & 200 & 215 & 198 & 204 & 2.47 \\
\hline 2 & 8.5 & $24>$ & 198 & 176 & 200 & 191 & - & 537 & 469 & 535 & 510 & 2.25 \\
\hline 3 & 9.7 & 48 & 215 & 160 & 183 & 186 & - & 177 & $2 \geq 9$ & 200 & 202 & 1.60 \\
\hline 4 & 8.5 & 48 & 90 & 58 & 32 & 60 & 2.23 & 125 & 143 & 107 & 125 & 2.04 \\
\hline 5 & 9.5 & 48 & 81 & 63 & 75 & 73 & 3.79 & 110 & 131 & 104 & 115 & 3.79 \\
\hline
\end{tabular}

Sólo uno de los cinco perros, el No 2 (suprarrenoprivo desde 24 horas), tuvo una recomposición normal. En los restantes, las recomposiciones han sido incompletas, aunque hubo un leve ascenso en el No 1 y más leve aún en los de 48 horas.

Basándonos en los precedentes resultados, podemos concluir que la inyección de glucosa a los perros suprarrenoprivos no mejora en mayor grado la recomposición del glucógeno muscular. Aunque es probable que la glucosa inyectada en la sangre haya favorecido el aumento del glucógeno, éste no es muy significativo, pues es subnormal y no es mayor que el que puede observarse en algunos suprarrenoprivos de 24 horas que no han recibido glucosa.

ACCIÓN DEL EXTRACTO CORTICOSUPRARRENAL SOBRE LA RECOMPOSICIÓN DE GLUCÓGENO DESPUÉS DE LA FATIGA. - Hemos visto que los perros suprarrenoprivos no son capaces de reconstruir, en una hora, el glucógeno muscular descompuesto durante una tetanización de 15 minutos. En la forma anteriormente descrita hemos estudiado la formación de glucógeno después de la fatiga en perros suprarrenoprivos que recibieron extracto corticosuprarrenal. Los de 24 horas recibieron 15 cc. repartidos así: 10 cc. subcutáneos, la tarde de la operación; y 5 cc. intraperitoneales, dos horas antes de la fatiga. Los suprarrenoprivos de 48 horas recibieron en total $20 \mathrm{cc}$. de 
extracto: 5 cc. la tarde de la operación; 5 y 5 al día siguiente; y 5 cc. intraperitonales dos horas antes del experimento.

Cuadro $16^{\circ}$

Perros suprarrenoprivos tratados con extracto corticosuprarrenal

\begin{tabular}{|c|c|c|c|c|c|c|c|c|c|c|c|c|}
\hline \multirow{3}{*}{ N. ${ }^{0}$} & \multirow{3}{*}{$\begin{array}{c}\text { Peso } \\
\mathrm{kg} .\end{array}$} & \multirow{3}{*}{$\begin{array}{c}\text { Tiempo } \\
\text { de } \\
\text { opera- } \\
\text { dos }\end{array}$} & \multicolumn{10}{|c|}{ Glucógeno en mgrs. por 100 grs. de músculo fresco } \\
\hline & & & \multicolumn{5}{|c|}{ En seguida de la fatiga } & \multicolumn{5}{|c|}{ Después de 1 hora de reposo } \\
\hline & & & $\begin{array}{c}\text { Tibial } \\
\text { ante- } \\
\text { rior }\end{array}$ & $\begin{array}{c}\text { Exten- } \\
\text { sor } \\
\text { común }\end{array}$ & Gemelo & $\begin{array}{c}\text { Termi- } \\
\text { no } \\
\text { medio }\end{array}$ & $\begin{array}{c}\text { Gluce- } \\
\text { mia }\end{array}$ & $\begin{array}{l}\text { Tibial } \\
\text { ante- } \\
\text { rior }\end{array}$ & $\begin{array}{c}\text { Exten- } \\
\text { sor } \\
\text { común }\end{array}$ & Gemelo & $\begin{array}{c}\text { Termi- } \\
\text { no } \\
\text { medio }\end{array}$ & $\begin{array}{l}\text { Gluce- } \\
\text { mia }\end{array}$ \\
\hline 1 & 9.5 & 24 h8. & 198 & 103 & 156 & 152 & 0.88 & 878 & 1613 & 581 & 1. 024 & 0.69 \\
\hline 2 & 8.5 & $24>$ & 84 & 196 & 140 & 140 & 1.30 & 763 & 1289 & 1072 & 1.041 & 1.28 \\
\hline 3 & 10.6 & $24>$ & 207 & 130 & 178 & 172 & 0.84 & 394 & 595 & 474 & 488 & 0.91 \\
\hline 4 & 11.6 & 24 & 120 & 146 & 150 & 139 & 0.82 & 789 & 846 & 659 & 765 & 0.82 \\
\hline 5 & 11.8 & 48 & 214 & 60 & 111 & 128 & 0.88 & 370 & 398 & 205 & 324 & 0.99 \\
\hline 6 & 9.0 & 48 & 207 & 74 & 132 & 138 & - & 699 & 671 & 800 & 723 & - \\
\hline 7 & 13.3 & $48 \quad$ & 39 & 63 & 50 & 51 & - & 392 & 314 & 305 & 337 & - \\
\hline 8 & 12.0 & 48 ? & 111 & 89 & .195 & 132 & 0.63 & 941 & 1002 & 877 & 940 & 0.56 \\
\hline
\end{tabular}

En tres de los suprarrenoprivos desde 24 horas se obtuvieron cifras de recomposición más altas que en los perros normales, en los cuales no pasa en general de 600 mgrs. por 100 grs. de músculo. En el restante ( $\mathrm{N}^{\circ} 3$ ), el glucógeno llegó a 488 , cantidad que es normal; tal vez este perro no tuvo más elevación porque recibió la última inyección por vía subcutánea.

De los cuatro suprarrenoprivos desde 48 horas, dos (No 6 y 8) dieron cifras: muy altas; los restantes tuvieron mala recomposición. Es de observar que denotaron acentuados síntomas de insuficiencia suprarrenal, atribuíble quizás a la poca actividad de la remesa de extracto con que fueron tratados.

Por lo tanto, estos resultados nos permiten concluir que el extracto corticosuprarrenal no sólo compensa la mala recomposición del glucógeno muscular de los perros suprarrenoprivos, sino que llega a determinar en ellos recomposiciones mayores que la de los perros normales no tratados. Ello se observa claramente en el gráfico I.

ACCIÓN DEL EXTRACTO CÓRTICOSUPRARRENAL SOBRE LA RECONSTITUCIÓN DEL GLUCÓGENO MUSCULAR EN PERROS NORMALES. - Habiendo observado que el extracto córticosuprarrenal determinaba en los perros suprarrenoprivos una resíntesis super- 
normal del glucógeno muscular, hemos creído tener suficiente fundamento para suponer que igual efecto podría obtenerse en perros normales.

\section{Gráfico I.}

Recomposición del glucógeno muscular después de la fatiga.
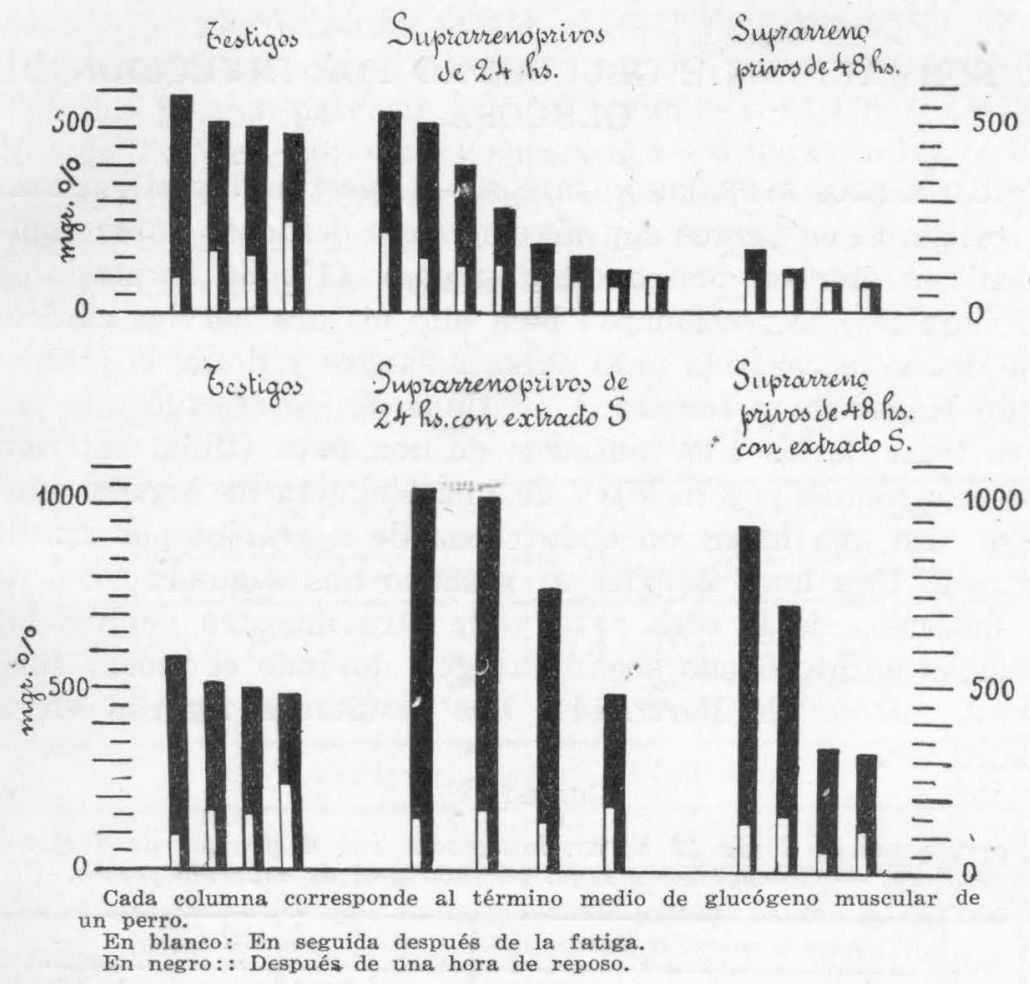

Suprarrence

Administramos a tres perros por vía intraperitoneal 10 cc. de extracto, dos horas antes de la fatiga, y 5 cc. al concluir ésta. Los resultados figuran en el cuadro $17^{\circ}$.

\section{CuAdro $17^{\circ}$}

Perros normales tratados con extracto corticosuprarrenal.

\begin{tabular}{c|c|c|c|c|c|c|c|c}
\hline \multirow{3}{*}{$\begin{array}{c}\text { Peso } \\
\text { kg. }\end{array}$} & \multicolumn{6}{|c|}{ Glucógeno en mgrs. por 100 grs. de músculo fresco } \\
\cline { 2 - 9 } & \multicolumn{3}{|c|}{ En seguida de la fatiga } & \multicolumn{3}{|c}{ Después de 1 hora de reposo } \\
\cline { 2 - 9 } & $\begin{array}{c}\text { Tibial } \\
\text { anterior }\end{array}$ & $\begin{array}{c}\text { Extensor } \\
\text { comán }\end{array}$ & Gemelo & $\begin{array}{c}\text { Termino } \\
\text { medio }\end{array}$ & $\begin{array}{c}\text { Tibial } \\
\text { anterior }\end{array}$ & $\begin{array}{c}\text { Extensor } \\
\text { común }\end{array}$ & Gemelo & $\begin{array}{c}\text { Termino } \\
\text { medio }\end{array}$ \\
\hline 8.7 & 180 & 270 & 142 & $\mathbf{1 9 7}$ & 701 & 509 & 533 & 581 \\
6.5 & 97 & 74 & 80 & $\mathbf{8 3}$ & 662 & 612 & 553 & 609 \\
5.9 & 145 & 122 & 97 & $\mathbf{1 2 1}$ & $\mathbf{6 9 7}$ & 571 & 494 & $\mathbf{5 6 4}$ \\
\hline
\end{tabular}


La cantidad de glucógeno hallada después de una hora de reposo, si bien es elevada, no puede considerarse como mayor que la de los perros normales no tratados. Creemos que estos resultados negativos deben atribuirse a la dosis insuficiente de extracto que recibieron estos perros.

\section{LA FORMACION DE GLUCOGENO POR INYECCION DE GLUCOSA.}

EN PERROS SUPRARRENOPRIVOS. - Nuestras investigaciones se realizaron en perros suprarrenoprivos desde 48 horas (operados con éter en uno o dos tiempos) (1). Se anestesiaron con cloralosa, se seccionaron bien alto los dos nervios ciáticos y se disecó la carótida para extraer sangre y dosar la glucosa según Hagedorn y Jensen. A continuación se efectuó una primera toma de los tres músculos de una pata (tibial anterior, extensor común y gemelo) y de una lengüeta de hígado. Luego se hizo una inyección endovenosa de 2 gramos por kg. de dextrosa. Una hora después se practicó una segunda toma de los músculos de la otra pata y de otra muestra de hígado. (Dosajes de glucógeno según Pflüger, dosando el azúcar final por el método de Bertrand). Los resultados figuran en el cuadro $18^{\circ}$.

\section{Cuadro $18^{\circ}$}

Suprarrenoprivos desde 48 horas, inyectados con 2 gramos de dextrosa por kg. - Glucógeno en mgs. por 100 grs. de músculo fresco.

\begin{tabular}{|c|c|c|c|c|c|c|c|c|c|c|c|}
\hline \multirow{2}{*}{ N. ${ }^{0}$} & \multirow{2}{*}{$\begin{array}{l}\text { Peso } \\
\text { kg. }\end{array}$} & \multicolumn{5}{|c|}{ Antes de inyectar la dextrosa } & \multicolumn{5}{|c|}{ Una hora después } \\
\hline & & $\begin{array}{c}\text { Higa- } \\
\text { do }\end{array}$ & $\begin{array}{c}\text { Tibial } \\
\text { anterior }\end{array}$ & $\begin{array}{c}\text { Extensor } \\
\text { común }\end{array}$ & Gemelo & $\begin{array}{c}\text { Termino } \\
\text { medio }\end{array}$ & Higado & $\begin{array}{c}\text { Tibial } \\
\text { anterior }\end{array}$ & $\left|\begin{array}{c}\text { Extensor } \\
\text { común }\end{array}\right|$ & Gemelo & $\begin{array}{c}\text { Termino } \\
\text { medio }\end{array}$ \\
\hline A-4 & 81.0 & 92 & 471 & 400 & 362 & 411 & 148 & 449 & 391 & 339 & 393 \\
\hline A-5 & 11.4 & 59 & 617 & 556 & 543 & 572 & 370 & 529 & 589 & 406 & 488 \\
\hline A-6 & 12.8 & 82 & 452 & 565 & 511 & 509 & 222 & 398 & 451 & 480 & 443 \\
\hline A-7 & 15.2 & 95 & 617 & 807 & 603 & 676 & 87 & 590 & 600 & 501 & 563 \\
\hline
\end{tabular}

(Ver las glucemias en el Cuadro $N^{\circ}$ 22)

Puede observarse que el glucógeno muscular, en lugar de - aumentar, disminuyó en todos los casos. En el hígado hubo un ligero ascenso en algunos. Pero las cifras iniciales y finales

(1) Estas experiencias fueron realizadas en colaboración con los doctores Foglia V. Fernández R. y Novelli A. 
son muy bajas en comparación con las halladas en perros normales clorosados que fueron de 1877, 2203, 2183 y 1700 mgs. por 100 grs. de hígado.

EN PERROS SUPRARRENOPRIVOS INYECTADOS CON EXTRACTO. - Con la técnica anteriormente descrita hemos estudiado la formación de glucógeno en perros suprarrenoprivos desde 48 horas antes tratados con un extracto corticosuprarrenal preparado con una técnica parecida a la de Swingle y Pfiffner. La dosis fué de $7-8$ cc. por vía subcutánea, 5 - 6 horas antes, y 5 cc. intraperitonal $1 / 2$ hora antes del experimento (cada cc. correspondía a 20 grs. de glándula bovina fresca). El cuadro $19^{\circ}$ detalla los resultados obtenidos.

\section{CUADRO $19^{\circ}$}

Suprarrenoprivos desde 48 horas inyectados con dextrosa y extracto (Glucógeno en mgs. por 100 grs.)

\begin{tabular}{|c|c|c|c|c|c|c|c|c|c|c|c|}
\hline \multirow{2}{*}{ N. ${ }^{\circ}$} & \multirow{2}{*}{$\begin{array}{c}\text { Peso } \\
\text { kg. }\end{array}$} & \multicolumn{5}{|c|}{ Antes de la inyección } & \multicolumn{5}{|c|}{ Una hora después } \\
\hline & & $\begin{array}{c}\text { Higa- } \\
\text { do }\end{array}$ & $\begin{array}{c}\text { Tibial } \\
\text { anterior }\end{array}$ & $\left|\begin{array}{c}\text { Extensor } \\
\text { comán }\end{array}\right|$ & Gemelo & $\begin{array}{c}\text { Término } \\
\text { medio }\end{array}$ & Hígado & $\begin{array}{c}\text { Tibial } \\
\text { anterior }\end{array}$ & $\left|\begin{array}{c}\text { Extensor } \\
\text { común }\end{array}\right|$ & Gemelo & $\begin{array}{c}\text { Término } \\
\text { medio }\end{array}$ \\
\hline B-1 & 10.0 & 667 & 746 & 583 & 695 & 675 & 712 & 856 & 849 & 603 & 770 \\
\hline B-2 & 17.5 & 127 & 729 & 784 & $48 z$ & 665 & 160 & $8: 8$ & 918 & 744 & 830 \\
\hline B-3 & 8.3 & 202 & 730 & 757 & 692 & 726 & 120 & 890 & 1021 & 674 & 862 \\
\hline B-4 & 12.5 & 103 & 640 & 513 & 501 & 551 & 260 & 697 & 785 & 475 & 652 \\
\hline
\end{tabular}

(Ver las glucemias en Cuadro $22^{\circ}$ )

Hubo en los perros así tratados un depósito de glucógeno comparable al de los normales. El aumento en 5 perros normales fué: de 508 a $715 ; 732$ a $839 ; 613$ a $864 ; 560$ a 620 ; 912 a 1036. (Término medio de tres músculos en mgs. por 100 grs. de músculo).

En el hígado, las cifras iniciales fueron siempre más altas que en los no tratados, y hubo un aumento que, aunque no muy acentuado, sólo faltó en un caso.

EN PERROS SUPRARRENOPRIVOS INYECTADOS CON INSULINA. - Tanto la extirpación del páncreas como la de los suprarrenales disminuye la capacidad del músculo de formar glucógeno. Con el objeto de averiguar si la insulina era capaz de compensar, igual que el extracto corticosuprarrenal, la deficiente formación de glucógeno de los suprarrenoprivos, se realizó, en 
dos perros sin suprarrenales desde 48 horas antes, el mismo experimento, pero inyectando insulina en lugar de extracto córticosuprarrenal. La dosis fué de dos unidades por kg., media hora antes del experimento, y dos unidades endovenosas junto con la glucosa en el perro. C-1 y una unidad en el C-2.

CUADRO $20^{\circ}$

Suprarrenoprivos desde 48 horas, inyectados con dextrosa e insulina

\begin{tabular}{|c|c|c|c|c|c|c|c|c|c|c|c|}
\hline \multirow{2}{*}{ N. ${ }^{0}$} & \multirow{2}{*}{$\begin{array}{l}\text { Peso } \\
\text { kg. }\end{array}$} & \multicolumn{5}{|c|}{ Antes de la inyección } & \multicolumn{5}{|c|}{ Una hora después } \\
\hline & & $\begin{array}{c}\text { Higa- } \\
\text { do }\end{array}$ & $\begin{array}{c}\text { Tibial } \\
\text { anterior }\end{array}$ & $\left|\begin{array}{c}\text { Extensor } \\
\text { comán }\end{array}\right|$ & Gemelo & $\begin{array}{c}\text { Término } \\
\text { medio }\end{array}$ & Hígado & $\begin{array}{c}\text { Tibial } \\
\text { anterior }\end{array}$ & $\begin{array}{c}\text { Extensor } \\
\text { común }\end{array}$ & Gemelo & $\begin{array}{c}\text { Término } \\
\text { medio }\end{array}$ \\
\hline C-1 & 9.5 & 167 & 556 & 705 & 402 & 554 & 185 & 858 & 1068 & 667 & 864 \\
\hline C-2 & 9.0 & 158 & 508 & 678 & 465 & 550 & 494 & 762 & 736 & 491 & 663 \\
\hline
\end{tabular}

Glucemias por mil

\begin{tabular}{l|l|l|l|l|l|}
\hline N. & Antes & $\begin{array}{c}\text { Inmediata- } \\
\text { mente }\end{array}$ & 1 hora & 2 horas & 3 horas \\
\hline C-1 & \begin{tabular}{l|l|l|l}
0.62 \\
C-2
\end{tabular} & $\begin{array}{l}7.50 \\
9.60\end{array}$ & $\begin{array}{l}3.44 \\
2.08\end{array}$ & 1.12 & 1.86 \\
\hline
\end{tabular}

El efecto obtenido, en hígado y músculo, fué igual o mayor que con el extracto córticosuprarrenal.

INFLUENCIA DEL EXTRACTO CÓRTICOSUPRARRENAL EN LOS PERROS PANCRÉATOPRIVOS. - Habiendo comprobado que la insulina podía imitar el efecto del extracto córticosuprarrenal, nos hemos propuesto: averiguar si este podía compensar la falta de insulina, y, por otra parte, eliminar la posibilidad de que el extracto cortical obrara aumentando la secreción insular pancreática.

Los perros pancreatoprivos desde 24 horas antes, inyectados con $2 \mathrm{gr}$. de glucosa, por vía endovenosa, no forman glucógeno muscular. En efecto: los términos medios de tres músculos de una pata sacados antes y los de la otra pata sacados una hora después de la inyección de glucosa son los siguientes: 415 y $439 ; 411$ y $402 ; 569$ y $456 ; 443$ y $449 ; 650$ y 642 .

Cuatro perros pancreatoprivos desde 24 horas fueron tratados con extracto córticosuprarrenal. En los dos primeros 
(D-1 y D-2) la dosis fué igual que la usada en los suprarrenoprivos. En los otros dos fué de 10 cc. subcutáneos, tres horas antes; 10 cc. intraperitoneales, media hora antes; y 5 cc. endovenosos junto con la glucosa. Detalles en el cuadro $21^{\circ}$.

Cuadro 21?

Pancreatoprivos desde $24 \mathrm{hs}$. inyectados con extracto corticosuprarrenal

\begin{tabular}{|c|c|c|c|c|c|c|c|c|c|}
\hline \multirow{2}{*}{ N. 0} & \multirow{2}{*}{$\begin{array}{c}\text { Peso } \\
\text { kg. }\end{array}$} & \multicolumn{4}{|c|}{ Antes de la inyección } & \multicolumn{4}{|c|}{ Una hora después } \\
\hline & & $\begin{array}{c}\text { Tibial } \\
\text { anterior }\end{array}$ & $\begin{array}{c}\text { Extensor } \\
\text { común }\end{array}$ & Gemelo & $\begin{array}{c}\text { Término } \\
\text { medio }\end{array}$ & $\begin{array}{c}\text { Tibial } \\
\text { anterior }\end{array}$ & $\begin{array}{l}\text { Extensor } \\
\text { común }\end{array}$ & Gemelo & $\begin{array}{c}\text { Término } \\
\text { medio }\end{array}$ \\
\hline $\begin{array}{l}\text { D-1 } \\
\text { D-2 } \\
\text { D-3 } \\
\text { D-4 }\end{array}$ & $\begin{array}{l}6.0 \\
7.5 \\
8.0 \\
6.0\end{array}$ & $\begin{array}{l}988 \\
728 \\
844 \\
556\end{array}$ & $\begin{array}{l}835 \\
782 \\
737 \\
600\end{array}$ & $\begin{array}{l}742 \\
459 \\
603 \\
581\end{array}$ & $\begin{array}{l}855 \\
656 \\
730 \\
579\end{array}$ & $\begin{array}{l}819 \\
641 \\
853 \\
655\end{array}$ & $\begin{array}{l}849 \\
808 \\
890 \\
667\end{array}$ & $\begin{array}{l}753 \\
455 \\
657 \\
497\end{array}$ & $\begin{array}{l}807 \\
635 \\
800 \\
606\end{array}$ \\
\hline
\end{tabular}

Glucemias por mil

\begin{tabular}{l|l|c|c|c|c|c|c|c}
\hline N.0 & Antes & $\begin{array}{c}\text { Inmediata- } \\
\text { mente }\end{array}$ & $1 / 2$ hora & 1 hora & 2 horas & 3 horas & $\begin{array}{c}\text { Aumento de } \\
\text { gluégeno }\end{array}$ \\
\hline D-1 & 2.19 & 7.50 & 3.92 & 3.92 & 3.06 & 2.92 & -48 \\
D-2 & 2.51 & 7.50 & 4.12 & 4.50 & 2.84 & 2.92 & -21 \\
D-3 & 3.80 & 14.30 & 9.00 & 7.60 & 7.08 & 6.86 & +70 \\
D-4 & 2.70 & 11.30 & 4.68 & 3.96 & 3.70 & 3.76 & +27 \\
\hline
\end{tabular}

Los dos primeros perros se comportaron igual que los pancreatoprivos no tratados. De los dos tratados con dosis más alta, el D-1 tuvo un aumento bastante neto (70 mgs.); el D-2, un aumento pequeño (27 mgs.). Las glucemias son en todos más o menos iguales que en los no tratados. El D-3, que fué el que fijó más glucógeno, fué también el que tuvo una curva más alta.

INFLUENCIA DEL EXTRACTO CÓRTICOSUPRARRENAL SOBRE LA TOLERANCIA A LA GLUCOSA. - Dimos en el capítulo I un resumen de las experiencias anteriores y de las nuestras referentes a las curvas de glucemia halladas después de inyectar glucosa en los animales suprarrenoprivos; daremos aquí el detalle de las experiencias:

Hemos seguido, durante tres horas, la variación glucémica de los mismos perros en que se dosó el glucógeno: Suprarrenoprivos de 48 hs.; suprarrenoprivos de 48 horas inyectados con extracto córticosuprarrenal y perros normales cloralosados. Las cifras se hallarán en el cuadro No $22^{\circ}$. 


\section{GRÁFICO II.}

Formación de glucógeno muscular por inyección de glucosa.

(2 grs. por kg.)

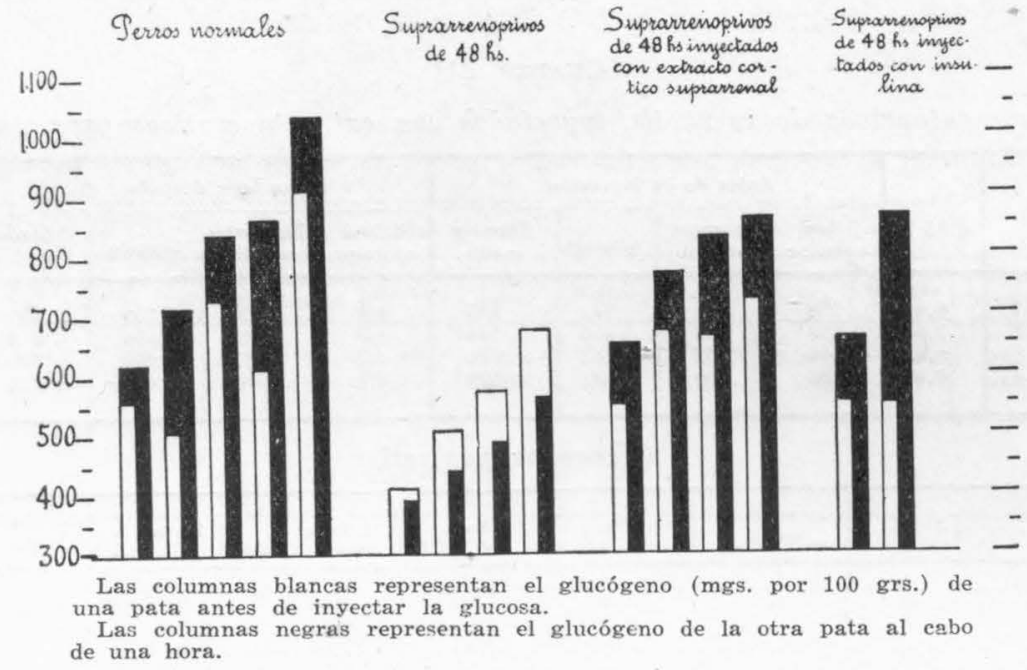

CuAdro $22^{\circ}$

Perros cloralosados inyectados con glucosa, 2 grs. por $\mathrm{kg}$.

(Glucemias:en $\mathrm{gr}$. por mil)

Perros normales

\begin{tabular}{|c|c|c|c|c|c|c|}
\hline Antes & $1 / 2$ hora & 1 hora & $11 / 2$ hora & 2 horas & 3 horas & $\begin{array}{l}\text { Aumento de glué- } \\
\text { geno en mgs. por } \\
100 \text { grs. de músculo }\end{array}$ \\
\hline $\begin{array}{l}1.04 \\
1.06 \\
0.88 \\
1.29 \\
1.26\end{array}$ & $\begin{array}{l}4.44 \\
3.36 \\
2.64 \\
2.96 \\
2.68\end{array}$ & $\begin{array}{l}2.43 \\
2.54 \\
1.90 \\
1.40 \\
1.60\end{array}$ & $\begin{array}{l}1.95 \\
1.86 \\
1.22\end{array}$ & $\begin{array}{l}1.86 \\
1.58 \\
1.12 \\
1.16 \\
1.16\end{array}$ & $\begin{array}{l}1.27 \\
1.48 \\
0.90 \\
0.88 \\
0.98\end{array}$ & $\begin{array}{r}+107 \\
+107 \\
+\quad 251 \\
+\quad 60 \\
+\quad 124\end{array}$ \\
\hline T. M. 1.10 & 3.21 & 1.97 & 1.67 & 1.37 & 1.10 & +110 \\
\hline
\end{tabular}

Perros suprarrenoprivos de $48 \mathrm{hs}$.

\begin{tabular}{|c|c|c|c|c|c|c|c|}
\hline Antes & $\begin{array}{l}\text { Inmediata- } \\
\text { mente }\end{array}$ & $1 / 2$ hora & I hora & $11 / 2$ hora & 2 horas & 3 horas & $\begin{array}{l}\text { Aumento de glué. } \\
\text { geno en mgs. por } \\
100 \text { grs. de músculo }\end{array}$ \\
\hline $\begin{array}{l}1.10 \\
0.93 \\
0.56\end{array}$ & $\begin{array}{r}8.76 \\
7.40 \\
10.20\end{array}$ & $\begin{array}{l}5.16 \\
4.00 \\
\mathbf{3 . 4 0}\end{array}$ & $\begin{array}{l}3.92 \\
2.56 \\
2.60\end{array}$ & $\begin{array}{l}4.18 \\
2.28 \\
3.14\end{array}$ & $\begin{array}{l}3.56 \\
1.78 \\
2.68\end{array}$ & $\begin{array}{l}3.53 \\
1.78 \\
2.53\end{array}$ & $\begin{array}{l}81 \\
-\quad 66 \\
-\quad 113\end{array}$ \\
\hline T. M. 0.86 & 8.74 & 4.18 & 3.02 & 3.20 & 2.67 & 2.61 & . \\
\hline
\end{tabular}


Perros suprarrenoprivos de $48 \mathrm{hs}$, inyectados con extracto

\begin{tabular}{|c|c|c|c|c|c|c|c|}
\hline Antes & $\begin{array}{l}\text { Inmediata- } \\
\text { mente }\end{array}$ & $1 / 2$ hora & 1 hora & $11 / 2$ hora & 2 horas & 3 horas & $\begin{array}{l}\text { Aumento de glucó- } \\
\text { geno en mgs. por } \\
100 \text { grs. de músculo }\end{array}$ \\
\hline $\begin{array}{l}0.74 \\
0.98 \\
0.77 \\
0.57\end{array}$ & $\begin{array}{r}14.90 \\
11.70 \\
7.10 \\
6.40\end{array}$ & $\begin{array}{l}5.04 \\
5.96 \\
4.9 .2 \\
4.20\end{array}$ & $\begin{array}{l}2.76 \\
4.88 \\
3.56 \\
3.00\end{array}$ & $\begin{array}{l}3.20 \\
4.48\end{array}$ & $\begin{array}{l}2.38 \\
3.52 \\
2.82 \\
2.28\end{array}$ & $\begin{array}{l}1.84 \\
2.66\end{array}$ & $\begin{array}{r}95 \\
+\quad 165 \\
+\quad 136 \\
+101\end{array}$ \\
\hline T. M. 0.76 & 10.10 & 5.03 & 3.55 & & 2.78 & & \\
\hline
\end{tabular}

\section{GRÁFICO III.}

Tolerancia a la glucosa.

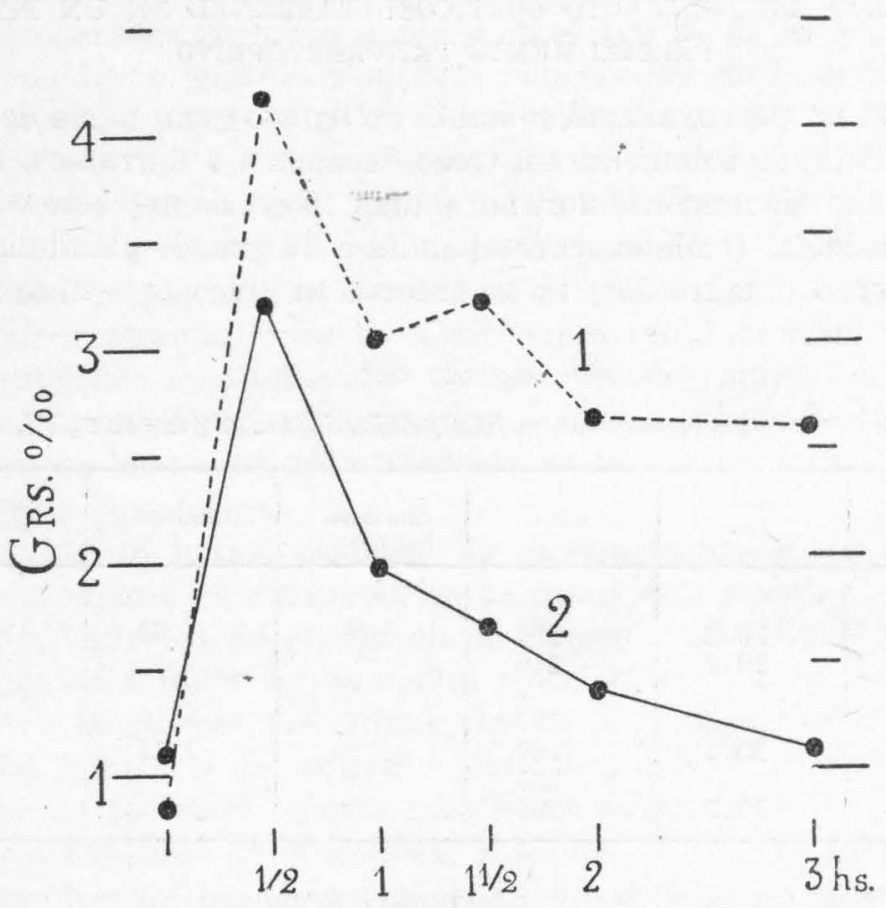

I. - Media de las glucemias de tres perros suprarrenoprivos de 48 horas inyectados con glucosa ( 2 grs. por 12 grs.)

2. - Media de cinco perros normales.

Comparando las cifras, es bien manifiesto el hecho de que la curva glucémica fué más alta y prolongada en los suprarrenoprivos que en los normales: A la hora, hora y media y tres horas, ninguno de los normales tuvo una glucemia tan alta como 
la más baja de los suprarrenoprivos. (Ver gráfico III). Los suprarrenoprivos inyectados con extracto tuvieron también glucemias netamente más altas que los normales. Es este un hecho que llama particularmente la atención, puesto que la formación de glucógeno muscular fué normal.

Se observa, por lo tanto, que la curva glucémica no es capaz de informarnos sobre la formación de glucógeno muscular, puesto que con curvas altas y prolongadas puede haber formación normal de glucógeno. Así sucede en los suprarrenoprivos inyectados con extracto córticosuprarrenal.

\section{ACCIÓN DEL EXTRACTO CÓRTICOSUPRARRENAL EN UN PERRO PARCIALMENTE PANCREATOPRIVO}

En un perro, al cual se había extirpado gran parte del páncreas dejando solamente un trozo de unos 4 a 6 gramos, hemos inyectado diariamente durante 6 días $10 \mathrm{cc}$. de extracto córticosupprarrenal (cada cc. correspondía a 30 grs. de glándula). En este perro (cuadro $23^{\circ}$ ) no se observó ni glucosuria ni aumento de la glucemia.

Cuadro $23^{\circ}$

Perro $N^{\circ}$ 3, páncreatoprivo parcial, dejando 4 - 6 grs. el 9, VI, 1932

\begin{tabular}{r|c|c|c|c|c}
\hline Feeha & $\begin{array}{c}\text { Peso } \\
\text { kgs. }\end{array}$ & Orina & Glucosuria & Glucemia & $\begin{array}{c}\text { Dosis de } \\
\text { extracto }\end{array}$ \\
\hline VIII & & & & & \\
20 & 10.2 & 250 & 0 & 1.30 & $10 \mathrm{cc.}$ \\
21 & 10.0 & 340 & 0 & & $"$, \\
22 & & 190 & 0 & & $"$ \\
23 & 10.1 & 260 & 0 & 1.11 & $"$ \\
24 & 10.0 & 285 & 0 & - \\
25 & & 0 & - & - \\
26 & 105 & & & \\
\hline
\end{tabular}

En el mismo perro se pudo provocar hiperglucemia y 'glucosuria con la inyección diaria de 5 ó 20 cc. de extracto alcalino de lóbulo anterior de hipófisiș. También dió resultado positivo la inyección de extracto de músculo. En cambio, con extracto de riñón, tiroides y lóbulo posterior, no hubo ni hiperglucemia ni glucosuria.

Por consiguiente, no se ha logrado comprobar que el extracto córticosuprarrenal tuviera una acción diabetizante, como la posee el de lóbulo anterior de hipófisis. 


\section{DISCUSION}

La acción 'hiperglucemiante del extracto córticosuprarrenal es bien manifiesta. Sin embargo, cabe la posibilidad de que ella sea debida a impurezas que acompañan a la hormona. A propósito de ésto conviene recordar que la híperglucemia ínicial provocada por la insulina no se observa desde que se ha llevado más a fondo la purificación de esta hormona.

El trastorno en la resíntesis del glucógeno muscular después de la fatiga es un síntoma bastante precoz de la insuficiencia suprarrenal, puesto que se observa en el $63 \%$ de los perros operados 24 horas antes y en ei $100 \%$ de los suprarrenoprivos de 48 horas. La médula suprarrenal no interviene en este proceso, puesto que un perro privado de ella recompuso su glucógeno en la misma forma que los normales.

Hemos comprobado que no es la hipoglucemia la responsable de este trastorno, puesto que, elevando la glucemia por inyección de glucosa, no se obtiene ninguna mejoría. En cambio, administrando extracto córticosuprarrenal, se obtienen recomposiciones más altas que en los animales normales.

La formación de glucógeno muscular, después de inyectar glucosa en las venas, está afectada en la misma forma que la resíntesis post-fatiga.

A las 48 horas, después de la operación, e inyectando glucosa, ningún suprarrenoprivo es capaz de aumentar, en una hora, la cantidad de glucógeno de sus músculos. En el hígado hubo en casi todos- un aumento, pero, antes y a la hora de inyectar la glucosa, las cifras fueron muy bajas.

La influencia del extracto córticosuprarrenal es clara: Los perros así tratados forman glucógeno muscular como los normales a expensas de la glucosa, y tienen cantidades iniciales y finales de glucógeno hepático más altas que los no tratados.

El efecto obtenido con la insulina en los suprarrenoprivos es igual o mayor al del extracto córticosuprarrenal. Este hecho nos hizo pensar que dicho extracto pudiera actuar aumentando la secreción insular. Fué por eso que su acción se estudió en pancreatoprivos.

El efecto obtenido con el extracto córticosuprarrenal en los pancreatoprivos no es del todo neto; pero parece ser que 
dicho extracto puede determinar la formación de glucógeno, aun en ausencia del páncreas. Podría descartarse, pues, el hecho de que el extracto aumentara la formación de glucógeno indirectamente estimulando la secreción insular pancreática.

De todas maneras, el papel del páncreas parece más importante; pues la pancreatectomía afecta mucho antes que la adrenalectomía la capacidad del músculo de formar glucógeno. Además, la insulina es hasta ahora más potente que el extracto córticosuprarrenal para hacer fijar glucógeno en normales, pancreatoprivos o suprarrenoprivos.

En cuanto a las cifras glucémicas, es bien claro el hecho de que en los suprarrenoprivos la curva es más alta y prolongada que en los normales. Pero lo curioso es que en los tratados con extracto, y a pesar de que formaron glucógeno muscular en cantidades comparables a las de los normales, la curva glucémica quedó alta, y fué más alta en los que formaron más glucógeno. Esto hace pensar que en los suprarrenoprivos tratados con extracto existe algún otro trastorno: sea una menor oxidación de glucosa, sea un depósito menor de glucógeno en el hígad́o, o bien una mayor neoformación de glúcidos que en los normales.

\section{CONCLUSIONES}

$1^{\circ}$ - El extracto córticosuprarrenal eleva la glucemia.

$2^{\circ}$ - Los perros suprarrenoprivos de 48 horas no llegan a normalizar su glucógeno muscular en una hora de reposo después de una fatiga intensa. Este trastorno ya se observa a las 24 horas de la operación y no se observa en perros con extirpación medular solamente.

$3^{\circ}$ - La inyección endovenosa de glucosa mejora parcial o imperfectamente la mala recomposición de glucógeno muscular después de la fatiga.

- $4^{\circ}$ - El extracto córticosuprarrenal no sólo la compensa, sino que provoca recomposiciones supernormales.

- $\quad 5^{\circ}$ - La falta de suprarrenales determina a las 48 horas una incapacidad del músculo de formar, en una hora, glucógeno a expensas de la glucosa inyectada en las venas.

$6^{\circ}$ - Esta incapacidad es compensada por el extracto córticosuprarrenal y también por la insulina. 
$7^{\circ}-\mathrm{El}$ extracto córticosuprarrenal parece actuar independientemente de la insulina y ser capaz de aumentar la formación de glucógeno en los pancreatoprivos.

$8^{\circ}$ - La tolerancia a la glucosa es menor en los suprarrenoprivos y aún en los inyectados con extracto.

$10^{\circ}$ - En un perro con pancreatectomía parcial (Diabetes de Sandmeyer) el extracto córticosuprarrenal no manifestó acción diabetógena. 


\section{CAPITULO V}

\section{PAPEL DE LAS SUPRARRENALES EN LA PRODUCCION DE DIVERSAS HIPERGLUCEMIAS Y GLUCOSURIAS}

Generalidades, p. 75 - Papel de la médula suprarrenal, p. 76 - Papel de la corteza, p. 78 - Influencia de las operaciones, p. 78 - HIPERGLUCEMIAS Y GLUCOSURIAS PROVOCADAS POR INFLUENCIAS FISIOLÓGICAS, p. 79 - Hiperglucemia emotiva, p. 79 - Hiperglucemia por contención, p. 80 - Hiperglucemia refleja, p. 80- Hiperglucemia por excitación del esplácnico, p. 81 - Hiperglucemia asfíctica, $p .81$ Choque anafiláctico y peptona, p. 83-Hemorragia, p. 84-Hiperglucemia por picadura del IV ventrículo, $p$. 85 - Hiperglucemia producida por el frío, p. 87 - HIPERGLUCEMIAS Y GLUCOSURIAS PROVOCADAS POR DIVERSOS AGENTES FARMACODINÁMICOS, p. 87 - Anestésicos, p. 87 - Betatetrahidronaftilamina, p. 88 - Betadimetilteluronio, p. 88 - Cloretona, p. 88 - Cianuro de potasio, p. 89 - Diuretina y cafeina, 89 - Eserina, p.89-Estricnina, p. $90-$ Floridcina, $p$. 90 - Guanidina y sintalina, p. 90 - Histamina, p. 90 - Hordenina, p. 91 - Lobelina, p. 91 - Morfina, p. 91 - Nicotina, p. 93 - Picrotoxina, p. 93 - Pilocarpina, p.93 - Pituitrina, p. 94 - Quinina, p. 95 - Sinomenina y parasinomenina, p. 95 - Sales concentradas, p. 95 - Tiroxina, p. 96 - Toxina diftérica, p. 96 - Vacunas, p. 97 - Hiperglucemia Nicotínica, p. 97\%-Generalidades, p. 97 - Investigaciones personales, $p .100$ - Hiperglucemia nicotínica en esplacnicotomizados y suprarrenoprivos recientes, $p$. 100 - Suprarrenoprivos, p. 102 - Esplacnicotomizados, p. 102 - Hiperglucemia nicotínica en esplacnicotomizados antiguos $y$ en desmedulizados, $p$. 103 - Desmedulizados, p. 103 - Esplacnicotomizados, p. 106 - Anastomosis suprarrenoyugular, p. 106 - Mecanismo de la inhibición operatoria, p. 108 - Influencia de la anestesia, p. 109 - Influencia de la ergotamina, p. 109 - Influencia de la atropina, p. 110 Discusión, p. 111 - Conclusiones, p. 112.

\section{GENERALIDADES.}

Después que se comprobó la acción hiperglucemiante de la adrenalina y que la secreción de esta substancia dependía de la acción de los nervios esplácnicos mayores, cuya acción hiperglucemiante ya era conocida, fué preciso averiguar cuál era el papel de la secreción adrenalínica suprarrenal en esas elevaciones glucémicas que antes se creían debidas a la acción directa de los nervios sobre el hígado.

Estas investigaciones fueron iniciadas por Mayer (1906), quien no pudo observar la glucosuria por picadura bulbar en los conejos suprarrenoprivos. 
Desde entonces se han efectuado numerosísimos experimentos, utilizando diversas influencias fisiológicas o farmacodinámicas, de las que daremos un resumen. Estos experimentos no han dado siempre resultados claros y concordantes; lo cual puede atribuirse a varias causas: especie animal, tiempo de operación, defectos de técnica, etc.

Papel de la médula suprarrenal. - Es indudable que la médula suprarrenal interviene por medio de la secreción de adrenalina en la producción de numerosas hiperglucemias. Para saber si una substancia eleva la glucemia por intermedio de la médula, puede procederse de dos maneras: una indirecta, que consiste en investigar si esa substancia provoca una hipersecreción de adrenalina; y otra directa, que consiste en ver si la hiperglucemia se produce aún después de haber inactivado la médula suprarrenal.

Método indirecto. - Numerosos son los métodos que pueden utilizarse para estudiar la secreción de adrenalina por las suprarrenales. Estos se encontrarán descritos en la tesis de Molinelli (1926). Pero de todos estos métodos hay algunos que tienen más valor para las investigaciones que nos ocupan y son: el de anastomosis suprarrenoyugular y los que miden la cantidad de adrenalina recogida de la vena capsular en animales con o sin anestesia.

El método de anastomosis suprarrenoyugular de Tournade y Chabrol, en el cual la sangre suprarrenal de un perro dador pasa a la carótida de otro perro receptor, es un buen método, puesto que nos informa no sólo si hay aumento de secreción adrenalínica, sino también si ésta se produce en una cantidad suficiente para elevar la glucemia.

La medición de la cantidad de adrenalina segregada por las suprarrenales se efectúa recogiendo la sangre de la vena suprarrenal y dosando en ella la adrenalina; para lo cual se utiliza generalmente la acción inhibidora sobre un segmento aislado de intestino. La sangre puede ser recogida en animales anestesiados o deaferentados. Este último procedimiento consiste en seccionar algún tiempo antes todas las raíces posteriores desde la primera torácica hasta la segunda lumbar. En esta forma se pueden abordar las venas capsulares sin que el 
animal sienta dolor alguno haciendo innecesaria la anestesia que puede intervenir modificando la acción de la substancia estudiada. Una vez establecida la cantidad de adrenalina segregada por la influencia de la droga, se puede comparar la hiperglucemia producida por esa misma cantidad de adrehalina con la hiperglucemia que provoca la inyección de la droga, y, además, con la hiperglucemia que aparece inyectando 'simultáneamente la droga y la ya citada cantidad de adrenalina. Estas experiencias hechas en animales con las suprarrenales inactivadas nos permiten conocer el papel que le corresponde a la hipersecreción adrenalínica en la determinación de esa hiperglucemia. Puede suceder por ejemplo (ver peptona) que la hiperglucemia que provoca la droga sola sea mayor que la que provoca la inyección simultánea de la adrenalina y de la droga, de lo que puede deducirse que la hipersecreción médolosuprarrenal interviene más bien en sentido negativo sobre la acción hiperglucemiante de dicha droga.

Métodos directos. - Los métodos directos para investigar el papel de la médula suprarrenal en una hiperglucemia consisten en averiguar si dicha hiperglucemia se produce y con qué intensidad después de haber inactivado la médula suprarrenal. La inactivación puede efectuarse sea por desnervación, sea por extirpación del tejido medular de las suprarrenales.

La desnervación suprarrenal puede obtenerse por sección de los filetes nerviosos que llegan a la glándula, o por sección bilateral de los esplácnicos. Este último método no es tan electivo, puesto que pueden agregarse los efectos de la falta de inervación de otros órganos abdominales. Con cualquiera de estos procedimientos no se obtiene una inactivación segura de las suprarrenales, puesto que hay substancias (nicotina, etc.), que excitan directamente la médula suprarrenal.

La extirpación de la médula suprarrenal es un buen procedimiento. Su inconveniente está en que el traumatismo podría influir sobre la función cortical inhibiéndola y en que, además, podría producirse una hipertrofia del sistema cromafínico extraadrenal. Según Negrin (1922) se produce en el conejo después de la adrenalectomía una hipertrofia del tejido cromafínico. En el perro con extirpación incompleta (Crowe y Wislocki, 1914) o en desmedulizados (Houssay, Biasotti y Mo- 
linelli, inédito), no se ha encontrado esta hipertrofia. La distribución irregular de este tejido hace su estudio sumamente difícil, y la mayor parte de las veces no puede confiarse completamente en los resultados obtenidos en esta investigación. En cuanto a las substancias simpáticominéticas (simpatina) liberadas por la excitación de los nervios simpáticos, serían según Bacq (1933) también capaces de elevar la glucemia. Pero el papel que pueden desempeñar la simpatina o el sistema cromafínico extraadrenal no nos interesa, puesto que sólo estudiamos aquí el que corresponde a las suprarrenales.

Papel de la corteza. - El papel de la corteza en las diversas hiperglucemias es también difícil de precisar. En el perro y el gato, siendo la supervivencia corta, no puede hacerse los experimentos en momentos suficientemente alejados de la operación como para poder descartar la influencia de ésta. La única manera sería mantenerlos durante algunos días con extracto cortical. En la rata y el conejo que sobreviven largo tiempo a la suprarrenalectomía, si bien se puede descartar la influencia de la operación, ocurre que el tejido cortical accesorio, al hipertrofiarse paulatinamente, vicia los resultados; en efecto: estos animales ya no pueden considerarse fisiológicamente como córticosuprarrenoprivos. La falta de corteza suprarrenal disminuye o suprime la intensidad de las reacciones hiperglucémicas, quizás por la enorme disminución de glucógeno hepático que puede provocar.

Influencia de las operaciones. - Un factor importante de tener en cuenta en el estudio de las hiperglucemias es la influencia depresora ejercida por las operaciones recientes. Hemos tenido ocasión de observarlo al estudiar la hiperglucemia nicotínica. Esta fué mucho menor en los perros laparotomizados desde $3-5$ horas antes que en los normales, y menor también en los esplacnicotomozados recientes que en los operados desde varios días atrás. La depresión es debida al acto operatorio propiamente dicho y no a la anestesia, puesto que no se ob'servó en los perros que habían sido simplemente anestesiados durante media hora. En nuestros casos la disminución en la intensidad de la hiperglucemia pareció deberse a un agotamiento de la médula suprarrenal. En efecto: si bien la hiperglu- 
cemia nicotínica era menor en los operados que en los normales, la hiperglucemia provocada por la adrenalina, más o menos en la misma proporción con que la segregan las suprarrenales, fué igual en ambos grupos. Por lo tanto, el ideal sería llevar a cabo esta clase de investigaciones en animales 'sin anestesia, ni contención y en tiempos alejados de la operación.

HIPERGLUCEMIAS Y GLUCOSURIAS PROVOCADAS POR INFLUENCIAS FISIOLÓGICAS.

\section{Hiperglucemia emotiva}

Cannon, Shohl y Wright (1911) observaron que la glucosuria que aparecía en los gatos sometidos a una excitación emotiva no se producía después de la suprarrenalectomía.

Stewart y Rogoff (1917) demostraron que había aún hiperglucemia emotiva en gatos con una suprarrenal extirpada y la otra desnervada desde algún tiempo antes, y, como consideraban que en estos animales no puede haber secreción de adrenalina, concluyeron que esta última no era necesaria para la aparición de dicha hiperglucemia.

Bulatao y Cannon (1925) en experimentos agudos en gatos, que, con la extirpación de la corteza cerebral se ponen en un estado especial que se ha denominado pseudoafectivo, observaron hiperglucemia, sólo mientras duraba dicho estado. Pero, cuando faltaban ambas suprarrenales o cuando faltaba una sola, estando lã otra desnervada, esa pseudoafectividad no elevaba ya la glucemia. En cambio, la desnervación del hígado no sólo no disminuía la hiperglucemia sino que la hacía más intensa.

Britton (1928), en el gato excitado por el perro, observa hiperglucemia marcada (más de $100 \%$ en 4 minutos). La desnervación del hígado la modifica poco; en cambio, la extirpación de la médula suprarrenal la suprime, lo cual no obedeció a la falta de glucógeno hepático, pues se comprobó que éste era normal. 


\section{Hiperglucemia por contención (Fesselungshyperglykämie)}

Es conocido el fenómeno de que el solo hecho de sujetar a un animal es suficiente para elevar la glucemia. Veamos qué papel tienen en ello las suprarrenales.

En experimentos agudos realizados en gatos, Cannon, Shohl y Wright (1911) no observaron glucosuria por contención después de la suprarrenalectomía. En un conejo suprarrenoprivo de 37 días antes, Kisch (1924) obtuvo hiperglucemia por contención, menor que en los normales. Sataké (1926) e Hirayama (1926), confirman este resultado.

La sección de los esplácnicos disminuye manifiestamente la hiperglucemia por contención en el conejo (Fujii, 1921; Hirayama, 1926; Sataké, 1926: experimentos correctos y no agudos).

Por lo tanto, podemos concluir que la falta de suprarrenales o su desnervación disminuyen la intensidad de la hiperglucemia provocada por el simple hecho de sujetar al animal.

\section{Hiperglucemia refleja}

Starkenstein (1911) observó que las excitaciones centrípetas del vago pueden aumentar la glucemia del conejo aunque esté privado de sus suprarrenales. Kisch (1924) encuentra que la hiperglucemia refleja (excitación del ciático) es algo menor en los conejos suprarrenoprivos recientes que en los normales; y Griffith (1923) observó una hiperglucemia refleja menor en los gatos cuyas suprarrenales fueron extirpadas o extirpada una y desnervada la otra. (Excitaba el crural, el ciático o el vago). Por su parte, Babkin (1925), practicando una excitación centrípeta del ciático en gatos y perros descerebrados, observa elevación glucémica, y, extirpando la suprarrenal o cortando los esplácnicos, nota que ese efecto disminuye sin desaparecer.

En cambio, Schtscherbakow y colaboradores (1930) no consiguen hiperglucemia por estimulación del ciático en gatos con suprarrenales extirpadas o las venas capsulares ligadas; y Lumley y Nice (1930) tampoco observan hiperglucemia en 
las ratas suprarrenoprivas excitadas con corriente farádica. Según Brooks (1933) la estimulación del ciático en el gato espinal eleva la glucemia aunque en menor grado si se han inactivado las suprarrenales y desnervado el hígado. Ohmi (1933) observa que en los conejos la hiperglucemia por estimulación del ciático es casi igual en los normales que en los suprarrenoprivos de cierto tiempo antes, pero que la sección de los esplácnicos la disminuye en alto grado. Por lo tanto, se puede concluir que la suprarrenalectomía o esplacnicotomía disminuyen, pero no suprimen la hiperglucemia provocada por la estimulación del cabo central de diversos nervios.

\section{Hiperglucemia por excitación del esplácnico}

La excitación del esplácnico mayor no, produjo glucosuria en los experimentos demasiado agudos de Gautrelet y Thomas (1909) sobre perros suprarrenoprivos. Según Macleod y Pearce (1912) no se observaría glucosuria excitando el esplácnico o los nervios hepáticos de los perros decapsulados y suponen que el hígado no reacciona a sus nervios si no está influenciado por la adrenalina; pero tal vez el resultado obedeció a la insuficiente cantidad de glucógeno hepático. La acción hiperglucemiante de la adrenalina segregada durante la excitación de los nervios esplácnicos mayores fué demostrada de una manera decisiva por Tournade y Chabrol (1922), quienes, con el método de la anastomosis suprarrenoyugular, observaron en el transfundido aumentos glucémicos de 0.10 a 1.10 gr. por mil.

\section{Hiperglucemia asfíctica}

Se ha comprobado que la asfixia provoca secreción de adrenalina: La ligadura de la tráquea produce una fuerte descarga a los 2 - 5 minutos con su máximo a los 5-6, pudiendo alcanzar hasta $0.045 \mathrm{mgs}$. por minuto. Esta descarga asfíctica se produce también durante la parálisis respiratoria provocada por el curare o la ponzoña de cobra y por la acción del cianuro de potasio. No es el aumento de anhídrido carbónico el que provoca la descarga, sino la disminución de la tensión de oxígeno. La excitación actúa sobre el sistema nervioso cen- 
tral y se transmite a las suprarrenales por vía de los esplácnicos (1).

La influencia de la desnervación y la extirpación de las suprarrenales sobre la hiperglucemia asfíctica ha sido estudiada por numerosos investigadores. Ya Pollak (1909) observó que la sección de los esplácnicos impedía en los conejos la hiperglucemia provocada por el óxido de carbono. Igual efecto produciría según Starkeknstein (1912) la suprarrenalectomía. Este hecho ha sido negado por Bornstein y Holm (1922), quienes comprueban que tampoco la atropina es capaz de contrarrestar la hiperglucemia asfíctica.

Según Kellaway (1919) la anoxemia moderada produce, en el gato, hiperglucemia, que falta si se cortan los nervios esplácnicos o se extirparon las suprarrenales. Si la disminución de oxígeno es grande, la hiperglucemia se produce aún. La dosis hiperglucemiante de adrenalina es menor que la pupilodilatadora, y, como la asfixia es capaz de provocar dilatación de la pupila desnervada, es lógico pensar que la adrenalina segregada en estas condiciones puede elevar la glucemia. Supone este autor que el aumento glucémico obedece a tres mecanismos: nervioso, neuroadrenal y directo sobre el hígado.

Stewart y Rogoff (1917-18-20-22) niegan que las suprarrenales intervengan en la hiperglucemia asfíctica; pues han observado netas elevaciones en conejos suprarrenoprivos o en perros y gatos con una suprarrenal extirpada y desnervada o desmedulizada lá otra.

Exner (1920) observó igual hiperglucemia asfíctica en las ratas suprarrenoprivas que en los testigos; y Binswanger (1922) logró provocar con anhídrido carbónico hiperglucemia en los gatos suprarrenoprivos.

Según Tachi y Saito (1928) la sangre de la circulación general de los perros asfixiados no contendría adrenalina, a juzgar por los dosajes efectuados por el método del intestino aislado.

Hay otras experiencias que demuestran el importante papel de las suprarrenales en la hiperglucemia asfíctica: Así Mikami (1926) halla gran disminución de la hiperglucemia

(1) Los detalles y la bibliografía pueden hallarse en la tesis de Molinelli "La secreción de adrenalina", Bs. As., 1926. 
producida por el óxido de carbono en los conejos con los esplácnicos seccionados; Puche Alvarez (1927) comprueba que en perros con hígado desnervado y sin suprarrenales la asfixia produce hipoglucemia en lugar de hiperglucemia como en los normales. Por fin, Sato, Inaba y Takahashi (1932) observan que la sección esplácnica disminuye la hiperglucemia y suprime la secreción de adrenalina provocadas por la asfixia. Además Olmsted (1926) observa que la asfixia eleva la glucemia, ya de por sí alta en el gato decapitado. Después de seccionar los esplácnicos o extirpar las suprarrenales ya no se observa la elevación glucémica.

Se desprende de todas estas experiencias que las suprarrenales toman parte en el aumento glucémico determinado por la asfixia; pero no parece que sean el único factor en juego.

\section{Choque anafiláctico y peptona}

La inyección de peptona puede aumentar la secreción de adrenalina (Molinelli, 1926; Watanabe, 1927, etc.) y provoca una elevación de la glucemia, aunque los efectos varían con la preparación utilizada. Según La Barre (1926 - 27) la hiperglucemia por choque anafiláctico sería igual en los cobayos con o sin suprarrenales. Zeckwer y Nadler (1929) en perros con sección del esplácnico de un lado y extirpación de la suprarrenal del otro lado observaron importantes disminuciones en la hiperglucemia peptónica. Según Demant (1930) la plata coloidal no provoca en los perros suprarrenoprivos la hiperglucemia que determina en los normales.

Kaiwa (1933) ha realizado las siguientes experiencias en perros esplacnicatomizados bilateralmente: $1^{\circ}$ Estudio de la hiperglucemia provocada por la peptona. $2^{\circ}$ Estudio de la hiperglucemia provocada por la inyección endovenosa de adrenalina en la misma proporción y con la misma velocidad como la segrega la suprarrenal bajo la influencia de la peptona. $3^{\circ}$ Estudio de la hiperglucemia producida por la inyección simultánea de ambas substancias. La hiperglucemia obtenida con peptona solamente fué mayor que la producida por la ya citada dosis de adrenalina. La inyección simultánea de ambas substancias produjo una hiperglucemia de igual magnitud o 
a veces menor que la obtenida con peptona solamente. Concluye el autor de estas experiencias que la hipersecreción adrenalínica producida por la peptona no es la responsable de la hiperglucemia y que, por el contrario, más bien la disminuye. Es tal vez algo aventurado deducir de estos experimentos indirectos y difíciles que la hipersecreción adrenalínica no interviene en la hiperglucemia peptónica; tanto más cuanto que, en los conejos suprarrenoprivos de algún tiempo antes, la hiperglucemia peptónica fué menor que en los normales, aunque está más disminuída aún en los esplácnicotomizados. En el perro, la desmedulización de las suprarrenales disminuye notablemente la hiperglucemia peptónica (Kaiwa, 1933). Según el mismo autor, en los conejos suprarrenoprivos, la administración de peptona disminuye la intensidad de la hiperglucemia adrenalínica.

Frente a estos resultados, es difícil comprender el papel de la hiperadrenalinemia en la hiperglucemia provocada por la peptona; pero los experimentos de extirpación demuestran que cierta intervención tienen las suprarrenales.

\section{Hemorragia}

Una sangría de 25 grs. por kg. provoca hiperglucemia en el perro; con 35 grs. por kg. puede haber una elevación de 2 grs. por mil. En el conejo una hemorragia de 15 grs. por kg. produce hiperglucemia y glucosuria (Tachi, 1928). La elevación de la glucemia se produce en el conejo aún después de seccionar ambos esplácnicos (Nishi, 1909; Tachi, 1926, etc.). En los suprarrenoprivos también hay hiperglucemia (Kisch, 1924) menor que en los normales, aunque según Tachi, la esplacnicotomía disminuye más la hiperglucemia que la suprarrenalectomía. En los gatos suprarrenoprivos, Mulinos (1928) halló las mismas elevaciones glucémicas que en los normales.

En el perro no aparecía la hiperglucemia por hemorragia después de la suprarrenalectomía (Agazzotti, 1927, etc.), ni después de seccionar los esplácnicos (Tachi, 1928; Pi y Suñer, 1926, etc.). 


\section{Hiperglucemia por picadura del IV ventrículo}

Cuando Claudio Bernard descubrió en 1855 que la picadura del IV ventrículo producía hiperglucemia y glucosuria, atribuyó el fenómeno a una acción nerviosa directa sobre el hígado. 25 años después, Blum, estudiando la acción hiperglucemiante de la inyección de extracto capsular, pensó que el estímulo podría transmitirse por vía nerviosa a las cápsulas suprarrenales aumentando su secreción, y que ésta sería la productora de la hiperglucemia.

Desde entonces se ha discutido si las cápsulas suprarrenales eran indispensables o no para la producción de la hiperglucemia por picadura bulbar. Hay muchos experimentos que prueban que no lo son; pero, por otra parte, se ha observado que la picadura provoca secreción de adrenalina en cantidad suficiente para prodüir hiperglucemia.

La picadura del IV ventriculo provoca secreción de adrenalina en cantidades hiperglucemiantes. - Que la picadura del IV ventrículo provoca secreción de adrenalina es un hecho que se ha comprobado, ya sea dosando la adrenalina de la suprarrenal antes y después de la excitación, observando la disminución de la reacción cromafínica, dosando la adrenalina en la vena suprarrenal, etc. Se ha comprobado también el aumento simultáneo de la glucemia y de la cantidad de adrenalina segregada (Yen y Kaiwa, 1931; Yen, Kaiwa y Wada, 1931, etc.) pero la prueba definitiva de que la picadura provoca una descarga de adrenalina capaz de elevar la glucemia se ha dado con el método de la anastomosis suprarrenoyugular de Tournade y Chabrol.

Houssay y Molinelli (1924) han comprobado en numerosos experimentos que la picadura bulbar en el transfusor es capaz de aumentar la secreción de adrenalina en el mismo y, como consecuencia, elevar la glucemia del trasfundido. El mismo resultado obtuvieron excitando eléctricamente el bulbo.

El importante papel de las suprarrenales en la determinación de la hiperglucemia por picadura se pone de manifiesto en las experiencias de Jarisch (1914), quien en conejos con hígado desnervado y suprarrenales intactas observó hiperglu- 
cemia y glucosuria. En cambio, desnervando la suprarrenal y conservando la inervación hepática, no obtuvo hiperglucemia ni glucosuria. Pero, desgraciadamente, estos experimentos se hicieron con anestesia etérea y no se midió la glucemia inicial.

Las suprarrenales no son indispensables para que haya hiperglucemia por picadura del IV ventrículo. - En algunas experiencias sólo se ha buscado la glucosuria y no se la ha encontrado después de la picadura en conejos suprarrenoprivos (Mayer, 1906; Landau, 1907; Kahn, 1909; Kahn y Starkenstein, 1911; Borberg, 1913; Freund y Marchand, 1914; Biberfeld, 1917; Negrin, 1922) ni en las ratas suprarrenoprivas (Exner, 1920).

Vidal (1933) tampoco encuentra hiperglucemia en un conejo suprarrenoprivo, y la halla disminuída después de extirpar la suprarrenal de un solo lado. Pero hizo sus observaciones pocas horas después de la operación y bajo anestesia con uretano, por lo que los niveles iniciales fueron altos.

Sin embargo, Wertheimer y Battez $(1910-14)$ han logrado probar que puede producirse glucosuria por picadura en gatos y perros suprarrenoprivos. También Quinquand (1915) obtuvo glucosuria, excluyendo la acción de las suprarrenales por sección esplácnica de un lado y ligadura venosa del otro.

En lo que se refiere a la hiperglucemia, que es el fenómeno fundamental, ha sido observada en conejos suprarrenoprivos de horas antes (Freund y Marchand, 1914) o mucho tiempo antes (Stewart y Rogoff, 1918; Catan, Houssay y Mazzocco, 1920, etc.).

En perros desmedulizados, Houssay y Molinelli (inédito) obtuvieron las siguientes elevaciones glucémicas (grs. por mil) $: 0.17$ y 0.93 en anestesiados con cloralosa; 0.11 y 0.00 en anestesiados con éter. En perros con una sola suprarrenal, las elevaciones fueron de 0.18 y 0.07 (éter), 1.84 y 0.43 en los cloralosados. En los testigos cloralosados la glucemia 'aumentó en $0.20,1.90$ y 0.17 . Prueban estos experimentos que sin médula suprarrenal la picadura bulbar puede todavía elevar la glucemia.

Conclusión. - Podemos, pues, concluir que la picadura del piso del IV ventrículo provoca una secreción de adrenalina en 
cantidad suficiente para elevar la glucemia; pero la supresión completa de esta secreción no anula la hiperglucemia. De manera que si bien la suprarrenal desempeña un papel importante, cabe suponer que han de intervenir también otros factores.

\section{Hiperglucemia producida por el frío}

Freund y Marchand (1913) observaron que en los conejos, aunque fueran suprarrenoprivos, se producía una hiperglucemia neta, si se los somete al frío. Según Britton (1928) los gatos con una suprarrenal extirpada y la otra ligada o desnervada, puestos al frío, estando en hipoglucemia insulínica, no recuperan su glucemia como los normales.

\section{HiPERgLUCEMIAS Y GLUCOSURIAS PROVOCADAS POR DIVERSOS AGENTES FARMACODINÁMíicos}

\section{Anestésicos}

Según Pollak (1909) la glucosuria clorofórmica no se observa en los animales esplacnicotomizados. Fujii (1921) en iguales condiciones, observó que el éter produce hiperglucemia y glucosuria, aunque menor que en los animales normales. Este autor demostró en conejos (1921) y en perros (1925) que solamente disminuye la cromafinidad en la glándula que conserva su inervación o sea que el estímulo llega por el sistema nervioso. Hirayama (1926) observó que la hiperglucemia y glucosuria provocadas por el uretano no eran, en el conejo, influenciadas por la sección esplácnica. Más o menos a la misma conclusión llegan Stewart y Rogoff en gatos con una suprarrenal desnervada y extirpada la otra (1917) o en conejos con ablación de ambas cápsulas (1920) .Bertram (1923) observó que la hiperglucemia etérea era pequeña en el perro suprarrenoprivo. Tachi y Hirayama (1926) observaron que la hiperglucemia provocada por el éter era menor en los conejos con es- plácnicos cortados (1.4-1.5) y en los suprarrenoprivos de algún tiempo antes (1.3-1.5 o/oo) que en los testigos (2.2-2.9). A la misma conclusión llegan experimentando con el uretano (1928). 
Según Reid (1932) y Banerji y Reid (1933) la elevación glucémica provocada por el éter sería menor en los conejos sin médula suprarrenal que en los normales y menor aún en los suprarrenoprivos. Dando al mismo tiempo amytal, había también una hiperglucemia menor. También Ohmi (1933) encuentra menor hiperglucemia etérea en los conejos suprarrenoprivos antiguos, pero sólo con anestesia profunda; en el caso contrario, la hiperglucemia sería más o menos igual en normales y suprarrenoprivos.

La cloralosa no modifica casi la glucemia (Magenta 1927), y según Sato y Ohmi (1933) no provoca secreción de adrenalina.

\section{Betatetrahidronaftilamina}

Es sabido que la inyección de esta substancia simpáticomimética produce elevación de la temperatura y de la glucemia. Según Bouckaert y Heymans (1928) en los perros suprarrenoprivos, la betatetrahidronaftilamina ya no eleva la glucemia aunque puede aún elevar la temperatura. Lo mismo se observaría después de seccionar los esplácnicos. Por la acción de esta substancia se produce, según Boukaert (1930), una disminución de los glucógenos hepático y muscular.

\section{Betadimetilteluronio}

Kaiwa (1931 - 32) ha comprobado que el bicloruro de betadimetilteluronio eleva la glucemia en el conejo. Observó que la dosis letal mínima era de $0.75 \mathrm{mg}$. por vía endovenosa. Con $0.5-0.7 \mathrm{mg}$. por vía endovenosa y $1 \mathrm{mg}$. por $\mathrm{kg}$. por vía subcutánea, se produce una hiperglucemia neta. La esplacnicotomía doble, realizada muchos días antes, disminuye el efecto, y la suprarrenalectomía más aún.

\section{Cloretona}

La cloretona (triclorobutanol) eleva la glucemia en los conejos normales. La esplacnicotomía reduce mucho la hiperglucemia, llegando a anularla en algunos casos. La suprarrena- 
lectomía la reduce también, pero menos cuando ha pasado mucho tiempo desde la operación (Tada, 1931).

\section{Cianuro de potasio}

Hemos visto, al tratar de la hiperglucemia asfíctica, que el cianuro de potasio puede provocar una descarga de adrenalina. Según Ohmi (1933) la inyección de 2.5 mgs. por kg. en conejos provoca una hiperglucemia moderada; la suprarrenalectomía doble, realizada muchos días antes, no modifica en mayor grado esta reacción; pero la esplacnicotomía doble reduce mucho llegando casi a abolir la hiperglucemia.

\section{Diuretina y cafeína}

Según Pollak (1909) la sección de lọs esplácnicos impide la glucosuria producida por la cafeína en el conejo. No habría tampoco hiperglucemia por diuretina después de cortar ambos esplácnicos o de extirpar una cápsula y desnervar la otra (Nishi, 1909).

Según Jarisch (1914) los resultados se modifican si los experimentos no son agudos y si el hígado contiene suficiente cantidad de glucógeno. En estas condiciones, la diuretina podría elevar la glucemia aun después de seccionar los esplácnicos. El defecto de estos experimentos está en que no se ha medido la glucemia inicial.

Sin embargo, otros investigadores han encontrado, después de seccionar los esplácnicos: hiperglucemia (Mikami, 1926) y glucosuria (Naito y Fujii, 1917) aunque menores que en los animales normales.

En los conejos suprarrenoprivos de algún tiempo antes, Sakaguchi, Hayashi y Katayama (1919) habrían observado hipoglucemia en lugar de hiperglucemia.

\section{Eserina}

Según Tada (1933) la eserina $(0.5 \mathrm{mg}$. por kg. subcutáneo) eleva la glucemia en el conejo. El aumento es menor seccionando los esplácnicos y menor si se han extirpado las suprarrenales aun muchos días antes. 


\section{Estricnina}

Según Pollak (1909) la estricnina produce hiperglucemia y glucosuria en el conejo, y esta última faltaría después de seccionar los esplácnicos. La eliminación de las suprarrenales no impediría la hiperglucemia que provoca la vomicina (Ruickoldt, 1930) .

\section{Floridcina}

La floridcina produce glucosuria, aunque se hayan extirpado las suprarrenales en la rata (Schwarz, 1910) y en el conejo (Mayer, 1908; Mac Guigan, 1910, etc.). Los resultados negativos de Gautrelet y Thomas (1909) en el perro, no son probantes porque hubo otros factores en juego: Shock, supervivencia corta, etc.

\section{Guanidina y Sintalina}

Según Chahovitch (1930) la sintalina (decametilendiguanidina) provoca en el conejo una hiperglucemia inicial que sería más durable con dosis pequeñas. La extirpación de las suprarrenales (3 horas antes) impide esta hiperglucemia o la reduce (Tada, 1932).

En los perros suprarrenoprivos falta también la hiperglucemia inicial (Zunz y La Barre, 1930).

El clorhidrato de guanidína (0.25-0.4 gr. por kg.) provoca también una primera fase de hiperglucemia seguida de hipoglucemia. La sección de los esplácnicos disminuye, en el conejo, la hiperglucemia inicial, y la suprarrenalectomía la impide (Tada, 1932). En el perro, después de la sección esplánica, sólo hay hipoglucemia (Tada, 1932).

Por lo tanto, la hiperglucemia inicial provocada por la guanidina o sintalina parece producirse exclusivamente por intermedio de las suprarrenales.

\section{Histamina}

La acción provocada por la histamina sobre la glucemia es variable. Algunos investigadores han hallado aumentos, y otros, disminuciones. Según Ni (1926) la histamina no eleva la glucemia en los perros suprarrenoprivos como en los norma- 
les. En cambio, La Barre (1927), en los cobayos, y Kinoshita (1928), en conejos, suprarrenoprivos, observaron marcadas hiperglucemias histamínicas.

Ohmi (1933) observa que la histamina $(0.7 \mathrm{mg}$. por $\mathrm{kg}$. endovenoso) baja la glucemia de los conejos normales. Muchos días después de cauterizar la médula suprarrenal, la reacción a la histamina era igual que en los normales. Pero, a los pocos días de la cauterización y en los suprarrenoprivos de algún tiempo antes, la hipoglucemia era más intensa.

\section{Hordenina}

La acción de la hordenina es semejante a la de la nicotina. A la dosis de 0.05-0.1 gr. por kg., en el perro, eleva en 10 a 20 minutos, la glucemia a $1.60 \cdot 2.50$ grs. por mil (Tournade y Malmejac, 1931).

En los perros suprarrenoprivos, la hordenina baja la glucemia en lugar de elevarla, aunque todavía puede elevar la presión arterial. La acción hiperglucemiante sería también suprimida por la yohimbina (Tanret, 1933).

\section{Lobelina}

La lobelina, igual que la nicotina, provoca una secreción de adrenalina estimulando directamente la médula suprarrenal (1).

Randles (1931) inyectó 22 - $44 \mathrm{mgs}$. por $\mathrm{kg}$. de alfa lobelina a ratas normales y suprarrenoprivas, obteniendo en estas últimas, aun muchos días después de la operación, elevaciones glucémicas $1 / 3$ a $1 / 5$ menores que en las normales.

\section{Morfina}

La glucosuria provocada por la morfina es impedida, en el conejo, por la sección de los nervios esplácnicos, según Pollak (1909). En los conejos suprarrenoprivos, Sakaguchi, Hayashi y Katayama (1919) observaron que la morfina determinaba hipoglucemia en lugar de hiperglucemia.

(1) Ver Molinelli: "Tesis de doctorado", Buenos Aires, 1926. 
Stewart y Rogoff (1922) estudiaron la hiperglucemia morfínica en conejos suprarrenoprivos, gatos y perros con extirpación de una glándula y desnervación o desmedulización de la otra. En todos los animales la hiperglucemia fué menor que en los testigos normales. Pero, a pesar de todo, no creen que este hecho deba imputarse a la falta de secreción adrenalínica, puesto que no obtuvieron aumento de ésta inyectando morfina a perros y determinando cuantitativamente la adrenalina de la sangre suprarrenal recogida en la "bolsa cava". Por esta" razón, estos autores atribuyeron la disminución de la hiperglucemia no a falta de médula suprarrenal, sino a la corteza.

Houssay y Lewis (1923) observaron que la sección de los esplácnicos mayores disminuye fuertemente la hiperglucemia, que la desmedulización suprarrenal la disminuye algo menos y que la extirpación de las suprarrenales lo hace fuertemente.

Después de la desnervación simpática del abdomen, la morfina determina hipoglucemia en lugar de hiperglucemia (Marenzi, 1926). La sección de los nervios del pedículo hépatopancreático o hepático no sólo no disminuye la intensidad de la hiperglucemia sino que.la aumenta (Houssay, Lewis, Molinelli y Marenzi, 1928). Después de un ayuno completo de seis días, la hiperglucemia es menor, y además se comprobó que la hiperglucemia no es debida al descenso del $\mathrm{pH}$. porque este fenómeno puede producirse sin que aumente la glucemia.

Se ha comprobado que la morfina aumenta la secreción de adrenalina gracias a la cual puede elevar la glucemia (anastomosis suprarrenoyugular, Houssay, Lewis y Molinelli, 1924; dosaje de adrenalina: Hayashi, 1928; Sato y Ohmi, 1933, etc.). Además, demıstraron estas experiencias que el estímulo se transmitía por el esplácnico; en efecto, seccionado éste, cesaba la secreción de adrenalina.

En el conejo, la esplacnicotomía y la suprarrenalectomía reducen considerablemente la hiperglucemia morfínica (Tada, 1932).

Se ha intentado aplicar estos conocimientos a la clínica para descubrir los estados de insuficiencia suprarrenal: Targowla (1930) y posteriormente Pardo Urdapilieta y Martínez (1932), estudian la elevación glucémica que se produce a los sesenta minutos de inyectar un centígramo de clorhidrato de 
morfina. Normalmente se produce una elevación de unos 0.20 gr. por mil, y pueden considerarse bajos los valores inferiores a 0.15 . La reacción faltaría o sería baja en los estados de insuficiencia suprarrenal, pero también lo fué en casos de demencia precoz, mixedema, estados depresivos, etc. La pruẻba tiene, por lo tanto, cierto interés clínico, pero es poco específica y, además, dada la gan sensibilidad a los tóxicos, que existe en la insuficiencia suprarrenal, resulta muy peligroso inyectar un centígramo de morfina.

\section{Nicotina}

Como la consideración de este punto requiere mayor desarrollo que los demás, le consagraremos una sección especial al final de este capítulo.

\section{Picrotoxina}

Tatum (1922) observó que la sección de los nervios esplácnicos impide la hiperglucemia por picrotoxina en el conejo; obtuvo igual resultado, cortando el esplácnico derecho y extirpando la suprarrenal izquierda.

\section{Pilocarpina}

Bornstein y Holm (1922) obtuvieron hiperglucemia pilocarpínica en perros suprarrenoprivos, pero la mitad menor que en los normales. Viale (1928) y Puche Alvarez (1926-28) observan que la pilocarpina no sólo no eleva la glucemia de los perros suprarrenoprivos, sino que puede determinar hipoglucemia. En los conejos suprarrenoprivos, Orrú (1928) no encuentra hiperglucemia; por su parte, Inouye (1931) la encuentra mucho menor que en los normales. Observa este último autor que en los conejos normales la atropina o la descerebración impiden el efecto de la pilocarpina, mientras que la extirpación de los hemisferios cerebrales no la modifica; concluye que esta substancia obraría excitando una región del cerebro intermedio y que luego el estímulo llegaría a las suprarrenales por vía del esplácnico.

La fuerte disminución de la hiperglucemia en el conejo con sección esplácnica o extirpación de las suprarrenales ha 
sido también observada por Tada (1933). La ergotamina (5 mgs. por kg.) reduce la hiperglucemia pilocarpínica (2 mgs. por kg.)

\section{Pituitrina}

El papel de las suprarrenales en la hiperglucemia originada por la pituitrina, ha sido investigado por Clark (1925), quien afirma que no intervienen en su producción. En cambio, según Fritz (1928), ésta no se produce si se han extirpado los adrenes (conejo, cobayo, rata), en cuyo caso puede haber aún descenso de la glucemia (conejo y cobayo), de donde deduce que la hiperglucemia se debe a una hipersecreción de adrenalina. Para La Barre (1930) la hiperglucemia inicial por pituitrina se debe a una hiperadrenalinemia, pues falta saber si se han suprimido las suprarrenales.

Según Bischoff y Long (1931) en los conejos sin médula suprarrenal los extractos retropituitarios elevan o bajan la glucemia según las reservas de glucógeno hepático existentes y la hiperglucemia no se debería a una aumentada secreción de adrenalina.

En perros privadós de las suprarrenales $1-2$ horas antes y cloralosados, Houssay y Di Benedetto (1933) observaron que la inyección durante una hora de $2.5 \mathrm{mgs}$. por $\mathrm{kg}$. y hora de polvo standard del lóbulo posterior de hipófisis no eleva la glucemia como lo hace en los normales. En siete experimentos de anastomosis suprarrenoyugular no obtuvieron, inyectando lóbulo posterior de hipófisis al dador, ningún aumento significativo de la glucemia en el receptor (1). Habiendo, por lo tanto, comprobado que el extracto retropituitario no provocaba una secreción hiperglucemiante de las suprarrenales, trataron de averiguar si la inyección de lóbulo posterior de hipófisis en perros suprarrenoprivos que recibían una infusión continua de adrenalina en cantidades más o menos fisiológicas, elevaba la glucemia. El resultado fué positivo: la administración de adrenalina, 0.01 a $0.02 \mathrm{mg}$. por kg. y hora, determinó la aparición de la acción hiperglucemiante del extracto retropituitario en los perros suprarrenoprivos.

(1) Molinelli (1926), en tres experimentos de anastomosis suprarrenoyugular, no observó descarga de adrenalina por inyección de extracto de lóbulo posterior de hipófisis al dador. 
La sección de los esplácnicos mayores y menores y la extirpación de la cadena simpática lumbar, hecha una hora antes de comenzar la inyección, no impidió la hiperglucemia retropituitaria, aunque ésta fué ligeramente menor y seguida de una caída secundaria que alcanzó su máximo a las cinco horas. Este descenso secundario se observó también en los esplácnicotomizados que no recibieron extracto.

\section{Quinina}

Tatum y Cutting (1922) comprobaron que la sección de esplácnicos o el corte del derecho con extirpación de la suprarrenal izquierda impiden la hiperglucemia por la quinina en el conejo. El mismo efecto tendría la suprarrenalectomía (Kuno, 1929).

En perros desmedulizados, Houssay y Molinelli (inédito) inyectando en la vena $0.02 \mathrm{gr}$. por $\mathrm{kg}$. de sulfato neutro de quinina, obtuvieron las siguientes elevaciones glucémicas: $+0.09 ;-0.22 ;-0.74 ;-0.35 ;-0.38 ;+0.48$ (grs. por mil). En los perros testigos, que sufrieron la operación, pero sin que se les extirpara la médula, las hiperglucemias fueron de $:+0.93 ;+0.02 ;+0.11 ;-0.25 ;-0.28 ;-0.40 ;+0.10$. Como se ve, no hubo diferencia significativa entre ambos lotes.

\section{Sinomenina y parasinomenina}

Según Kuno (1929) pequeñas dosis de estas substancias producen, en el conejo, hipoglucemia; con fuertes dosis habría hiperglucemia, que faltaría seccionando los esplácnidos o extirpando las suprarrenales.

\section{Sales concentradas}

Stewart y Rogoff (1919) observaron que una solución concentrada de carbonato de sodio podía provocar un aumento de la secreción de adrenalina, la cual era mayor con pequeños volúmenes de solución concentrada que con grandes volúmenes de solución diluída. Según Nikolaeff (1925), el efecto se produciría también sobre la suprarrenal aislada.

La acción hiperglucemiante de las inyecciones de cloruro de amonio no se observa en el gato después de seccionar los 
esplácnicos (Naito, 1920). Sin embargo, la sección esplácnica no tendría influencia sobre la hiperglucemia producida por el sulfato de magnesio (Morita, 1922). Según Mc Guigan (1910) la extirpación de las suprarrenales impide la hiperglucemia salina $\left(\mathrm{SO}_{4} \mathrm{Na}_{2}\right)$ en el conejo, la hace menos intensa en el perro y no la modifica en el gato.

En los conejos suprarrenoprivos, Sakaté (1926) observó que, mucho tiempo después de la operación, el cloruro de amonio podía producir intensa hiperglucemia y ligera glucosuria. Las elevaciones más altas las observó en los normales (de $1.00-1.10$ a $3.10-4.00$ grs. por mil) en los suprarrenovivos, era un poco menor (de $1.00-1.10$ a $2.40-2.90$ ) les siguieron los conejos con una sola suprarrenal y. esplácnico cortado (de $0.90-1.00$ a $1.50-2.00)$; y, por fin, la menor elevación la tuvieron aquellos con sección esplácnica bilateral $(0.90-1.00$ a $1.40-1.70$ gr. por mil).

\section{Tiroxina}

Sakaguchi, Hayashi y Katayama (1919) obtuvieron con la tiroidina hiperglucemia en conejos suprarrenoprivos de algún tiempo antes. Según Sundberg (1925) la tiroxina hace bajar algo la glucemia tanto en los normales como en los suprarrenoprivos; pero, dando tiroxina y luego adrenalina, se obtiene hiperglucemia, que sólo en los decapsulados es seguida de hipoglucemia. Como observó hipoglucemia secundaria en conejos con restos de corteza, cree que el hecho debe imputarse a la falta de médula suprarrenal.

Zunz y La Barre (1931) observan que la inyección endovenosa de 1 - $3 \mathrm{mgs}$. de tiroxina, en perros normales, eleva la g'ucemia con el máximo a las 3 horas; en los decapsulados, hubo más bien hipoglucemia, y, en un caso, muerte en hipoglucemia.

\section{Toxina diftérica}

La inyección intravenosa de toxina diftérica produce una hiperglucemia inmediata en el conejo, con agotamiento de la adrenalina contenida en la suprarrenal (Mikami, 1925), la cual no se observa si se cortan previamente los nervios esplácnicos (Iino, 1922; Mikami, 1925). Si la supervivencia es larga, 
al aumento del azúcar sanguíneo sigue una hipoglucemia con agotamiento del glucógeno hepático y de la adrenalina suprarrenal.

En perros que sólo conservaban una suprarrenal desmedulizada, Molinelli (1926) observó que la toxina diftérica prơvocaba, en general, pequeños aumentos de la glucemia, pero más o menos en la misma proporción que en los normales. Watanabe (1928), inyectando una dosis mortal en 24 horas a perros, no pudo encontrar ni secreción de adrenalina ni elevación de la glucemia.

\section{Vacunas}

La inyección de bacilos coli o proteus muertos produce hiperglucemia en conejos. Si previamente se extirpa una suprarrenal y se desnerva la otra, se produciría hipoglucemia tan intensa que puede determinar convulsiones. La hiperglucemia podría ser abolida por la ergotamina (Evans y Zeckwer, 1927).

\section{HIPERGLUCEMIA NICOTINICA}

Generalidades. - La nicotina determina, primero, una fase fugaz de excitación, luego la depresión, y, por fin, la parálisis de las células ganglionares del sistema nervioso autónomo. Se pueden agrupar con ella por su acción análoga: la lobelina, citisina, gelsemina, conina esparteína, diversos amonios cuaternarios, etc.

La inyeción de nicotina produce un aumento de la secreción de adrenalina suprarrenal, lo cual se ha comprobado de muchas maneras: por la dilatación de la pupila desnervada en el gato (Dale y Laidlaw, 1912; Stewart y Rogoff, 1919; Shimidzu, 1924); por la acción inhibitoria sobre el intestino aislado que adquiere la sangre obtenida de la vena cava (Cannon, Aub y Binger, 1912), o la sangre suprarrenal recogida en una bolsa cava (Stewart y Rogoff, 1919; Sugawara, 1925; por la acción vasoconstrictora de la sangre suprarrenal de perro sobre un preparado de sistema vascular de rana (Eichholtz, 1923); por la acción que produce la nicotina en experimentos de anastomosis suprarrenoyugular, en los que se observa, en el perro, reactivo, que recibe la sangre suprarrenal: hiperten- 
sión, taquicardia, relajación intestinal, constricción de la pata o bazo desnervados, hiperglucemia (Houssay y Molinelli, 1925) o hipertensión y apnea (Tournade, 1925; Tournade y Chabrol, 1926) o síncope adrenalino-clorofórmico (Tournade, Chabrol y Malméjac, 1926).

La nicotina estimula la secreción de adrenalina directamente, es decir, sin intervención del sistema nervioso: lo prueba el hecho de que la hipersecreción se observa aún después del corte de los nervios esplácnicos mayores y menores, extirpación de los ganglios celíacos y mesentéricos, desnervación suprarrenal (Eichholtz, 1923; Houssay y Molinelli, 1925; Sugawara, 1925; Tournade y Chabrol, 1926). La acción de la nicotina se observa también sobre una suprarrenal superviviente, en la que produce aumento de la secreción de adrenalina, seguida más tarde de una disminución (Schkawera y Kusnetzow, 1923; Kudrjawzew, 1924; Kusnetzow, 1927). La descarga de adrenalina se produce también inyectando la nicotina en plena suprarrenal (Houssay y Molinelli, 1925) o en la sangre arterial que llega a una suprarrenal injertada en el cuello (Houssay y Molinelli, 1925). La hipersecreción de adrenalina se observa en animales con el sistema nervioso central destruído, en los que eleva la presión arterial (Wertheimer, 1891; Gley, 1895) y relaja el útero (Dale y Laidlaw, 1912). La extirpación o exclusión de las suprarrenales reduce y casi anula estos efectos.

A la acción estimulante de la nicotina, que es de breve duración (1 a 3 minutos después de una inyección endovenosa) sigue una disminución de la secreción de adrenalina (Stewart y Rogoff, 1919; Eichholtz 1923; Houssay y Molinelli, 1925). Pero mientras, según Stewart y Rogoff, la depresión es el efecto típico, según Houssay y Molinelli es pasajera. Estos autores han demostrado que, en el perro, una infusión continua de nicotina puede mantener la hipersecreción de adrenalina, aunque con declinación paulatina (1). La hiperadrenalinemia se hą observado también en el hombre (Stroomann, 1925).

(1) En las publicaciones de Houssay y Molinelli y de Molinelli se zencontrará un resumen detallado de los trabajos que citamos y de algunos más; pero, posteriormente, han aparecido los de Sugawara (1925), Tournade (1926), Tainter (1926), Tournade, Chabrol y Malméjac (1926), Kusnetzow (1927), Rydin (1927), Burstein y Goldenberg (1928), Inaba y Oikawa (1930), ete. 
La acción sobre la glucemia fué estudiada por Houssay y Molinelli (1925) con el método de la anastomosis suprarrenoyugular de Tournade y Chabrol. La inyección endovenosa de un miligramo de nicotina ( $0.052 \mathrm{mg}$. por $\mathrm{kg}$.) elevó, a los 30 minutos, la glucemia del transfusor de 0.69 a 0.99 y la del transfundido de 0.89 a 1.21 , a los 45 minutos. La elevación glucémica del transfundido no se debió al paso de nicotina por la vena suprarrenal, porque la inyección al mismo de igual volumen de sangre yugular del transfusor no modificó la glucemia.

La acción hiperglucemiante de la nicotina ha sido también estudiada, en perros, con administración aguda o crónica, por Burstein y Goldenberg (1928), quienes suponen que es debida a la hiperadrenalinemia.

Los experimentos de Houssay y Molinelli probaban que la nicotina produce una hiperadrenalinemía capaz de provocar una hiperglucemia, pero no indicaban si esta substancia tenía una acción hiperglucemiante propia independiente de las suprarrenales. Podía suceder, como en el caso de la elevación de la presión arterial consecutiva a la inyección de nicotina, que no se debe únicamente al aumento de secreción adrenalínica, puesto que, suprimiendo esta última, se observa todavía una neta hipertensión. Por lo tanto, con el fin de averiguar si, eliminada la secreción médulosuprarrenal, puede producirse aún la hiperglucemia nicotínica, se han efectuado experimentos en animales suprarrenoprivos o privados solamente de la substancia medular.

Conocíase también la estimulación directa de la médula suprarrenal por la nicotina, pero se ignoraba si la secreción seguiría produciéndose cuantitativamente en la misma forma después de eliminada la influencia del sistema nervioso. Para resolver esta cuestión, se procedió a comparar la hiperglucemia en dos grupos de animales, unos con suprarrenales normales y otros con suprarrenales desnervadas. Según Imahashi (1928), la sección de los esplácnicos impide la hiperglucemia nicotínica en el conejo. A conclusiones opuestas llegan Inaba y Oikawa (1930) experimentando en conejos normales, esplacnicotomizados 2 a 3 semanas antes y suprarrenoprivos desde 8 a 16 meses. La dosis inyectada fué de $5 \mathrm{mgs}$. por $\mathrm{kg}$. El 
término medio del valor inicial y de la mayor elevación glucémica de 4 normales fué de 1.09 a 1.97 ; en 7 esplacnicotomizados fué de 1.02 a 1.75. La máxima se observó a los 45 minutos y la duración de la hiperglucemia fué de unas tres horas. Concluyen estos autores que la sección de los esplácni$\cos$ no modifica esencialmente la hiperglucemia nicotínica, mientras que la presencia de las suprarrenales es indispensable.

\section{INVESTIGACIONES PERSONALES}

En primer lugar, se determinó cuál era la dosis hiperglucemiante óptima, para lo cual se inyectaron, por vía subcutánea, tres perros normales no anestesiados, con distintas dosis de nicotina. Cada 15 minutos, durante 3 horas, se sacaba sangre de la oreja para dosar la glucosa por el método de Hagedorn y Jensen. Damos a continuación los resultados obtenidos. (Cuadro $\left(24^{\circ}\right)$.

\section{CuAdro $24^{\circ}$}

Glucemias por mil antes y después de la inyección de nicotina en perros normales sin anestesia.

\begin{tabular}{|c|c|c|c|c|c|c|c|c|c|}
\hline $\begin{array}{l}\text { Dosis de nicotina } \\
\text { subcut, por kg. }\end{array}$ & $0^{\prime}$ & $15^{\prime}$ & $30^{\circ}$ & 45' & $60^{\prime}$ & $90^{\prime}$ & $120^{\prime}$ & $150^{\prime}$ & $180^{\circ}$ \\
\hline $\begin{array}{c}10 \text { mgs. } \\
5 \\
1\end{array}$ & $\begin{array}{l}1.31 \\
1.21 \\
1.40\end{array}$ & $\begin{array}{l}1.60 \\
1.92 \\
1.21\end{array}$ & $\begin{array}{l}1.31 \\
1.85 \\
1.21\end{array}$ & $\begin{array}{l}1.53 \\
1.45 \\
1.07\end{array}$ & $\begin{array}{l}1.21 \\
0.82 \\
0.96\end{array}$ & $\begin{array}{l}1.35 \\
0.96 \\
1.07\end{array}$ & $\begin{array}{l}1.35 \\
0.92 \\
1.03\end{array}$ & $\begin{array}{l}1.49 \\
1.00 \\
1.09\end{array}$ & $\begin{array}{l}1.31 \\
1.07 \\
1.21\end{array}$ \\
\hline
\end{tabular}

La dosis de $1 \mathrm{mg}$. por $\mathrm{kg}$. de peso no provocó una hiperglucemia notable. (Ignoramos a qué se debió el alto nivel inicial). La dosis de $10 \mathrm{mgs}$. por $\mathrm{kg}$. de peso produjo una curva glucémica irregular, por lo cual decidimos adoptar, para nuestros experimentos, la de $5 \mathrm{mgs}$. por $\mathrm{kg}$. Esta dosis produce invariablemente polipnea, temblor, vómitos, defecación, etc.

\section{HIPERGLUCEMIA NICOTÍNICA EN - SUPRARRENOPRIVOS Y ESPLACNICOTOMIZADOS RECIENTES}

* Hemos realizado dos grupos de experiencias: Las primeras, pocas horas después de la operación (esplecnicotomía o supra rrenalectomía); las otras en animales operados algún tiempo atrás (esplacnicotomía o desmedulización). Lo que nos indujo 
a separar estas experiencias en tal forma fué el hecho de que la operación influye considerablemente sobre la altura de la hiperglucemia nicotínica.

Influencia de la operación. - Hemos estudiado la hiperglucemia con una dosis de nicotina de $5 \mathrm{mgs}$. por $\mathrm{kg}$. en dos grupos de testigos: $1^{\circ}$ en 9 perros completamente normales (cuadro 26) ; $2^{\circ}$ en 7 perros que habían sufrido una laparotomía bajo anestesia etérea 3 a 5 horas antes (cuadro 25).

\section{CUADRO 25}

Hiperglucemias provocadas en perros operados 3 a 5 horas antes (anestesia etérea), por la inyección de $5 \mathrm{mgs}$. de nicotina por $\mathrm{kg}$. por vía subcutánea. - Glucemias por mil

Testigos laparotomizados

\begin{tabular}{|c|c|c|c|c|c|c|c|c|c|}
\hline N. ${ }^{0}$ & $\begin{array}{l}\text { Tiempo de } \\
\text { operados }\end{array}$ & Antes & $15^{\prime}$ & $30^{\prime}$ & $45^{\prime}$ & $60^{\prime}$ & $90^{\prime}$ & $120^{\prime}$ & $\begin{array}{l}\text { Elevación } \\
\text { grs. } \% \text { \% }\end{array}$ \\
\hline $\begin{array}{l}33 \\
38 \\
52 \\
82\end{array}$ & $\begin{array}{ll}3 & \text { hs. } \\
5 & \\
4 & \\
4 & \\
5 & \\
5 & \\
5 & \end{array}$ & $\begin{array}{l}1.20 \\
1.08 \\
1.09 \\
1.24 \\
0.99 \\
1.17 \\
1.01\end{array}$ & $\begin{array}{l}1.68 \\
1.10 \\
1.23 \\
1.27 \\
1.17 \\
1.31 \\
1.65\end{array}$ & $\begin{array}{r}1.45 \\
1.47 \\
1.21 \\
1.38 \\
1.27 \\
1.51 \\
1.52\end{array}$ & $\begin{array}{l}1.18 \\
1.33 \\
1.11 \\
1.20 \\
1.15 \\
1.47 \\
1.29\end{array}$ & $\begin{array}{l}1.06 \\
1.05 \\
1.14 \\
1.11 \\
1.04 \\
1.34 \\
1.13\end{array}$ & $\begin{array}{l}0.92 \\
1.15 \\
1.05 \\
1.06 \\
0.92 \\
1.27 \\
0.92\end{array}$ & $\begin{array}{l}1.06 \\
0.91 \\
1.07 \\
1.02 \\
0.94 \\
1.17 \\
0.99\end{array}$ & $\begin{array}{l}0.48 \\
0.39 \\
0.14 \\
0.14 \\
0.28 \\
0.30 \\
0.64\end{array}$ \\
\hline Media & & 1.11 & 1.34 & 1.38 & 1.24 & 1.12 & 1.04 & 1.02 & 0.33 \\
\hline
\end{tabular}

Esplacnicotomizados

\begin{tabular}{|c|c|c|c|c|c|c|c|c|c|}
\hline N. ${ }^{0}$ & $\begin{array}{c}\text { Tiempo de } \\
\text { operados }\end{array}$ & Antes & $15^{\prime}$ & $30^{\prime}$ & $45^{\prime}$ & $60^{\prime}$ & $90^{\prime}$ & $120^{\prime}$ & $\begin{array}{l}\text { Elevación } \\
\text { gra. } \% \text { \% }\end{array}$ \\
\hline $\begin{array}{l}34 \\
40 \\
42 \\
53 \\
80 \\
90 \\
91 \\
92\end{array}$ & $\begin{array}{l}3 \text { hs. } \\
5 \text { > } \\
3> \\
4> \\
4> \\
5 \\
5> \\
5>\end{array}$ & $\begin{array}{l}0.90 \\
0.87 \\
1.07 \\
0.94 \\
1.06 \\
0.94 \\
1.03 \\
1.06\end{array}$ & $\begin{array}{r}1.03 \\
0.83 \\
1.05 \\
1.44 \\
1.84 \\
1.25 \\
1.17 \\
1.04\end{array}$ & $\begin{array}{l}1.11 \\
0.91 \\
1.07 \\
1.38 \\
1.54 \\
1.12 \\
1.34 \\
1.04\end{array}$ & $\begin{array}{l}1.13 \\
1.05 \\
1.17 \\
1.09 \\
1.38 \\
0.92 \\
1.04 \\
0.99\end{array}$ & $\begin{array}{l}1.13 \\
1.08 \\
1.24 \\
1.11 \\
1.24 \\
0.77 \\
0.94 \\
0.83\end{array}$ & $\begin{array}{l}0.99 \\
1.10 \\
1.14 \\
1.17 \\
1.24 \\
0.94 \\
0.97 \\
1.03\end{array}$ & $\begin{array}{l}0.99 \\
1.01 \\
1.14 \\
1.12 \\
1.38 \\
0.81 \\
0.95 \\
0.86\end{array}$ & $\begin{array}{r}0.23 \\
0.18 \\
0.17 \\
0.50 \\
0.78 \\
0.31 \\
0.31 \\
-0.02\end{array}$ \\
\hline Media & & 0.98 & 1.20 & 1.19 & 1.09 & 1.04 & 1.07 & 1.03 & 0.30 \\
\hline
\end{tabular}

Suprarrenoprivos

\begin{tabular}{|c|c|c|c|c|c|c|c|c|c|}
\hline N. ${ }^{\circ}$ & $\begin{array}{c}\text { Tiempo de } \\
\text { operados }\end{array}$ & Antes & $15^{\prime}$ & $30^{\prime}$ & $45^{\prime}$ & $60^{\prime}$ & $90^{\prime}$ & $120^{\prime}$ & $\begin{array}{l}\text { Elevación } \\
\text { grs. } \% 00\end{array}$ \\
\hline $\begin{array}{l}35 \\
36 \\
39 \\
41 \\
54 \\
81\end{array}$ & $\begin{array}{ll}3 & \text { hs. } \\
5 & ? \\
5 & 3 \\
3 & \\
4 & 3 \\
4 & \text { ? }\end{array}$ & $\begin{array}{l}0.97 \\
1.07 \\
0.80 \\
0.96 \\
1.05 \\
1.02\end{array}$ & $\begin{array}{l}0.83 \\
1.07 \\
0.91 \\
0.98 \\
0.91 \\
1.02\end{array}$ & $\begin{array}{l}0.83 \\
0.97 \\
0.89 \\
0.93 \\
0.89 \\
0.95\end{array}$ & $\begin{array}{l}0.94 \\
1.10 \\
0.92 \\
0.98 \\
0.93 \\
0.93\end{array}$ & $\begin{array}{l}0.85 \\
1.02 \\
0.82 \\
0.89 \\
1.00 \\
0.92\end{array}$ & $\begin{array}{l}0.99 \\
0.95 \\
0.80 \\
0.96 \\
1.00 \\
0.95\end{array}$ & $\begin{array}{l}0.85 \\
0.95 \\
0.91 \\
0.89 \\
0.98 \\
0.84\end{array}$ & $\begin{array}{r}0.02 \\
0.03 \\
0.12 \\
0.02 \\
-0.05 \\
-0.07\end{array}$ \\
\hline Media & & 0.98 & 0.95 & 0.91 & 0.96 & 0.91 & 0.94 & 0.90 & 0.01 \\
\hline
\end{tabular}


La hiperglucemia fué mucho menos marcada en los perros que habían sufrido la laparatomía. (Gráfico IV).

\section{Gráfico IV.}

Hiperglucemia nicotínica.

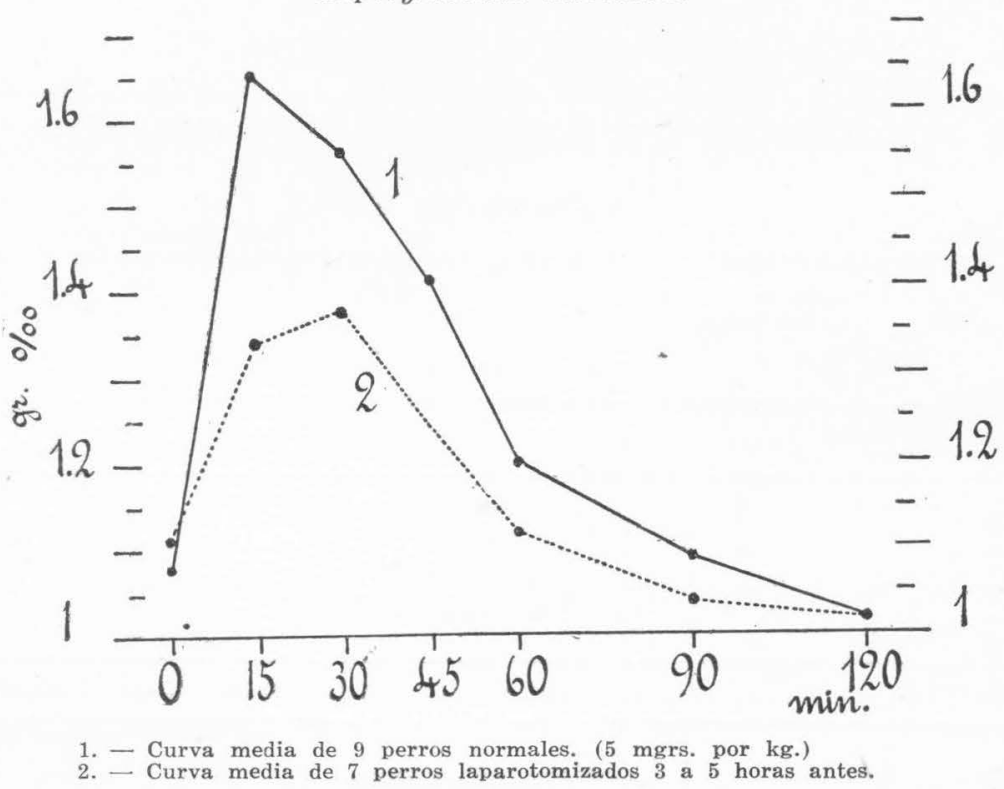

Suprarrenoprivos. - Con la misma técnica se estudió la hiperglucemia en 6 perros a los cuales se extirparon en un tiempo las dos suprarrenales por vía abdominal en casi todos; por vía lumbar y en dos tiempos en otros. La anestesia se hizo con éter, y la curva glucémica se estudió 3 a 5 horas después. (Cuadro 25\%).

En estos perros la hiperglucemia faltó en casi todos los casos o hubo más bien hipoglucemia. Sólo en uno hubo una elevación de un $15 \%$ (0.80 a 0.91$)$ sobre el nivel inicial. (Cuadro 25\%, Gráfico V).

Esplacnicotomizados recientes. - En 8 perros se seccionaron ambos esplácnicos mayores y menores y se resecaron las cadenas simpáticas lumbares bajo anestesia etérea.

La hiperglucemia fué en estos perros bastante marcada, aunque algo menor que en los testigos (cuadro 25), lo que 
puede explicarse por shock o inhibición médulo-adrenal, por haber sido la operación algo más larga y más traumatizante. En el gráfico V construído con las curvas medias puede verse claramente la diferencia entre los distintos lotes. Se ve que la esplacnicotomía sólo disminuye ligeramente la altura de la hiperglucemia, mientras que la suprarrenalectomía la anula. Es interesante observar que el nivel inicial es bastante más bajo en los esplacnicotomizados y suprarrenoprivos que en los testigos.

GRÁFICO V.

Hiperglucemia nicotinica en operados recientes.

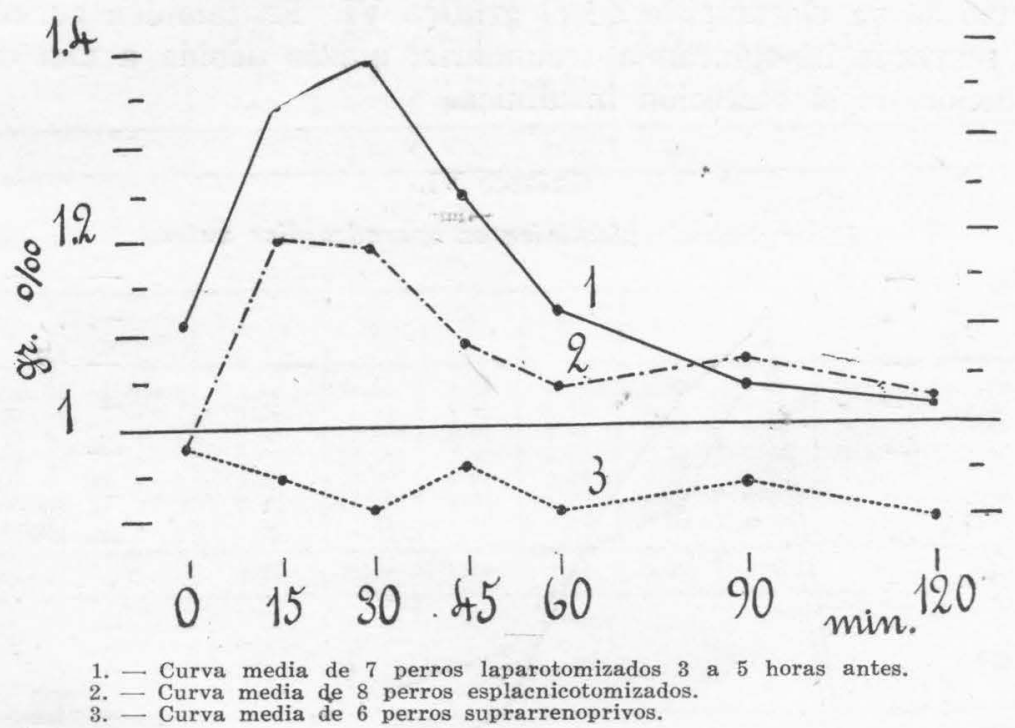

HIPERGLUCEMIA NICOTÍNICA EN ESPLACNICOTOMIZADOS ANTIGUOS Y EN DESMEDULIZADOS

Otros grupos de animales fueron estudiados en tiempos alejados de la operación, cuando ya estaban completamente repuestos de ella.

Desmedulizados. - Estos perros sufrieron la extirpación del tejido medular de la suprarrenal izquierda, siguiendo la técnica de Houssay y Lewis (1921). Muchos días después, cuando ya estaban repuestos de la primera operación, se extirpó la suprarrenal derecha. Los 6 perros así operados fueron 
sometidos a la prueba de la nicotina. Es de notar, en primer lugar, el nivel glucémico inicial bajo de alguno de estos perros. En segundo lugar, el hecho de que la elevación nunca llegó a ser tan alta como en los perros testigos. (La hiperglucemia más alta fué de un $44.8 \%$, mientras que en los normales llegó a $91.9 \%$ sobre la cifra inicial). Es además curioso el hecho de que los mismos perros tuvieron elevación en unos casos y descenso en otros. Otros perros ( $N$ \% 111) nunca tuvieron hiperglucemia. Comparando la curva media de estos perros privados de médula suprarrenal con la de los normales, se nota una enorme disminución en la capacidad de elevar la glucemia, como se ve claramente en el gráfico VI. Es también curiosa la marcada hipoglucemia secundaria, quizás debida a una excitación de la secreción insulínica.

\section{Gráfico VI.}

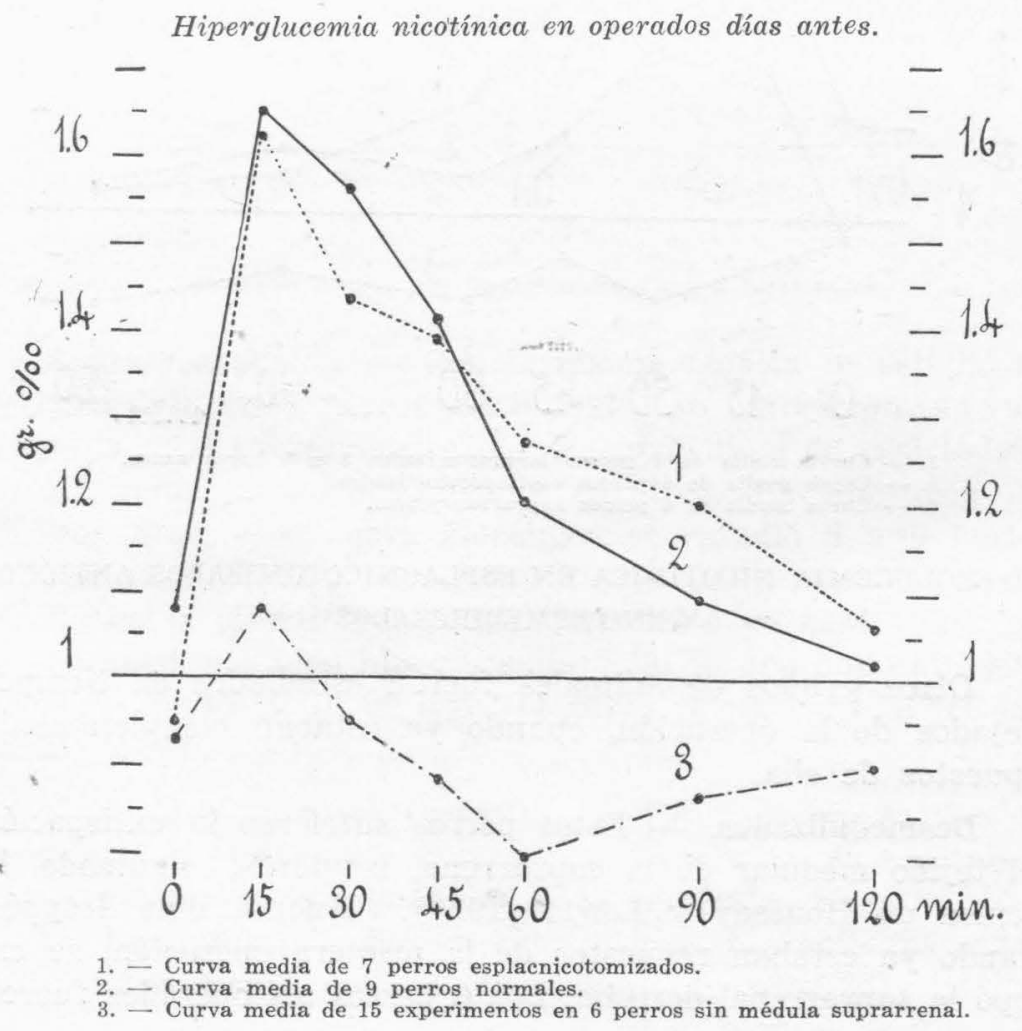


CuAdro $26^{\circ}$

Hiperglucemia producida por $5 \mathrm{mgs}$. de nicotina por $\mathrm{kg}$. vía subcutánea, en perros no anestesiados, operados varios días antes.

Glucemias por mil.

Testigos sin operar

\begin{tabular}{|c|c|c|c|c|c|c|c|c|}
\hline & Antes & $15^{\prime}$ & $30^{\prime}$ & $45^{\prime}$ & $60^{\prime}$ & $90^{\prime}$ & $120^{\prime}$ & $\begin{array}{c}\text { Elevación } \\
\text { grs. } \% 00\end{array}$ \\
\hline . & $\begin{array}{l}1.21 \\
1.12 \\
0.94 \\
1.10 \\
1.17 \\
1.31 \\
0.88 \\
0.85 \\
1.18\end{array}$ & $\begin{array}{l}1.92 \\
1.26 \\
1.73 \\
2.10 \\
1.70 \\
1.63 \\
1.56 \\
1.38 \\
1.60\end{array}$ & $\begin{array}{l}1.85 \\
1.37 \\
1.67 \\
1.71 \\
1.69 \\
1.72 \\
1.32 \\
1.24 \\
1.47\end{array}$ & $\begin{array}{l}1.45 \\
1.02 \\
1.44 \\
1.42 \\
1.70 \\
1.59 \\
1.40 \\
0.96 \\
1.72\end{array}$ & $\begin{array}{l}0.82 \\
1.02 \\
1.33 \\
1.14 \\
1.60 \\
1.40 \\
0.85 \\
0.83 \\
1.83\end{array}$ & $\begin{array}{l}0.96 \\
1.09 \\
1.26 \\
1.10 \\
1.47 \\
1.22 \\
0.83 \\
1.78 \\
1.17\end{array}$ & $\begin{array}{l}0.92 \\
1.05 \\
1.15 \\
1.21 \\
1.26 \\
1.18 \\
0.67 \\
0.65 \\
1.08\end{array}$ & $\begin{array}{l}0.71 \\
0.25 \\
0.79 \\
1.00 \\
0.53 \\
0.41 \\
0.68 \\
0.53 \\
0.41\end{array}$ \\
\hline Media & 1.08 & 1.65 & 1.56 & 1.41 & 1.20 & 1.09 & 1.02 & 0.62 \\
\hline
\end{tabular}

Esplacnicotomizados.

\begin{tabular}{|c|c|c|c|c|c|c|c|c|c|}
\hline N. ${ }^{0}$ & $\begin{array}{l}\text { Tiempo de } \\
\text { operados }\end{array}$ & Antes & $15^{\prime}$ & $30^{\prime}$ & $45^{\prime}$ & $60^{\prime}$ & $90^{\prime}$ & $120^{\prime}$ & $\begin{array}{c}\text { Elevacióa } \\
\text { gra. } \% 00\end{array}$ \\
\hline $\begin{array}{l}34 \\
40 \\
42 \\
42 \\
\\
90 \\
92\end{array}$ & $\begin{array}{rl}3 & \text { dias } \\
5 & \text { ? } \\
10 & ? \\
71 & > \\
40 & ? \\
11 & ? \\
11 & >\end{array}$ & $\begin{array}{l}1.12 \\
0.95 \\
0.95 \\
1.07 \\
1.05 \\
0.61 \\
0.88\end{array}$ & $\begin{array}{l}1.95 \\
1.14 \\
1.84 \\
1.38 \\
2.61 \\
1.31 \\
1.15\end{array}$ & $\begin{array}{l}1.74 \\
1.21 \\
1.01 \\
1.49 \\
2.29 \\
1.11 \\
1.18\end{array}$ & $\begin{array}{l}1.52 \\
1.26 \\
1.06 \\
1.69 \\
2.18 \\
1.05 \\
0.99\end{array}$ & $\begin{array}{r}1.33 \\
+1.14 \\
0.99 \\
1.30 \\
2.10 \\
1.03 \\
0.99\end{array}$ & $\begin{array}{l}1.34 \\
1.16 \\
0.93 \\
1.38 \\
1.70 \\
0.97 \\
0.96\end{array}$ & $\begin{array}{l}1.01 \\
1.12 \\
1.02 \\
1.17 \\
1.38 \\
0.79 \\
0.94\end{array}$ & $\begin{array}{l}0.83 \\
0.31 \\
0.89 \\
0.62 \\
1.56 \\
0.70 \\
0.30\end{array}$ \\
\hline Media & & 0.95 & 1.62 & 1.43 & 1.39 & 1.27 & 1.20 & 1.06 & 0.74 \\
\hline
\end{tabular}

Desmedulizados

\begin{tabular}{|c|c|c|c|c|c|c|c|c|c|}
\hline N. ${ }^{0}$ & $\begin{array}{c}\text { Tiempo de } \\
\text { operados }\end{array}$ & Antes & $15^{\prime}$ & $30^{\prime}$ & $45^{\prime}$ & $60^{\prime}$ & $90^{\prime}$ & $120^{\prime}$ & $\begin{array}{c}\text { Elevación } \\
\text { grs. } \% \text { \%o }\end{array}$ \\
\hline 17 & 19 dias & 0.87 & 1.26 & 0.85 & 0.89 & 0.94 & 0.98 & 0.87 & 0.39 \\
\hline 17 & $37>$ & 1.02 & 1.39 & 1.02 & 0.88 & & 0.74 & 0.94 & 0.37 \\
\hline 17 & $97>$ & 1. 21 & 1.58 & 1.24 & 1.08 & 1.14 & 1.12 & 1.07 & 0.37 \\
\hline 31 & 93 & 0.84 & 0.92 & 1.06 & 0.92 & 0.83 & 0.95 & 0.96 & 0.22 \\
\hline 31 & $60>$ & 1.07 & 1.24 & 1.21 & 0.96 & 1.03 & 0.96 & 0.98 & 0.17 \\
\hline 93 & 42 & 1.05 & 1.40 & 1.22 & 1.22 & 1.12 & 1.09 & 1.14 & 0.35 \\
\hline 93 & $79>$ & 0.97 & 0.92 & 0.85 & 0.70 & 0.74 & 0.74 & 0.65 & 0.00 \\
\hline 93 & $87>$ & 0.91 & 0.96 & 0.85 & 0.78 & 0.74 & 1.14 & 1.04 & 0.05 \\
\hline 99 & $20>$ & 0.96 & 1.31 & 1.19 & 0.96 & 0.87 & 1.12 & 1.07 & 0.35 \\
\hline 99 & $58>$ & 0.94 & 0.92 & 0.78 & 0.72 & 0.79 & 0.69 & 0.60 & 0.00 \\
\hline 99 & $66>$ & 0.60 & 0.92 & 0.78 & 0.82 & 0.74 & 1.03 & 1.06 & 0.32 \\
\hline 111 & $17>$ & 0.88 & 0.81 & 0.74 & 0.63 & 0.67 & 0.76 & 0.52 & 0.00 \\
\hline 111 & $25>$ & 0.80 & 0.78 & 0.82 & 1.12 & $0.8 \mathrm{z}$ & 1.05 & 1.02 & 0.00 \\
\hline 116 & $17>$ & 1.03 & 0.81 & 0.90 & 0.72 & 0.79 & 0.63 & 0.52 & 0.00 \\
\hline 116 & $25>$ & 0.78 & 0.94 & 0.83 & 0.96 & 0.83 & 1.10 & 1.10 & 0.16 \\
\hline Media & & 0.93 & 1.08 & 0.95 & 0.89 & 0.80 & 0.87 & 0.90 & 0.18 \\
\hline
\end{tabular}


Esplacnicotomizados. - Los mismos perros esplacnicotomizados que fueron estudiados pocas horas después de la operación fueron sometidos a la prueba de la nicotina días más tarde (Cuadro 26ㅇ, Gráfico VI). Comparando con las hiperglucemias obtenidas poco después de la operación (Cuadro $25^{\circ}$ ), se observa el efecto depresor ejercido por ésta. Además, comparando con el término medio de las glucemias de los perros normales, puede observarse que el nivel inicial fué algo más bajo, pero que el nivel alcanzado fué igual.

\section{ANASTOMOSIS SUPRARRENOYUGULAR}

Hemos realizado, además, dos experiencias de anastomosis suprarrenoyugular; pero, en lugar de inyectar $0.052 \mathrm{mg}$. por kg. de nicotina endovenosa como hicieron Houssay y Molinelli (1925), se administraron $5 \mathrm{mgs}$. por $\mathrm{kg}$. por vía subcutánea para tener efectos más claros y comparables con los demás experimentos nuestros. Se tuvo la precaución de extirpar al perro dador la cápsula suprarrenal derecha y al receptor ambos adrenes. En esta forma no podía haber descarga de adrenalina suprarrenal en el perro dador, y en el receptor quedaba eliminada la influencia de las suprarrenales propias excitadas por una llegada de nicotina.

Primera experiencia de anastomosis suprarrenoyugular.Perro dador: $28.4 \mathrm{kgs}$. Perro receptor: $9.5 \mathrm{kgs}$. Anestesia con cloralosa. Se extirpa la suprarrenal derecha al dador y ambas suprarrenales al receptor. Se anastomosa la vena suprarrenal izquierda del dador con la yugular del receptor, usando para ello un trozo de vena yugular. La sangre para los análisis fué tomada de la carótida y desproteinizada por el ácido tungstico. Quince minutos después que comenzó a funcionar la anastomosis se inyectó la nicotina. Por error se inyectaron $4.6 \mathrm{mgs}$. por $\mathrm{kg}$. en lugar de 5. A continuación se hicieron tomas a $\operatorname{los} 15,30,45,60$ y 90 minutos. Resultados en el cuadro $27^{\circ}$.

En esta primera experiencia la elevación glucémica fué muy pequeña en el dador ( 0.88 a 1.04$)$, en cambio, fué mucho más grande en el receptor (1.28 a 2.01$)$. 
CuAdro $27^{\circ}$

Primera experiencia de anastomosis suprarrenoyugular. En $O^{\prime}$, inyección de 4.6 mgs. por $\mathrm{kg}$. de nicotina al dador, vía subcutánea.

\begin{tabular}{|c|c|c|c|c|c|c|}
\hline & $0^{\circ}$ & $15^{\prime}$ & $30^{\prime}$ & 45' & $60^{\circ}$ & 90' minutos \\
\hline $\begin{array}{l}\text { Perro dador } \\
28.4 \mathrm{kgs} \text {. }\end{array}$ & 0.88 & 1.04 & 1.00 & 0.95 & 0.95 & 0.93 \\
\hline $\begin{array}{l}\text { Perro recep- } \\
\text { tor: } 9.5 \mathrm{kgs} \text {. }\end{array}$ & 1.28 & 2.01 & 1.93 & 1.86 & 1.79 & 1.61 \\
\hline
\end{tabular}

Segunda experiencia de anastomosis suprarrenoyugular. Perro dador: $21 \mathrm{kgs}$. Perro receptor: $8 \mathrm{kgs}$. Fué realizada en la misma forma que la anterior. La dosis de nicotina fué de 5 mgs. por kg. Se hizo una toma de sangre al comenzar a funcionar la anastomosis, y se inyectó la nicotina 15 minutos después. Resultados en el cuadro ...

\section{Cuadro $28^{\circ}$}

Segunda experiencia de anastomosis suprarrenoyugular.

En O', inyección de 5 mgs. por $\mathrm{kg}$. de nicotina al dador, vía subcutánea.

\begin{tabular}{l|c|c|c|c|c|c|c}
\hline & $-15^{\prime}$ & $\mathbf{0}^{\prime}$ & $\mathbf{1 5}$ & $\mathbf{3 0}$ & $\mathbf{4 5}$ & $\mathbf{6 0}$ & $\mathbf{9 0} \mathbf{0}^{\prime}$ minutos \\
\hline $\begin{array}{c}\text { Perro dador } \\
\text { 21 kgs. }\end{array}$ & 1.07 & 1.00 & 1.14 & 1.21 & 1.21 & 1.23 & 1.21 \\
\hline $\begin{array}{c}\text { Perro recep- } \\
\text { tor 8 kgs. }\end{array}$ & 1.00 & 0.93 & 1.25 & 1.80 & 2.01 & 1.86 & 1.43 \\
\hline
\end{tabular}

Los resultados son casi iguales a los de la primera experiencia. Elevación de $1 \mid 00$ a 1.23 en el dador y de 0.93 a 2.01 . en el receptor. Es un hecho comprobado que la simple transfusión no eleva la glucemia en más de 0.25 gr. por mil. (Houssay, Lewis y Molinelli, 1924).

Estos experimentos demuestran que en los perros la inyección bajo piel de $5 \mathrm{mgs}$. de nicotina provoca una secreción suprarrenal de adrenalina capaz de producir una hiperglucemia intensa en el perro transfundido o receptor. La pequeña elevación glucémica del perro transfusor inyectado con nicotina puede deberse a pequeñas cantidades de adrenalina de su 
suprarrenal izquierda, que pasan por pequeñas anastomosis vasculares no visibles o no ligadas.

\section{MECANISMO DE LA INHIBICIÓN OPERATORIA}

Con el fin de averiguar si la inhibición operatoria de la hiperglucemia nicotínica era debida a una menor secreción de adrenalina o a una disminución de la capacidad del organismo de elevar la glucemia, hemos inyectado a dos grupos de perros, operados y no operados, la cantidad de adrenalina que calculábamos podía ser segregada durante la excitación nicotínica. La dosis de adrenalina empleada fué de $0.025 \mathrm{mg}$. por $\mathrm{kg}$., repetida dos veces con 5 minutos de intervalo, por vía endovenosa. Cuatro perros laparotomizados bajo anestesia etérea y 5 normales fueron así tratados. (Cuadro $29^{\circ}$ ).

\section{CuAdro $29^{\circ}$}

Hiperglucemia adrenalínica

(Mgr. 0.025, endovenoso, dos veces con 5 minutos de intervalo).

Perros laparotomizados 3 horas antes.

\begin{tabular}{c|c|c|c|c|c|c|c|c}
\hline Peso kgs. & Antes & 15' & 30' & 45' & 60' & 90' & 120' & $\begin{array}{c}\text { Elevación } \\
\text { en gs. \%00 }\end{array}$ \\
\hline 6.3 & 1.21 & 1.54 & 1.17 & 1.14 & 1.07 & 1.14 & 1.01 & 0.33 \\
7.5 & 1.54 & 1.74 & 1.67 & 1.47 & 1.38 & 1.26 & 1.17 & 0.24 \\
4.4 & 0.96 & 1.30 & 1.02 & 1.16 & 1.14 & 1.05 & 0.95 & 0.34 \\
6.8 & 1.23 & $1.69^{\circ}$ & 1.62 & 1.57 & 1.33 & 1.19 & 1.09 & 0.46 \\
\hline T. medio & 1.23 & 1.56 & 1.37 & 1.33 & 1.23 & 1.16 & 1.08 & 0.34 \\
\hline
\end{tabular}

Perros normales.

\begin{tabular}{|c|c|c|c|c|c|c|c|c|}
\hline Peso kg8. & Antes & $15^{\prime}$ & $30^{\prime}$ & $45^{\prime}$ & $60^{\prime}$ & $90^{\prime}$ & $120^{\prime}$ & $\begin{array}{l}\text { Elevación } \\
\text { en g5. } \% / 00\end{array}$ \\
\hline 4.2 & 1.00 & 1.45 & 1.29 & 1.14 & 1.07 & 1.01 & 0.92 & 0.45 \\
\hline 5.8 & 1.09 & 1.33 & 1.26 & 1.23 & 1.09 & 1.12 & 0.96 & 0.24 \\
\hline 5.1 & 1.02 & 1.42 & 1.42 & 1.23 & 1.14 & 1.00 & 0.84 & 0.40 \\
\hline 9.4 & 0.94 & 1.31 & 1.05 & 0.94 & 0.98 & 0.98 & 0.78 & 0.26 \\
\hline 15.0 & 1.01 & 1.74 & 1.40 & 1.34 & 1.29 & 0.96 & 1.05 & 0.73 \\
\hline T. medio & 1.21 & 1.45 & 1.28 & 1.17 & 1.11 & 1.01 & 0.91 & 0.42 \\
\hline
\end{tabular}

La hiperglucemia obtenida fué más o menos igual en ambos grupos. Por lo tanto, siendo la hiperglucemia provocada por la adrenalina igual en operados y no operados, es probable 
que la menor acción de la nicotina en los operados sea provocada por una menor secreción de adrenalina debida a un agotamiento o inhibición de la médula suprarrenal.

\section{INFLUENCIA DE LA ANESTESIA}

La influencia producida por la laparotomía sobre la hiperglucemia nicotínica podía atribuirse ya sea a la anestesia etérea o a la laparotomía propiamente dicha. Con el objeto de averiguar si la anestesia sola era capaz de inhibir la hiperglucemia, hemos inyectado nicotina ( $5 \mathrm{mgs}$. por $\mathrm{kg}$.) a 4 perros, a los cuales se anestesió con éter durante media hora, cuatro horas antes del experimento. (Cuadro $30^{\circ}$ ).

\section{Cuadro $30^{\circ}$}

Hiperglucemia nicotínica en perros anestesiados 4 horas antes.

\begin{tabular}{c|c|c|c|c|c|c|c|c}
\hline Peso kgs. & Antes & 15' & 30' & 45' & 60' & 90' & 120' & $\begin{array}{c}\text { Elevación } \\
\text { en grs, \%o }\end{array}$ \\
\hline 7.0 & 1.14 & 1.96 & 1.66 & 1.46 & 1.18 & 1.14 & 0.98 & 0.82 \\
4.3 & 1.00 & 1.96 & 1.57 & 1.14 & 1.04 & 1.04 & 0.98 & 0.96 \\
8.6 & 1.09 & 1.33 & 1.26 & 1.16 & 1.06 & 1.06 & 0.97 & 0.24 \\
5.8 & 0.98 & 1.33 & 1.32 & 1.25 & 1.21 & 1.07 & 0.98 & 0.35 \\
\hline T. medio & 1.05 & 1.64 & 1.46 & 1.25 & 1.12 & 1.07 & 0.98 & 0.59 \\
\hline
\end{tabular}

La elevación glucémica fué mayor que en los perros laparotomizados (cuadro $25^{\circ}$ ) y comparable a la de los normales (cuadro 26). Por lo tanto, la inhibición operatoria no debe atribuirse a la anestésia.

\section{INFLUENCIA DE LA ERGOTAMINA}

La ergotamina paraliza las terminaciones nerviosas del simpático, anula o invierte el efecto de la adrenalina sobre la presión arterial. Además, tiene la propiedad de disminuir la hiperglucemia adrenalínica en el conejo (Micucilich, 1912; Pollack, 1929, etc.) Houssay y Molinelli (1925) no lograron obtener que la ergotoxina (330 mgs. a un perro de $23.5 \mathrm{kgs}$.) impidiera la descarga de adrenalina provocada por la nicotina. 
A fin de comprobar si la ergotamina era capaz de suprimir el efecto hiperglucemiante de la nicotina, hemos inyectado por vía subcutánea, a 4 perros, $1 \mathrm{mg}$. por kg. de tartrato de ergotamina (Ginergeno Sandoz). Treinta minutos después, les inyectamos la nicotina ( $5 \mathrm{mgs}$. por $\mathrm{kg}$.). Resultados en el Cuadro $31^{\circ}$.

CUADRO $31^{\circ}$

Hiperglucemia nicotínica con inyección previa ergotamina, $1 \mathrm{mg}$. por $\mathrm{kg}$. (En — «o', inyección de ergotamina. Én O', nicotina 5 mgs. por kg.)

\begin{tabular}{c|c|c|c|c|c|c|c|c}
\hline Peso kgs. & 30' & 0' & 20' & 30' & 45' & 70' & 120' & Elevación \\
\hline 6.9 & 1.16 & 1.10 & 1.37 & 0.93 & 1.10 & 1.02 & 1.08 & 0.27 \\
5.8 & 1.23 & 1.29 & 1.81 & 1.06 & 1.36 & 1.22 & 1.39 & 0.52 \\
7.5 & 1.08 & $\mathbf{1 . 2 3}$ & 1.59 & 1.13 & 1.36 & 1.30 & 1.34 & 0.36 \\
6.7 & 1.20 & $\mathbf{1 . 0 4}$ & 1.32 & 1.32 & 1.23 & 1.15 & 0.99 & 0.26 \\
\hline T. medio & 1.16 & 1.16 & $\mathbf{1 . 5 2}$ & 1.11 & 1.26 & $\mathbf{1 . 1 7}$ & $\mathbf{1 . 2 0}$ & 0.35 \\
\hline
\end{tabular}

La hiperglucemia observada es un poco menor en altura que la de los perros no tratados (cuatro 26:), pero la duración fué algo menor.

\section{INFLUENCIA DE LA ATROPINA}

La atropina no impediría la hipersecreción adrenalínica provocada por la excitación del esplácnico mayor (Biedl, 1897 y Tscherboksaroff, 1910) o por el hecho de pinzar y soltar la aorta (Popielski, 1911). Sin embargo, con dosis altas se ha observado que la atropina suprime la hipersecreción adrenalínica que se produce al excitar el esplácnico (Kure, Wada y Okinaka, 1931; Lewis y Ludueña, inédito).

Con el método de la bolsa cava (Stewart y Rogoff, 1920) o en la suprarrenal aislada (Schkawera y Kusnetzow, 1923) no se ha observado aumento de secreción de adrenalina después de inyectar atropina. Tampoco lo observaron Houssay y Molinelli (1925) en experimentos de anastomosis suprarrenoyugular.

Por nuestra parte, hemos inyectado a 8 perros $1 \mathrm{mg}$. por $\mathrm{kg}$. de atropina. A 5 de ellos se les administró, $15 \mathrm{minu}$ tos después, la nicotina (cuadro $32^{\circ}$ ). Los que recibieron atropina sola no presentaron modificación importante de la glu- 
cemia, mientras que los que recibieron también nicotina, tuvieron una hiperglucemia más o menos parecida a la de los perros no atropinizados, pero algo menor.

Cuadro $32^{\circ}$

Hiperglucemia nicotínica con inyección previa de sulfato de atropina (1 $m g$. por $\mathrm{kg}$.)

(En-15', inyección de atropina. En O', nicotina 5 mgs. pon $\mathrm{kg}$.)

\begin{tabular}{|c|c|c|c|c|c|c|c|c|c|}
\hline Peso & $-15^{\prime}$ & $0^{\prime}$ & $15^{\prime}$ & $30^{\prime}$ & $45^{\prime}$ & $60^{\prime}$ & $90^{\prime}$ & $120^{\prime}$ & Elevación \\
\hline $\begin{array}{r}7.5 \\
10.0 \\
6.6 \\
7.9 \\
7.4\end{array}$ & $\begin{array}{l}0.82 \\
0.99 \\
0.99 \\
0.71 \\
0.73\end{array}$ & $\begin{array}{l}0.86 \\
0.86 \\
\\
0.73 \\
0.79\end{array}$ & $\begin{array}{l}1.09 \\
1.53 \\
1.30 \\
1.28 \\
0.93\end{array}$ & $\begin{array}{l}1.02 \\
1.37 \\
1.30 \\
0.98 \\
1.12\end{array}$ & $\begin{array}{l}0.84 \\
1.20 \\
1.23 \\
0.84 \\
1.11\end{array}$ & $\begin{array}{l}0.79 \\
1.20 \\
0.81 \\
0.89 \\
1.09\end{array}$ & $\begin{array}{l}0.82 \\
0.97 \\
0.75 \\
1.16\end{array}$ & $\begin{array}{l}0.77 \\
0.90 \\
0.84 \\
0.68 \\
0.97\end{array}$ & $\begin{array}{l}0.23 \\
0.67 \\
0.21 \\
0.75 \\
0.33\end{array}$ \\
\hline T, medio & 0.85 & 0.81 & 1.22 & 1.16 & 1.04 & 0.95 & $0.9 \mathrm{z}$ & 0.83 & 0.44 \\
\hline
\end{tabular}

Con atropina solamente

\begin{tabular}{l|l|l|l|l|l|l|l|l|l|l|l|l|l}
\hline 6.6 & 0.81 & & 0.99 & & & 0.97 & 0.81 & \\
6.7 & 0.77 & 0.75 & & 0.79 & & 0.82 & 0.89 & 0.73 & \\
8.4 & 0.80 & 0.80 & & 0.89 & & 1.04 & 1.02 & 1.11 & \\
\hline
\end{tabular}

\section{Discusión}

La disminución de la acción hiperglucemiante de la nicotina en los recién operados (laparotomía, Gráfico IV; sección de los esplánicos y cadena simpática, gráficos V y VI debe atribuirse a una menor secreción de adrenalina por las suprarrenales, agotadas o inhibidas por la influencia no de la anestesia sino del traumatismo operatorio. No está disminuída la sensibilidad de estos-perros a la acción hiperglucemiante de una dosis dada de adrenalina (cuadro $29^{\circ}$ ).

La extirpación de las suprarrenales impide la producción de la hiperglucemia; y ésto no se debe a la operación reciente, porque los perros operados sin sacar estas glándulas tuvieron una hiperglucemia neta (gráfico IV).

La sección de los nervios esplácnicos y cadenas simpáticas no afecta sensiblemente la acción hiperglucemiante de la nicotina, una vez disipada la influencia operatoria inicial (gráfico VI). Por lo tanto, la acción esencial de la nicotina es directa sobre las suprarrenales, y no es llevada por los nervios simpáticos, ni proviene del sistema nervioso central. 
La anastomosis suprarrenoyugular demuestra que la nicotina provoca en la suprarrenal una hipersecreción de adrenalina, que es la responsable de la hiperglucemia nicotínica. La pequeña elevación producida por la nicotina en algunos perros sin médula suprarrenal puede deberse a descarga de adrenalina o simpatina en otras partes del organismo.

La atropina y la ergotamina (a la dosis de un $\mathrm{mg}$. por kg.) no disminuyen la acción de la nicotina sobre la glucemia.

\section{CONCLUSIONES}

$1^{\circ}$ - La hiperglucemia nicotínica falta o apenas se esboza en ausencia de las suprarrenales.

$2^{\circ}$ - Se produce, aunque estén resecados los nervios esplácnicos y las cadenas simpáticas lumbares, un poco disminuída a las pocas horas y normalmente después de varios días.

3 : - La nicotina produce una hipersecreción adrenalínica que provoca hiperglucemia (anastomosis suprarrenoyugular).

40 - La supresión de la médula adrenal, disminuye o suprime la hiperglucemia nicotínica. La hiperglucemia residual que se observa en algunos casos se debe probablemente a una secreción de adrenalina por el sistema cromafínico extraadrenal o la simpatina.

$5^{\circ}$ - La atropina y la ergotamina en la dosis de $1 \mathrm{mg}$. por $\mathrm{kg}$. no modifican manifiestamente la hiperglucemia nicotínica.

6. - La disminución de la hiperglucemia nicotínica provocada por las operaciones recientes no es debida a la anestesia; parece más bien causada por un agotamiento o una inhibición de la médula suprarrenal. 


\section{CAPITULO VI}

\section{SUPRARRENALES Y DIABETES}

Antagonismo entre la adrenalina y la insulina, $p$. 113 - SENSIBILIDAD A LA INSULINA, p. 114: En animales sin suprarrenales, p. 114; En animales con suprarrenales desnervadas, $p .114$; En animales desmedulizados, $p .115$ - HIPERSECRECIÓN ADRENALÍNICA PROVOCADA POR LA INSULINA, $p .115$ - DIABETES PANCREÁTICA EN LOS SUPRARRENOPRIVOS, p. 117: Experiencias personales, p. 119 -Discusión, p. 125 - DiABETES PANCREÁTICA EN LOS PERROS PRIVADOS DE MÉDULA SUPRARRENAL, p. 125 - Investigaciones personales, p. 126 - DIABETES ANTEROHIPOFISARIA EN LOS ANIMALES PRIVADOS DE MÉDULA SUPRARRENAL, $p .128$ - Investigaciones personales, p. 130 - DIABETES PANCREÁtICA EN LOS ANIMALES CON LAS SUPRARRENALES DESNERVADAS, $p .130$ - DIABETES ANTEROHIPOFISARIA EN LOS ANIMALES CON 'SUPRARRENALES DESNERVADAS, Investigaciones personales, $p .131$ - Resumen y conclusiones, p. 133.

\section{ANTAGONISMO ENTRE LA ADRENALINA Y LA INSULINA}

Mientras la adrenalina eleva la glucemia, la insulina la hace descender y los efectos de ambas hormonas se neutralizan mutuamente. La inyección simultánea o consecutiva de una, anula los efectos de la otra sobre la glucemia en el conejo (Banting, Best, Collip, Macleod, y Noble, 1922; Eadie y Macleod, 1923; Burn, 1923) y en el perro (Magenta y Biasotti, 1923, etc.). Sin embargo, el efecto de la insulina suele prolongarse más, llegando a aparecer una hipoglucemia tardía cuando ya se ha desvanecido el efecto de la adrenalina.

La insulina contrarresta además algunas otras acciones de la adrenalina: como ser la acción sobre la presión arterial (Csepai y Weiss, 1925; Kogan y Ponirowsky, 1925) sobre el aumento de secreción salivar (Kogan y Ponirowsky, 1925; Kogan, Kamenew y Mantz, 1926); sobre el corazón aislado de rana e intestino de cobayo y sobre los linfocitos (Boden, Determann y Wankell, 1926); sobre la acción restauradora en el músculo fatigado de paloma (Agazzotti, 1926) ; sobre el volumen de un miembro en el hombre (Hiks y Szakall, 1927), etc. 


\section{SENSIBILIDAD A LA INSULINA}

En animales sin suprarrenales. - Lewis (1923) observó que las ratas suprarrenoprivas son más sensibles que las normales a la insulina, la que puede matarlas en dosis diez veces menores que para las normales. Este hecho ha sido confirmado por Sundberg (1923). En cambio, Stewart y Rogoff (1923) no hallaron diferencia en la acción de la insulina sobre conejos normales y en los decapsulados 8 meses antes. Es de notar que estos autores hicieron pocos experimentos y que tiene importancia el tiempo transcurrido desde la suprarrenalectomía, pues la hipersensibilidad a la insulina puede llegar a disminuir con el tiempo.

En los gatos sin corteza cerebral, Bulatao y Cannon (1925) observaron que la extirpación de las suprarrenales acentúa la acción hipoglucemiante de la insulina.

En el perro también aumenta la sensibilidad a la insulina después de extirpar las suprarrenales (Lewis y Magenta, 1924; Hallion y Gayet, 1925). Este hecho se observa también en el conejo (Tada, 1931; Ohmi, 1933), aún muchos días (162) después de la suprarrenalectomía.

Los efectos de la insulina en el hombre con insuficiencia suprarrenal han sido estudiados especialmente por Marañón (1925), quien observa que en los addisonianos se produce una hipoglucemia más rápida, intensa y persistente que en los normales, llegándose a provocar la muerte con cantidades de insulina perfectamente toleradas por los hombres normales.

En animales con suprarernales desnervadas. - La sensibilidad a la insulina es mayor en los gatos con una suprarrenal extirpada y desnervada la otra (Cannon, Mc Iver y Bliss, 1923 - 24; Britton, Geiling y Calvery, 1928).

En los perros la sección de los esplácnicos aumenta la intensidad de la hiperglucemia insulínica y dificulta la recuperación (Lewis y Magenta, 1924; Takats, 1933). Lo mismo se observaría en el gato (Burn y Marks, 1925). En los conejos esplacnicotomizados, la hipoglucemia es más rápida e intensa que en los normales (Ohmi, 1933). El mismo efecto tendría también la sección bilateral de la cadena simpática en el gato (Dworkin, 1931). 
En animales desmedulizados. - La extirpación del tejido medular de la suprarrenal de un lado y de la glándula íntegra del otro aumenta la sensibilidad a la insulina, en el perro (Lewis y Magenta, 1924; Böggild, 1931 - 33) y en el gato (Britton, Geiling y Calvery, 1928). Sin embargo, en el perro, la hipersensibilidad no es tan acentuada como después de seccionar los esplácnicos.

En el conejo la desmedulización hace que la hipoglucemia insulínica aparezca antes y sea más marcada que en los normales. El aumento de sensibilidad tendría más o menos la misma intensidad que cuando se desnervan o se extirpan las suprarrenales (Ohmi, 1933).

HIPERSERCECIÓN DE ADRENALINA PROVOCADA POR LA INSULINA

Wilder y Boothby (1923), al estudiar el aumento en el consumo de oxígeno provocado por la insulina, supusieron que este efecto podría deberse a una hipersecreción de adrenalina. Stewart y Rogoff (1923) buscaron ese aumento en la secreción de adrenalina, en el gato, sin encontrarlo. Pero sus animales no llegaron a tener un nivel glucémico suficientemente bajo como para provocar la hipersecreción adrenalínica, pues como veremos más adelante no es la insulina misma la que provoca la hiperactividad de la médula suprarrenal, sino la hipoglucemia por ella producida.

Cannon, Mc Iver y Bliss (1923 - 24) observaron que en el gato en hipoglucemia insulínica se producía una aceleración del corazón desnervado, debida a la hiperadrenalinemia, ya que no se observaba al extirpar o desnervar las suprarrenales. Inyectando glucosa junto con la insulina y evitando de esta manera la hipoglucemia, no se producía la descarga de la adrenalina.

La prueba de que la hipoglucemia insulínica provoca descarga de adrenalina en cantidad suficiente para elevar la glucemia, ha sido dada por Houssay, Lewis y Molinelli (1924) con el método de la anastomosis suprarrenoyugular de Tournade y Chabrol. Inyectando al dador insulina hasta llevarlo a la hipoglucemia, se produjo en el receptor, en 7 casos sobre 8, una elevación glucémica, que fué de $0.64 ; 0.46 ; 1.89 ; 2.93 ; 0.28$; 0.54 y 0.61 (elevación en grs. por mil). Impidiendo en los 
dadores la hipoglucemia con inyección de glucosa, se observaron en los transfundidos elevaciones insignificantes de la glucemia $(0.21 ; 0.46 ; 0.27 ; 0.19 ; 0.29$ y 0.34$)$. La sección de los esplácnicos en el transfusor impidió la aparición de la hiperglucemia en el transfundido (7 experimentos).

Además de estas experiencias hay aún otras que prueban que la hipoglucemia insulínica provoca secreción de adrenalina. Así Abe (1924) observó que en el conejo se producía la dilatación de la pupila desnervada. Por otra parte, Tscherboksaroff y Malkin (1925) comprobaron que la acción hipertensora de la sangre suprarrenal es mayor después de inyectar insulina en el perro. Lo mismo ha sido observado, en el conejo, por Sapegno y Maestri (1931) (sobre preparado Trendelenburg). La hipersecreción adrenalínica es independiente de la hipotensión que produce a veces la insulina (La Barre y Houssay, 1932). La cantidad de adrenalina segregada durante la hipoglucemia insulínica ha sido medida en perros, sin anestesia y deaferentados, por Yen, Aomura e Inaba (1933) dosándola por el método del intestino aislado. En todos los casos, la cantidad segregada aumentó, unos 30 minutos después de inyectar la insulina, y el aumento duró dos o más horas cuando la dosis era mayor de tres unidades por $\mathrm{kg}$. El aumento corriente fué de 10 a 20 veces la cantidad inicial. Con 0.25 unidades por $\mathrm{kg}$., la adrenalina segregada se triplicó, siendo el máximo hallado de 0.0001 a $0.0007 \mathrm{mgs}$. por $\mathrm{kg}$. y minuto. La hipersecreción insulínica se observó al llegar la glucemia a 0.60 grs. por mil o menos (1).

Se ha llegado, por diversos métodos, a comprobar también en el hombre el aumento de secreción adrenalínica durante la hipoglucemia insulínica (Kugelmann, 1931; Fernbach y Dekker, 1931; Brandt y Katz, 1933).

Después de las inyecciones de insulina disminuiría la reacción cromafínica de la médula suprarrenal, en la rata, ratón, paloma y rana (Poll, 1925), en el conejo y en el perro (Kahn, 1926) y ratón blanco (Hofmann, 1926). Kahn observó también una disminución en el contenido de adrenalina (medida por la

(1) La hipersecreción de adrenalina es debida a la hipoglucemia y no al brusco cambio del nivel glucémico, puesto que en perros con hiperglucemia por pancreatectomía, la insulina no provoca secreción de adrenalina, siempre que la glucemia no descienda por debajo de la normal (Sato, Ohmi y Kanowoka, 1933). 
acción hipertensora) que no aparecía después de seccionar los esplácnicos. Perfundiendo la suprarrenal aislada con el mismo líquido de Ringer con que se ha perfundido un páncreas (Kusnetzow, (1925) o con Ringer con insulina (Nikolaeff, 1929), aumentaría la adrenalina en el líquido de perfusión. Según estas experiencias, la insulina excitaría directamente la médula suprarrenal, hipótesis que no se concilia con los ya citados experimentos de Houssay, Lewis y Molinelli y Cannon, Mc Iver y Bliss ni con los de Kahn y Münzer (1927), usando un método histológico, ni los de Saito (1928), quien observa que la adrenalina sólo disminuye en la suprarrenal cuando conserva su innervación intacta. Al impedir la hipoglucemia por inyección de azúcar, la insulina tampoco disminuye la adrenalina suprarrenal.

La administración de insulina puede provocar una hipertrofia de las suprarrenales y en especial del tejido cortical. Se la ha observado en la paloma (Riddle, Honeywell y Fischer, 1924). En el conejo, si bien no la halló Thatcher (1926), ha sido comprobada por Langecker (1928) y Harada (1930) después de haber administrado insulina durante largo tiempo.

\section{DIABETES PANCREÁTICA EN LOS SUPRARRENOPRIVOS}

Cuando se observó la acción hiperglucemiante de la adrenalina y la acción hipoglucemiante de la insulina, se supuso que el nivel glucémico normal se mantenía gracias a un antagonismo recíproco de las dos hormonas: pancreática y suprarrenal. Zuelzer, en 1907, fué quien sostuvo esta hipótesis y se basaba en el siguiente experimento: ligó en un perro las venas capsulares y luego extirpó el páncreas, observando que la glucosuria sólo duraba pocas horas. Numerosos son los experimentos en los cuales se observaron resultados similares a los de Zuelzer: Mayer (1908) extirpó en un solo tiempo las dos suprarrenales y el páncreas a un perro. El animal sólo vivió una hora y murió en hipoglucemia. El mismo investigador extirpó a un gato una suprarrenal, luego el páncreas, en dos tiempos, y, estando el animal francamente diabético, efectuó la segunda capsulectomía: se produjo un descenso glucémico, aunque sin llegar a la normal. 
Hédon y Giraud (1920), haciendo la triple extirpación, en un solo tiempo, no observaron hiperglucemia. Tampoco la obtuvieron por capsulectomía y extirpación de un injerto pancreático.

Además, Gayet, Gayet y Guillaumie (1928) han observado que en perros pancreatoprivos, en los cuales se mantenía normal la glucemia con un injerto de páncreas en el cuello, subía la glucemia cuando se sacaba el injerto. Si, además, se habían extirpado las suprarrenales, no subía ya la glucemia al extirpar el injerto. Por transfusión suprarrenoyugular, se obtenía otra vez la elevación. El traumatismo de la doble capsulectomía puede explicar la falta de ascenso de la glucemia, y la adrenalina es seguramente la causante de la elevación provocada por la anastomosis suprarrenoyugular.

Mencionemos, todavía los experimentos de Frouin (1908), Allen (1913), Hédon (1921), Turcatti (1929) y las recientes de Viale (1930). Este último autor, 'haciendo las extirpaciones en tiempos separados, observa que en todos los casos la extirpación de la suprarrenal restante determina un descenso de la glucemia, pudiendo producirse la muerte en hipoglucemia.

A estos resultados podemos oponer los de Banting y Gairns (1926), quienes, en un perro pancreatoprivo mantenido con insulina durante 7 días, observaron que después de extirpar las suprarrenales, la glucemia subía de 2.24 a 4.34 en 6 horas. En otro perro que vivió 30 horas subió de 2.43 a 4.08 grs. por mil. También Lépine (1921) observa que la ligadura o extirpación de las suprarrenales no hace bajar la glucemia en los perros pancreatoprivos.

Lewis y Turcatti (1933) han estudiado detenidamente el punto en un trabajo muy superior a los precedentes. En una primera serie de perros extirparon la suprarrenal derecha $\mathbf{y}$, muchos días después, el páncreas; mantuvieron los perros durante unos siete días con insulina, y, después de suspender la insulina y estando los animales en ayuno, extirparon la suprarrehal derecha. Las supervivencias fueron de 11 a 35 horas y la glucemia subió en 6 de los perros, y en uno quedó en el mismo nivel, oscilando las cifras finales entre 2.32 y 7.32. La glucosuria disminuyó, aunque en uno fué de 13 gramos en las 24 horas. En otra serie de 4 perros extirparon la segunda 
suprarrenal estando los perros en normo o hipoglucemia insulínica. La elevación máxima fué 2.05 a 5.92, siendo la glucemia final de 1.10 a 5.04. Concluyen los autores que la hiperglucemia por falta de páncreas se mantiene o aumenta después de la suprarrenalectomía y que en el período agónico hay un descenso inconstante, más marcado cuando la supervivencia es larga y los perros no se alimentan, y que las glucosurias pueden ser considerables.

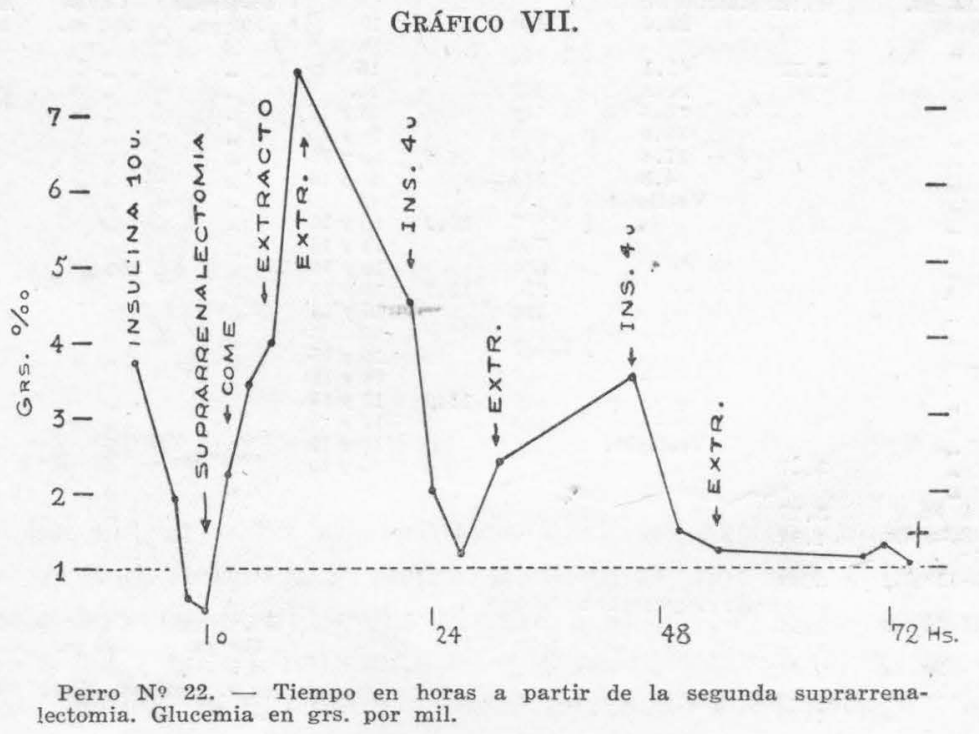

Experiencias personales. - Hemos estudiado la glucemia y glucosuria en perros privados de páncreas y suprarrenales, tratados con extracto córticosuprarrenal, llegando a obtener supervivencias hasta de tres días. Se procedió en la siguiente forma: Primero se extirpaba la suprarrenal derecha; una vez bien cicatrizada la herida operatoria, se extirpaba el páncreas. Luego se mantenía a los perros con insulina durante unos 10 a 20 días. Entonces se inyectaban 10 unïdades de insulina y, cuando la glucemia era de 0.46 a 0.84 por mil, se extirpaba la suprarrenal izquierda bajo anestesia etérea. En todos los casos se produjo un aumento de la glucemia que se hizo aún más intenso después de inyectar el extracto córticosuprarrenal. 
CUADRO $33^{\circ}$

Perro $N^{2} 22$ suprarrenopancretoprivo.

Primera suprarrenalectomía 4 de noviembre, 1932

Pancreatectomía 18 de noviembre, 1932

Segunda suprarrenalectomía 10 de diciembre, 1932

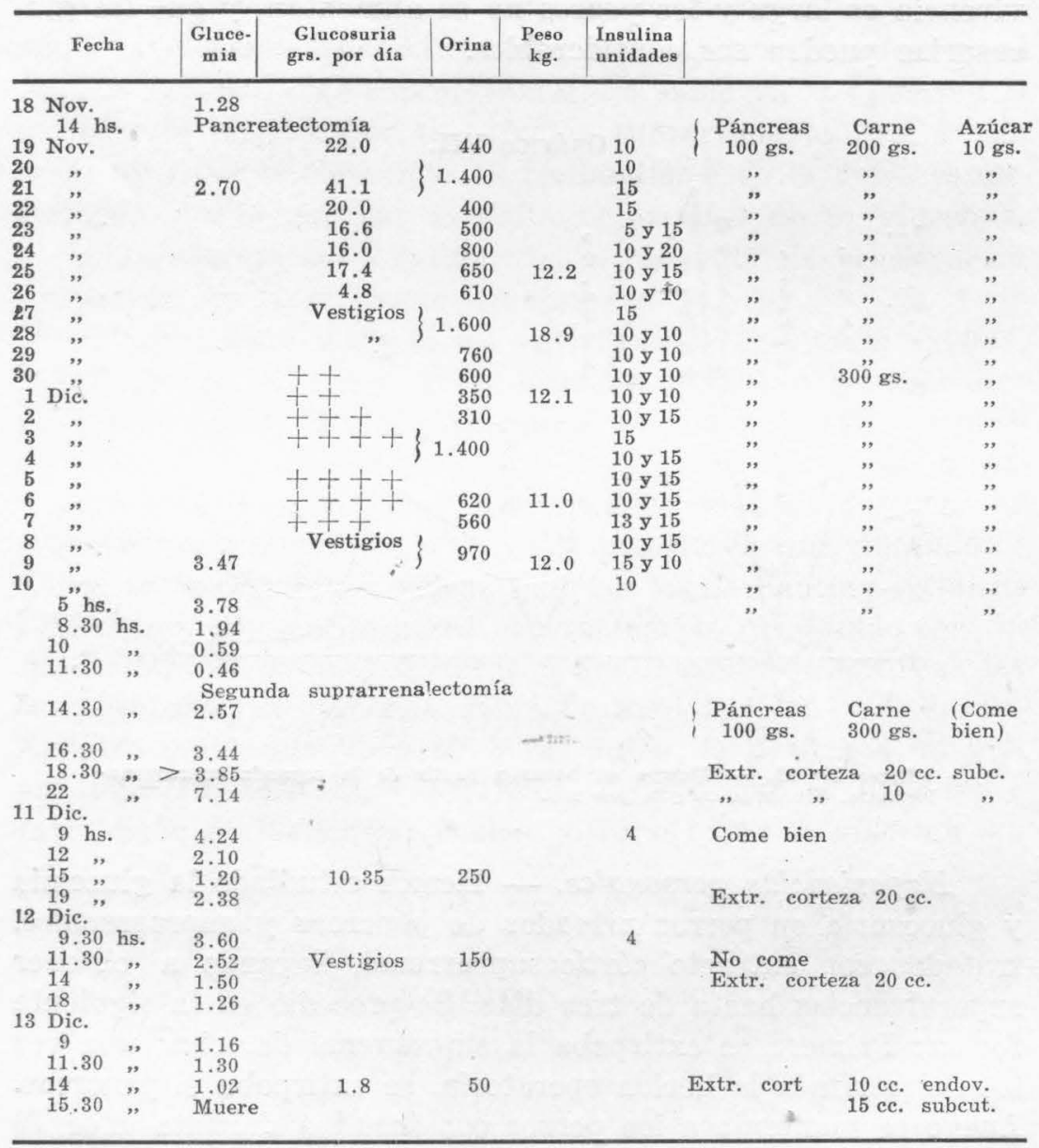

Cuerpos cetónicos, 13 de diciembre: 0.297 por mil $=0.014$.

La autopsia reveló un gran absceso subcutáneo en el flanco derecho; epiplón congeștionado; mucosa gástrica pálida, sin lesiones aparentes; duodeno normal. No pudieron encontrarse restos de suprarrenales ni de páncreas. 
GrÁfico VIII.

\section{Perro $N^{\circ}$ 26. Suprarrenopancreatoprivo}

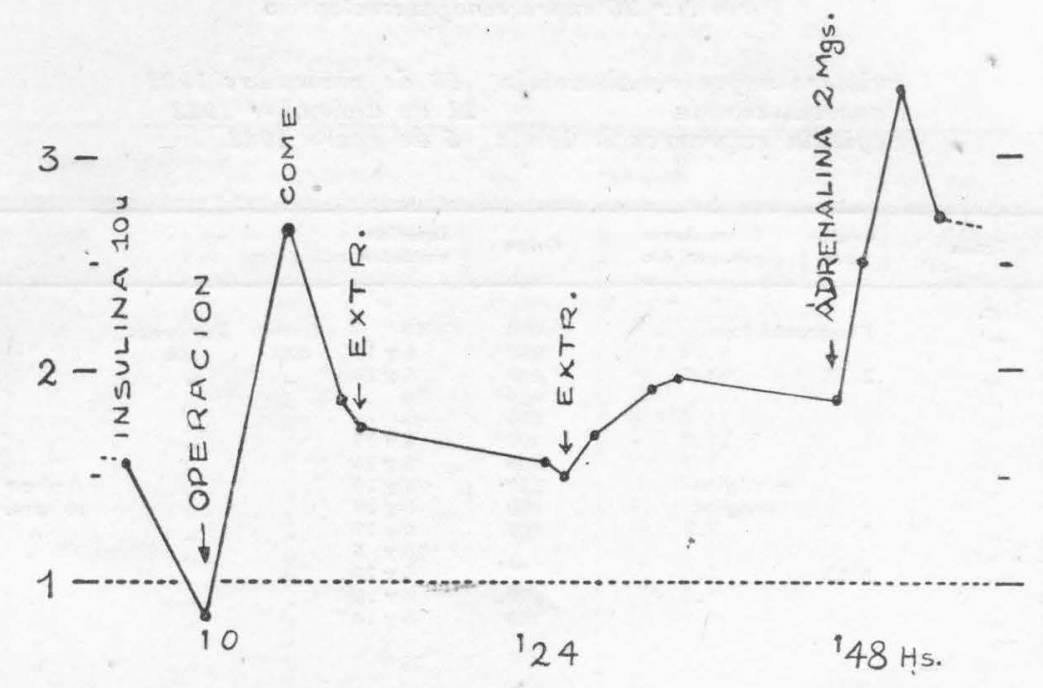

Glucemia en gramos por mil. Tiempo en horas a partir de la segunda suprarrenalectomía.

En el perro № 22 (gráfico VII), se extirpó la segunda suprarrenal, siendo la glucemia de $0.46 \mathrm{gr}$. por mil. Inmediatamente después, la glucemia empezó a subir llegando a más de 3.85 a las 7 horas, momento en que se inyectaron $20 \mathrm{cc}$. de extracto, siendo la glucemia a las 9 horas de 7.14 grs. por mil. La glucemia se mantuvo por encima de la normal durante los tres días de supervivencia y, en el momento de la muerte, era de $1 \mid 02$. La eliminación de azúcar fué de 10.35 grs. el primer día, vestigios el segundo y $1.08 \mathrm{gr}$. el tercero. Es de notar que el primero y segundo día se inyectaron 4 unidades de insulina. Después de muerto se halló un gran absceso en el flanco. 
CuAdro $34^{\circ}$

Perro N.० 26 suprarrenopancreatopriro

Primera suprarrenalectomía 18 de noviembre 1932

Pancreatectomía 21 de diciembre 1932

Segunda suprarrenalectomía 5 de enero 1933

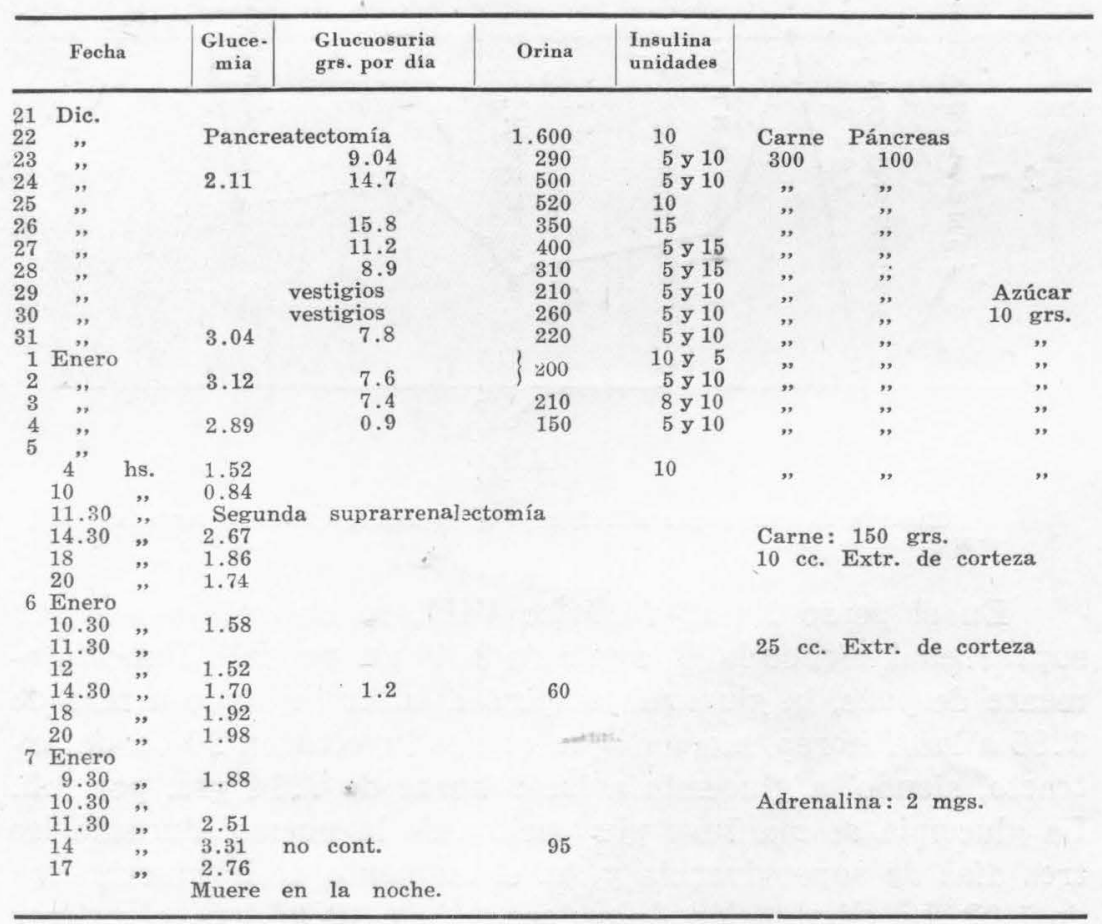

La autopsia no reveló restos de suprarrenales ni de páncreas.

El perro No 26 (gráfico VIII), vivió más de 30 horas. Después de la segunda suprarrenalectomía, la glucemia subió de 0.84 a 2.67 y no siguió subiendo con la inyección de extracto. A las 24 horas, la glucemia era de 1.88 grs. por mil y llegó a 3.31 por la inyección de $2 \mathrm{mgs}$. de adrenalina. La glucosuria fué de $1.2 \mathrm{gr}$. el primer día y 0 , el segundo. 


\section{CUADRO $35^{\circ}$}

Perro $N^{\circ} 50$ suprarrenopancreatoprivo

Primera suprarrenalectomía Marzo 15, 1933

Pancreatectomía Abril 18, 1933

Segunda suprarrenalectomía Mayo 18, 1933

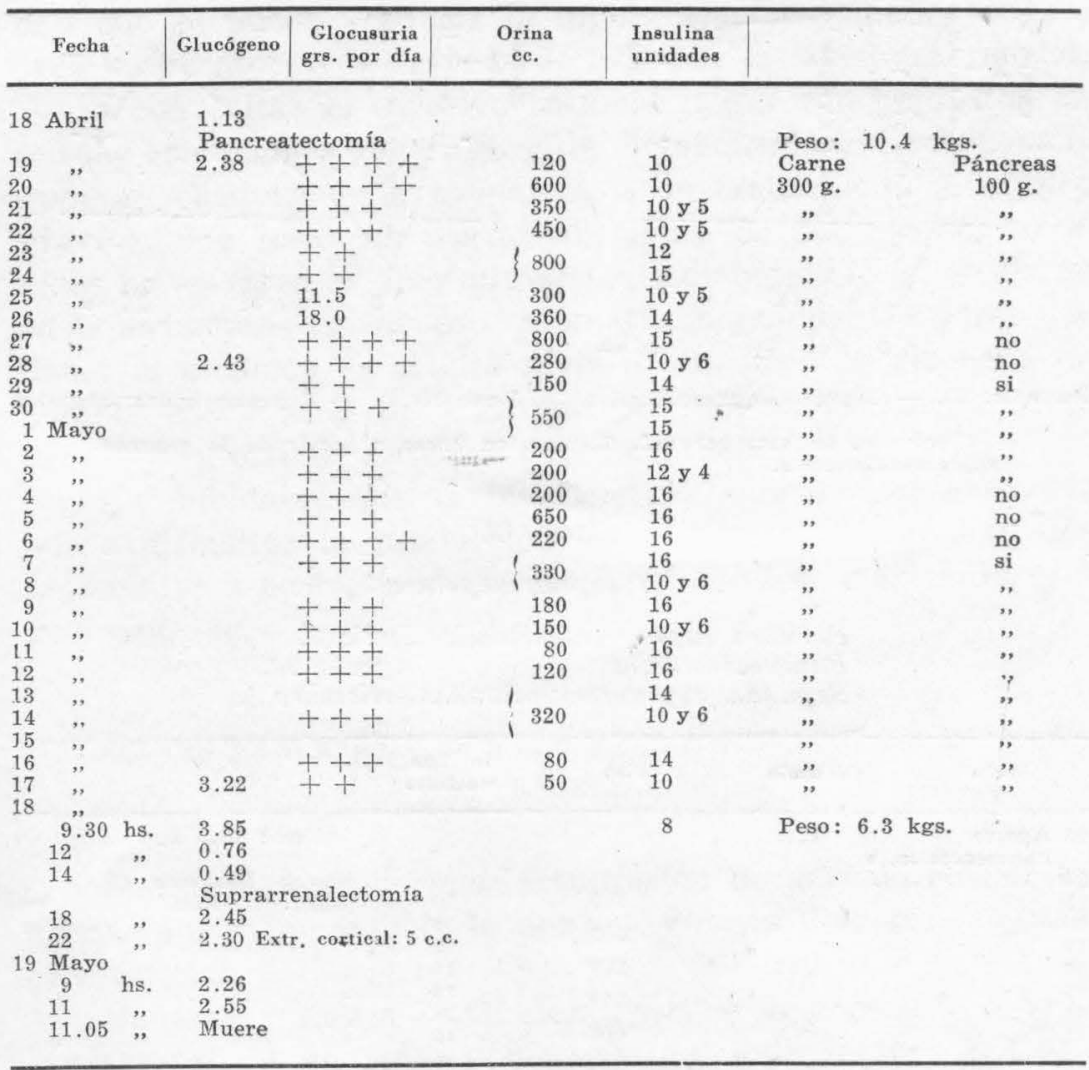

Autopsia: No se encuentran restos de suprarrenal ni de páncreas.

En el perro No 50 (gráfico IX), la glucemia subió de 0.49 a 2.45 a las 4 horas de la segunda suprarrenalectomía. Murió 21 horas después con una glucemia de 2.55 grs. por mil. 


\section{Gráfico IX.}

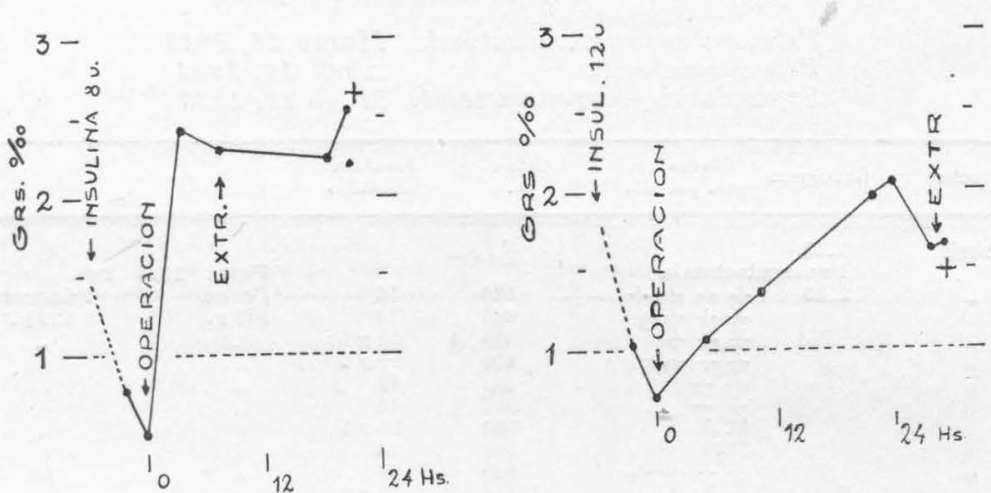

Perro No 50. - Suprarrenopancreatoprivo. Perro No 97. - Suprarrenopancreatoprivo.

Glucemias, en grs. por mil. Tiempo, en horas a partir de la segunda suprarrenalectomía.

\section{CUADRO $36^{\circ}$}

\section{Perro N.॰97 suprarrenopancreatoprivo}

Primera suprarrenalectomía Junio 8.

Pancreatectomía Agosto 23.

Segunda suprarrenalectomía Setiembre 4.

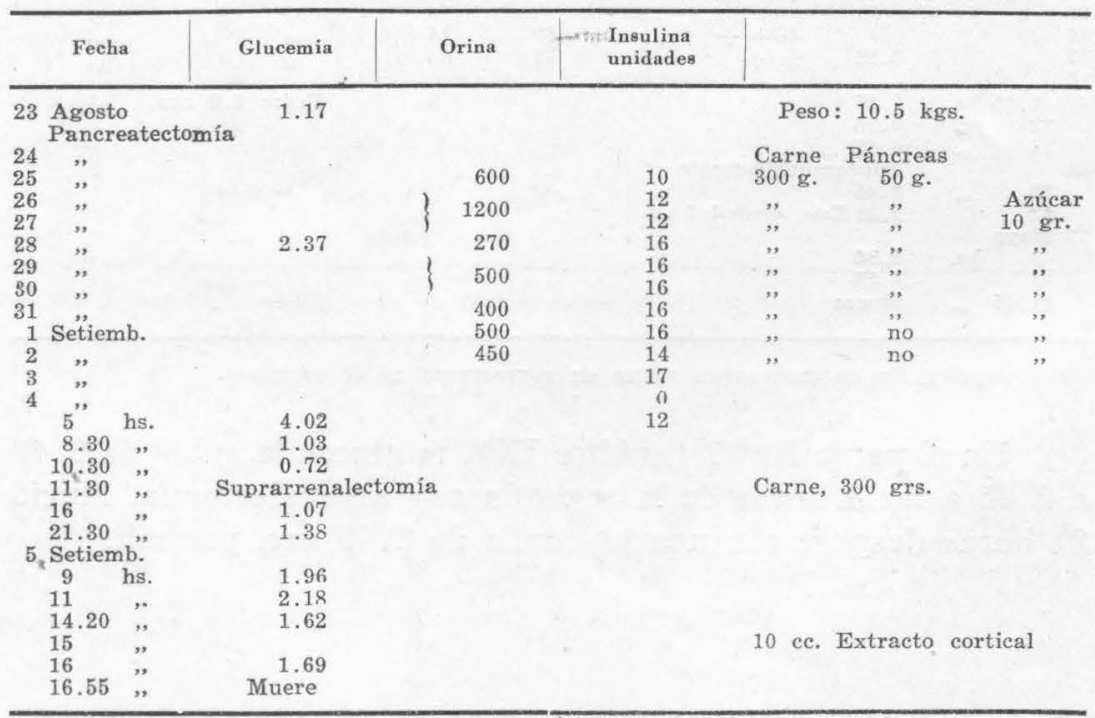

Autopsia: No se encuentran restos de suprarrenales ni de páncreas. 
El perro No 97 fué operado con una glucemia de 0.72. A las 24 horas y sin haber recibido extracto, tenía una glucemia de 2.18, y murió con 1.69 gr. por mil.

Discusión. - De nuestras experiencias así como de las de Banting y Gairns, Lewis y Turcatti, se deduce con toda claridad que se puede producir la hiperglucemia diabética en perros pancreatoprivos después de extirparles las suprarrenales. Basta con evitar el excesivo traumatismo y con que estén en buenas condiciones generales y de metabolismo hidrocarbonado (por ej. cicatrizados y sometidos a un tratamiento insulínico previo). Son inexactas las afirmaciones de que sin suprarrenales no se eleva la glucemia al nivel diabético, pues se basan en experimentos agudos con traumatismo grande. Un punto que llama la atención es el alto nivel a que llegó la glucemia en algunos casos (más de 7 gramos por mil en uno de nuestros perros y en otro de Lewis y Turcatti, 1933).

Es indudable que la insuficiencia suprarrenal avanzada puede dificultar la producción de la hiperglucemia diabética consecutiva a la pancreatectomía, así como hay menor diuresis, anorexia, etc.

\section{DIABETES PANCREÁTICA EN LOS PERROS PRIVADOS DE MÉDULA SUPRARRENAL}

Se ha demostrado que la supresión de adrenalina por las suprarrenales no impide la aparición de la diabetes por pancreatectomía.

Houssay y Lewis (1921) extirparon, en perros, la médula suprarrenal de un lado, y luego la glándula íntegra del otro lado. Dos de estos perros que vivieron 3 y 8 días, respectivamente, después de sacarles el páncreas, presentaron glucemias de 3.63 y 4 por mil, y glucosuria hasta de 100 gr. por mil. Más tarde obtuvieron con la misma técnica en dos perros supervivencias de 12 y 17 días, llegando la glucemia a 3 y 4 por mil con glucosurias de 40 y 100 grs. por mil.

Stewart y Rogoff (1923) y Turcatti (1929) observaron también diabetes en perros sin médula suprarrenal. En perros con pancreatectomía parcial la cauterización de la médula su- 
prarrenal disminuiría la intensidad de diabetes según Böggild (1923) ; pero sus resultados no son concluyentes porque esta intervención pudo por el traumatismo y la anorexia haber provocado variaciones de la glucemia.

Investigaciones personales. - Fueron realizadas en perròs a los cuales se extirpó, en un primer tiempo, la médula suprarrenal izquierda, siguiendo la técnica de Houssay y Lewis (1921), que es la siguiente: Se aborda la suprarrenal por vía lumbar; después de pinzar los vasos con un clamp, se abre la suprarrenal en dos mitades y se extirpa el tejido medular con una cureta, cosa que resulta muy fácil dada la friabilidad de este tejido. a los 30 y 40 días después, se extirpaba la suprarrenal derecha íntegra; $\mathrm{y}$, una vez bien cicatrizadas las heridas, se extirpaba el páncreas. Se mantuvo a los animales con insulina, procurando que se mejorara la cicatriz operatoria, y, dos o tres semanas después, se dejaba de dar insulina y se dosaban diariamente la glucemia y la glucosa y nitrógeno urinarios.

El primer perro que fué así tratado (No 31) vivió 14 días y tuvo glucemias hasta de 3.80 grs. eliminando por la orina 4 a 6 grs. de glucosa, a pesar de que casi no se alimentaba y recibía pequeñas dosis de insulina.

CuAdro $37^{\circ}$

Pérro $N^{\circ} 31$. Desmedulizado

Extirpación de la médula Diciembre 7, 1932.

Suprarrenalectomía Diciembre 28, 1932.

Pancreatectomía Marzo 31, 1938.

\begin{tabular}{|c|c|c|c|c|c|c|}
\hline & Fecha & $\begin{array}{c}\text { Glucemia } \\
\text { gr8. } \% \text {. }\end{array}$ & Glucosuria & $\begin{array}{c}\text { Orina } \\
\text { ce. }\end{array}$ & $\begin{array}{l}\text { Insulina } \\
\text { unidades }\end{array}$ & \\
\hline 31 & Marzo & \multicolumn{2}{|c|}{$\begin{array}{l}0.95 \\
\text { Pancreatectomía }\end{array}$} & & & Peso: $11.5 \mathrm{kgs}$. \\
\hline & Abril & 2.90 & 9.5 & 670 & 4 & No come \\
\hline $\begin{array}{l}4 \\
5\end{array}$ & $"$ & $\begin{array}{l}3.80 \\
3.46\end{array}$ & $\begin{array}{l}5.25 \\
4.6\end{array}$ & $\begin{array}{l}210 \\
150\end{array}$ & & Casi no come \\
\hline & $"$ & & 4.6 & 220 & $\begin{array}{l}4 \\
6\end{array}$ & . " " " " \\
\hline $\begin{array}{l}7 \\
8\end{array}$ & ", & 2.28 & 4.2 & 180 & 6 & No" come " \\
\hline & ? & & $\begin{array}{l}\text { no cont. } \\
++++\end{array}$ & $\begin{array}{r}30 \\
200\end{array}$ & 10 & C" " \\
\hline 10 & ; & & $++t+$ & 160 & 10 & , , \\
\hline $\begin{array}{l}11 \\
12\end{array}$ & $"$ & & $+t+t$ & 210 & 10 & Carne: 300 grs. \\
\hline $\begin{array}{l}12 \\
13\end{array}$ & " & & $\begin{array}{l}++4+ \\
\text { vestigios }\end{array}$ & $\begin{array}{l}210 \\
140\end{array}$ & 10 & $\begin{array}{l}\text { Carne: } 300 \text { grs. } \\
\text { Muere con convulsiones. }\end{array}$ \\
\hline & & & & & & 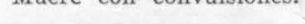 \\
\hline
\end{tabular}


El perro No 99 vivió 20 días y no recibió insulina durante los 8 últimos días en que su glucemia alcanzó a 3.66, llegando a eliminar 27.75 grs. de glucosa mientras sólo se alimentaba con carne.

\section{CUADRO $38^{\circ}$}

Perro No 99. - Desmedulizado

Extirpación médula suprarrenal izquierda Suprarrenalectomía derecha

Junio 10, 1933.

Pancreatectomía

Julio 4, 1933.

Octubre 10, 1933.

\begin{tabular}{|c|c|c|c|c|c|c|c|}
\hline Fecha & Glucemia & $\begin{array}{l}\text { Glucosuria } \\
\text { grs. por día }\end{array}$ & Orina & $\begin{array}{l}\text { Nitróg. } \\
\text { grs. }\end{array}$ & $\begin{array}{l}\text { Insulina } \\
\text { unidades }\end{array}$ & & \\
\hline 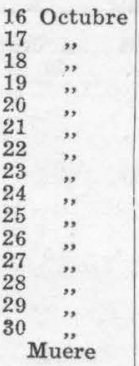 & $\begin{array}{l}2.26 \\
2.20 \\
3.66 \\
\\
2.10 \\
1.72\end{array}$ & $\begin{array}{l}t+ \\
+t+ \\
+t+ \\
+ \pm+ \\
+t+ \\
++t \\
+++t \\
27.75 \\
4.96 \\
7.5 \\
3.33 \\
1.25\end{array}$ & $\begin{array}{l}300 \\
200 \\
200 \\
300 \\
300 \\
300 \\
600 \\
250 \\
500 \\
120 \\
150 \\
100 \\
250\end{array}$ & $\begin{array}{l}5.97 \\
7.42 \\
3.09 \\
4.35 \\
1.51\end{array}$ & $\begin{array}{l}14 \\
12 \\
12 \\
12 \\
14 \\
14 \\
\text { no }\end{array}$ & $\begin{array}{l}\text { Carne } \\
300 \text { g. } \\
\text { ", } \\
, \\
, \\
\text { ", } \\
, \\
\text { no } \\
\text { no }\end{array}$ & $\begin{array}{l}\text { Peso: } \\
9.1 \mathrm{k}\end{array}$ \\
\hline
\end{tabular}

El perro № 111 vivió 21 días, los 10 últimos sin insulina. Poco antes de morir, la glucemia era de 3.85. La eliminación de azúcar varió entre 7.7 y 52.9 grs.

\section{CUADRO $39^{\circ}$}

\section{Perro No 111. - Desmedulizado}

Extirpación médula suprarrenal izquierda Junio 15, 1933.

Suprarrenalectomía derecha

Agosto 14, 1933.

Pancreatectomía

Octubre 10, 1933 .

\begin{tabular}{|c|c|c|c|c|c|c|c|c|}
\hline Fecha & Glucemia & $\begin{array}{l}\text { Glucosuria } \\
\text { grs. por día }\end{array}$ & Orina & $\begin{array}{l}\text { Nitróg. } \\
\text { gr8. por día }\end{array}$ & $\begin{array}{l}\text { Insulina } \\
\text { unidades }\end{array}$ & & & \\
\hline 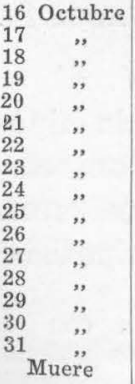 & $\begin{array}{r}1.86 \\
2.46 \\
+3.85\end{array}$ & $\begin{array}{l}t+t \\
+ \pm+ \\
+ \pm+t \\
+ \pm+t \\
+ \pm+ \\
+ \pm+ \\
+ \pm+t \\
+ \pm+t \\
52.9 \\
49.9 \\
20.0 \\
30.5 \\
24.8 \\
19.2 \\
19.2 \\
7.7\end{array}$ & $\begin{array}{r}800 \\
700 \\
750 \\
800 \\
900 \\
850 \\
650 \\
650 \\
900 \\
1300 \\
400 \\
550 \\
600 \\
500 \\
500 \\
325\end{array}$ & $\begin{array}{r}9.57 \\
16.38 \\
8.06 \\
7.85 \\
\\
15.40 \\
1.09\end{array}$ & $\begin{array}{l}16 \\
16 \\
16 \\
16 \\
18 \\
18\end{array}$ & $\begin{array}{l}\text { Carne. } \\
300 \mathrm{~g} .\end{array}$ & $\begin{array}{l}\text { Páner. } \\
100 \mathrm{~g} .\end{array}$ & $\begin{array}{l}\text { Azúcar } \\
10 \mathrm{~g} \text {. }\end{array}$ \\
\hline
\end{tabular}


El perro No 116 vivió 29 días, los 8 últimos sin insulina. La glucemia osciló entre 1.91 y 3.11 ; y la eliminación de azúcar entre 6.6 y 51.7 gramos.

\section{CUADRO $40^{\circ}$}

Perro $N^{0}$ 116. - Desmedulizado

Extirpación médula suprarrenal izquierda

Suprarrenalectomía derecha

Pancreatectomía

Julio 29, 1933 .

Agosto 14, 1933.

Peso: $9.0 \mathrm{kgs}$.

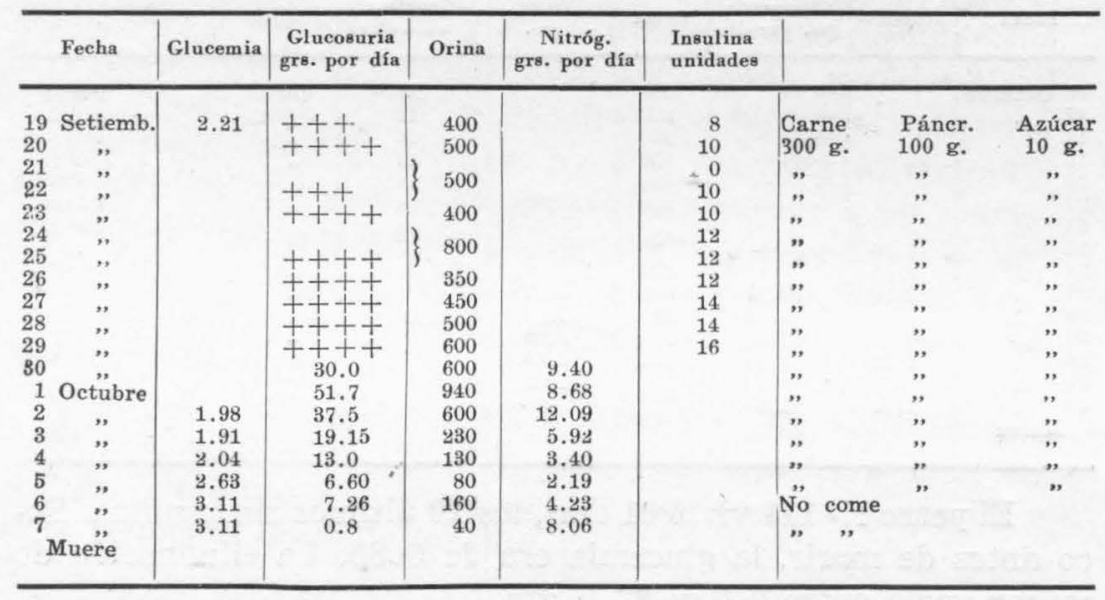

Este perro se sacrifica estando casi en coma. Se comprueba la presencia de un absceso en la cicatriz operatoria de la región lumbar derecha. Se saca la suprarrenal izquierda para dosar la adrenalina. Resultado del dosaje (Dr. Mazzoceo): Vestigios.

Todos nuestros perros desmedulizados presentaron una diabetes franca cuando se les extirpó el páncreas; y no podemos decir que ella haya sido menos intensa que la que presentan los animales con suprarrenales intactas.

\section{LA DIABETES ANTEROHIPOFISARIA EN LOS ANIMALES PRIVADOS DE MÉDULA SUPRARRENAL (1).}

Nuestros conocimientos acerca de la influencia de la hipófosis sobre el metabolismo de los hidratos de carbono son relativamente recientes. Houssay y Biasotti, en 1929, demostraron 'que, en el sapo, cuando se extirpaban el páncreas y la hipófisis,

(1) Estas experiencias fueron realizadas en colaboración con el Dr. A. Biasotti, a quien también debemos agradecer el habernos guiado en las técnicas de laboratorio. 
la diabetes no aparecía. En este mismo animal, la implantación de un lóbulo anterior de hipófisis, hacía aparecer una diabetes intensa. En 1930 los mismos autores observaron igual fenómeno en el perro. Es decir, que si a un perro sin hipófisis se le extirpaba el páncreas, la diabetes no se producía o era muy atenuada. En efecto: la glucemia permanecía dentro de los límites normales o apenas se elevabı; la glucosuria era escasa, desapareciendo con el ayuno; la eliminación de nitrógeno urinario permanecía baja como es característico en perros hipofisiprivos. La supervivencia era mucho mayor (hasta 5 - 6 meses) y algunos de estos animales presentaron crisis de hipoglucemia espontánea, fenómeno nunca observado en animales privados de páncreas. Dos años más tarde, Houssay, Biasotti y Rietti, con un extracto alcalino de lóbulo anterior de hipófisis (extracto de crecimiento de Evans y Simpson) consiguieron provecar, en perros normales, hiperglucemia, glucosuria y cetonuria. Estas modificaciones aparecían después de 5 - 7 días de inyecciones intraperitoneales diarias, de $7 \mathrm{cc}$. por $\mathrm{kg}$. de peso (extracto correspondiente a $1.5 \mathrm{gr}$. de glándula). Otros extractos: de riñones, bazo, hígado, músculo, preparados en igual forma no ejercieron acción alguna.

Por otra parte, la acción diabetógena del extracto de hipófisis se manifiesta igualmente en perros hipofisoprivos, hipofisoprancreatoprivos, castrados y tiroprivos. Es importante señalar la diferencia que media entre esta diabetes y las hiperglucemias y glucosurias provocadas por numerosas substancias, con las cuales nunca se ha podido producir un estado diabético prolongado como el que se logra con el lóbulo anterior de hipófisis. Houssay y Biasotti (inédito), inyectaron $1 / 2$ mg. por kg. y por día de adrenalina en perros durante 6 días sin obtener diabetes. Sanson y Jacobs (1932), inyectando adrenalina hasta durante 13 días, sólo obtuvieron hiperglucemia y glucosuria pasajeras; al suspender las inyecciones, observaron una brusca hipoglucemia.

Dado que se puede provocar la diabetes por la inyección de extracto de lóbulo anterior de hipófisis, y como además se la observa en un alto porcentaje de enfermos con adenomas hipofisorios, creemos que se puede usar en estos casos la denominación de diabetes anterohipofisaria. 
Investigaciones personales. - Dos perros a los cuales se había extirpado la médula suprarrenal del lado izquierdo y la glándula íntegra del lado derecho, fueron inyectados con extracto alcalino de lóbulo anterior de hipófisis preparado por el Dr. Rietti, según el método de Evans y Simpson.

El perro No 1 recibió 7 cc., por kg., de extracto por vía intraperitoneal, diariamente durante 7 días. La glucemia que era de $0.84 \mathrm{gr}$. o/oo, llegó al séptimo día a 1.75 con una eliminación de 3 grs. de glucosa.

El perro № 2, tratado en la misma forma, llegó a tener, el quinto día, una glucemia de 1.83 , y eliminó 13 grs. de glucosa.

Por lo tanto, la falta de médula suprarrenal no impide la aparición de la diabetes provocada por extracto de lóbulo anterior de hipofisis.

CUAdro $41^{\circ}$

Perro desmedulizado $N^{0} 1$

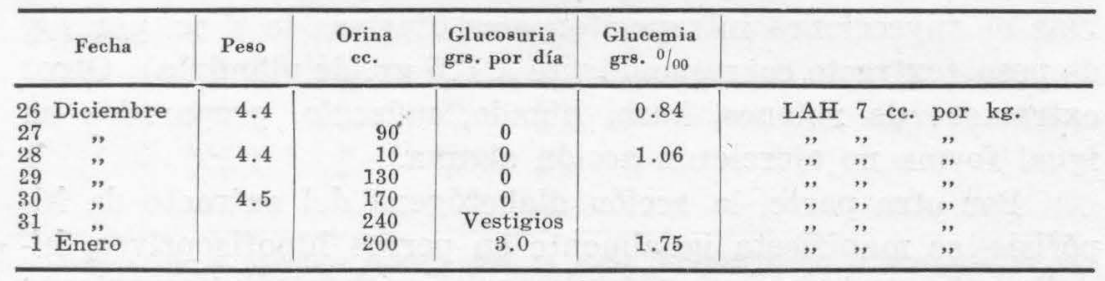

Perro desmedutizado $N^{\circ} 2$

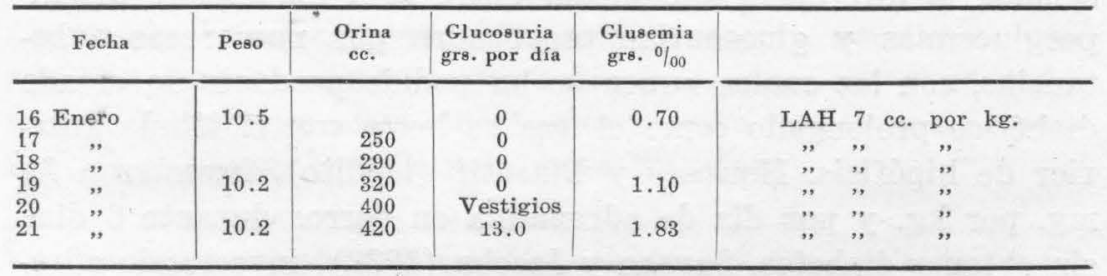

\section{LA DIABETES PANCREÁTICA EN LOS ANIMALES CON LAS SUPRARRENALES DESNERVADAS}

Dado que la desnervación de las suprarrenales aumenta ta sensibilidad a la insulina, se ha pensado que esta operación sería capaz de influenciar favorablemente el curso de la diabetes pancreática.

Ciminata (1928-32), después de extirpar, en dos tiempos, el páncreas a un perro, desnervó en él las suprarrenales, y en- 
tonces observó: Que la glucemia, que antes de la operación subía de 1.41 a 2.46 después de administrar 100 grs. de glucosa, sólo aumentaba de 0.98 a 1.41 o/oo después que se hubieron desnervado las suprarrenales, notándose además una hipoglucemia consecutiva. Sobre la base de estas experiencias aconseja la desnervación suprarrenal como tratamiento de la diabetes. Las conclusiones a que arriba Ciminata no nos parecen muy sólidas, puesto que sólo se basan en dos experiencias y no han sido confirmadas por otros investigadores que las han repetido.

Turcatti (1929) extirpó, en un perro, la suprarrenal derecha, y, algunos días después, desnervó la glándula izquierỏa y extirpó el páncreas, observando que aparecía la diabetes. En perros con pancreatectomía total o parcial, la desnervación suprarrenal no tiene influencia sobre la evolución de la diabetes según Carrasco Formiguera y Puche, 1931; Gondard, 1933; Ljvraga, 1933. Además, según Ring y Hampel (1933) el aumento de metabolismo basal, que se observa al extirpar el páncreas, aparece con la misma intensidad, aun cuando se hayan desnervado las suprarrenales.

En cuanto a los resultados favorables obtenidos en el tratamiento de la diabetes humana con la desnervación suprarronal por Donati (1929) ; Simarro y Corachán (1930), no prestan mayor apoyo a las conclusiones de Ciminata, dado que se trata sólo de dos casos, y que la diabetes en el hombre presenta variaciones espontáneas que pueden ser falsamente atribuídas a otras causas.

\section{DIABETES ANTEROHIPOFISARIA EN LOS ANIMALES CON SUPRARRENALES DESNERVADAS}

Vimos en páginas anteriores que la acción diabetógena del extracto anterohipofisario se manifestaba igualmente en los perros desmedulizados que en los normales. En perros con suprarrenales desnervadas, los resultados fueron análogos.

Tres perros, en los cuales se habían seccionado los espláenicos mayores y menores y extirpado las cadenas simpáticas lumbares, fueron sometidos a inyecciones diarias intraperitoneales de extracto alcalino de lóbulo anterior de hipófisis. La cantidad inyectada varió entre 2 y 7 cc. por $\mathrm{kg}$. 
El perro $\mathrm{N}^{\circ} 1$ alcanzó a tener al $6^{\circ}$ día de inyección una glucemia de 1.55 , y de 2.10 al $8^{\circ}$ día. La glucosuria fué importante y los cuerpos cetónicos aumentaron de 2 a $15 \mathrm{mgs}$ o/oo.

En el perro $N^{\circ} 2$ la glucemia era de 1.50 al $4^{\circ}$ día y 1.80 al $8^{\circ}$; hubo también glucosuria y aumento en la eliminación de cuerpos cetónicos.

\section{CUADRO $42^{\circ}$}

Perro esplacnicotomizado $N^{2} 1$

\begin{tabular}{|c|c|c|c|c|c|c|c|}
\hline & Fecha & Peso & $\begin{array}{c}\text { Orina } \\
\text { ec. }\end{array}$ & $\begin{array}{c}\text { Glucosuria } \\
\text { grs. }\end{array}$ & $\begin{array}{l}\text { Glucemia } \\
\text { grs. } \% 00\end{array}$ & $\begin{array}{c}\text { Cuerpos } \\
\text { cetónicos }\end{array}$ & \\
\hline $\begin{array}{l}10 \\
11 \\
12 \\
13 \\
14 \\
15 \\
16 \\
17 \\
18 \\
19 \\
20 \\
21\end{array}$ & $\begin{array}{c}\text { Julio } \\
\text { ", } \\
\text { ", } \\
\text { ", } \\
\text { ", } \\
\text { ", } \\
\text { ", } \\
\text { ", }\end{array}$ & $\begin{array}{l}13.1 \\
13.6\end{array}$ & $\begin{array}{r}140 \\
110 \\
140 \\
40 \\
360 \\
180 \\
220 \\
300 \\
490 \\
350\end{array}$ & $\begin{array}{c}0 \\
0 \\
0 \\
0 \\
0 \\
0 \\
0 \\
0 \\
10-4.90 \\
0 \\
45 \quad 0 / 00\end{array}$ & $\begin{array}{l}1.19 \\
1.55 \\
2.10\end{array}$ & 12.5 & 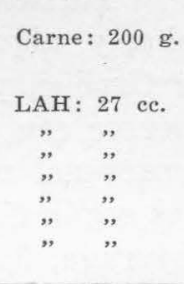 \\
\hline
\end{tabular}

Perro esplacnicotomizado $\mathrm{N}^{\circ}{ }_{2}$

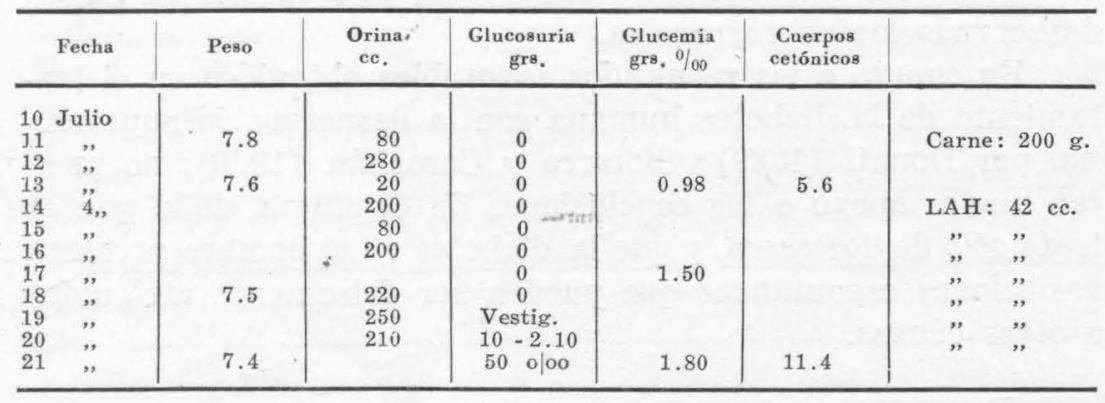

Perro esplacnicotomizado $\mathrm{N}^{\circ} 3$

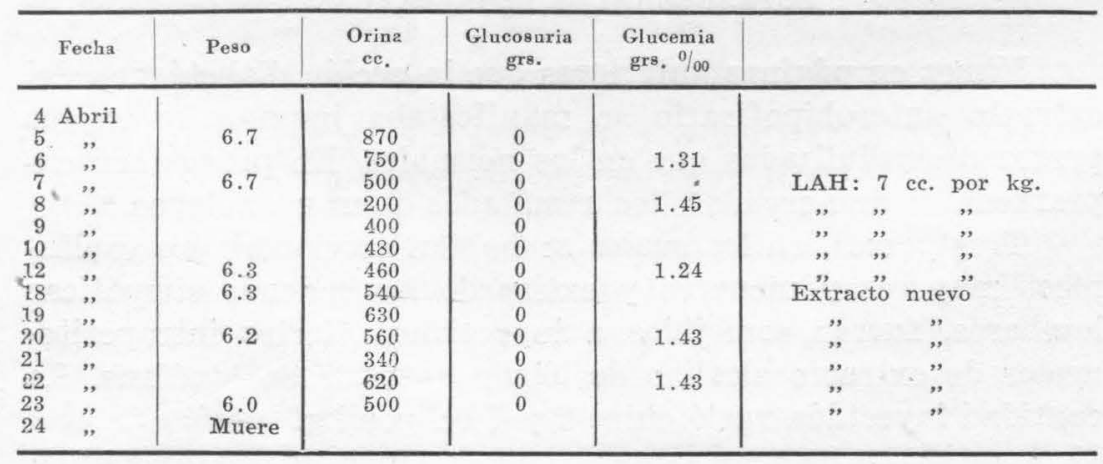


Otro perro Ne 3 tuvo aumentos glucémicos poco marcados, hecho que puede atribuirse a la falta de actividad del extracto.

\section{RESUMEN Y CONCLUSIONES}

La adrenalina contrarresta el efecto de la insulina sobre la glucemia, y la inyección de esta última, al provocar hipoglucemia, determina una hipersecreción compensadora de la primera.

La supresión de la secreción médulosuprarrenal por desnervación o desmedulización de las suprarrenales aumenta la sensibilidad de los animales a la insulina. La suprarrenalectomía aumenta más que esas operaciones la sensibilidad a la insulina (1), lo que hace pensar que también la corteza desempeña algún papel en ese trastorno.

La diabetes pancreática-aparece con toda intensidad en los perros privados de médula suprarrenal, sin que se observe mayor diferencia con la que aparece en los perros con suprarrenales intactas.

En los perros sin páncreas, extirpando después la suprarrenales estando en hipoglucemia insulínica, pueden observarse fuertes aumentos hiperglucémicos con gíucosuria (Gráficos VII, VIII y IX). Sin embargo, la diabetes aparece modificada o atenuada si hay síntomas de insuficiencia corticosuprarrenal ya manifiesta.

La diabetes provocada por la inyección de extracto anterohipofisario se produce aun cuando se hayan desnervado o desmedulizado las suprarrenales.

(1) En los conejos suprarrenoprivos, después de un tiempo de supervivencia, la sensibilidad a la insulina es más o menos igual, sea que se extirpen, desnerven o desmedulicen las suprarrenales; pero como se produce en ellos una hipertrofia del tejido cortical accesorio, y quizás del cromafínico, puede considerarse que fisiológicamente no son suprarrenoprivos, por lo menos en lo referente al tejido cortical, y posiblemente también al medular. 


\title{
CAPITULO VII
}

\section{ALGUNOS ESTUDIOS SOBRE EL EXTRACTO CORTICOSUPRARRENAL}

\begin{abstract}
La titulación, 135 - Discusión, 139 - La preparación, p. 140 - Tentativa de descubrir su presencia en la sangre de la vena suprarrenal, p. 141 - Acción sobre las glándulas endócrinas, p. $142-$ Técnica y animales empleados, $p .143$ - Resumen, $p$. 148.
\end{abstract}

\section{LA TITULACIÓN}

Nuestro primer objetivo, antes de emprender los estudios sobre la acción del extracto córticosuprarrenal sobre el metabolismo hidrocarbonado, fué el de encontrar un método económico y rápido para determinar la potencia de nuestros extractos. El método utilizado por Swingle y Pfiffner para conocer la actividad de los extractos ha consistido en mantener con ellos la vida de los perros o gatos suprarrenoprivos. Ellos titulan el extracto buscando cuál es la mínima cantidad necesaria por kg. para mantener al animal en buenas condiciones a juzgar por la conservación del peso y la normalidad del nitrógeno no proteico.

Lewis (1920 - 21 - 23) demostró que en las ratas suprarrenoprivas se halla disminuída la resistencia a la morfina y a otros tóxicos. Estos resultados fueron confirmados por Scott (1923). Lewis y Torino (1926), Mac Kay (1926 - 31). Houssay y Marenzi (1931) demostraron la acción protectora que el tratamiento con extracto córticosuprarrenal, preparado según Swingle y Pfiffner, ejerce sobre las ratas suprarrenoprivas frente a la morfina y a la histamina.

Esta acción protectora fué estudiada también por De Meio y Lewis (1932), quienes proponen un método de titulación de la actividad de los extractos córticosuprarrenales, basado en esa acción. Estudiaron la acción protectora de diversas dosis de varias muestras de dicho extracto suprarrenal y llegaron a las siguientes conclusiones:

$1^{\circ}$ - Hay cierta relación entre la dosis de extracto inyectada y el efecto producido. Así, mientras que de 5 ratas inyec- 
tadas con dosis correspondientes a 10 grs. de glándula fresca para 100 grs. de peso de rata mueren 3 por la acción de la morfina, de 5 tratadas con 20 grs. de glándula sólo muere una.

$2^{\circ}$ - Cuando se inyectan cantidades muy grandes de extracto, el efecto obtenido es igual que con dosis algo menores. Ejemplo: de 5 ratas tratadas con 40 grs. muere una, y de 5 tratadas con 60 grs. muere igualmente una.

En algunos casos parece como si el efecto protector disminuyera o se agregara un factor tóxico al curativo. Así, por ejemplo, mientras que de 5 ratas inyectadas con 10 grs. no muere ninguna, con 20 grs. se obtiene igual resultado; con 30 grs. de 5 mueren 4 ; con 40 grs. de 5 mueren 2 ; con 50 grs. de 5 mueren 4 ; con 60 grs. de 5 mueren 5 y con 80 grs. de 5 mueren 4 . Como se ve, los resultados son completamente irregulares. Dichos investigadores proponen una unidad rata que definen como la cantidad mínima de extracto que debe administrarse por 100 grs. de rata para que asegure la supervivencia total observada a las 48 horas en un lote de 5 ratas suprarrenoprivas inyectadas con $5 \mathrm{mgs}$. de clorhidrato de morfina por 100 grs.

El interesante problema planteado para la titulación de los extractos córticosuprarrenales nos llevó (1) a estudiar de cerca el método propuesto por Lewis y De Meio.

Aunque este método es de interés considerable, la unidad de estos autores nó es satisfactoria, bajo varios aspectos, por razones que discutiremos al analizar nuestros resultados. Si la acción preventiva del extracto de Swingle y Pfiffner frente a la intoxicación por morfina es proporcional a la dosis inyectada, debería ser posible construir una curva que representara esa proporcionalidad entre la cantidad inyectada y su acción preventiva. Como es sabido, las llamadas "curvas de actividad" y las "curvas de toxicidad" son las que representan con mayor exactitud la proporcionalidad entre cantidad y acción.

Los extractos que utilizamos fueron preparados por nosotros siguiendo el método de Swingle y Pfiffner. (La técnica ,

(1) Estas investigaciones fueron realizadas en colaboración con el Dr. Armando Novelli, el que tuvo a su cargo la laboriosa tarea de preparar el extracto. 
utilizada para la titulación fué la indicada por De Meio y Lewis). Distintos lotes de ratas suprarrenoprivas (de un peso que oscilaba entre 150 y 300 gramos) fueron inyectadas bajo la piel, 24 horas después de la operación, con cantidades variables de extracto, continuando diariamente durante tres días. Al tercero, seis horas después de la última inyección de extracto, recibieron por vía subcutánea una dosis de clorhidrato de morfina de $8 \mathrm{mgs}$. por cada 100 grs. de peso de rata, cantidad que mata invariablemente a las ratas suprarrenoprivas.

En una primera serie de experimentos, hechos todos el mismo día, obtuvimos con extractos preparados en distinta época, mantenidos en hielo y mezclados antes de comenzar la experiencia, los resultados consignados en el cuadro $43^{\circ}$.

Analizando estos resultados, observamos que parece existir, por lo menos dentro de las dosis inyectadas, una proporcionalidad entre la cantidad-inyectada y la acción preventiva, o sea entre gramos de glándula inyectada y el porcentaje de supervivencia.

Los extractos actualmente utilizados son poco activos, según queda demostrado por la cantidad que necesita inyectarse para prevenir la muerte por la morfina. Además, su acción parece que dura pocas horas, mientras que la eliminación del tóxico es relativamente lenta. Por eso creemos más lógico aceptar como supervivencia la observada a las 24 horas, o, de lo contrario, volver a inyectar con extracto a las 24 horas y observar la supervivencia a las 48 horas.

\section{CuAdro $43^{\circ}$}

Experimento primero. (Setiembre 5 de 1932)

\begin{tabular}{|c|c|c|c|}
\hline $\begin{array}{l}\text { N. }{ }^{0} \text { de ratas } \\
\text { inyectadas }\end{array}$ & $\begin{array}{l}\text { Cantidad de glándula } \\
\text { suprarrenal total in- } \\
\text { yectada en grs. por } \\
100 \text { grs. de rata }\end{array}$ & $\begin{array}{l}\text { Porcente } \\
24 \mathrm{hs} .\end{array}$ & $\begin{array}{l}\text { vivencia } \\
48 \mathrm{hs} .\end{array}$ \\
\hline $\begin{array}{l}15 \\
20 \\
15 \\
10 \\
14\end{array}$ & $\begin{array}{r}2.5 \\
5.0 \\
7.5 \\
10.0 \\
15.0\end{array}$ & $\begin{array}{r}0 \\
15 \\
25 \\
50 \\
65\end{array}$ & $\begin{array}{r}0 \\
7 \\
7 \\
30 \\
50\end{array}$ \\
\hline
\end{tabular}


En una segunda serie de ensayos empleamos dosis mayores de extractos, con el objeto de completar la curva. En esta ocasión el extracto utilizado fué preparado de una sola vez.

CUADRO $44^{\circ}$

Experimento segundo

\begin{tabular}{|c|c|c|c|}
\hline $\begin{array}{l}\mathrm{N} .{ }^{0} \text { de ratas } \\
\text { inyectadas }\end{array}$ & $\begin{array}{l}\text { Cantidad de glándula } \\
\text { suprarrenal total in- } \\
\text { yectada en grs. por } \\
100 \text { grs. de rata }\end{array}$ & $\begin{array}{l}\text { Porcent } \\
24 \text { hs. }\end{array}$ & $\begin{array}{l}\text { rvivencia } \\
48 \mathrm{hs} \text {. }\end{array}$ \\
\hline $\begin{array}{l}11 \\
14 \\
12 \\
16\end{array}$ & $\begin{array}{l}10 \\
20 \\
30 \\
40\end{array}$ & $\begin{array}{l}65 \\
20 \\
85 \\
70\end{array}$ & $\begin{array}{l}55 \\
50 \\
50 \\
50\end{array}$ \\
\hline
\end{tabular}

En estos datos observamos el mismo fenómeno señalado por De Meio y Lewis: a partir de cierta dosis, la proporcionalidad desaparece o permanece estacionada. Dejando de lado la pequeña diferencia no significativa de la supervivencia de las ratas inyectadas con 10 y 20 grs. (65 y $60 \%$ respectivamente) observamos que una dosis de 40 grs. sólo salva el $70 \%$ (véase la curva, Figura $\mathrm{X}$ ).

Antes de concluir queremos llamar la atención sobre un hecho de importancia en la titulación. En el curso de cierto ensayo, habiendo la temperatura ambiente descendido apreciablemente (de $22^{\circ}$ a $17^{\circ}$ ) y para evitar la mortalidad de las ratas operadas (es conocida su hipersensibilidad al calor y al frío. Lewis, De Marval, 1926, etc.), dejamos encendida una estufa eléctrica en la habitación en que se hallaban las jaulas. A la mañana siguiente, hallamos una mortalidad anormal, siendo mayor en las jaulas que recibían más directamente la irradiación de la estufa. Las ratas sobrevivientes de estas jaulas se hallaban en un estado de agotamiento, casi inmóviles a diferencia de las de otras jaulas que estaban más vivaces. Con la àdministración de 2 cc. de solución fisiológica, las ratas mejoraron inmediatamente.

Discusión. - El método propuesto por De Meio y Lewis permite saber, en poco tiempo, si un extracto córticosuprarrenal es activo, pero no suministra una apreciación cuantitativa segura. No es posible, por lo menos con el extracto actual, exi- 
gir la supervivencia total. Ellos la obtuvieron pocas veces y sólo en lotes pequeños. En los nuestros, que eran más grandes, no se observó con ninguna dosis.

Además, no conviene tomar como unidad un efecto máximo, puesto que puede obtenerse con dosis distintas. (En nuestro caso, el efecto fué más o menos igual con 10, 20, 30 y 40 grs.)

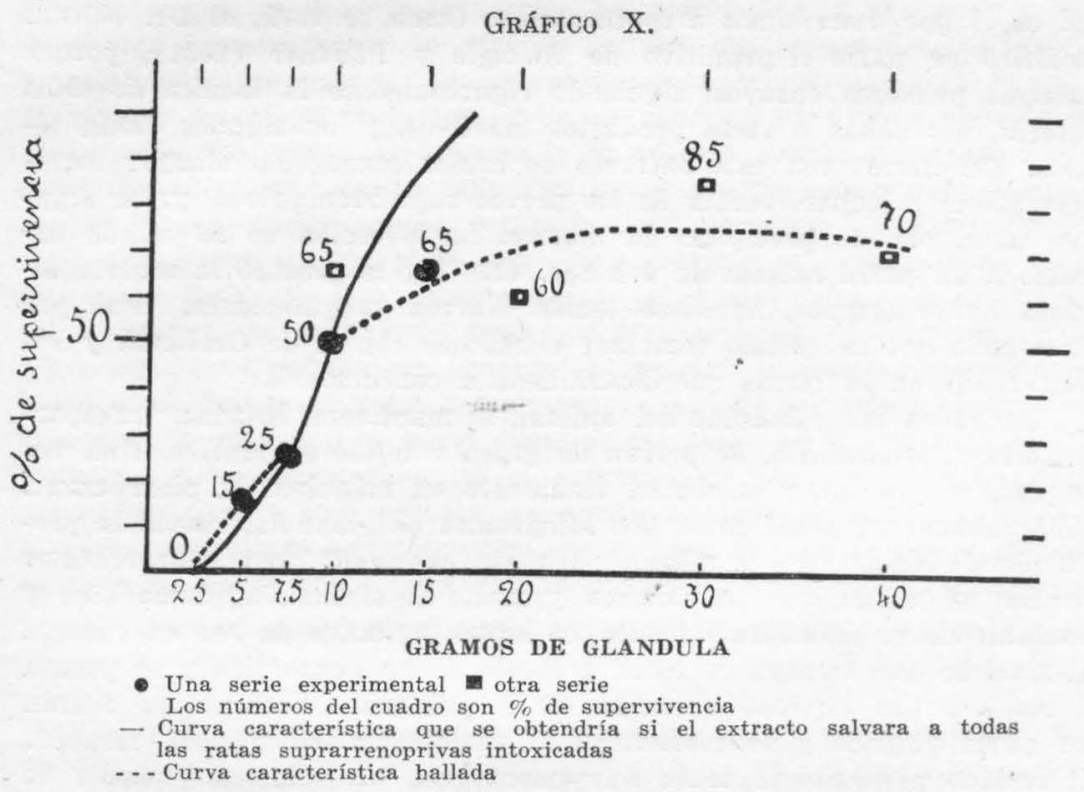

Como la acción del extracto va creciendo sólo hasta llegar al $60 \%$ de supervivencia, es únicamente hasta allí que la curva es utilizable. Convendría, pues, marcar la unidad en la parte media de esta porción ascendente de la curva. Lo más apropiado sería proceder en la siguiente forma: administrar el extracto en los tres días que siguen a la suprarrenalectomía. Al tercer día, inyectar $8 \mathrm{mgs}$. de clorhidrato de morfina por 100 grs. Utilizar un lote de no menos de 10 ratas y observar la supervivencia a las $24 \mathrm{hs}$., tomando como unidad la cantidad de extracto que salva al $30 \%$ de las ratas.

A pesar de que, usando lotes grandes, se aleja la posibilidad de error, por la distinta sensibilidad individual, hay lotes de ratas que mueren espontáneamente después de la suprarrenalectomía. De manera que la única manera de conocer exacta- 
mente la actividad de un extracto sería por comparación, como se hace con la insulina.

Con todo, el método es algo más rápido que el de mantener vivo un gato o perro suprarrenoprivo.

\section{LA PREPARACIÓN DEL EXTRACTO}

El método utilizado para la preparación de extracto córticosuprarrerial es el que describimos a continuación. Como se verá, el Dr. Novelli modificó en parte el primitivo de Swingle y Pfiffner (1931), porque nuestros primeros ensayos, siguiendo rigurosamente la técnica de estos autores, nos daban a veces productos inactivos, y, en algunos casos, tóxicos. En efecto: con este extracto no hemos conseguido alargar manifiestamente la supervivencia de los perros suprarrenoprivos, y, en algunos casos, pareció precipitar la muerte. La inyección de 50 cc. de extracto a un perro normal de $4.4 \mathrm{kgs}$. (N 77 ) le provocó la muerte algunas horas después, habiendo tenido diarrea sanguinolenta. Fué por esta razón que se decidió combinar el método con el de Grollman y Firor (1933) en la forma que describimos a continuación:

Retiradas las glándulas del animal, se mantienen heladas, transportándolas al laboratorio. Se privan de grasa y tejido conjuntivo. Una vez limpias, se prensan y se cortan finamente en máquina de picar carne. (Generalmente, trabajábamos dos kilogramos de glándula, siendo la proporción de disolventes la misma para esa cantidad). Las suprarrenales picadas se tratan con un volumen y medio de alcohol, agitando bien y manteniendo en heladera durante 24 horas, agitando de vez en cuando. Al final de este tiempo, se filtra a través de un lienzo fino y se prensa el residuo. Los líquidos obtenidos de la primera extracción se filtran por papel plegado y se concentran al vacío como indicaremos después. El residuo prensado se trata nuevamente con un volumen y medio de alcohol, se agita bien, se deja en contacto a la temperatura ambiente durante 12 horas, y luego se lleva a la estufa de $37^{\circ}$ durante 6 horas, agitando a menudo. Se retira de la estufa, se filtra por lienzo fino, y los líquidos filtrados se enfrían fuertemente $\left(-5^{\circ}\right)$. Precipita una gran cantidad de grasa. Se filtra en la heladera por papel plegado. Los líquidos obtenidos en ésta y en la primera extracción se destilan al vacío separadamente a una temperatura de $50-60^{\circ}$, concentrando hasta reducir cada litro de extracto a un volumen de 90 a 100 ce. Los residuos acuosos se pasan a ampollas de decantación, y se extraen en la mitad de su volumen de benceno, agitando enérgicamente y dejando luego separar los líquidos en la heladera. Se separa el líquido acuoso del benceno por centrifugación; se repite la extracción bencénica del líquido acuoso en las mismas condiciones cuatro veces más. Los líquidos bencénicos de extracción, límpidos, se evaporan al vacío a una temperatura externa de $45-50^{\circ}$, eliminando totalmente el benceno. El residuo se trata en el mismo balón con 200 cc. de acetona y se repite el tratamiento acetónico del residuo, agitando y dejando durante 24 horas en heladera. Decan- 
tada la acetona y filtrada, se evapora al vacío a temperatura inferior a $45^{\circ}$. El residuo seco se trata con $148 \mathrm{cc}$. de alcohol a $95^{\circ}$, calentando suavemente, con lo que se disuelve totalmente. Se pasa el alcohol cuantitativamente a un balón y se enfría este líquido $\left(-5\right.$ a $\left.-10^{\circ}\right)$ durante 2 - 3 horas. Precipita una gran cantidad de grasa bien cristalizada. Se filtra agitando el residuo, que se desecha, y el líquido filtrado en ampoIla de decantación se trata con 52 cc. de agua. El líquido se extrae con 50 ce. de éter de petróleo (P. E. $30-60^{\circ}$ ). Producida la separación de la capa etérea, se decanta la porción hidroalcohólica, y se vuelve a extraer tres o cuatro veces con éter de petróleo que se desecha. El líquido hidroalcohólico se evapora en el vacío a una temperatura de 50-55?. El residuo acuoso se trata con $30 \mathrm{cc}$. de benceno, pasando a ampolla de decantación. Se separa el benceno, y la porción acuosa se extrae 5 o 6 veces con 20 cc. de benceno cada vez. Los extractos bencénicos se tratan con 5 cc. de solución acuosa saturada de bicarbonato de sodio. Se separa por centrifugación y los líquidos bencénicos se lavan varias veces con agua para eliminar completamente el bicarbonato. Se centrifuga para separar las gotitas de agua que pueden estar emulsionadas y se filtra con papel mojado con benceno. El extracto bencénico se coloca en balón y se destila al vacío a temperatura de $45-50^{\circ}$ mientras se hace caer gota a gota por la parte superior del balón 10 cc. de solución fisiológica. Eliminado totalmente el benceno por destilación, el residuo acuoso se pasa a una probeta, se enfría en heladera $\left(0^{\circ}\right)$, se elimina la grasa precipitada con filtro Seitz, y se lleva el residuo con agua hasta alcanzar un volumen final de $100 \mathrm{cc}$.

El extracto está pronto para ser usado y cada cc. equivale a 20 gramos de glándula total.

\section{UN ENSAYO PARA DESCUBRIR LA PRESENCIA DE HORMONA CORTICAL EN LA SANGRE DE LA VENA SUPRARRENAL}

Extrajimos sangre de la vena suprarrenal de un perro, valiéndonos para ełlo de un trozo de vena yugular que fué anastomosada con la vena suprarrenal. En esta forma podía recogerse la sangre que iba vertiéndose lentamente por la anastomosis.

Una vez recogida la sangre, tratamos de descubrir en ella la presencia de hormona córticosuprarrenal basándonos en la propiedad de esta hormona de ejercer una acción protectora contra la morfina en las ratas suprarrenoprivas. Catorce ratas - suprarrenoprivas desde ocho días antes fueron inyectadas con el suero centrifugado por la sangre suprarrenal. Siete de ellas recibieron 5 cc. y diez recibieron 10 cc. Al día siguiente aparecieron muertas tres del primer lote y cuatro del segundo; por lo cual repetimos el experimento, pero sometiendo la sangre a un tratamiento previo. 
Se añadieron a la sangre cuatro volúmenes de alcohol y se filtró a través de un lienzo. Luego se evaporó al vacío a una temperatura inferior a $55^{\circ}$ hasta reducir a un volumen de 50 o 70 cc. Luego se extrajo con benceno tres veces y se decantó el benceno. A continuación se evaporó al vacío y se extrajo con acetona. Se evaporó esta última y se extrajo con éter de petróleo. Luego se agitó con alcohol de $70^{\circ}$ y se evaporó. Se extrajo con benzol y luego se agitó con una solución de bicarbonato de sodio. Luego se lavó con agua y se evaporó el benzol. El residuo se disolvió en solución fisiológica y se filtró a través de un filtro de Seitz. Unos 500 cc. de sangre suprarrenal y $500 \mathrm{cc}$. de sangre carotídea fueron así tratados y se inyectaron a ratas suprarrenoprivas desde el día anterior.

Cuatro ratas recibieron un cc. diario de extracto de sangre suprarrenal, durante tres días. Otras cuatro recibieron, en la misma forma, extracto de sangre carotídea. Al tercer día se inyectó a ambos lotes $8 \mathrm{mgs}$. por $100 \mathrm{grs}$. de clorhidrato de morfina. Al día siguiente se hallaron muertas tres ratas de cada lote.

En vista del resultado negativo, se abandonaron estas experiencias.

INFLUENCIA DEL EXTRACTO CÓRTICOSUPRARRENAL SOBRE LAS GLÁNDULAS ENDOCRINAS. (1)

Los resultadoș hasta ahora obtenidos por los numerosos investigadores que se han ocupado de las relaciones funcionales entre corteza suprarrenal y gonadas son contradictorias. En época reciente se ha estudiado con predilección la acción de los extractos córticosuprarrenales. Para algunos autores, estos extractos parecen tener cierta influencia sobre el desarrollo de los órganos genitales machos, "en el sentido de aumentarlo: en ratas (Mc Kinley y Fisher, 1926; Corey y Britton, 1931; Klein, 1931; Asher y Klein, 1931; Kaplan, 1932; Grollmann y Howard, 1932, etc.) y en cobayos (Castaldi, 1926, etc.). Sobre los órganos genitales femeninos, algunos han encontrado aumento de desarrollo: en la rata (Corey y Britton, 1931), en la laucha (Migliavacca, 1932), en gallinas (Eaton, Insko, Thompson y Chi-

(1) Estas experiencias fueron realizadas en colaboración con los doctores Enrique B. del Castillo y Armando Novelli. 
dester, 1929) y en ranas hipofisoprivas (Atwell, 1932). Otros autores no hallaron modificación alguna (Grollmann y Howard, 1931; Gaunt y Parkins, 1932; Cleghorn, 1932; Loos y Ritman, 1933). Por último, algunos investigadores han observado degeneración del ovario (Connor, 1931), detención del desarrollo de las gonadas o hipoplasia (Müller, 1930; Klein, 1931). En lo que respecta al ciclo sexual, Corey y Britton han observado prolongación de los celos o inhibición; Connor, (1931), inhibición con un extracto acuoso y nada con el de Swingle y Pfiffner; Hartman, Brownell y Lokwood (1932) y Martin y Kroc (1933) no observaron ninguna influencia. En la hipófisis, Corey y Britton (1931) obtuvieron con el extracto córticosuprarrenal una hipertrofia con aumento de las células eosinófilas. En la tiroides atrófica de las ratas hipofisoprivas, Atwell (1932) no obtuvo modificación con el extracto suprarrenal.

Hemos investigado la acción del extracto de Swingle y Pfiffner sobre las gonadas, suprarrenales, tiroides e hipófisis, estudiando también las acciones éxcito-tiroidea y éxcito-sexual del lóbulo anterior de esta última.

Técnica y animales empleados. - Hemos utilizado un primer lote de 21 ratas machos y 18 ratas machos testigos. Estos animales fueron inyectados con el extracto de Swingle y Pfiffner durante 20 días a razón de 0.5 cc. diarios (lo cual correspondía a 15 gramos de glándula fresca). Al sacrificarlos se pesaron y estudiaron histológicamente: las suprarrenales (también se dosó la adrenalina), tiroides, testículos e hipófisis. El poder éxcito-sexual de la hipófisis se investigó en la siguiente forma: a ratitas hembras, hermanas, prepúberes, de 20 - 22 días, se les implantaron intramuscularmente dos hipófisis el primer día, una el segundo día, y se sacrificaron al $4^{\circ}$ día, examinando si había apertura de la vagina y el peso e histología de los ovarios, etc. (Técnica de Evans y Simpson). En el cuadro $45^{\circ}$ damos los pesos de las ratas y de cada glándula.

No existe diferencia significativa entre ratas inyectadas y testigos. En el examen histológico no pudo observarse tampoco ninguna diferencia. El dosaje de la adrenalina de las suprarrenales (Dr. Mazzocco), dió los siguientes resultados:

Ratas inyectadas (término medio) $0.59 \mathrm{mgs}$. para cada glándula. 
Ratas testigos (término medio) $0.62 \mathrm{mgs}$. para cada glándula.

El poder éxcito-sexual se investigó con 18 de las hipófisis de las ratas inyectadas y 15 de los testigos (machos). Ver cuadro $\left.46^{\circ}\right)$.

\section{CUADRO $45^{2}$}

Ratas machos inyectadas con extracto córticosuprarrenal

Lote I

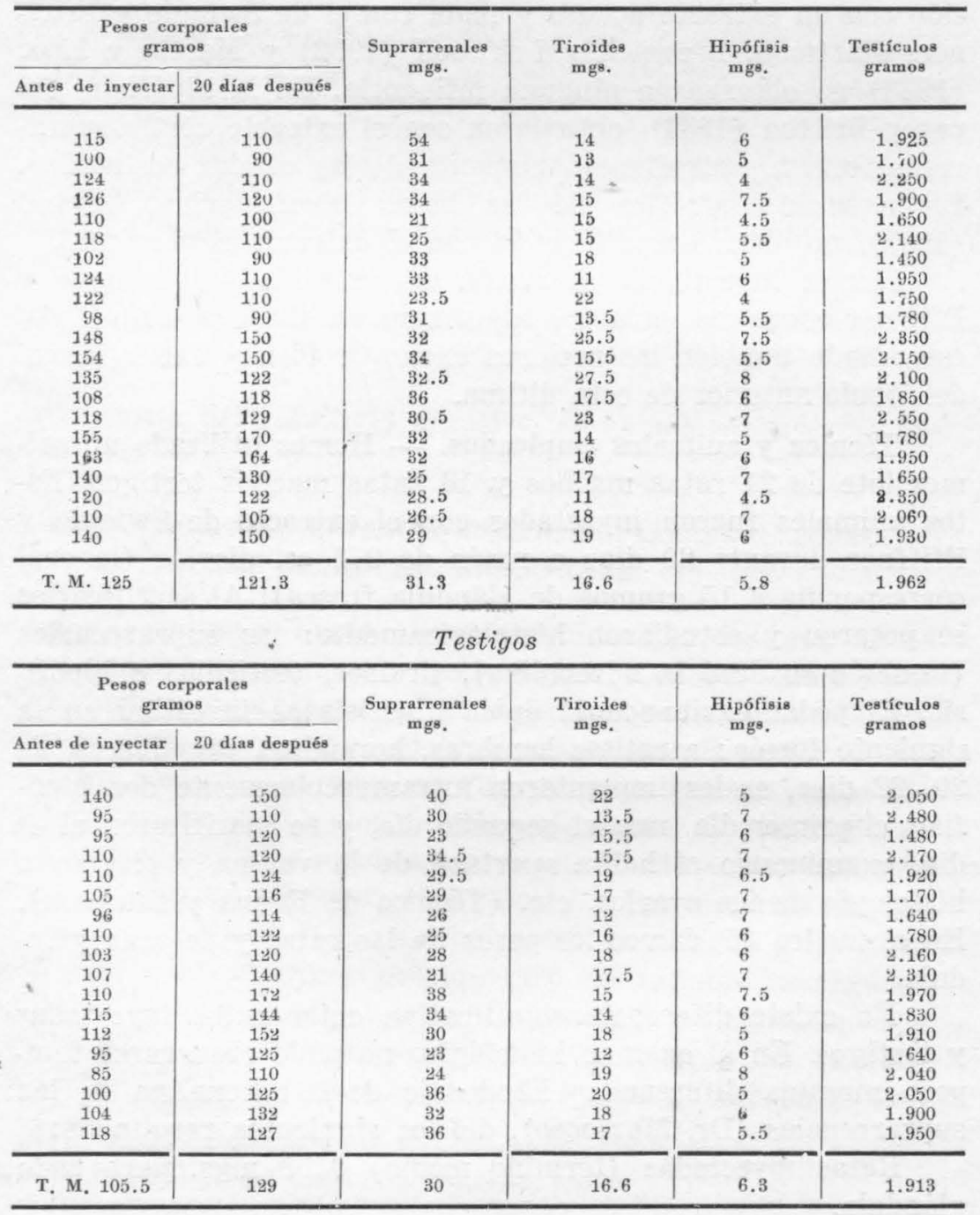




\section{CUADRO $46^{\circ}$}

Poder éxcito-sexual de las hipófisis del lote 1

Ratitas con implantación de hipófisis de ratas inyectadas con extracto

\begin{tabular}{|c|c|c|c|c|}
\hline $\begin{array}{l}\text { Peso corporal } \\
\text { gramos }\end{array}$ & $\begin{array}{c}\text { Peso ovarios } \\
\text { mgs. }\end{array}$ & $\begin{array}{c}\text { Peso átero } \\
\text { mgs. }\end{array}$ & Vagina & Ciclo \\
\hline $\begin{array}{l}31 \\
31 \\
32 \\
28 \\
30 \\
29 \\
\end{array}$ & $\begin{array}{l}71 \\
42 \\
52 \\
33 \\
38 \\
38\end{array}$ & $\begin{array}{l}185 \\
166 \\
118 \\
102 \\
178 \\
130\end{array}$ & $\begin{array}{cc}\text { No } & \text { abrió } \\
" & , \\
" & " \\
" & " \\
" & \text { ". }\end{array}$ & $\begin{array}{l}\text { Z } \\
\text { - } \\
\text { - }\end{array}$ \\
\hline T. M. 30 & 45.6 & 146.5 & & \\
\hline
\end{tabular}

Ratitas con implantación de hipófisis de ratas testigos

\begin{tabular}{r|c|c|cc|c}
\hline 30 & 38 & 151 & No abrió & - \\
33 & 43 & 122 &, &, & - \\
29 & 40 & 160 &, &, & - \\
29 & 40 & 82 &, &. & - \\
33 & 52 & 153 &, &, & - \\
\hline T. M. 31 & 52 & 153 & & & \\
\hline
\end{tabular}

Este cuadro pone de manifiesto que no había ninguna diferencia constante o significativa en el poder éxcito-sexual de la hipófisis entre los animales que habían recibido extracto córticosuprarrenal y los testigos, hecho que fué corroborado por el examen histológico de los ovarios.

El segundo lote estaba formado por 10 ratas hembras (que fueron inyectadas como las del primer lote) y 10 testigos. Las investigaciones se hicieron en la misma forma que en las otras, estudiando además el ciclo sexual y el poder éxcito-tiroideo de la hipófisis, para lo cual se procedió de esta manera: a cobayos de $200 \mathrm{grs}$. se inyectaron intraperitonealmente las hipófisis desleídas en agua salada; una hipófisis el primer día, otra el segundo y, al tercer día, se sacrificó a los animales para examinar el peso y la histología de las tiroides (técnica de Aron). Damos en el cuadro 47 los pesos de las ratas y de sus glándulas. El ciclo sexual fué estudiado durante los 20 días en que se inyectó extracto. Hubo ciclos irre- 
gulares en cuanto a los períodos de dioestrus, tal como es habitual en nuestras ratas normales.

CuAdro $47^{\circ}$

Ratas hembras inyectadas con extracto córticosuprarrenal

Lote 2

\begin{tabular}{c|c|c|c|c|c}
\hline \multicolumn{2}{c|}{$\begin{array}{c}\text { Pesos corporales } \\
\text { gramos }\end{array}$} & $\begin{array}{c}\text { Suprarrenales } \\
\text { mgs. }\end{array}$ & $\begin{array}{c}\text { Tiroides } \\
\text { mgs. }\end{array}$ & $\begin{array}{c}\text { Hipófisis } \\
\text { mgs. }\end{array}$ & $\begin{array}{c}\text { Ovarios } \\
\text { mgs. }\end{array}$ \\
\hline Comienzo & Fin & & & & \\
\hline 120 & 104 & 38.5 & 14.5 & 6 & 45 \\
140 & 127 & 31 & 17 & 6 & 30 \\
125 & 110 & 47 & 26.5 & 5 & 70 \\
105 & 98 & 35.5 & 15 & 5.5 & 46 \\
133 & 122 & 45 & 19 & 6 & 41.5 \\
148 & 139 & 37 & 19 & 5.5 & 71 \\
126 & 120 & 35 & 26 & 6 & 68 \\
150 & 136 & 42 & 16 & 7.5 & 69 \\
140 & 125 & 38 & 14 & 5 & 79 \\
120 & 105 & 38 & 15 & 4.5 & 80 \\
\hline T. M. 130.7 & 118.6 & 38.7 & 18.2 & 5.7 & 59.95 \\
\hline
\end{tabular}

Ratas testigos (hembras) no inyectadas

\begin{tabular}{l|l|l|l|l|l}
\hline 155 & 135 & 50 & 20 & 6 & 69 \\
170 & 175 & 44 & 14.5 & 5 & 77.5 \\
148 & 135 & 37 & 19 & 6 & 70 \\
124 & 128 & 45 & 24 & 6 & 89 \\
155 & 140 & 53 & 21 & 5 & 73.5 \\
130 & 120 & 22 & 15 & 4.5 & 45 \\
160 & 155 & 36.5 & 16 & 5 & 60 \\
105 & 104 & 28 & 11 & 7 & 55 \\
135 & 129 & 36 & 23 & 6 & 66 \\
150 & 115 & 43 & 21 & 6 & 66 \\
\hline T. M. 143.2 & 133.6 & 39.4 & 18.4 & 5.6 & 67 \\
\hline
\end{tabular}

- No hubo entre ratas inyectadas y testigos diferencia alguna en el peso de las glándulas. Tampoco el estudio histoló'gico pudo revelar diferencia alguna.

Las hipófisis de estas mismas ratas inyectadas a cobayos no acusaron diferencia en cuanto al poder éxcitotiroideo (cuadro $\left.48^{\circ}\right)$. 
CUADRO $48^{\circ}$

Poder éxcito-tiroideo de la hipófisis del lote 2

Cobayos inyectados con hipófisis de ratas inyectadas con extracto

\begin{tabular}{c|c}
\hline $\begin{array}{c}\text { Peso corporal } \\
\text { gramos }\end{array}$ & $\begin{array}{c}\text { Peso tiroides } \\
\text { mgs. }\end{array}$ \\
\hline 235 & 35 \\
289 & 32 \\
209 & 38 \\
224 & 48 \\
236 & 35 \\
\hline T. M. 237.6 & 37.6 \\
\hline
\end{tabular}

Cobayos inyectados con hipófisis de ratas testigos

\begin{tabular}{l|l}
\hline 206 & 52 \\
197 & 38 \\
272 & 35 \\
204 & 32 \\
229 & 37 \\
\hline 221.6 & 39 \\
\hline
\end{tabular}

El peso y aspecto histológico fueron iguales en las tiroides de ambos grupos de cobayos.

Es de notar que los resultados negativos no se deben a un defecto del extracto; pues éste tenía actividad; prueba de ello es que protegía a las ratas suprarrenoprivas de la acción tóxica de la morfina y que aumentaba la formación de glucógeno en los perros suprarrenoprivos.

Resumen. - Se investigó en la rata blanca la influencia del extracto córticosuprarrenal (inyectado durante 20 días) sobre gonadas, tiroides, suprarrenales e hipófisis. El peso, el resultado del examen histológico, el dosaje de adrenalina suprarrenal, las acciones éxcito-sexual y éxcito-tiroidea de la hipófisis y el ciclo sexual, fueron iguales que en las ratas no inyectadas. 


\section{RESUMEN Y CONCLUSIONES}

GLUCEMIA. - La extirpación de las cápsulas suprarrenales produce habitualmente, al cabo de cierto tiempo, un descenso de la glucemia que, aunque suele faltar en algunos casos, puede llegar a ser muy acentuado en los momentos finales. La insuficiencia suprarrenal en el hombre también provoca, en la mayor parte de los casos, hipoglucemia. Pero éste no es un signo ni precoz, ni constante, ni específico de la insuficiencia suprarrenal. En los animales dotados de tejido cortical accesorio y que pueden sobrevivir a la suprarrenalectomía, como la rata y el conejo, la glucemia es más baja en los primeros días, llegando después a normalizarse.

La extirpación del tejido medular solamente no modifica en mayor grado el nivel glucémico. Algunos ligeros descensos observados en los primeros días podrían atribuirse a la insuficiencia cortical determinada por el acto operatorio.

$\mathrm{Ni}$ la desnervación de las suprarrenales, ni la sección esplácnica bilateral, modifican de manera evidente la glucemia normal. Sin embargo, algunas hiperglucemias tienen una intensidad menor después que se ha inactivado la médula suprarrenal, de manera que debe atribuírsele ur papel, aunque no muy importante en la regulación glucémica.

TOLERANCIA A LA GLUCOSA. - Las investigaciones llevadas a cabo por diversos autores sobre este punto son contradictorias. Muchos no han hallado modificaciones; pero tal vez ello se deba a que trabajaron con animales que compensan su insuficiencia (conejos) o que no esperaron que apareciera una insuficiencia suprarrenal acentuada. No hemos estudiado especialmente el punto, pero, según nuestros resultados, la tolerancia es menor (gráfico III).

Después de inyectar 2 grs. por kg. de glucosa, la curva glucémica fué más alta y prolongada en los perros suprarrenoprivos que en los normales. Después de administrar extracto córticosuprarrenal y a pesar de que la formación de glucógeno muscular fué normal, la curva glucémica quedó alta, revelándose más alta en los que formaron más glucógeno. 
ACCIÓN DE LA GLUCOSA EN LA INSUFICIENCIA SUPRARRENAL. - La muerte de los animales suprarrenoprivos no es debida a la hipoglucemia, puesto que, aunque se eleve la glucemia por inyección de glucosa o por extirpación del páncreas, no se consigue alargar la supervivencia. Sin embargo, en algunos casos, es probable que la hipoglucemia pueda precipitar la muerte o producir algunas de las crisis de agravación que se observan en los addisonianos.

GLUCógeno. - La extirpación suprarrenal provoca una gran disminución en la cantidad de glucógeno hepático, el que puede llegar, en algunos casos, a desaparecer. El glucógeno muscular también disminuye, aunque en mucho menor grado que el hepático.

Después de la fatiga, la resíntesis del glucógeno muscular se produce rápidamente en los perros normales. En cambio, en los suprarrenoprivos de 48 horas antes no hay recomposición de glucógeno después de una hora de reposo. En los suprarrenoprivos de 24 horas, este trastorno se observa en la mitad de los casos. Elevando İa glucemia por inyección de glucosa, no se consigue acelerar la resíntesis del glucógeno después de la fatiga en los perros suprarrenoprivos (gráfico I).

Inyectando glucosa en las venas de los animales normales se produce, en una hora, un aumento del glucógeno muscular. En los perros suprarrenoprivos de 48 horas no sólo no se observa este aumento, sino que se produce una disminución (gráfico II).

ACCIÓN DE LA ADRENALINA. - La inyección de adrenalina determina un aumento de la glucemia, de la lactacidemia y una disminución del glucógeno muscular. Sobre el glucógeno hepático, su efecto es bifásico en la rata y en el conejo, habiendo primero una disminución seguida de una fase de aumento. En el perro los resultados han sido variables. El consumo de oxígeno aumenta por la acción de la adrenalina, y la fugaz elevación del cociente respiratorio parece obedecer no a un aumento de la combustión de glúcidos sino a la hiperventilación pulmonar. La glucosa que se vierte en la sangre por la acción de la adrenalina parece provenir del hígado. Los músculos sólo 
podrían proporcionarla indirectamente por intermedio del ácido láctico, que en el hígado se transformaría en glucosa.

ACCión DEL EXTRACTO CORTICOSUPRARREnAL. - Este eXtracto normaliza la glucemia en los animales suprarrenoprivos y la eleva en los normales. Sin embargo, este último efecto podría deberse a substancias extrañas que acompañan a la hormona. Las cantidades de glucógeno hepático y muscular aumentan en la rata, conejo y gato por la acción del extracto según Britton y Silvette. Nuestros resultados sobre este punto no fueron claros.

El extracto restituye a los perros suprarrenoprivos la facultad de resintetizar el glucógeno muscular después de la fatiga y llegan a obtenerse con él recomposiciones supernormales.

Los perros suprarrenoprivos, en los cuales está dificultada la formación de glucógeno muscular, que se produce cuando se inyecta glucosa, recuperan esta capacidad por la acción del extracto córticosuprarrenal. Este efecto del extracto no se debe a una excitación de la secreción de insulina, puesto que parece observárselo también en los perros pancreatoprivos.

PAPEL DE LAS SUPRARRENALES EN LAS DIVERSAS HIPERGLUCEMIAS. - Hemos pasado en revista las experiencias que se relacionan con la intervención de las suprarrenales en las diversas hiperglucemias. Para muchos agentes farmacológicos e influencias fisiológicas, los experimentos no son completos y muchos de ellos contradictorios. De ahí la dificultad de hacer una clasificación según el mecanismo de producción.

En algunas hiperglucemias la médula suprarrenal juega un papel importante: es ella, por la secreción de adrenalina, la que determina, en gran parte, el aumento glucémico, actuando independientemente del sistema nervioso. En este grupo de hiperglucemias que no son influenciadas por la desnervación suprarrenal o la sección esplácnica y que disminuyen fuertemente con la extirpación medular, estarían comprendidas la nicotina y las substancias de acción análoga (lobelina, amonios cuaternarios, etc.) (gráficos V y VI).

En otro grupo de hiperglucemias, el papel de la médula suprarrenal parece ser menor. Ella actuaría solamente como 
una parte del sistema simpático-adrenal. Estas hiperglucemias son fuertemente disminuídas por la sección esplácnica y menos por la extirpación de la médula. Es explicable que la esplacnicotomía disminuya más estas hiperglucemias que la simple inactivación suprarrenal, puesto que influye sobre otros órganos abdominales: hígado, etc. A este grupo corresponden la mayoría: La emotiva, la de contención, la refleja, la asfíctica, la hemorrágica, la de la picadura bulbar, la del éter, la de la betatetrahidronaftilamina, cloretona, cianuro de potasio, diuretina, cafeína y estricnina, la hiperglucemia inicial de la guanidina y sintalina, morfina, picrotoxina, cloruro de amonio, etc.

En otro grupo de hiperglucemias parece ser indispensable la secreción de adrenalina, que podríamos llamar de base. Estas hiperglucemias son abolidas por la extirpación suprarrenal, pero aparecen si concomitantemente se hace una inyección continua de adrenalina en cantidades fisiológicas. Una substancia que actuaría en esa forma sería el extracto de lóbulo posterior de hipófisis (1).

Por fin, para otras substancias (peptona), se ha afirmado que la secreción de adrenalina suprarrenal no sólo no sería la responsable de la elevación glucémica sino que la disminuiría (Kaiwa, 1933).

Damos esta división como un esquema general y provisional que deberá ser completado y modificado con los resultados de nuevas experiencias.

Pero no es sóló la parte medular de las suprarrenales la que interviene en las reacciones hiperglucémicas, puesto que la falta de corteza disminuye fuertemente la cantidad de glucógeno hepático haciendo que las elevaciones de la glucemia sean menores.

SUPRARRENALES Y DIABETES. - La adrenalina contrarresta el efecto de la insulina sobre la glucemia, y la hipoglucemia insulínica produce una hipersecreción compensadora de la médula suprarrenal. Cuando se suprime esta última secreción, ya sea por desnervación o desmedulización de las suprarrenales, aumenta en los animales la sensibilidad a la insulina. La extir-

(1) Es de notar que esta substancia no acelera la secreción adrenalínica suprarrenal. 
pación completa de las suprarrenales aumenta aún más esta sensibilidad a la insulina.

Sobre la base de estos hechos se ha supuesto que inactivando las suprarrenales no aparecería la diabetes por pancreatectomía; y esto último ha sido afirmado por un grupo de investigadores. Sin embargo, hemos llegado a la conclusión de que la Diabetes pancreática aparece con toda intensidad en los perros privados de médula suprarrenal, sin que se observe mayor diferencia con la que aparece en los perros con suprarrenales intactas, y que en los perros sin páncreas, extirpando después las suprarrenales estando en hipoglucemia insulínica, pueden observarse fuertes aumentos hiperglucémicos con glucosuria (Gráficos VII, VIII y IX). Sin embargo, la diabetes aparece modificada o atenuada si hay síntomas de insuficiencia corticosuprarrenal ya manifiesta.

La diabetes anterohipofisaria, es decír, la hiperglucemia y glucosuria prolongadas que produce la inyección de extracto alcalino de lóbulo anterior de hipófisis aparece aun cuando se hayan desnervado o desmedulizado las suprarrenales. 


\section{B I B L I O G R A F I A}

ABDeRHALDEN E. UND GellhoRn E. - Vergleichende Versuche über die Wirkung von $l$ und $d$-Adrenalin auf den Gaswechsel von Organen in vershiedenem Zustande. Pflüg. Archiv. 1926, CCXII, 523.

$\mathrm{ABE}$ Y. - Das Verhalten der Adrenalinsekretion bei der Insulinvergiftung. Arch. Exp. Path. Pharm. 1924, CIII, 73.

AdLer L. - Schilddrüse und Wärmeregulation. Arch. Exp. Path. Pharm. 1920, LXXXVI, 159.

Idem. - Uber den Angriffspunkt der Blutdrüsenhormone bei der Wärmeregulation. Arch. exp. Path. Pharm. 1920, LXXXVII, 406.

ADLER L. UND LiPSCHITZ W. - Die Wirkung von Hormonen auf die Zelloxydation und den Wärmehaushalt des Organismus. Arch. exp. Path. Pharm. 1922, XCV, 1 1S1.

AgADSCHANIANZ K. - Uber den Einfluss des Adrenalins auf das in Leber und Muskeln enthaltene Glykogen. Bioch. Zeitschr. 1907, II, 148.

Agazzotti A. - L'iperglicemia da salasso. Arch. d. Sc. Biol. 1930, XIV, 511-572 (in Berichte G. Phys. u. E. Phar. LIX, 274).

Idem. - L'azione antagonistica dell'insulina e dell'adrenalina sull'attivitá muscolare. Bollet. Soc. Biol. Sperim. 1926, I, N: 5, 553.

Idem. - Ricerche sulla iperglicemia da salasso. Nota IV; Influenza delle capsule surrenali e dei nervi splancnici. Bollet. Soc. Biol. Sperim. 1927 , II, fase. 7,875 .

Idem. - L'hyperglycémie par saignée. Arch. Intern. de Biol. 1931, LXXXVI, fase. 1.11.

Idem. - Ricerche sulla iperglicemia da salasso. Nota III. Il contenuto di adrenalina nelle capsule e di glicogeno nel fegato e nei muscoli, prima e dopo il dissanguamento. Bollet. Soc. Biol. Sperim. 1927, II, fase. 7,870 .

AHLGREN G. - Zur Kenntnis der tierischen Gewebsoxydation sowie ihrer Becinflussung durch Insulin, Adrenalin, Tiroxin und Hypophysepreparate. Skand. Arch. Physiol. 1926, XLVII, 467.

AlLen F. M. - Experimental Siudies in diabetes. II. Internal pancreatic function. Relation of suprarenals to diabetes. Jour. Metabol. Res. 1923, III, 589.

Allen F. M. - Glycesuria and diabetes. Harvard Univ. Press. 1913.

ARtundo A. - Metabolismo de las raias suprarrenoprivas. Tesis de Facultad de Bioquímica y Farmacia. Bs. As., 1926.

ARVAY A. UND LENGYEL L. - Die Milchsäurebildung bei Muskelarbeit nach Entfernung der Nebennieren. Biochem. Zeitschr. 1931, CCXXXIX, 128.

ASHER. L. UND KLEIN O. - - Der Einfluss der Hyperinterrenalisierung auf die Entwicklung der männlichen Geschlechtsorgane. Klin. Woch. 1931, $\mathrm{N}^{\circ} 23,1076$.

Atwell G. H. - Experimental analysis of certain pituitary adrenal gonad relationship. Endocronology, 1932, XVI, 597.

Aub J. C., BRIght E. M., AND Forman J. - Metabolic effect of adrenalectomy. upon the uretanized cat. Amer. Jour. Physiol. 1922, LXI, 349.

BABKIN B. P. - The influence of the blood supply on pancreatic secretion. Reflex hyperglycaemia. Jour. Physiol. 1925, LIX. 153. Proc. Physiol. Soc. 1925, LXVI.

BACQ Z. M. - Recherches sur la physiologie du système nerveux, autonome. III. Les propriété biologiques et physicochimiques de la sympatine comparées a celles de l'adrénaline. Arch. Intern. Physiol. 1933, XXXVI, fase. 2-3. 
BANERJI H. AND REID CH. - The adrenals and anaesthetic hyperglycaemia. Journ. of Physiol. 1933, LXXVIII, 370.

BANG I. -Die Zuckerbildung der Froschleber. Biochem. Zeitschr. 1913, XLIX, 81.

Banting F. G., Best Ch., Collia B., Macleod J. J. R. and Noble E. C. - The effect of insulin on experimental hyperglycaemia in rabbits. Amer. Jour. Physiol. 1922, LXII, 559.

Bantiñg F. G. AND GaIrns S. - Adrenal insufficiency. Amer. Jour. Physiol. 1926, LXXVII, 100.

BARANOW W. G. - Le rôle des glandes surrénales dans la régulation du sucre du sang. Arch. Biol. M. 1928, XXVIII, 139.

BARLOW O. W. - AND Ellis M. M. - Effect of double adrenalectomy on the blood coagulation time in cats. Amer. Jour. Physiol. 1924, LXX, 58.

BAUSCH W. - Blutzuckerspiegel vor und nach therapeutischen Nebennierenreduktion bei Krampfkranken nach Henr. Fisher. Deut. Mediz. Woch. 1920, XLVI, No 49, 1353.

BERNSTEIN S. - Ueber die Blutzuckergehalt bei Addisonischer Krankheit. Berlin. Klin. Woch. 1911, $\mathrm{N}^{\circ} 40$.

Bertram F. - Inhalationsnarcose und Blutzucker. Zeitschr. ges. exper. Mediz. 1923, XXXVII, 99.

Bertram F. AND BoRnStein A. - Ueber Umstimmung der Reaktion des Zuckerstoffwechsels auf Adrenatin. Zeitschr. exper. Mediz. 1923, XXXVII, 133.

Best Ch., HoEt J. P. AND Marks H. P. - Fate of the sugar disappearing under action of insulin. Proc. Roy. Soc. 1926, B CX, 55.

Biasotti A. - Influencia de las glándulas suprarrenales sobre la regulación de la presión arterial. Tesis de doctorado, Buenos Aires, 1927.

Biberfeld J. - Ueber die Beziehungen der Nebennieren zur Piqúre. Arch. Exp. Path. Pharm. 1917; LXXX, 164.

BiedL A. - Beiträge zur Physiologie der Nebenniere. Pflüg. Arch. 1897, LXVII, 443.

Bierry M. H. et Gatin-Gruzewska Z. - Action physiologique de l'adrénaline pure. C, R. Soc. Biol. 1905, LVII, 902.

Bierry M. H. ET Malloizer R. - Hypoglycémie après décapsulation. Effets de l'injection d'adrénaline-sur les animaux décapsulés. C. R. Soc. Biol. 1908, LX, 232.

BILLIGHEIMER E. - Ueber die Wirkungsweise der probatorischen Adrenalininjection. Deut. Arch. Klin. Mediz. 1921, CXXXVI, 1.

BINSWANGER F. - Ueber Einwirkung der Kohlensäure auf den Blutzucker im Organismus. Pflüg. Archiv. 1922, XCIII, 296.

BischofF F. AND LoNG M. L. - Studies in carbohidrate metabolism following guanidine deglycogenation. Jour. Nutr. 1930, III, 201.

Iidem. - The posterior pituitary hormone in metabolism. Amer. Jour. Physiol. 1931, XCVII, 215.

BLATHERWICH K. AND SAHYUN M. - The influence of epinephrine and insulin upon the distribution of glycogen. Jour. Biol. Chem. 1929, LXXXI, 123.

Blum F. - Ueber Nebennierendiabetes. Deut. Archiv. Klin. Mediz. 1901, LXXI, 146.

Idem. - Weitere Mitteilungen zur Lehere von dem Nobennierendiabetes. Pflüg. Arch. 1902, XC, 617.

BODEN, DETERMANN UND WAN KELL. - Klinische und experimentelle Studien über den Antagonismus Insulin-Adrenalin. Klin. Woch. 1926, $\mathrm{N}^{\circ} 38,1761$.

Bodo R. C., BenAglia A. E. AND Friedman. - The relationship of epinephrine to muscle and liver glycogen. Amer. Jour. Physiol. 1933, CV, $\mathrm{N}^{2} 1,8$. 
BOEGGILD D. H. - Influences des glandes surrénales sur l'hyperglycémie diabétique. C. R. Soc. Biol. 1923, LXXXVIII, 816.

Idem. - Versuche über die Bedeutung des Nebennierenmarkes für die Vorbeugung des Insulinshockes. Bioch. Zeit. 1931, CCXXXVI, 372. In Berichte, Ges. Phys. u. E. Pharm. 1932, LXIV, 153.

Idem. - Weitere Versuche über die Bedeutung des Nebennierenmarkes für die Vorbeugung des Insulinshockes. Acta Med. Scand. 1933, LXXIX, 458. In Berichte, Ges. Phys. u. E. Pharm. 1933, LXXIV, 129.

Bollman J. L., ManN F. C. AND Magath T. B. - XII. Muscle glycogen following total removal of the liver. Amer. Jour. Physiol. 1925, LXXIV, 238.

BOOTHBY W. M. AND SANDIFORD I. - Calorigenic action of adrenalin chloride. Amer. Jour. Physiol. 1923, LXVI, 93.

Bornstein A. - Wirkung des Adrenalins auf Oxydationsprozesse. Arch. Exp. Path. Pharmak. 1927, CXXVII, 63.

Bornstein A. und Holm K. - Ueber den Mechanismus der Parasympathicusglykämie. Bioch. Zeit. 1922, CXXXII, 138.

Iidem. - Ueber den respiratorischen Stoffwechsel bei alimentärer Glykämie. Bioch. Zeit. 1922, LXXX, 209.

Iidem. - Ueber die Ausfallserscheinungen nach Nebennierenextirpation. Zeit. Exp. Med. 1923, XXXVII, 1.

BORNSTEIN A. UND HORNEMAN C. - Ueber die Ausfallserscheinungen nach Nebennierenextirpation. III. Mitteil. Ueber die Beziehungen der Nebenniere zum Zuckerstoffwechsel. Zeit. Exper. Med. 1923, XXXVII, 24.

BORNSTEIN A. UND MULLER E. - Ueber den respiratorischen Stoffwechsel bei toxischen Glykämien. Biochem. Z. 1921, CXXVI, 64-74.

BORBERG N. C. - Das chromaffine Gewebe Nebennierenuntersuchungen. Skand. Arch. Physiol. 1913, XXVIII, 81 (cit. por QUINQUAUD).

BOUCKAERT J. J. - Hyperthermie par lá béta-tetra-hydronaphtylamine et métabolisme hydrocarboné. Róle du pancréas, du foie et des capsules surrénales. Arch. Intern. Pharmacodynamie, 1930, XXXIX, 41-73. In Berich, Ges. Phys. u. E. Pharm. 1931, LIX, 414.

BouCKAERT J. J. ET HeYMANS C. - Hyperthermie et hyperglycémie par la béta-tetra-hydronaphtylamine. Arch. Intern. Pharm. 1928, XXXV, fasc. II, 153.

BRANDT F. UND KATZ G. - Ueber den Nachweis von Adrenalinsekretion beim Menschen. I. Die Insulinhypoglykämie. Zeit. Klin. Med. 1933, CXXIII, 23. In Berich, Ges. Phys. u. E. Pharm. 1933, LXXIII, 145.

BRITTON S. W. - Studies of the conditions of activity in endocrine glands XXII. Adrenalin secretion on exposure to cold together with a possible explanation of hibernation. Amer. Jour. Physiol. 1928, LXXXIV, $\mathrm{N}^{\circ} 1,119$.

Idem. - Neural and Hormonal factors in bodily activity. The prepotency of madulliadrenal influence in emotional hyperglycaemia. Amer. Jour. Physiol. 1928, LXXXVI, 340.

Britton. S. W., Geiling E. M. K. And Calvery H. O. - Medulliadrenal secretion and carbohydrate metabolism. Amer. Jour. Physiol. 1928, LXXXIV, 141.

BRitton S. W. AND Silvette H. - Effects of cortico-adrenal extract on carbohydrate metabolism in normal animals. Amer. Jour. Physiol. 1932 , C. $\mathrm{N}^{\circ} 3,693$.

Iidem. - The apparent prepotent function of the adrenal glands. Amer. Jour. Physiol. 1932, C. 701.

Iidem. - Some effects of cortico adrenal extract and other substances and other substances on adrenalectomized animals. Amer. Jour. Physiol, 1931, XCIX, 15. 
Brockmeyer J. - Blutzucker bei Morbus Addisonii. Deut, Med. Woch. 1914, XL, 1562.

Brooks C. M. - Reflex acivation of the sympathetic system in the spinal cat. Amer. Jour. Physiol. 1933, CVI, 251.

BUlatao E. AND CANNON W. B. - The role of the adrenal medulla in pseudo-affective hyperglycaemia. Amer. Jour. Physiol. 1925, LXXII, 295.

BURN J. H. - The modification of the action of insulin by pituitary extract and other substances. Jour. Physiol. 1923, LVII, 318.

BURN J. H. AND MARKS H. P. The relation of the thyroid gland to the action of insulin. Jour. Physiol. 1925, LX, 131.

BuRstein A. J. UND GoldENBERG J. D. - Der Blutzuckerspiegel bei Nicotinvergiftung. Bioch. Zeit. 1928, CC, 115.

Campos F. A., Cannon W. B., Lundin H. and Walker T. T. - Some conditions affecting the capacity for prolonged muscular work. Amer. Jour. Pysiol. 1928-9, LXXXVII, 680.

Cannon W. B., Aub J. C. And Binger C. L. - A note on the effect of nicotine injection on adrenal secretion. Jour. Pharm. Exp. Therap. 1912, III, 379.

Cannon W. B., Shohl A. T. And Wright W. S.-Emotional Glygosuria. Amer. Jour. Physiol. 1911, XXIX, 280.

Cannon W. B., MC Iver M. A. And Bliss S. W. - The effect of the blood sugar level on adrenal secretion and sympathetic activity. A preliminary note. Boston Med. Surg. Jour. 1923, CLXXXIX, 141.

Iidem. - Studies on the conditions of activity in endocrine glands. XIII. A sympathetic and adrenal mechanism for mobilizing sugar in hypoglycaemia. Amer. Jour. Physiol. 1924, LXIX, 46.

CAPRI A. - Comportamento del diabete sperimentale dopo surrenalectomia parziale. Boll. Soc. Ital. Biol. Sper. 1933, VIII, fasc. III, 436.

Carrasco Formiguera R. ex PUChe J. - Enervation des surrénales et diabéte expérimental. C. R. Soc. Biol. 1931, CVIII, 171.

Carrasco Formiguera R. - Action de l'adrenaline sur glycémie chez le chien surrenalectomisé. Annales de Physiol et Physicochim.. 1933, IX, 911.

Carrasco Formiguera R. et Bieto E. - Sur le mécanisme de l'hyperglycémie adrénalinique. C. R. Soc. Biol. 1933, CXIII, 333.

CASTALDI L. - Le ricerche sperimentali sullinfluenza della corticale surrenale sull'accrescimento corporeo. Rev. Sudamer. Endocrin. 1926, IX, 861.

Catán M. A., Houssay B. A. y Mazzocco P. - Metabolismo hidrocarbonado en los animales privados de las suprarrenales. Rev. Asoc. méd. Arg. 1920, XXXIII (Soc. Biol., I, 151).

Iidem. - Métabolisme hydocarboné chez les animaux sans surrénales. C. R. Soc. Biol, 1921, LXXXIV, 164.

Снаноvitch X. - Róle des capsules surrénales dans l'hypergylycémie produite par le décamethylénediguanidine. C. R. Soc. Biol. 1930, CIII, 328.

ChaIkofF I. L. AND WeBer J. J. - The formation of sugar from fatty acids in the depancreatized dog inyected with epenephrine. Jour. Biol. Cem. 1928, LXXVI, 813.

Ciminata A. - Risultati di Ricerche sperimentali sull'enervazione bilaterale delle capsule surrenali. Bollet. della Soc. di Biol. Sperim. 1926, I, $\mathrm{N}^{0} 4$.

Idęm. - Operative Heilung des experimentellen Pankreasdiabetes. Wiener Biol. Ges. Nov. 1927. Klin. Woch. 1928, VII, 189.

Idem. - Guarigione del diabete pancreatico sperimentale con la enervazione operatoria delle glandule surrenali. Boll. Soc. Ital. Biol. Sper. 1928, III, 1251. Arch. Patol. y Clín. méd. 1929, VIII, 79, $34^{\circ}$ Congresso Soc. Ital. Cir. Parma, 1927. 
Idem. - Ulteriore contributo all'influenza dell'enervazione operatoria delle surrenali sul diabete pancreatico sperimentale. Boll. Soc. Ital. Biol. Sper. 1931, VI, 776.

Idem. - Einfluss der Durchschneidung der Nebennieren auf den Diabetes mellitus. Weitere Beiträge. Klin. Woch. 1932, XI, 150. In Berichte, Ges. Phys. u. E. Pharm. 1932, LXVI, 745.

Idem. - Einfluss der Durchscheinung der Nebennieren auf den Diabetes mellitus. Bemerkungen zu dem gleichnamigen Artikel von $M$. Nothmann in Jg. 1932, S. 77/4 dieser Wochenschrift. Klin. Woch. 1933, $\mathrm{N}^{5} 2,71$.

ClarK G. A. - The influence of the vagus on the islets of Langerhans. Part. I. Vagus hypoglycaemia. Jour. Physiol. 1925, LIX, 466.

CLEGHORN R. A. - The effect of injections of extracts of adrenal cortex on the development and sex functions of the albino-mouse. Jour. Physiol. 1932, LXXVI, 193.

CLOEDT J. DE ET VAN CANNEYT J. - Influence de l'insuline sur la respiration des tissus isolés. C. R. Soc. Biol. 1924, XCI, 92.

Collazo J. A. und Puyal J. - Adrenalinwirkung auf die Blutmilchsäure. Klin Woch. 1932, XI, 1947.

Collens J. L., Shelling D. H. And Byron C. S. - Proc. Soc. Exper. Biol. and Med. 1926, XXIII, 545.

CoLWEL A. R. AND BRIGHT E. M. - The use of constant glucose injections for the study of induced variations in carbohydrate metabolism. Amer. Jour. Physiol. 1930, XCII, 543, 555.

CoNNOR C. L. - Effects of adrenal cortical extracts upon the sex organs of animals. Proc. Soc. Exp. Biol. and Med. 1931, XXIX, 131-34. In Berichte, Ges, Phys. u. E. Pharm. 1932, LXVI, 476.

COREY E. L. AND BRITTON S. W. - The induction of precocious sexual maturity by cortico-adrenal extract. Amer. Jour. Physiol, 1931. XCIX. $33-43$.

CORI C. F. - Influence of insuline and epinephrine on lactic acid content of blood and tissues. Jour. Biol. Chem. 1925, LXIII, 253.

Idem. - Mamalian carbohydrate metabolism. Physiol. Rev. 1931, XI, 143.

CORI G. T. - Changes in the glygogen, lactic acid and phosphate content of muscle. Amer. Jour. Physiol. 1930, XCIV, 557.

CORI C. F. AND BUCHWALD K. W. - Effect of continuous intravenous injections of epinephrine on carbohydrate metabolism, basal metabolism and vascular system of normal men. Amer. Jour. Physiol. 1930, $\mathrm{XCV}, 71$.

Iidem. - Effect of epinephrine on the oxygen consumption of frogs before and after hepatectomy. Proc. Soc. Exp. Biol. Med 1930, XXVIII, 104.

Iidem. - Action of epinephrine and insulin under anaerobic conditions. Proc. Amer. Soc. Biol. Chem. 1930, VII, 38.

Cori C. F. AND ConI G. T. - The fate of sugar in the animal body. VII. The carbohydrate metabolism of adrenalectomized rats and mice. Jour. Biol. Chem. 1927, LXXIV, 473.

Iidem. - The mechanism of epinephrine action. I. The influence of epinephrine on the carbohydrate metabolism of fasting rats, with a note on new formation of carbohydrates. II. The influence of epinephrine and insulin on the carbohydrate metabolism of rats in the post-absorptive-state. III. The influence of epinephrine on the utilization of absorbed glucose. Jour. Biol. Chem. 1928, LXXIX, 309-55.

Cori G. T., Cori C. F. AND Buchwald K. W. - V. Changes in liver glycogen and blood lactic acid after injection of epinephrine and insulin. Jour. Biol. Chem. 1930, LXXXVI, 375.

Iidem. - VI. Changes in blood sugar, lactic acid and blood pressure during continuous intravenous injections of epinephrine. Amer. Jour. Physiol. 1930, XCIII, 273. 
CoRi C. F. AND CORI G. T. - IV. Influence of epinephrine on lactic acid production and blood sugar utilization. Jour. Biol. Chem. 1929, LXXXIV, 683.

Iidem. - Effect of epinephrine on arterial and venous blood sugar in men. Jour. Biol. Chem. 1929, LXXXIV, 699.

Iidem. - Influence of constant intravenous injection of epinephrine on blood sugar of rats. Proc. Soc. Exp. Biol. \& Med. 1930, XXVII, 560.

CORKILL A. B. AND MARKS H. P. - The effect of adrenalin on muscle glycogen. Jour. Physiol. 1930, LXX, 67-86.

Crivellari C. A. - Sensibilidad de las ratas suprarrenoprivas a la acción de ciertos tóxicos. R. Soc. Arg. Biol. 1926, II, N² 6, 448.

Idem. - Sensibilité des rats décapsulés à l'égard de la nicotine, du cyanure, de l'acétylcholine et de l'histamine. C. R. Soc. Biol., 1927, XCVI, $\mathrm{N}^{\circ} 3,223$.

Idem. - Sensitiveness of adrenalectomized rats to certain toxic substances. Amer. Jour. Physiol. 1927, LXXXI, 414.

Crowe S. J. AND WISLOCKI G. B. - Experimental observations on the suprarenal glands with special reference to the functions of their interrenal portions. John Hopkins Hos. Bull. 1914, XXV, 287.

CSEPAI AND WeISS R. - Antagonism of insulin and epinephrine. Wiener arch. für innere Medzin. 1925, X, 195.

DALE H. H. AND LAIDLAW P. P. - The significance of the suprarenal capsules in the action of certain alkaloids. Jour. Physiol. 1912, XLV, 1.

Dambrosi R. G. Y LeloIr L. F. - Papel de las suprarrenales en la reconstitución del glucógeno muscular después de la fatiga. Rev. Soc. Arg. Biol. 1933, IX, N* 7, 413.

DAMBrosi R. G., LELOIR L. F. Y Nioveldi A. - Influencia del extracto cortico-suprarrenal y de la glucosa sobre la recomposición del glucógeno muscular en los suprarrenoprivos. Rev. Soc. Arg. Biol. 1933, IX, $\mathrm{N}^{2} 7,417$.

Iidem. - Rôle des surrénales dans la resynthèse du glycogene musculaire aprés la fatigue. C. R. Soc. Biol. 1933, CXIV, 1219.

DeBoIs G. - Sur la reconstitution du glycogéne musculaire perdu par le travail. C. R. Soc. Biol. 1930, CIII, 546.

Idem. - L'influence de l'excitation des nerfs vagues sur la reconstitution du glycogéne musculaire perdu par le travail. C. R. Soc. Biol. 1930, CIII, 943.

Idem. - Sur le mécánisme de la glycopexie musculaire aprés injection de glucose. C. R. Soc. Biol. 1930, CIII, 944.

Del Castillo E. B., Leloir L. F. Y Novelui A. - Influencia del extracto cortico-suprarrenal sobre las glándulas endócrinas. R. Soc. Arg. Biol. 1933, IX, N ${ }^{9} 8 ; 536$.

Demant P. - Le rôle des glandes surrénales dans l'hyperglycémie aprés injection intraveineuse de l'argent colloidal. Medyc. Dosivian. i Spoteyno. 1930, XI, 81. In Jour. Physiol. Path. Gen. 1932, XXX, N 3 , 743 .

De MeIo R. H. Y Lewis J. T. - Un método para la titulación biológica del extracto de corteza suprarrenal. R. Soc. Arg. Biol. 1932, VIII, 145.

Iidem. - Une méthode pour la titration bilogique de l'extrait du cortex surrénal. C. R. Soc. Biol. 1932, CXI, 822.

Donati M. - Tentativo di trattamento chirurgico del diabete con la enervazione di una capsula surrenale. Arch. Ital. di Chirurgia. Vol. XXIV.

DoRNer G. - Ein Beitrag zur Zuckerbestimmung im Blute. Zitschr. Klin. Med. 1913, LXXIX, 287.

DOYON M. ET KAREFF N. - Action de l'adrénaline sur le glycogéne du foie. C. R. Soc. Biol. 1904, LVI, 66.

Doyon M., Morel A. ET KarefF N. - Action de l'adrénaline sur le glycogéne hépatique et sur le sucre du sang. C. R. Soc. Biol. 1905, LIX, 202. 
Iidem. - Action de l'adrénaline sur le glycogéne du foie. Róle du pancréas. Jour. Physiol. Path. Gen. 1905, VII, 998. C. R. Soc. Biol. 1905, LIX, 202.

DWoRKIN S. - The response of sympathectomized animals to insulin. Amer. Jour. Physiol. 1931, XCVIII, 467.

EAdie G. S. - Epinephrine and Hyperglycaemia. Amer. Jour. Physiol., 1929, LXXXIX, 46.

Idem. - A comparison of the effects of epinephrine on carbohydrate metabolism in the cat and rat. Amer. Jour. Physiol. 1930, XCIV, N⿳亠 1.

EADIE G. S. AND MACLEOD J. J. R. - The physiological assay of insulin based on its effects on the hyperglycaemia following glucose injections and epinephrine. Amer. Jour. Physiol. 1923, LXIV, 285.

Eaton A. G., Insko W. M. Thompson G. P. AND Chidester F. E. - The influence of suprarenal cortex and medulla on the growth and maturity of young (white leghorn) chicks. Amer. Jour. Physiol, 1929, LXXXVIII, 187.

EICH HoLTZ F. - Ueber den Einfluss von Nicotin und nicotinartig wirkenden substanzen auf die adrenalinsekretion. Arch. Exp. Path. Phar. 1923, XCIX, 172.

EPPINGER H., FALTA W. Und RUdingeR C. - Ueber die Wechselswirkungen der Drüsen mit innerer Sekretion. I. Mitt. Zeitschr. Klin. Med. 1908, LXVI, 1.

Iidem. - Ueber die Wechselswirkungen der Drüsen mit innerer Sekretion. II. Mitteil. Zeit. Klin. Med. 1909, LXVII, 380.

ERICHSON K. - Adrenalinglykämie und respiratorisches Stoffwechsel. Zeit. Exp. Med. 1926, L, 637.

EUler von U. - Ueber Hyperadrenalinämie bei Fieberzustanden. Pflüg. Arch. 1927, CCXVII, 699.

Evans C., TSAI AND Young. - The action of adrenalin on glycogen distribution in the cat. Jour. Physiol. 1931, LXXIII, 103.

Evans C. L. AND ZEKWER J. T. - On the nature of the hyperglycemic response to injections of certain killed bacteria. British Jour. of Exp. Path. 1927, VIII, 280.

EXNER H. V. - Some observations on the functions of the suprarenal glands in white rats. Dublin Jour. Med. Science, 1920, ser. 4, $\mathrm{N}^{\circ} 2,79$.

FAlta W. UND PRIesley J. G. - Beiträge zur Regulation von Blutdruck und Kohlenhydratstoffwechsel durch das Cromaffine System. Berlin Klin. Woch. 1911, N* 47, 2102.

FARRAR G. E. AND DUFF A. M. - Ergotamine tartrate its direct hyperglycemic action and its influence on the hyperglycaemia produced by epinephrine in normal unanaesthetized dogs. Jour. Pharm. Exp. Ther. 1928, XXXIV, 197.

Fernbach J. UND Dekker A. - Insulinhypoglykämie bei Morbus Addisonii. Klin. Woch. 1931, $\mathrm{N}^{\circ} 38,1755$.

FIROR W. M. AND EADIE G. S. - The effect of epinephrine on muscle glycogen in the abscence of the liver and a modification of the operation for liver removal. Amer. Jour. Physiol. 1930, XCIV, 615.

Fiske C. H. And Subbarow Y. - Phosphocreatine. Jour. Biol. Chem. 1929, LXXXI, 629.

Foglia V. G., Fernández R., Leloir L. F. Y Novelit A. - Corteza suprarrenal y formación del glucógeno. R. Soc. Arg. Biol. 1933, IX, No 8,522 .

Forschbach und Severin. - Verhalten des Kohlehydratstoffwechsels bei Erkrankungen von Drüsen mit innerer Sekretion. Arch. Exp. Path. Pharm. 1914, LXXV, 168.

Foster G. L. - Comparisons of blood sugar concentrations in venous blood and in finger blood. Jour. Biol. Chem. 1923, LV, 291. 
FrRANK E. UND IsAaC S. - Die Bedeutung des Adrenalins und des Cholins für die Erforschung des Zuckerstoffwechsels. Pflüg. Arch. 1911, CXXXIX, 182

Iidem. - Beiträge zur Theorie experimenteller Diabetesformen. Arch. Exp. Path. Pharm. 1911, LXIV, 293.

Freund H. und Marchand D. - Ueber die Beziehungen der Nebennieren zu Blutzucker und Wärmeregulation. Arch. Exp. Path. Pharm. 1913, LXXII, 56.

Iidem. - Ueber der Wirkung des Zuckerstiches nach Nebennierenextirpation. Arch. Exp. Path. Pharm. 1914, LXXVI, 324.

FREUND H. UND SCHLAGENWEIT E. - Ueber Zuckerstichwirkung und Wärmeregulationn. Arch. Exp. Path. Pharm. 1914, LXXVI, 303.

Freund H. UND GRAFe E. - Beeinflussung des Gesamtstoffwechsels und des Eiweissumsatzes beim Warmblüter durch operative Eingriffe am. Zentralnervensystem. Arch. Exp. Path. Pharm. 1922, XCIII, 285.

FRITZ F. - Beiträge zum Mechanismus der Blutzuckerbeeinflussung durch. Hypophysenextracte. Pflüg. Arch. 1928, CCXX, 101.

Frouin A. - Ablation des surrénales et diabéte panereatique. C. R. Soc. Biol. 1908, LXIV, 216.

FUJII I. - On the influence of Ether anaesthesia on the epinephrine content of the suprarenals of dogs. Tohoku Jour. Exp. Med. 1925, $\mathrm{V}, 566$.

Idem. - Ether Hyperglycaemia and Glyoosuria on the rabbit. Tohoku Jour. Exp. med. 1921, II, 169.

FURTH O. UND SchWARZ C. - Ueber die Hemmung der Suprarrenin glycosurie und der sekretorischen Nierenleistung durch peritoneale Reize. Biochem. Zeitschr. 1911, XXXXI, 113.

Gatin-Gruzewska Z. - Action de l'adrénaline sur la teneur du muscle en glycogéne. C. R. Académie. 1906, CXLII, 1165.

GAUNT R. AND PARKINS W. - The alleged interrelationship of the adrenal: cortical hormone and the gonads. Amer. Jour. Physiol. 1932, CIII, 511.

GAUTIER CL. - Sur la glycosurie adrénalinique chez la grenouille. C. R. Soc. Biol. 1913, LXXV, 339.

Gautrelet J. et Thomas L. - L'ablation des surrénales supprime la glycosurie adrénalinique et la glycosurie phloridzinique. C. R. Soc. Biol. 1909, LXVI, 798.

Iidem. - Chez le chien decapsulé l'excitation du splanchnique ne produit pas de glycosurie: C. R. Soc. Biol. 1909, LXVII, 233.

Gayet R., Gayet T. ET Guillaumie M. - L'intervention des capsules surrénales dans la genése de l'hyperglycémie diabétique. Ann. Physiol. et Physico-chim. Biol. 1928, IV, 693.

GEIGER E. -Mobilisierung des Muskelglycogens durch Adrenalin. Biochem. Zeitschr. 1930, CCXXIII, 190.

GeIger E. UND SCHMIDT E. - Mobitisierung des Muskelglycogens durch Adrenalin. Arch. Exp. Path. Pharm. 1929, CXLIII, 321.

Giménez Díaz C. y Mansera J. - Acerca de la glucemia en la enfermedad de Addison. Anales de la clínica del Prof. C. Giménez Díaz, 1928, I, 177. Arch. Endocrin. y Nutr. 1928, VI, N: 2, 369.

GLeY E. - Du rôle des glandes surrénales dans l'action des substances vasoconstructives. I,es substances vasoconstrictives indirectes. C. R. Acad. Scienc. 1914, CLVIII, 2008.

GoldBLATT M. W. - Ergotamine and the effect of adrenalin on blood lactate. Jour. Physiol., 1933, LXXVIII, 96.

Idem. - Insulin and adrenalin. Jour. Physiol. 1933. LXXIX, 286.

GONDARD L. - L'énervation des capsules surrenales guérit-elle le diabéte paneréatique expérimental? C. R. Soc. Biol. 1933, CXII, 1036.

Idem. - Diabéte et capsules surrénales. Résultats expérimentaux de la suppression de l'activité médullaire (Premier mémoire). Arch. Intern. de Physiol. 1933, XXXVI, 329. 
Grafe E. - In Ergebn. Physiol. 1933, XXI.

GRIFFITH F. R. - Further evidence regarding the relationship of the adrenals to the amount of sugar in the blood. Amer. Jour. Physiol. 1923, LXVI, 659.

Idem. - Reflex Hyperglycaemia. A study of the carbohydrate mobitization effected by afferent crural, sciatic and vagus stimulation. Amer. Jour. Physiol. 1923, LXVI, 618.

Grollman A. AND Firor W. M. - Studies on the adrenal. III. The preparation of an active extract of the hormone of the adrenal cortex. Jour. Biol. Chem. 1933, C., 429.

GROLlman A. AND How ARD E. - The effects of adrenal cortex extract on the reproductive system. Amer. Jour. Physiol. 1933, CV, 42.

Grote L. R. - Blutzucker und Diättherapie bei Morbus Addisonii. Münch. Mediz. Woch. 1916, LXIII, 1614, N².

HALLION L. ET GAYET R. - L'augmentation de la sensibilité á l'insuline à la suite de l'ablation des capsules surrénales. C. R. Soc. Biol. 1925, XCII, 945 .

HARADA T. - Die histologischen Veränderungen der Nebennierenrinde nach Wiederholter Injektion von Insulin an Kaninchen. Fukuoka Ikwadaigaku Zasshi, 23. Dtch Zusammenfassung, 1930. - in Berich ges. Phys. u. E. Pharm. 1930, LVII, 462.

HARI P. - Einfluss des Adrenatins auf den Gaswechsel. Biochem. Zeitschr. 1912, XXXVIII, 23.

Harrop G. A., SWingle W. W. And Pfiffner J. J. - Metabolism Studies on the adrenal cortical hormone. Scientific Proc. Soc. Biol. Chem. 1931. XXV, 56. Jour. Biol. Chem. 1931, XCII, N ${ }^{9} 1$.

HARROP G. A. AND WEINSTEIN A. - Addison disease treated with suprarrenal cortical hormone. Jour. Amer. Med. Assoc. 1932, XCVIII, 1925.

Hartman F. A., Brownell K. A. AND Lockwood J. E. - Cortin as a general tissue hormone. Amer. Jour. Physiol. 1932, CI, 50.

Iidem. - Studies indicating the function of cortin. Endocrinology, 1932, XVI, 521.

Hartman F. A., Thorn G. W., Lockie L. M., Greene C. W. and Bowen B. D. - Treatment of Addisons disease with an extract of suprarrenal cortex. Jour. Amer. Med. Assoc. 1932, XCVIII, 788.

HAYASHI A. - Morphine hyperglycaemia and blood serum adrenalin. Jour. Orient. Med. 1928, IX, 62. - in Berich. ges. Phys. u. E. Pharm., 1929, XLIX, 702.

HEDON E. - Relation entre le pancréas et les surrénales su point dé vue du diabéte. Arch. Int. Physiol. 1921, XVIII, 213.

Hedon E. et Giraud C. - Relation entre le pancréas et les capsules surénales. C. R. Soc. Biol. 1920, LXXXIII, 1310.

HENRIQUEZ V. und EGE R. - Vergleichende Untersuchungen über die Glykosekonzentration in dem arteriellen und in dem venösen Blut aus den Muskeln. Bioch. Zeitschr. 1921, CXIX, 121.

HeRter C. A. and Richards A. N. - Note on the glycosuria following experimental injections of adrenalin. Medical News, 1902, LXXX, 201.

Herter C. A. und Wakeman A. S. - Ueber Adrenalinglykosurie und verwandte durch die Wirkung reduzierender Substanzen und anderer Gifte auf die Pankreaszellen hervor gerugene experimentelle Glykosurien. Wirchows Arch. 1902, CLXIX, 479.

Hiks M. UND Szakall A. V. - Der Insulinadrenalinantagonismus in Plethysmogramm und dessen zusammenhang mit der Konstitution. Deutsch Arch. f. Klin. Med. 1927, CLIV, 365. In Berichte, Ges. Phys. u. E. Pharm., 1927, XLII, 544.

HILL E. AND KOEHLER A. E. - Effect of suprarenalectomy on sugar tolerance. Proc. Soc. Exp. Biol. Med. 1932, XXX, 244. 
Hirayama S. - Urethane Hyperglycaemia and Glycosuria in the rabbit. Tohoku Jour. Exp. Med., 1926, VII, 364.

Idem. - Fesselungshyperglykämie beim nebennierenlosen Kanninchen. Tohoku Jour. Exp. Med. 1926, VIII, 37.

HoFMANN E. - Ueber die Veränderungen des Nebennierensorgans nach Insulinwirkung. Krankheitsforschung, 1926, 2H4, 295.

Houssay B. A. - Diabetesrregende Wirkung des Hypophysenvorderlappenextractes. Klin. Woch. 1933, $\mathrm{N}^{\circ} 20$, p. 1.

Houssay B. A. Y BiasotTi A. - Hypophysektomie und Pankreasdiabetes bei der Kröte. Pflüg. Arch. 1931, CCXXI, 239.

Iidem. - Pankreasdiabetes und Hypophyse beim Hund. Pflüg: Arch. 1931, CCXXVII, 664.

Iidem. - The Hypophysis, carbohydrate metabolism and diabetes. Endoerin. 1931, XV, 511.

Iidem. - Hypophyse et diabéte. Presse Med. 1931, XIV, 1.

Houssay B. A. BiasotTi A. Y Rietti C. T. - Acción diabetógena del extracto anterohipofisario. Rev. Soc. Arg. Biol. 1932, VIII, 469.

Iidem. - Action diabétique de l'extrait anterohypophysaire. C. R. Soc. Biol. 1932, CXI, 479.

Houssay B. A. Y DI Benedetto E. - Acción hiperglucemiante del extracto de lóbulo posterior de la hipófisis. R. Soc. Arg. Biol. 1933, IX, 300 .

Iidem. - Papel de las suprarrenales, hígado, páncreas y sistema nervioso vegetativo en la hiperglucemia por extracto retropituitario. Rev. Soc. Arg. Biol. 1933, IX, 310.

HoussaY B. A. Y LEWIS J. T. - Suprarrenales y diabetes pancreática. R. Asoc. Med. Arg. 1921, XXXIV, 1099. (Soc. Biol. II, 261).

Iidem. - Diabéte pancréatique chez les chiens privés de la partie médullaire des surrénales. C. R. Soc. Biol, 1921, LXXXV, 1212.

Iidem. - The relative importance to life of cortex and medulla of the adrenal glands. Amer. Jour. Physiol. 1923, LXIV, 512.

Iidem. - Importancia respectiva de la corteza y de la médula suprarrenal. Libro en honor de Santiago Ramón y Cajal, 1922, II, 455.

Iidem. - Las funciones de los perros privados de la médula suprarrenal. R. Asoc. Med. Arg. 1922, XXXV, 129. (Soc. Biol. III, 55).

Iidem. - Les fonctions des chiens privés de la substance médullaire surrénale. C. R. Soç. Biol. 1922, LXXXVII, 565.

Iidem. - Estudio sobre las hiperglucemias experimentales. - 1 Mecanismo nervioso de la acción de la morfina. R. Asoc. Med. Arg., 1923, XXXVI, No 228. (Soc. Biol. IV, 208).

Iidem. - Etudes sur les hyperglycémies expérimentales. Mécanisme nerveux de l'action de la morphine. C. R. Soc. Biol. 1923, LXXXIX, 1120 .

Houssay B. A., Lewis J. T. y Molinelli E. A. - Influencia de la insulina sobre la acción de la adrenalina. R. Asoc. Med. Arg. 1924, XXXVII. N 237 (Soc. Biol. V, 486).

Iidem. - Róle de la sécrétion d'adrénaline pendant l'hypoglycémie produite par l'insuline. C. R. Soc. Biol. 1924, XCI, 1011.

Iidem. - Róle physiologique de l'adrénaline dans la production de l'hyperglycémie produite par la morphine. C. R. Soc. Biol. 1924, XCI, 1013.

Houssay B. A., Lewis J. T., Molinelli E. A. y Marenzi A. D. - Estudio de los mecanismos nerviosos y humorales (suprarrenal) que producen la hiperglucemia por inyección de morfina. R. Soc. Arg. Biol. 1928, IV, 230.

Iidem. - Etudes sur l'hyperglycémie consécutive á l'injection de morphine. Róle du sympathique. C. R. Soc. Biol. 1928, XCIX, 1406.

Iidem. - Etudes sur l'hyperglycémie consécutive á l'injection de morphine. Róle des surrénales. - C. R. Soc. Biol. 1928, XCIX, 1408. 
Iidem. - Etudes sur l'hyperylycémie consécutive á l'injection de morphine. Róle de l'innervation hépatique. C. R. Soc. Biol. 1928, XCIX, 1411.

Iidem. - Etudes sur l'hyperglycémie consécutive á l'injection de morphine. Róle de l'innervation parasympathique. C. R. Soc. Biol. 1928, XCIX, 1413.

Houssay B. A. Y Marenzi A. D. - Extracto córticosuprarrenal y resistencia de las ratas suprarrenoprivas a los tóxicos. R. Soc. Arg. Biol. 1931, VII, N² 2, p. 158.

Iidem. - L'extrait cortico-surrénal protége les surrénaloprives contre les toxiques. C. R. Soc. Biol. 1931, CVII, 1199.

Houssay B. A. Y Mazzoco P. - Glucógeno cerebral y cardíaco y ácido láctico muscular de las ratas suprarrenoprivas. R. Soc. Arg. Biol. 1927, III, 491.

Iidem. - Variations du glycógéne cardiaque et cérebral de l'ácide lactique et du lactacidogéne musculaire chez les rats décapsulés. C. R. Soc. Biol. 1927, XCVII, No 26, 1032.

Houssay B. A. y Molinelui E. A. - Papel de la liberación de adrenalina producida por la picadura o excitación eléctrica del bulbo. R. Asoc. Med. Arg. 1924, XXXVII, No 234 (Soc. Biol. V, 235).

Iidem. -Sécrétion d'adrénaline produite par la piqúre ou l'excitation électrique du bulbe. C. R. Soc. Biol. 1924, XCI, 1045.

Iidem. - Acción de la nicotina, cytisina, lobelina, coniina, piperidina y amonios cuaternarios sobre la secreción de adrenalina. R. Soc. Arg. Biol. 1925, I, N⿳亠 5, 441.

Iidem. - Action de la nicotine, de la cytisine, de la lobeline, de la conicine, de la piperidine et de diverses bases d'ammonium sur la secretion de l'adrenaline. C. R. Soc. Biol. 1925, XCIII, 1124.

Iidem. - Effect of nicotin, cytisin, lobelin, coniin, piperidin and quaternary ammoniums on adrenal secretion. Amer. Jour. Physiol., 1926, LXXVI, 551.

HunT A. B. AND BRIGHT E. M. - Locus of the calorigenic action of adrenalin with observations on the tissue metabolism. Amer. Jour. Physiol. 1926, LXXXVII, 353.

Iıno J. - Zika Zasshi, 1922, N²60. (Citado por Mikami).

IMAfiAsi T. - Okayama Igakkai Zasshi, 1928, XL, 2172. (Citado por Inaba y Oikawa).

INABA T. AND OIKAWA K. - Indispensability of the suprarenal glands in causing nicotine hyperglycaemia in rabbits. The Tohoku Jour. of Exp. Med. 1930, XVI, 169.

INOUYe T. - Ueber das Wesen der Pilocarpinhyperglykämie. Jour. Bioch. Tokyo, 1931, XIV, 215. (In Phys. Abs. 1932, XVII, 349).

JACOBSON C. - A study on the carbohidrate tolerance in Eck fistula and hipophysectomized animals (posterior lobe removal). Amer. Jour. Phys., LII, 233, 1920.

JARISCH A. - Uber den Mechanismus der Piquire Glykosurie. Pflüg. Arch. 1914, CLVIII, 478.

Idem. - Uber den Mechanismus der Diuretinglykosurie. Pflüg. Arch. 1914, CLVIII, 502.

Juschtschenko A. J. - Der Einfluss des Thyroidins und Adrenalins sowie der Entfernung der Schilddrüse und der Testikeln auf die Oxydationsprozesse, der Atmungsgasaustausch und die Giftkeit des Harns. bei Tieren. Biochem. Zeitsch. 1909, XV, 365.

KAHN R. H. - Zur Frage nach der innere Selvetion des cromaffinen Gewebes. Pflüg. Arch. 1909, CXXVIII, 519.

Idem. - Uber die Zentrale Reizung der Nebennieren und der Paraganglien waehrend der Insulinvergiftung. Pflüg. Arch. f. Physiol. 1926, CCXII, 54. 
KAHN R. H. UND MUNZER T. F. - Uber nervös bedingte Veränderungen der Nebennierenrinde während der Insulinvergiftung. Pflüg. Arch. f. Physiol. 1927, CCXVII, 521.

KAhN R. H. UND STARKENSTEIN E. - Ueber das Verhalten des Glykogens nach Nebennierenextirpation. Pflüg. Arch. f. Physiol. 1911, CXXXIX, 181.

KaIWA T. -Hyperglycaemic action of B. Dimethyltelluronium Dichloride. Tohoku Jour. Exp. Med. 1932, XX, 163.

Idem. - Blood sugar determination in the uni and bilaterally desuprarenalized rabbits after subcutaneous injection of $B$ Dimethyltelluronium Dichloride. Jap. J. Med. Scie. Trans. III, Biophysics, 1931, II, 89. (In Berich. ges. Phys. u. E. Pharm., 1932, LXVIII, 334).

Idem. - On the mechanism of peptone hyperglycaemia. Tohoku J. exp. Med. 1933, XX, 365. (In Berich. ges. Phys. u. E. Pharm., 1933, LXXIII, 697).

Idem. - Peptone Hyperglycaemia in the animals deprived of suprarenals or suprarenal medulla. Tohoku J. exp. Med. 1933, XXI, 1.

Idem. - Significance of the augmented epinephrine discharge on peptone poisoning upon hyperglycaemia simultaneously ocurring. Tohoku J. exp. Med. 1933, XX, 471.

KAPLAN S. - Nebennierenrinde Hormone und Genitalsystem. Endokrin. 1932 , XI, 321.

Kausch W. - Zuckerverbrauch in Diabetes Mellitus des Vogels. Arch. Exp. Path. Pharm. 1897, XXXIX, 219.

KELLAWAY C. H. - The effects of diminished tension of oxigen with special reference to the activity of the adrenal glands. Medical Research Comitee. Spec. reports series N 37, 1919.

Idem. - The hyperglycaemia of asphyxia and the part played therein by the suprarenals. Jour. Physiol. 1919, LIII, 210.

Kinoshita. - Igaku Kenkiu, 1928, II, 899. (Citado por Ohmi).

KISCH B. - Experimentelle Untersuchungen über die Funktion der Nebennieren. Klin. Woch. 1924, $\mathrm{N}^{2} 3,1661$.

KLeIN F. AND WeIss R. - Wirkung des Adrenalins auf den respiratorischen Stoffwechsel. Endokrin. 1928, I, 264.

KLeIN O. - Der Einfluss der Nebennierenrinde auf die Entwilklung der männlichen Geschlechtsorgane. Endokrin. 1931, IX, 401.

Kleiner. I. S. AND MelTzer S. J. - The effect of painting the pancreas with adrenalin upon hyperglycaemia and glycosuria. Jour. Exp. Med. 1918, XXVII, 647.

Kogan V. M. Kamenew M. J. und Mantz N. B. - Die Mehrphasenwirkung der Hormone. Klin. Woch. 1926, $\mathrm{N}^{\circ}$ 6, p. 221.

Kogan V. M. UND Ponirowsky N. - Der Antagonismus zwischen Adrenalin und Insulin in Bezug auf das autonome Nervenssystem. Zeitschr. f. ges. Exp. Med. 1925, XLVII, 557.

KUDRJAZEW N. N. - Ueber die verschiedenen Bedingungen der Wirkung der Nebennierenflussigkeit. auf die Gefässe isolierten Organe. Zeitschr. f. exp. ges. Med. 1924, XLI, 114.

KugelmanN B. - Ueber die Beziehungen zwischen Insulin und Adrenatin in menschtichen Organismus. Klin. Woch. 1931, N² 2, p. 59.

Kuno J. - Ueber den Einfluss des Sinomenins, des Parasinomenins und des Chinins auf den Blutzuckerspiegel des Kaninches. Proc. of the Japanese Pharmacol. Soc. 1929, July 10-11, 33.

KURE K. WADA Y. AND OKINAKA. - The spinal parasympathetic. VI. The nerve supply of the suprarrenal gland. Quarterly J. Exp. Physiol. 1931, XXI, 227.

KURIYAMA S. - The adrenals in relation to carbohydrate metabolism. 1. The Influence of repetition of epinephrine injection upon the intensity of glycosuria and hyperglycaemia and the glycogen content of the liver. Jour. Biol. Chem. 1918, XXXIV, 269. 
Idem. - The adrenals in relation to carbohydrate metabolism. II. The influence of adrenalectomy upon the glycogenetic power of the liver. Jour. Biol. Chem. 1918, XXXIV, 287.

KUSNETZOW A. J. - Ueber die Wirkung des Nikotins auf die Funktion der isolierten Nebenniere. Arch. Exp. Path. Pharm. 1927, CXX, 156.

Idem. - Die Wirkung des Pankreotoxins auf die Absonderung des Adrenalins durch die Nebennieren. Zeitschr. f. ges. Exp. Med. 1925, XLV, 123.

LA BARRE J. - Ueber die Ursachen der bei Meerchweinschen in akuten anaphylactischen shock auftrende Hyperglykämie. Arch. f. Exp. Path. u. Pharm. 1926, CXIII, 368.

Idem. - Sur les causes des variations de la glycémie au cours des chocs anaphylactique, histaminique et peptonique. Arch. Inter. Med. Exp. 1927, III, Fasc. $1 ; 41$.

LA BARRE J. ET RENAULT P. - Recherches sur l'action de l'extrait hypophysaire sur la glycémie. C. R. Soc. Biol. 1927, XCVI, 823.

LA BARRe J. ET Houssa P. - A propos des variations de l'adrénalinémie au cours de l'hypoglycémie insulinique. C. R. Soc. Biol. 1932, CIX, 967.

LANDAU E. G. - Materiali dlya mikroskopicheskoi anatomii, fiziologii $i$ pathologii nadpochechnikov; eksperimentalnoye izsliedovaniye (Contribution á l'anatomie microscopique, á la physiologie et a la pathologie des surrénales; recherches experimentales). Thése méd. Yuryev, Bergmann, 1907. (Citado por Quinquaud).

LANG. - Nebennierenrinde und Muskelchemismus. Pflügers Arch. 1932, CCXXIX, 60.

LANGECKER H. - Der Einfluss chronischer Insulinzufuhr auf die Nebennieren beim Kaninchen. Naunyn Schmiedbergs Archiv. 1928, CXXXIV, 155.

LAscano GonzÁlez J. M. - Las suprarrenales accesorias de la rata blanca. R. Soc. Arg. Biol. 1934, X, $\mathrm{N}^{\circ}$ 1, 28.

LELOIR L. F. - Papel de las suprarrenales en la hiperglucemia nicotínica. Rev. Soc. Arg. Biol. 1933, IX, N 8; 474.

LELOIP. L. F. Y NOVELLI A. - Titulación de la hormona corticosuprarrenal por la resistencia a la morfina. Rev. Soc. Arg. Biol. 1933, IX, $\mathrm{N}^{2} 6,273$.

Iidem. - Titration de l'hormone cortico-surrénale par la résistance a la morphine. C. R. Soc. Biol. 1933, CXIV, 798.

LEPINe R. - Lyon Médical, 1902, XCI, 151.

Idem. - Le sucre du sang. París, 1921, Alcan., Editeur, p. 217.

LEWIS J. T. - Sensibilité des rats privés de surrénales envers les toxiques. C. R. Soc. Biol. 1921, LXXXIV, N² 3, p. 163.

Idem. - Sensibilidad de las ratas suprarrenoprivas a los tóxicos. R. Asoc. Méd. Arg. 1920, XXXIII, 629 (Soc. Biol. I, 147).

Idem. - Sensibilidad de las ratas suprarrenoprivas a los tóxicos (2a. nota). R. Asoc. Méd. Arg. 1921, XXXV, 529 (Soc. Biol. II, 131).

Idem. - Sensibilité des rats décapsulés envers les toxiques. C. R. Soc. Biol. 1921, LXXXV, 685. (Amer. Jour. Physiol. 1923, LXIV, 506).

Idem. - Acción de la insulina sobre las ratas suprarrenoprivas. R. Asoc. Méd. Arg. 1923, XXXVI, N²28 (Soc. Biol. 1923, IV, 203).

Idem. - Action de l'insuline sur les rats privés des surrénales. C. R. Soc. Biol. 1923, LXXXIX, 1118.

Lewis J. T. Y MAgenta M. A. - Algunos factores que intervienen en la recuperación de la hipoglucemia por la insulina. R. Asoc. Méd. Arg. 1924, XXXVII, 236 (Soc. Biol. V, 370).

Iidem. - Sur les mécanisnes de la récupération de la glycémie aprés l'action de l'insuline. C. R. Soc. Biol. 1925, XCII, 821.

Lewis J. T. Y ToRINo A. - Sensibilidad de las ratas suprarrenoprivas a la morfina. R. Soc. Arg. Biol. 1926, II, N²; 459. 
Iidem. - Sensibilité a la morphine des rats surrénalectomisés. C. R. Soc. Biol. 1927, XCVI, 217.

LEWIS J. T. Y TURCATTI E. - Suprarrenales y diabetes pancreática. Rev. Soc. Arg. Biol. 1933, IX, 115.

Iidem. - Glandes surrénales et diabéte pancréatique. C. R. Soc. Biol. 1933, CXIV, 403.

LEYS D. - The influence of adrenalin on carbohydrate metabolism. Jour. Physiol. 1931, LXXI, 275.

LJVRAGA P. - Surrenali e diabete. Contributo alla fisiopatologia dei surrenali. Riv. Pat. Sper. 1933, X, 107. (In Berich. ges. Phys. u. E. Pharm. 1933, LXXIII, 536).

LOEPER M. ET CRouzón O. - L'action de l'adrénaline et des extraits surrénaux sur le sang. C. R. Soc. Biol. 1903, LV, 1376.

Loewit M. - Der Pankreasdiabetes beim Frosche. Arch. Exp. Path. Pharm. 1910, LXII, 47.

LoHMAN K. - Vorkommen und Umsatz von Pyrophosphat in Zellen. I, II, III. Bioch. Zeitschr, 1928, CII, 466; CIII, 164-172.

Loos H. O. UND RITMANN R. - Nebennierenrinde und Geschlechtsentwicklung. Endokrin. 1933, XIII, 82.

Lumley Hills F. AND Nice L. B. - Blood sugar of adrenalectomized rats. Amer. Jour. Physiol. 1930, XCIII, N ${ }^{\circ} 1$; 152 .

LundsgaARD E. AND WILson A. T. - Muscle Phosphorus compounds in adrenal insufficiency. Proc. of physiol. Soc. Dec. 16, 1933, 29 P. Jour. Physiol. 1934, LXXX, N 4.

LusK G. AND RICHE J. A. - Animal calorimetry; Paper VIII. The alleged influence of the adrenals on diabetic metabolism. Arch. Intern. Med. 1914, XIII, 673 .

Lyman R. S., Nicholls E. AND Mc CANN W. M. - The respiratory exchange and blood sugar curves of normal and diabetic subjects after epinephrine and insulin. Jour. Pharm. and Exp. Therap. 1923, XXI, 343 .

MaC GUIGAN H. - Adrenalectomy and glycosuria. Amer. Jour. Physiol. 1910, XXVI, 287.

Macleod J. J. R. AND PeARce K. G. - Siudies in experimental glycosuria. VIII. The relationship of the adrenal glands to sugar production by the liver. Amer. Jour. Physiol. 1912, XXIX, 419.

MAO KAY E. M. AND MAC KAY L. L. - Susceptibility of adrenalectomized rats to morphine intoxication. Proc. Soc. Exp. Biol. Med. 1926, XXIV, 129. Jour. Pharm. Exp. Therap. 1929, XXXV, 67.

Iidem. - Enlargement of the adrenal cortex in experimental uremia. Jour. Exp. Med. 1927, XLVI, 429.

MACKENZIE G. M. - The suprarrenal system and carbohydrate metabolism. Arch. Intern. Med. 1917, XIX, 593.

MC KINLEY E. B. AND Fisher N. F. - Effects obtained from feeding fresh adrenal cortex medulla and whole gland to the standard white rat. Amer. Jour. Physiol 1926, LXXVI, 268.

Magenta M. A. - Acción de la cloralosa sobre la gluceria. R. Soc. Biol. 1927, VIII, 681.

Idem. - Action du chloralose sur la glycémie. C .R. Soc. Biol. 1928, XCVIII, 171.

MAgenta M. A. Y Biasotti A. - Acción de algunas substancias sobre el efecto de la insulina. R. Asoc. Med. Arg. 1923, XXXVI, (Soc. Biol. IV, 192) .

Iidem. - Action de quelques substances glycémientes sur les effects de l'insuline. C. R. Soc. Biol. 1923, LXXXIX, 1125.

MAJOR S. G. AND MANN F. C. - Glycogenolitic effect of epinephrine on skeletal muscle. Amer. Jour. Physiol. 1932, CI, 462.

MANN F. C. - Modified physiologic proceses following total removal of the liver. Jour. Amer. Med. Assoc. 1925, LXXXV, N 19; 1472. 
ManN F. C. AND Magath T. B. - Studies on the physiologie of the liver. II. Effect of the removal of the liver on the blood sugar level. Arch. Intern. Med. 1922, XXX, 73.

MARAÑ́n G. - Action de l'insuline dans l'insuffisance surrénale. Presse Med. $1925, \mathrm{~N}^{0} 101 ; 1665$.

Idem. - Trabajos del servicio de patología médica. - V. e Hijos Jaime Ratés, Edit. Madrid, 1927.

Idem. - Sur la pathogénie des accidents graves de l'insuffisance surrénale. Presse Med. 1929, N 63; 1021.

Marañón G., Carrasco E. Y Soler A. - Sobre la glucemia de los Addisonianos. Bolet. Soc. Exp. Biol. 1923, X, 183. Archiv. Medic. Cirujía y Especialidades, 22 de marzo, 1924.

Marenzi A. D. - Acción de la morfina sobre la glucemia y la concentración de hidrogeniones de la sangre en perros normales y con los nervios esplácnicos cortados. Tercer Congreso Nac. de Med. Subsección Fisiología, julio 14, 1926.

Markowitz J. - Glyconeogenesis. Amer. Jour. Physiol. 1925, LXXIV, 22.

MaRtín S. J. AND Kroc R. L. - Effects of cortical extracts on the oestrual cycle of completly suprarrenalectomized rats. Amer. Jour. Physiol. 1933, CV, No 1; 71.

MARVAL L. - Sensibilidad de las ratas suprarrenoprivas al frío. $R$. Soc. Arg. Biol. 1926, $\mathrm{N}^{\text {2 }} 3$; 226.

Idem. - Sensibilité au froid des rats décapsulés. C. R. Soc. Biol. 1926, $\mathrm{XCV}, 1087$.

MAUTHNER H. - Referencia en "Gesellschaft für innere Medizin und Kinderheilkunde in Wien". Wiener Klin. Woch. 1912, XXV, No 28; 858.

MAYER A. - Sur le mode d'action de la piqúre diabétique. Róle des capsules surrénales. C. R. Soc. Biol. 1906, LVIII, 1123.

Idem. - Ablation des surrenales et diabéte pancréatique. C. R. Soc. Biol. 1908, LX, T. I, 219.

MAZZOCo P. - El ácido láctico muscular en las ratas suprarrenoprivas. R. Soc. Arg. Biol. 1928, IV, N 1 y 2 ; 50.

Idem. - L'acide lactique musculaire des rats surrenaloprives. C. R. Soc. Biol. 1928, XCIX, No 20; 174.

MEYERHOF O. - Chimie de la contraction musculaire. (Traducido del alemán por L. Genevois): Hermann y Cie. Editeurs. París, 1932.

Miculicich M. - Ueber den Einfluss von Ergotoxin auf die adrenalin und Diuretinglykosurie. Arch. Exp. Path. Pharm. 1912, LXIX, 133.

MighiavaCCA A. - Zentralbl. Gyn. 1932, LVI, 1874.

MiLroy T. H. - Quart. J., Exp. Phys., 1927, XVII, 161.

MOLINELli E. A. - La función adrenalínica suprarrenal en la intoxicación diftérica. Rev. Sudamer. Endocrin. Inmunol. y Quimioter. $1926, \mathrm{IX}, \mathrm{N}^{\circ} 10 ; 902$.

Idem. - La secreción adrenalínica. Tesis. Bs. Aires, 1926.

Molitor H. UND POLLAK L. - Der Zuckerhaushalt der Leber. I. Mitt. Der Einfluss von Adrenalin und Insulin auf Zuckerabgabe und Glykogengehalt der Leber. Arch. Exp. Path. Pharm. 1930, CLIV, 280.

Morita S. - Die Hyperglykämie und Glykosurie durch Ammoniumchlorat und Magnesiumsulfat an der Katze. Tohoku Jour. Exp. Med. 1922, III, 363 .

Mikami S. - The blood sugar level and epinephrine content of the suprarenals of the rabbit. in diphteric intoxication. Tohoku Jour. Exp. Med. 1925, VI, 299.

Idem. - CO Hyperglycaemia in the bilaterally splanchnicotomized rabbit. Tohoku Jour. Exp. Med. 1926, VIII, N², 113.

Idem. - Ueber den Mechanismus der Diuretinhyperglykämie und Glykosurie beim Kaninchen. Japan Jour. Med. Sciences. IV, Pharmacology, 1926, I, N $1,121$. 
Mima T. - Ueber den Einfluss der verschieden innersekretorischen Organe und den Blutzucker des Nebennierenlosen Kaninchens. Folia Endocr. Japanica, 1927, III, 32 -33. In Jour. Physiol. et Pathol. Génerale, 1928, XXVI, No 2, 303.

MULLER C. - Experimentelle Bedrüngung der funktionellen Beziehung der Nebennierenrinde zu den Geschlechtsorganen. Klin. Woch. 1930, $\mathrm{N}^{\circ} 42,1967$.

Mulinos M. G. Haemorrage hyperglycaemia. Amer. Jour. Physiol., 1928, LXXXVI, N* $1 ; 70$.

NaIto y FuJII J. - Tohoku Igakukwai Zasshi, 1917, II, 181. (Citado por Mikami).

Negrín J. - El papel de los adrenes en las glucosurias de origen bulbar. Libro en honor de Santiago Ramón y Cajal, 1922, II, 577.

Neumann J. - Zur Addisonischen Krankheit. Münch. Med. Woch. 1916, XLIII, 488.

NI T. G. - On the inverse change between the concentration of alycose and chloride in the blood. Amer. Jour. Physiol. 1926, LXXVIII, 158.

NIKolAefF M. P. - Ueber die Wirkung verschiedener Gifte auf die Funktion und die Gefässe der isolierten Nebenniere. Zeitschr. ges. Exp. Med. 1924, XLII, 213.

Idem. - Ueber die Wirkung des Pituitrins und Insulins auf die Selretion und Gefässe der isolierten Nebenniere. Arch. Exp. Path. Pharmak. 1929, CXL, 225.

Nishi M. - Ueber den Mechanismus der Diuretinglykosurie. Arch. Exp. Path. Pharmak. 1909, LXI, 401.

Idem. - Ueber den Mechanismus der Blutzuckerregulation. Arch. Exp. Path. Pharmak. 1909, LXI, 186. Pflüg. Arch. 1911, CXXXIX, 182.

Nitzescu I. I. ET MUNTEANU M. - L'ergotamine et l'hyperlactacidémie adrénalinique. C. R. Soc. Biol. 1932, CIX, 311.

NOORDEN C. V. - Handbuch der Stoffwechselpaíhologie, 1907.

NотнMAN M. - Einfluss der Durchschneidung der Nebennierennerven auf den Diabetes mellitus. Bemerkungen zu der Arbeit von A. Ciminata in Jg. 1932, S. 150 dieses Wochenschrift. Klin Woch. 1932, N: 11, 774. In Berich Ges. Phys. u. E. Pharm., 1932, LXVIII, 334.

OCHOA S. UND GRANDE F. - Der Phosphagengehalt in Meerschweinchen muskel nach Entfernung der Nébennieren. I Mitt. II Mitt. Pflüg. Arch. 1933, CCXXXI, 222 - 233.

OHARA T. - On the Adrenalin Hyperglycaemia. Tohoku Jour. Exp. Med. 1925, VI, 23.

OHGURI M. - The effect of the removal of the suprarenal and accesory cortical tissues, together upon some blood constituents of rabbits. Tohoku Jour. Exp. Med. 1931, N 3 y 4, 390.

Idem. - On effect of uni- and bilaieral suprarenalectomy upon some blood constituents of rabbits. Tohoku Y. Ex. Med. 1931, XVII, 378.

Онмі F. - On the intensity of the Ether Hyperglycaemia in the doubly suprarenalectomized rabbits. Tohoku Jour. Exp. Med. 1933, XXI, 116.

Idem. - Again on the hypoglyeaenaic ability of insulin upon rabbits doubly suprarenalectomized or splanchnicotomized. Tohoku Jour. Exp. Med. 1933, XXI, 211.

Idem. - The effect of sensory stimulation on the blood sugar content of rabbits, splanchnicotomized or suprarenalectomized. Tohoku Jour. Exp. Med. 1933, XX, 498.

Idem. - The hyperglycaemia after potassium Cyanide in rabbits splanchnicotomized or suprarenalectomized. Tohoku Jour. Exp. Med. 1933, XXI, $\mathrm{N}^{\circ} 1$ y $2,107$.

Idem. - A note on glycaemic action of histamine in rabbits. Tohoku Jour. Exp. Med. 1933, XXI, 314.

Okuво. - Citado por Rosenow y Yaguttis. 
OLMSTED J. M. D. - The blood sugar after asphyxia in decapitate cats and its relation to the adrenal glands. Amer. Jour. Physiol. 1926, LXXV, 487.

ORRU A. - Azione della pilocarpina sul tasso glicemico dei conigli privati delle capsule surrenali. Boll. Soc. Biol. Sper. 1928, III, Fasc. III, 1134 .

Pardo Urdapilleta J. M. - La enfermedad de Addison. Arch. Endocrin. Nutrición, 1924, II, 267.

Pardo URdapilieta J. M. und Martínez Díaz J. - Studien zur Physiologie der Nebennieren. III. Die Morphinprobe bei der Nebenniereninsuffizienz. An. Med. Int. 1932, I, 833.

PAtoN NoÉL L. - On the nature of adrenalin glyeosuria. Jour. Physiol. 1903, XIX, 286.

Pico Estrada O. - El metabolismo de los hidratos de carbono en la insuficiencia suprarrenal. Santa Fe Médico, 1926, I, N 4, 227.

Idem. - Estudios de la curva glucémica en el consumo de la glucosa, la formación de glucógeno y el contenido porcentual de azúcar en la sangre arterial $y$ venosa de los perros suprarrenoprivos. Semana Méd., 1926, XXXIII, 1653. Rev. Arg. Biol. 1926, II, 544.

Idem. - L'insuffisance surrénale chez le chien. C. R. Soc. Biol. 1926, $\mathrm{XCV}, 1378$.

Idem. - Sintomas de la insuficiencia suprarrenal en el perro. Rev. Soc. Biol. Arg., 1926, II, N? 4; 348.

Idem. - La sintomatología de la insuficiencia suprarrenal en el perro. Tesis de Profesorado. Cátedra de Fisiología. Escuela Medicina. Buenos Aires, 1928.

Pi SUÑer A. Y PUChe J. - La hiperglucemia por hemorragia y dilución sanguínea. Inst. Fisiol. Universidad Barcelona, 1926-28; 213.

Poll H. - Suprarenals after insulin. Mediz. Klinik, 1925, XXI, 1717.

POLLAK L. - Ueber Glykogenbildung bei Karenzkaninchen unter dem Einfluss von Adrenalin. Arch. Exp. Path. Pharmak. 1909, LXI, 166.

Idem. - Experimentelle Studien über Adrenalindiabetes. (Citado por Biedl). Arch. Exp. Path. Pharmak. 1909, LXI, 166.

Idem. - Kritisches und experimentelle zur Klassifikation der Glykosurien. Arch. Exp. Path. Pharm. 1909, LXI, 376.

Idem. - Untersuchungen bei Morbus Addisonii. Wien. Med. Woch. 1910, N? $15 ; 865$.

PopIELski L. - Ueber der innere Sekretion der Nebenniere. Pflüg. Arch. 1911, CXXXIX. 571.

PORGES O. - Ueber den Einfluss der Nebennierenextirpation bei Hunden auf deren Blutzucker. Wien. Klin. Woch. 1908, XXI, 1798.

Idem. - Hypoglykämie bei Morbus Addisonii sowie bei nebennierenlosen Ḧunden. Zeitschr. Klin. Med. 1909, XLIX, 341.

Idem. - Zur Pathologie des Morbus Addisonii. II. Ueber Glykogenschwund nach doppelzeitiger Nebennierenextirpation bei Hunden. Zeitschr. Klin. Med. 1910, LXX, 243.

Puche Alvarez J. - El sistema nervioso autónomo en la regulación de la glucemia. Rev. Méd. Barcelona. 1927, VIII, N* 45, 255. Instituto Fisiol. Univ. Barcelona, 1926-28; 92. Rev. Med. Barcelona, 1927, VIII, $\mathrm{N}^{9} 46 ; 344$.

PURJESZ B. - Blutzuckergehalt unter normalen und pathologischen Verhältnissen. Wien. Klin. Woch. 1913, 1420.

QUINQUAUD A. - Relations entre la piqúre diabétique et la sécrétion d'adrénaline. Thése. Faculté de Paris. 1915.

RANDLES F. S. - The effect of alpha-lobelin on the blood sugar level of adrenalectomized albino rats. Proc. Amer. Physiol. Soc. 1931. Amer. Jour. Physiol, 1931, XCVII, 553.

REgnier M. T. ET SimonNet M. H. - Sur le pouvoir hypergdycémiant de certains extraits de la substance corticale de la glande surrénale. Bullet. Soc. Chim. Biol. 1932, XIV, 616. 
REID C. - The tolerance of medulliadrenalectomized and adrenaleciomized rabbits to intravenous injections of glycose. Proc. of the Phys. Soc. 1932, XI, 25. Jour. of Phys. 1932, LXXV, N 4.

Idem. - The relation of the adrenals to anaesthetic hyperglycaemia. Ibidem.

Riddle O., Honeywell H. E. AND Fischer W. S. - Suprarenal enlargement under heavy dosage with insulin. Amer. Jour. Physiol. 1924, LXVIII, 461.

RING G. C. AND HAMPEL C. W. - Effects of adrenal medulla and thyroid on the respiratory metabolism of pancreatic diabetes. Amer. Jour. Physiol. 1933, CIV, 298.

RINGer. - Proc. Soc. Exp. Biol. Med., 1908, VII.

ROLLY F. UND OPPERMANN F. - Das Verhalten des Blutzuckers bei gesunden und kranken. Mitt. III. Der Blutzuckergehalt bei Anämie Leber, Darm und anderen Erkrankungen des Menschen. Bioch. Zeitschr. 1913, XLVIII, 471.

Rosenow G. UND JAGUTTIS. - Der Blutzucker bei addisonischer Krankheit und seine Beinflussung durch Adrenalin. Klin. Woch. 1922, I, 358 .

RothSCHILD P. - Atmung von Kaltblütermuskulatur in Gegenwart von Zucker und Hormonen. Bioch. Zeitschr. 1930, CCXVII, 365.

RUicKoLDT. - Ueber den Einfluss der Krampfgifte auf den Blutzucker. Mediz. Gesell. Gottingen. Dez. 4, 1930. In Klin. Woch. 1931, N 13 ; 619.

RYDiN H. - Importance des capsules surrénales au point de vue de l'action de la nicotine sur la pression du sang. C. R. Soc. Biol. 1927, XCVI, 810 .

SACKS J. - The effect of epinephrine on muscle and liver glycogen. Amer. Jour. Physiol. 1931, XCVII, 467.

SAHYUN M. AND LUCK J. M. - Influence of epinephrine and insulin on the distribution of glycogen in rabbits. Jour. Biol. Chem. 1929, LXXXV, 1.

Saito S., KAMEI B. AND TACHI H. - Simultaneous determination of the epinephrine liberation and the sugar content and coagulation time of blood in the non-fastened, non-anaesthetized dogs after haemorrage. Tohoku Jour. Exp. Med, 1928, XI, N² 3, 205.

SAITo S. - On the effect of insulin administration upon epinephrine content of the suprarenal body in rabbits. Tohoku Jour. Exp. Med. 1928, XII, 263. In Berich Ges. Phys. u. E. Pharm., 1929, LI, 110.

Sakaguchi, Hayashi, Katayama. - Ueber der Blutzuckergehalt bei der addisonischen Krankheit und bei adrenalektomierten Tieren. Mitt. a. d. Med. Fak. d. k. Univ. Z. Eokgo, 1919, XXIII, 33. (Citado por Rosenow und Jaguttis).

SAKAgUCHI, KasaI UND KinyosaI. - (Citado por Rosenow und Jaguttis, 1922).

SANSON P. C. AND JacoBS H. R. D. - Some chemical effects from constant intravenous epinephrine injection in dogs. Amer. Jour. Physiol. 1932, XCIX, 433.

SAPEgNo E. m MAestri L. - Sul potere vasocostrittore del suero di sangue dopo iniezione di insulina. Boll. Soc. Ital. Biol. Sper. 1931, VI. 'Fasc. $8,830$.

SATAKE Y. - Chlorammonium-Hyperglykämie beim nebennierenlosen Kaninchen. Tohoku Jour. Exp. 1926, VIII, 26.

SÅто H. AND Онмі F. - Epinephrine secretion and blood sugar content in dogs after chloralose. Tohoku Jour. Exp. Med. 1933, XXI, 433.

Iidem. - Action of morphine on the epinephrine output, blood sugar content and blood pressure in dogs. Tohoku Jour. Exp. Med. 1933, XXI. 411. 
SATO H. INABA T. AND TAKAHASHI A. - The intensity of augmented epinephrine liberation elicitable by asphyxiating the non-anaesthetized dog. Tohoku Jour. Exp. Med. 1932, XIX, 421.

Sato H., OHMi F. AND Kanowoka S. - A note on the effect of insulin in accelerating the epinephrine discharge. Tohoku Jour. Exp. Med. 1933, XXII, 53.

SATO H., WADA M. AND KaIWA T. - Variation of the blood pressure and blood sugar content of the suprarenalectomized dog after haemorrage. Jap. J. Med. Se. Trans. III. Biophysies, 1931, II, 90. In Berichte, Ges. Phys. u. E. Pharm., 1932, LXVIII, 335.

SCHENK P. - Ueber den Winterschlaf und seine Beeinflussung durch die Extracte innersekretorischer Drüsen. Pflüg. Arch. 1922, CXCVII, 66.

Sснісні SchiozaWA. - Zikken Igaku Zasshi, 1926, X, 128. (Citado por Satake, 1926).

SchiRoKAUER H. - Zum Zuckerstoffwechsel bei addisonischer Krankheit. Berlin Klin Woch. 1911, XLVIII, 1505.

SchKaWera G. L. AND Kusnetzow A. I. - Versuche an isolierten Nebenieren. Zeitschr. Ges. Exp. Med. 1923, XXXVIII, 37.

ScHWARZ O. - Ueber Stoffwechselstörungen nach der Extirpation beider Nebennieren. Pflüg. Arch .1910, CXXXIV, 259.

Schtscherbakow S. A., Simnitzky W. S. WischinieWsky A. A. ANd DiMITRIJEW W. R. - Der Einfluss der Schmerzreizes auf die Nebennierensekretion und den Blutzucker. Pflüg. Arch. 1930, CCXXIV, 670.

Schtscherbakow S. A., Simnitzky W. S. Wischniewsky A. A. AND ZATVORNICKAJA Z. - Der Einfluss des Schmerzreizes auf die innere Sekretion der Nebennieren der Bauchspeicheldrüse und auf den Zucker in Blute. Russk fiziol. Z. 1931, 152. In Berichte, ges. Phys. u. E. Pharm. 1932, LXV, 271.

ScotT W. J. M. - Jour. Exper. Med. 1923, XXXVI, 199.

Shimidzu K. - Quantitative Messungen der Adrenalinsekretion nach dem Zuckerstich und nach Vergiftungen. Arch. Exp. Path. Pharmak. 1924, CII, 52.

Simarro J. Y CoRAChan M. - Sobre un caso de diabetes mellitus tratado con resultado favorable por la enervación operatoria de una cápsula suprarrenal. Rev. Méd. Barcelona 1930, N⿳84, 513.

Simpson W. W. AND MACLEOD J. J. R. - The immediate products of post mortem glycogenolysis in mamalian muscle and liver. Jour. Physiol. 1927, .XIV, 255.

Soskin S. - On the calorigenic action of epinephrine. Amer. Jour. Physiol. 1927, LXXXIII, 162.

Idem. - Muscle glycogen as a source of blood sugar. Amer. Jour. Physiol. 1927, LXXXI, N N $^{\circ}$; 382.

Soskin S. PRIEST W. S. AND Schutz W. J. - The influence of epinephrine upon the exchange of sugar between blood and muscle. Proc. Amer. Physiol. Soc. Abril, 28, 1932. Amer. Jour. Physiol. 1932, CI, 1.

Starkenstein E. - Der Mechanismus der Adrenalinwirkung. Zeitschr. Exp. Path. Ther. 1911, X. 78.

Stewart G. N. AND RogofF J. M. - The influence of asphyxia upon the rate of liberation of epinephrine from the adrenals. Jour. Pharmac. Exp. Therap. 1917, X, 49.

Iidem. - The alleged relation of the epinephrine secretion of the adrenals to certain experimental hyperglycaemias. Amer. Jour. Physiol. 1917, XLIV, 543.

Iidem. - The relation of the adrenals to piquire hyperglycaemia and to the glycogen content of the liver. Amer. Jour. Physiol. 1918, LXVI, 90. 
Iidem. - The action of drugs on the output of epinephrine from the adrenals. II. Concentrated salt solutions (sodium carbonate) injected into the circulation. Jour. Pharm. Exp. Therap. 1919, XIII, 167.

Iidem. - The action of certain drugs on the output of epinephrine from the adrenals. III. Nicotine. Jour. Pharm. Exp. Therap. 1919, XIII, 183.

Iidem. - The action of certain drugs on the output of epinephrine from the adrenais. VI. Atropine; Pilocarpine. Jour. Pharm. Exp. Therap. 1920, XVI, 71. Jour. Physiol. 1919, XIII, 513.

Iidem. - Further observations on the relation of the adrenals to certain experimental hyperglycaemias (ether and asphyxia). Amer. Jour. Physiol, 1920, LI, 366.

Iidem. - The supposed relation of the adrenals to reflex volume changes in the denervated limb. Proc. Soc. Exp. Biol. Med. 1922, XX, 36.

Iidem. - The adrenals and pancreatic diabetes. Amer. Jour. Physiol. 1923, $\mathrm{LXV}, 319$.

Iidem. - The action of insulin on adrenalectomized rabbits. Amer. Jour. Physiol. 1923, LXV, 342.

Iidem. - Studies on adrenal insufficiency in dogs. II. Blood studies in control animals not subjected to treatment. Amer. Jour. Physiol. 1926, LXXVIII, 711.

Stroomann. - Ueber adrenalinvermehrung in menschlichen Blut nach Nikotin. 37 Kongress der Deutschen Gesellschatt für innere Medizin in Wiesbaden, April, 23, 1925 (in Klin. Woch. 1925, N*24, 1186).

SUGAWARA T. - Effect of nicotine upon the rate of epinephrine output from the suprarenal glands. Tohoku Jour. Exp. Med. 1925, VI, 430.

SUNDBERG C. G. - Sur l'action de l'insuline après l'extirpation des capsules surrénales. C. R. Soc. Biol. 1923, LXXXIX, 807.

Idem. - Studien über die Blutzuckerregulation bei epinephrektomierten Tieren. Svenka läkaresllskapets handl, 1925, LI, 61. Stokolm, Isaac Marcus, Edit., 1925. Beritche ges. Phys. Exp. Pharm. 1925, XXXIII; 161.

SWINGLE W. W. - Studies on the functional significance of the suprarevial cortex. 1 . Blood changes following bilateral epinephrectomy in cats. Amer. Jour. Physiol. 1927, LXXIX, 666.

Swingle W. W. AND PFIFfner J. J. - The preparation of adrenal cortical hormone. Endocrinology, 1931, XV, 335.

Iidem. - Studies on the adrenal cortex. IV. Further observations on the preparation and chemical proprieties of the cortical hormone. Amer. Jour. Physiol, 1931, XCVIII, 144.

TACHI H. - Influence of haemorrage upon the epinephrine (Folin) content of the suprarrenals of the rabbits. Tohoku Jour. Exp. Med. 1928, $\mathrm{X}, 409$.

Idem. - Ueber die Aderlasshyperglykämie beim Hunde. Tohoku Jour. Exp. Med. $1928, \mathrm{XI}, \mathrm{N}^{\circ} 1$ y $2 ; 14$.

Idem. - Beiträge zum Mechanismus der Aderlasshyperglykämie (versuch an Kaninchen). Tohoku Jour. Exp. Med. 1928, X, N 1 y 2; 95.

Idem. - Aderlasshyperglykämie bei sebennierenlosen Kaninchen. Tohoku Jour. Exp. Med. 1928, X, N: 4; 307.

TACHI H. und HiRAyama S. - Aetherhyperglykämie beim nebennierenlosen Kaninchen. - Tohoku Jour. Exp. Med. 1926, VIII, 41.

Iidem. - Urethanhyperglykämie beim nebennierenlosen Kaninchen. Tohoku Jour. Exp. Med. 1928, X, 191.

TACHI H. AND SAITo S. - Significance of the augmented epinephrine * secretion after haemorrage in dogs upon simultaneous occurrence of hyperglycaemia. Tohoku Jour. Exp. Med. 1928, XI, 218-32. (In Phys. Abs. 1929, XIV, No 5 ; 306).

Iidem. - Is the hyperglycaemia provoking capacity of asphyxial blood due to epinephrine? Tohoku Jour. Exp. Med. 1928, X, No 5, 426. 
TADA H. - The effect of Trichlor-tertiary butyl alcohol (Cloretone) upon the blood sugar content in normal bilaterally splanchnicotomized and billaterally suprarenalectomized rabbits. Tohoku Jour. Exp. Med. 1931, XVII, 489.

Idem. - On the hypoglycaemic action of insulin upon doubly suprarenalectomized rabbits. Tohoku Jour. Exp. 1931, XVII, 588, (in Berich. ges. Phys. u. E. Pharm. 1931, LXIII, 309).

Idem. - Effect of morphine upon the blood sugar content of rabbis deprived of either splanchnic nerves or suprarenals. Tohoku Jour. Exp. Med. 1932, XIX, 405.

Idem. - A note on the effect of guanidine hydrochloride and synthaline upon the blood sugar content of bilaterally suprarenalectomized or splachnicotomized rabbits. Tohoku Jour. Exp. Med. 1932, XIX, N 5 y $6 ; 584$.

Idem. - On the role of the augmented epinephrine secretion in dogs after guanidine upon the fluctuation of the blood sugar concentration simultaneously ocurring. Tohoku Jour. Exp. Med. 1932, XX. № 1 у $2 ; 1$.

Idem. - On the action of pilocarpine and physostigmine upon the blood sugar concentration in rabbits. normal, spalanchnicotomized, and suprarenalectomized. Tohoku Jour. Exp. Med. 1933, XX, 275.

TAINTEP M. L. - Prevention of the edema of paraphenylenediamine by drugs acting on the adrenals. Jour. Pharm. Exp. Therap. 1926, XXVII, 201.

TAKATS G. - Chirurgische Massnahmen zur Hebung der Zuckertoleranz. Klin Woch. 1933, N $\mathrm{N}^{\circ} 16 ; 623$.

TANRET M. G. - Sur l'action hyperglycémiante du sulfate d'hordenine. Bull. Soc. Chim. Biol. 1933, XV, 11.

TARGoWla R. - L'épreuve de la glycémie morphinique dans l'insuffisance surrénale. Presse Méd. 1930, Nº64; 1077.

TAtum A. L. - Picrotoxin Hyperglycaemia. Jour. Pharmac. Exp. Therap. $1922, \mathrm{XX}, 385$.

TAtum A. L. AND CutTing R. A. - The action of quinine in sugar mobilization with its bearing on the question of glycogenolysis. Jour. Pharmac. Exp. Therap. 1922, XX, 393.

THATCHER H. S. - Effects of insulin on the weight of the rabbit's suprarenal glands. Jour. Exp. Med. 1926, XLIII, 357.

Tolstor E., Loebel S., Levine S. and Richardson H. B. - Production of lactic acid in diabetes following administration of insulin. Proc. Soc. Exp. Biol. Med. 1924, XXI, 449.

Tournade A. ET ChABrol M. - Double mécanisme glyco et adrénalinosécrétoire de l'hyperglycémie par excitation splanchnique. Dissociation expérimentale. C. R. Soc. Biol. 1922, LXXXVI, 315.

Iidem. - Sur l'adrénalino-sécrétion que déclenche l'injection intraveineuse de nicotine. Part de l'hyperadrénalinémie dans l'apnée nicotinique C. R. Soc. Biol. 1926, XCIV, 1002.

Tournde A., Chabrol M. et Malmejac J. - Sur le mécanisme de la syncope nicotino-chloroformique. C. R. Soc. Biol. 1926, XCIV, 1005.

TOURNADE A. ET MALMEJAC J. - Hyperglycémie par injection intraveineuse de chlorhydrate d'hordénine. C. R. Soc. Biol. 1931, CVII, 165.

Trendelenburg P. - Ueber den Anteil der Adrenalinsekretion an der Zuckerstichwirkung. Pflüg. Arch. 1923, CCI, 39.

Idem. - Die Hormone. Julius Springer, Editor, Berlín, 1932.

Trendelenburg P. UND FleischHaUer K. - Einfluss des Zuckerstichs auf die Adrenalinsekretion. Zeitschr. ges. exp. Med. 1913, I, 369.

TSCHEBOKSAROFF M. - Ueber sekretorische Nerven der Nebennieren. Pflüg. Arch. 1910, CXXXVII, 59. 
TscheboksarofF M. UND MaLkin Z. J. - Zur Frage des Einflusses von Insulin auf die Adrenalinsekretion der Nebennieren. Zeitschr. ges. exp. Med. 1925, XLVII, 580.

Turcatti E. S. - Suprarrenales y diabetes panereática. R. Soc. Arg. Biol. 1929, X, 173.

Idem. - Surrénales et diabéte pancréatique. C. R. Soc. Biol. 1929, CII, 466.

Underhill F. P. AND Closson O. E. - Adrenalin Glycosuria and the influence of adrenalin upon nitrogenous metabolism. Amer. Jour. Physiol. 1906, XVII, 42.

VIALE G. - Surrenali e diabete. Lavori Inst. Fisiol. Genova, 1930-31.

Viale G., Combes T., Bruno A., Lira L. Y Turcatti T. - Nota preliminar acerca de la función de la cápsula suprarrenal. R. Soc. Arg. Biol. 1926, II, No 6; 528. R. Med. Rosario, 1926, XVI, 416.

Viale G. Y NAPOLEONI L. - Le mécanisme de l'hyperglycémie par la pilocarpine. C. R. Soc. Biol, 1928, XCIX, 2006.

Iidem. - El mecanismo de la hiperglucemia pilocarpínica. R. Soc. Arg. Biol. 1928, IV, 748 .

Viale G., Neuschlosz S. M. Y Turcatti E. - Sobre los hidratos de carbono en los músculos de los perros suprarrenoprivos. Rev. Méd. del Rosario, 1927, XVII, 24.

VIDAL J. - Influence de la surrénalectomie partielle ou totale sur les effets de la piqúre diabétique du bulbe. C. R. Soc. Biol. 1933, CXII, 762. Journal Physiol. Pathol Générale. 1933, XXXI, 348.

Idem. - Influence exercée par diverses substances anesthétiques sur la glycémie avant et aprés la piqúre du bulbe. C. R. Soc. Biol. 1933, CXII, 760 .

VeLICH A. - Beitrag zum experimental Studium von Nebennieren Glykosurie. Virch. Arch. 1906, CLXXXIV, 345.

WADI W. - Ueber Hyperglykämie bei Morbus Addisonii. Klin Woch. $1928, \mathrm{~N}^{2} 44 ; 2107$.

WATANABE M. - The blood sugar level and the epinephrine output from the suprarenal gland of the dog in diphteric intoxication. Tohoku Jour. Exp. Med. 1928, X, 29.

Idem. - Simultaneous determination of the blood sugar content and the epinephrine output from the suprarenal gland in the non-anaesthetized non fastened dog during peptone poisoning. Tohoku Jour. Exp. Med. 1927, IX, $\mathrm{N}^{\circ} 5 ; 412$.

Wertheimer A. - Pankreashormon und Zuckerverwentung. Med. Klin. $1924, \mathrm{XX}, 632$.

WERTHEIMER E. ET BATTEz G. - Sur la glycosurie par piqúre du quatriéme ventricule. Arch. Intern. Physiol. 1910, IX, 140.

Iidem. - Ablation des capsules surrénales et piqúre du quatriéme ventricule chez le chat et chez le chien. C. R. Soc. Biol. 1914, LXXVI, 617.

Iidem. - Sur les nerfs glycosécréteurs. Arch. Intern. Physiol. 1910, IX, 363.

WIEChMANN E. - Ueber die Glykosepermeabilität der peripheren Gewebe beim Adrenalindiabetes. Deutsch. Arch. Klin. Med. 1927, CLIV, 296.

WILDER R. M. AND BoоTHBY W. M. - Preliminary report on the effect of insulin on the rate of heat production and its significance in regard to the calorigenic action of adrenalin. Medical Clinies N. Amer. Phyladelphia, 1923, VII, 53.

Wilenko G. G. - Ueber den Einfluss des Adrenalins auf den respiratorischen Quotienten und die Wirkungsweise des Adrenalins. Biochem. Zeitschr. 1912, XLII. 44.

WoLOWNIK B. - Experimentelle Untersuchungen über das Adrenalin. Virchows Arch. 1905, CLXXX, 225.

WYMANN L. C. AND WALKER B. S. - Studies an suprarenal insufficiency. IV. The blood sugar in suprarenalectomized rats. Amer. Jour. Physiol. 1929, LXXXIX, N² 1; 215. 
Yen T. I., Aomura T. AND INABA T. - Epinephrine liberation during insulin Hypoglycaemia. Tohoku Jour. Exp. Méd. 1933, XXI, 542.

YEN T. I. AND KAIWA T. - Influence of piquire in the production of adrenal discharge, the sugar content of blood and the change in blood pressure. Jap. J. Med. Sc. III. Biophysics. II. N² 2, X, 1931. In Jour. Phys. Path. Gen. 1932, XXX, N 4; 971.

YEN T. I., KAIWA T. AND WADA M. - Influence of the piquire of $\mathrm{Cl}$. Bernard upon the epinephrine discharge, the blood sugar content and the blood pressure. Tohoku Jour. Exp. Med. 1931, XVII, 345.

Youmans J. B. AND Tremble W. H. - Effect of ergotamine on the blood sugar and epinephrine hyperglycaemia in trained unanaesthetized dogs. Jour. Pharm. Exp. Therap. 1930, XXXVIII, 121.

ZECKWER I. T. AND NADLER I, E. - The nature of the hyperglycaemia associated with anaphylactic shock in the dog. Jour. Exp. Med. 1929, XLIX, 481.

Zimmermann F. - Beiträge zur Altivierung des Adrenalins durch Thyroxin. Biochem. Zeitschr. 1929, CCVI, 369.

Zuelzer G. - Zur Frage des Nebennierendiabetes. Berlín. Klin. Woch. $1901, \mathrm{~N}^{\circ} 48 ; 1209$.

Idem. - Experimentelle Untersuchungen über den Diabetes. Berl. Klin. Woch. 1907, 475.

Zuelzer G., DOHRN M. UND MARXeR A. - Neuere Untersuchungen über den experimentellen Diabetes. Deutsche Med. Woch. 1908, XXXIV, 1380.

ZWEMER R. L., SMITH J. M. AND SHIRLEY II. - The adrenal cortex and blood sugar. Anatom. Record 1930, XLV, N? 3; 250.

ZUNZ E. ET LA BARRE J. - Róles des capsules surrénales dans l'hyperglycémie produite par le décamethylénediguanidine. C. R. Soc. Biol. 1930, CIII, N $N^{\circ} 11 ; 929$.

Iidem. - Action de la thyroxine sur la glycémie. C. R. Soc. Biol. 1931, CVIII, 225. 


\section{INDICE ALFABETICO DE AUTORES}

Abderhalden E., 48 .

Abe Y., 116.

Adler L., 47, 48.

Agadschanianz K., 40 . Agazzotti A., 84, 113.

Ahlgren G., 48 .

Allen F. M., 24, 118.

Aomura T., 116.

Artundo A., 19, 20, 30.

Arvay A., 32.

Asher L., 142.

Atwell G. H., 143.

Aub J. C., 47. 97

\section{B}

Babkin B. P., 80 .

Bacq Z. M., 78.

Banerji H., 88.

Bang I., 35 .

Banting F. G., 17, 24, 25, 28, 39, 113, 118, 125.

Baranow W. G., 23.

Barlow O, W., 17.

Battez G., 86.

Benaglia A. E., 41, 43.

Bernstein S., 21.

Bertram F., 87.

Best Ch., 37, 113.

Biasotti A., 22, 77, 113, 128, 129.

Biberfeld J., 86.

Biedl A., 110.

Bierry M. H., 16, 39.

Bieto E., 46.

Billigheimer E., 39.

Binger C. L., 97.

Binswanger F., 82.

Bischoff F., 43, 94.

Blatherwick K., 40.

Bliss S. W., 114, 115, 117.

Blum F., 13, 35, 37, 85 .

Boden, 113.

Bodo R. C., 41, 43.

Böggild D. H., 22, 115, 126.

Bollman J. L., 36.

Boothby W. M., 48, 49, 115.

Borberg N. C., 86 .

Bornstein A., 16, 18, 28, 48, 49, 82, 93.

Bouckaert J. J., 88.

Bowen B. D., 21.

Brandt F., 116.

Bright E. M., 43, 47, 48, 50 .

Britton S. W., 13, 17, 29, 30, 39, 53, 79, $87,114,115,140,142,143,151$.
Brockmeyer J., 20.

Brooks C. M., 81.

Brownell K. A., 143.

Bruno A., 28.

Buchwald K. W., $35,43,44,47,48$.

Bulatao E., 79, 114.

Burn J. M., 50, 113, 114.

Burstein A. J., 98, 99.

Byron C. S., 37.

\section{C}

Calvery H. O., 114, 115.

Campos F. A., 43.

Canneyt J., 48.

Cannon W. B., 43, 79, 80, 97, 114, 115, 117.

Capri A., 117.

Carrasco E., 21.

Carrasco Formiguera R., 39, 46, 131.

Castaldi L., 142.

Catan M. A., 19, 29, 31, 86.

Chabrol M., 76, 81, 85, 98, 99, 115.

Chahovitch X., 90.

Chaikoff I. L., 40.

Chidester F. E., 142.

Ciminata A., 23, 130, 131.

Clark G. A., 94.

Cleghorn R. A., 143.

Cloedt J. de, 48.

Closson O. E., 35.

Collazo J. A., 44

Collens J. L., 37.

Collip B., 113.

Colwell A. R., 45, 50.

Combes T., 28.

Connor C. L., 143.

Corachán M., 131.

Corey E. L., 140, 142, 143.

Cori C. F., $20,30,31,35,40,43,44,46$, $47,48,49$

Cori G. T., $20,30,31,35,40,43,44,46$, 47,49 .

Corkill A. B., 41, 43, 48.

Crivellari C. A., 19.

Crouzon O., 35, 42.

Crowe S. J., 24, 77.

Csepai, 113.

Cutting R. A., 95.

Dale H. H., 97, 98.

Dambrosi R. G., 58, 59, 60 .

Debois G., 59.

Dekker A., 116. 
Del Castillo E. B., 142.

Demant P., 83.

De Meio R. H., 135, 136, 137, 138.

Determann, 113.

Di Benedetto E., 94.

Dimitrijew W., 80.

Dohrn M., 117.

Donati M., 131.

Doyon M., 42.

Duff A. M., 50.

Dworkin S., 114.

\section{F}

Eadie G. S., 40, 43, 113.

Eaton A. G., 142.

Ege R., 46.

Eichholtz F., 98.

Ellis, 17.

Eppinger H., 24, 39.

Erichson K., 49.

Euler von U., 48.

Evans C., 41, 43, 97, 129, 130, 143.

Exner H. V., 82, 86.

\section{F}

Falta W., 24, 37, 39.

Farrar G. E., 50.

Fernández R., 64.

Fernbach J., 116.

Firor W. M., 140.

Fisher N. F., 143.

Fischer W. S., 117.

Fiske C. H., 33.

Fleischhauer K., 85.

Foglia V. G., 64 .

Forman J., 47.

Forschbach, 39.

Foster G. L., 46.

Frank E., 18, 37, 39.

Freund H., 37, 47, 86, 87.

Friedmann, 41, 43.

Fritz F., 94 ,

Frouin A., 118.

Fujii I., 80, 87.

Furth O., 39, 89 .

\section{G}

Gairns S., 17, 24, 25, 28, 39, 118, 125. Gatin-Gruzewska Z., 40.

Gaunt R., 143.

Gautier Cl., 35.

Gautrelet J., 16, 39, 81, 90.

Gayet R., 114, 118.

( Gayet T., 118.

Geiger E., 43, 44.

Geiling E. M. K., 114, 115.

Gellhorn E., 48.

Giménez Díaz C., 20.
Giraud C., 118.

Gley, 98 .

Goldblatt M. W., 41, 50 .

Goldenberg J. D., 98.

Gondard L., 137.

Grafe E., $47,49$.

Grande F., 32, 34.

Greene C. W., 21.

Griffith F. R., 23, 80.

Grollman A., 140, 143.

Grote L. R., 24, 40.

Guillaumie M., 118.

\section{H}

Hallion L., 114.

Hampel C. W., 131.

Harada T., 117.

Hari P., 47.

Harrop G. A., 21, 54.

Hartman F. A., 13, 21, 143.

Hayashi, 24, 89, 91, 92, 96.

Hédon E., 118.

Henríquez V., 46.

Herter C. A., 35, 37, 38.

Heymans C., 88.

Hiks M., 113.

Hill E., 24.

Hiramaya S., 19, 80, 87.

Hoet J. P., 37.

Hofmann E., 116.

Holm K., 16, 18, 28, 49, 82, 93.

Honeywell H. E., 117.

Horneman C., 16, 28.

Houssa P., 116.

Houssay B. A., 13, 17, 19, 21, 22, 26, 29, $31,32,33,34,39,77,85,86,92,94$, $95,98,99,103,106,107,109,110,115$, $117,125,126,128,129,135$.

Howard E., 142, 143.

Hunt A. B., 47, 48.

Iino J., 96.

Imahaski T., 98.

Inaba T., 98, 116.

Inouye T., 93.

Insko W. N., 142.

Isaac S., 18, 37, 39 .

\section{J}

Jacobs H. R. D., 129.

Jacobson C. A., 36.

Jaguttis, 39.

Jarisch A., 85, 89.

Juschtschenko A. J., 49.

\section{K}

Kahn R. H., 27, 29, 39, 86, 116, 117. Kaiwa T., 17, 83, 84, 85, 88, 152. 
Kamei B., 84.

Kamenew M. J., 113.

Kanowoka S., 116.

Kaplan S., 142.

Kareff N., 42.

Kasai, 21.

Katayama, 24, 89, 91, 96.

Katz G., 116.

Kausch W., 36.

Kellaway C. H., 82.

Kinoshita, 91.

Kinyosai, 21.

Kisch B., 18, 29, 34, 39, 80, 84 .

Klein F., 47.

Klein O., 142, 143.

Kleiner I. S., 39.

Koehler A. E., 24.

Kogan V. M., 113.

Kroc R. L., 143.

Kudrjazew N. N., 98.

Kugelmann B., 116.

Kuno J., 94.

Kure K., 110.

Kuriyama S., 19, 29, 31, 42.

Kusnetzow A. J., 98, 110, 117.

\section{L}

La Barre J., 83, 90, 91, 94, 96, 116.

Laidlaw P. P., 97, 98.

Landau E. G., 86.

Lang, 34 .

Langecker H., 117.

Lascano González J. M., 19.

Lengyel L., 32 .

Lépine R., 37, 118.

Levine S., 43.

Lewis J. T., 13, 16, 19, 21, 22, 25, 26, $28,39,92,103,107,114,115,117,118$, $125,126,135,136,137,138$.

Leys D., 43.

Lipschitz W., 48 .

Lira L., 28.

Ljvraga $0 ., 131$.

Lockie L. M., 21.

Lockwood J. E., 143.

Loebel S., 43.

Loeper M., 35, 42.

Loewit M., 35 .

Lohman K., 33.

Long M. L., 43, 94.

Loos H. O., 143.

Luck J. M., 41, 43.

Ludueña F. P., 110.

Lumley Hills F., 20, 80.

Lundin H., 43.

Lundsgaard E., 33, 34 .

Lusk G., 49.

Lyman R. S., 49.
Mac Guigan H., 90, 96.

Mac Kay E. M., 135 .

Mac Kay L. L., 135.

Mackenzie G. M., 30.

Macleod J. J., 81, 113.

Maestri L., 116.

Magath T. B., 35.

Magenta M. A., 16, 21, 88, 113, 114, 115 .

Major S. G., 42.

Malloizel R., 16, 39.

Malkin Z. J., 116.

Malméjac J., 91, 97, 98.

Mann F. C., 36, 42.

Mansera J., 20.

Mantz N. B., 113.

Marañón G., 20, 24, 114.

Marchand F., 86, 87.

Marenzi A. D., 19, 92, 135.

Markowitz J., 37, 42.

Marks H. P., 37, 41, 43, 48, 114.

Martín S. J., 143.

Martínez Díaz J., 92.

Marval L., 19, 138.

Marxer A., 117.

Mauthner H., 24.

Mayer A., 75, 86, 90, 117.

Mazzoceo P., 19, 29, 31, 32, 33, 34, 86, 143.

Mc Cann W. M., 49.

Me Iver M. A., 114, 115, 117.

Me Kinley E. B., 142.

Meltzer S. J., 39.

Meyerhof O., 50.

Miculicich M., 50, 109.

Migliavaeca A., 142.

Mima T., 19.

Mikami S., $82,89,96$.

Milroy T. H., 59.

Molinelli E. A., 22, 39, 76, 77, 83, 85, 86, $92,94,95,97,98,99,106,107,109$,

$110,115,117$.

Molitor H., 37.

Morel A., 42.

Morita S., 96.

Müller C., 143.

Müller E., 49.

Mulinos M. G., 84

Munteanu M., 50.

Munzer T. F., 117.

Nadler I. E., 83.

Naito, 89, 96.

Napoleoni L., 23.

Negrín J., 77, 86.

Neumann J., 21.

Neuschlosz S. M. 34 . 
Ni T. G., 90 .

Nicholls E., 49.

Nice L. B., 80.

Nikolaeff M. P., 95, 117.

Nishi M., 84, 89.

Nitzeseu I. I., 50.

Noble E. C., 113.

Noorden Von C., 35.

Nothman M., 117.

Novelli A., 64, 136, 140, 142.

\section{o}

Ochoa S., $32,34$.

Ohara T., $36,40$.

Ohguri M., 19.

Ohmi F., 81, 88, 91, 92, 114, 115, 116.

Oikawa K., 89, 98.

Okinaka, 110.

Okubo, 20.

Olmsted J. M. P., 83.

Oppermann F., 21.

Orrú A., 93.

\section{$\mathbf{P}$}

Pardo Urdapilleta J. M., 92.

Parkins W., 143.

Paton Noél L., 35, 39.

Pearce K. G., 81.

Pfiffner J. J., 13, 54, 65, 135, 136, 140 , 143.

Pí Suñer A., 84.

Pico Estrada O., 24, 28, 30.

Poll H., 116.

Pollak L., $35,37,39,42,82,87,89,90$, 91, 109.

Ponirowsky N., 113.

Popielski L., 110.

Porges O., 16, 20, 25, 36 .

Priest H. S., 46.

Priestley J. G., 37.

Puche J., 131.

Puche Alvarez J., 83, 93.

Puyal J., 44.

\section{Q}

Quinquaud A., 86.

\section{$\mathbf{R}$}

Randles F. S., 91.

Regnier M. T., 54.

Reid C., 24, 88.

Renault P., 94.

Richards A. N., 35, 37.

Richardson H. B., 43.

Riche J. A., 49.

Riddle O., 117.

Rietti C. T., $129,130$.

Ring G. C., 131.

Ringer, 37, 117.
Ritmann R., 143.

Rogoff J. M., 13, 17, 19, 23, 25, 29, 79, $82,86,87,92,97,98,110,114,115,125$.

Rolly F., 21.

Rosenow G., 39.

Rothschild P., 48.

Rudinger C., 24, 39.

Ruickoldt, 90.

Rydin H., 98.

Sahyun M., 40, 41, 43.

Saito S., 82, 117.

Sakaguchi, 24, 89, 91, 96.

Sacks J., 41, 43.

Sandiford J., 48, 49.

Sanson P. C., 129.

Sapegno E., 116.

Sataké Y., 19, 80, 96.

Sato H., 17, 88, 92, 116.

Schenk P., 47.

Schichi - Schiozawa, 24.

Schirokauer H., 21.

Schkawera C. L., 98, 110.

Schlagenweit E., 37.

Schmidt E., 43.

Schtscherbakow S. A., 80 .

Schutz W. J., 46.

Schwarz O., 29, 30, 39, 90.

Scott W. J. M., 135.

Severin, 39.

Shelling D. H., 37.

Shimidzu K., 97.

Shirley M., 21.

Shohl A. T., 79, 80.

Silvette H., 13, 17, 29, 30, 39, 54, 151.

Simarro J., 131.

Simnitzky W. S., 80 .

Simonnet M. H., 54.

Simpson W. W., 129, 130, 143.

Smith J. M., 21.

Soler A., 21.

Soskin S., 37, 46, 48.

Starkenstein E., 27, 29, 39, 80, 86.

Stewart G. N., 13, 17, 19, 23, 25, 29, 79, $82,86,87,92,95,97,98,110,114,115$, 125.

Stroomann, 98.

Subbarow Y., 33.

Sugawara T., 97.

Sundberg C. G., 19, 24, 96, 97, 98, 114.

Swingle W. W., 13, 17, 53, 65, 135, 136 , $140,143$.

Szakall A. V., 113.

\section{$\mathbf{T}$}

Tachi H., 82, 84, 87.

Tada H., 89, 90, 92, 94, 114.

Tainter M. L., 98. 
Takahashi A., 83.

Takats G., 114.

Tanret M. G., 91.

Targowla R., 92.

Tatum A. L., 93, 95.

Thateher H. S., 117.

Thomas L., 16, 39, 81, 90.

Thompson G. P., 142.

Thorn G. W., 21.

Tolstoi E., 43.

Torino A., 19, 135.

Tournade A., 76, 81, 85, 91, 97, 98, 99, 115.

Tremble W. H., 50.

Trendelenburg P., 35, 47, 116.

Tsai, 41, 43.

Tscherboksaroff M., 110, 116.

Turcatti E. S., 25, 34, 118, 125, 131.

\section{U}

Underhill F. P., 35.

\section{V}

Velich A., 35, 36, 39 .

Viale G., 28, 34, 39, 93, 118.

Vidal J., 86.

\section{W}

Wada M., 17, 85.

Wada Y., 110.

Wadi W., 20.
Wakeman A. S., 38.

Walker B. S., 20.

Walker T. P., 43.

Wankell, 113.

Watanabe M., 83, 97.

Weber J. J., 40.

Weinstein A., 21.

Weiss R., 47, 113.

Wertheimer E., 86.

Wertheimer A., 46.

Wiechmann E., 46, 98.

Wilder R. M., 115.

Wilenko G. G., 44, 50 .

Wilson A. T., 34.

Wischniewsky A. A., 80 .

Wislocki G. B., 24, 77.

Wolownik B., 42.

Wright W. S., 79,80 .

Wymann L. C., 20.

\section{$\mathbf{Y}$}

Yen T. I., 85, 116.

Youmans J. B., 50.

Young, 41, 43.

Z

Zeckwer I. T., 83, 96.

Zimmermann F., 40.

Zuelzer G., 13, 35, 39, 117.

Zunz E., 90, 96.

Zwemer R. L., 21. 


\section{INDICE ALFABETICO DE MATERIAS}

Acido LÁctico del músculo, 32.

- — acción de la adrenalina sobre el, 43.

AdDIson, glucemia en la enfermedad de, 20.

ADRENALINA, Acción hiperglucemiente, 35.

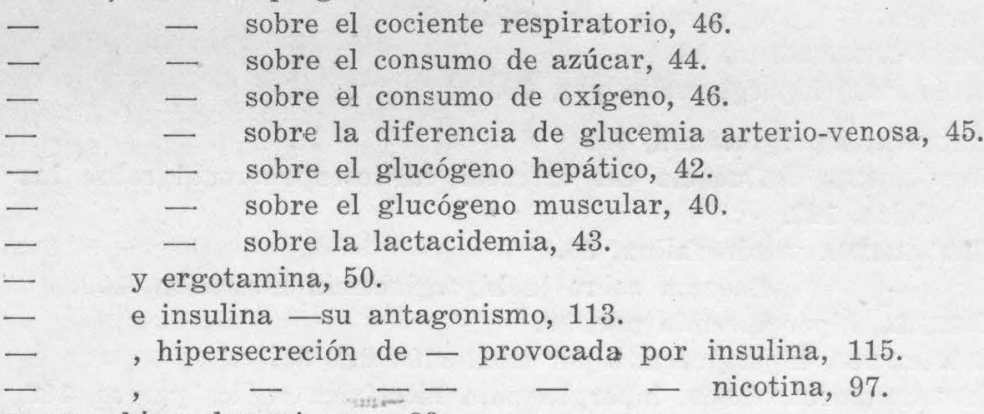

ANAFILAXIA, hiperglucemia por, 83.

ANASTOMOSIS SUPRARRENOYUGULAR (nicotina), 106.

Anestesia, influencia sobre las hiperglucemias, 109.

Anestésicos, hiperglucemia por, 87.

ANTAGONISMO, adrenalina e insulina, 113.

Asfixia, hiperglucemia por, 81 .

Atropina, influencia sobre la hiperglucemia nicotínica, 110.

y excitación del esplácnico, 110.

Betadimetilteluronio, hiperglucemia por, 88.

BETATETRAHIDRONAFTILAMina, hiperglucemia por, 88.

CAFEÍNA, hiperglucemia por, 89.

Cranuro de potasio, hiperglucemia por, 89.

Cloralosa, acción sobre glucemia, 88.

Cloretona, hiperglucemia por, 88.

Cloroformo, hiperglucemia por, 87 .

Cloruro de amonio, hiperglucemia por, 95.

Cociente respiratorio, acción de la adrenalina sobre el, 49.

Consumo de azúcar, acción de la adrenalina sobre el, 44.

Consumo de oxígeno, acción de la adrenalina sobre el, 46.

ConTENCIón, hiperglucemia por, 80.

Desmedulizados, glucemia en los perros, 21.

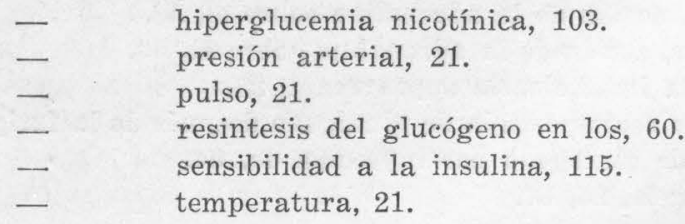


DESNERVACIón SUPRARRENAL y glucemia, 23.

- - - y sensibilidad a la insulina, 114.

DiABETES ANTEROHIPOFISARIA en perros desmedulizados, 128. 131.

Diabetes PANCREÁtica en perros desmedulizados, 125.

en perros con suprarrenales desnervadas, 130 .

en perros suprarrenoprivos, 117.

DIFTÉRICA, hiperglucemia por toxina, 96.

Dimetilteluronio, 88.

DiURetina, hiperglucemia por, 89.

Емотіva, hiperglucemia, 79.

ENDócrinas, influencia del extracto córticosuprarrenal sobre las glándulas, 142.

ERGotamina y adrenalina, 50.

- influencia sobre la hiperglucemiâ nicotínica, 109.

ESERINA, hiperglucemia por, 89.

EsPLACNic0, hiperglucemia por excitación del, 81.

ESPLACNiCOTOMIZADOS, hiperglucemia nicotínica en los perros, 102, 106.

ESTRICNINA, hiperglucemia por, 90 .

ETER, hiperglucemia por, 88.

EXTRACTO CóRticosupraRRENAL, acción sobre las glándulas endócrinas, 142.

$$
\begin{array}{lll}
\text { - } & - & \text { acción sobre los hidratos de carbono, } 53 . \\
\text { - } & - & \text { preparación del, } 140 .
\end{array}
$$

FLoRIdCINA, hiperglucemia por, 90 .

FOSFÁGENo del músculo en la insuficiencia suprarrenal, 34.

Fósforo del músculo en la insuficiencia suprarrenal, 33.

Frío, hiperglucemia por, 87.

GLUCEMIA, acción de la adrenalina sobre la, 35 .

- acción de la adrenalina sobre la diferencia arteriovenosa de la, 45 .

- acción del extracto córticosuprarrenal sobre la, 53.

- en los animales desmedulizados, 21.

- en los animales con suprarrenales desnervadas, 23.

- en la insuficiencia suprarrenal, 15.

GLUCóGENo, acción del extracto córticosuprarrenal sobre el, 55.

- del hígado y músculos en la insuficiencia suprarrenal, 27.

- formación por inyección de azúcares, 30, 64.

- recomposición después de la fatiga, $31,58$.

- hepático, acción de la adrenalina sobre el, 42.

- muscular, acción de la adrenalina sobre el, 40.

GLucosa, acción en la insuficiencia suprarrenal, 25.

- acción sobre recomposición de glucógeno después de la fatiga, 60 .

- formación de glucógeno por inyección de, 64 .

- tolerancia a la, 24, 67 . 
Guanidina, hiperglucemia por, 90 .

Hemorragia, hiperglucemia por, 84 .

HíGAD0, glucógeno del, 27.

- papel en la acción calorigénica de la adrenalina, 48.

- papel en la hiperglucemia adrenalínica, 36.

HIPERGLUCEMIAS y glucosurias provocadas por influencias fisiológicas, 79 . - $\quad$ - $\quad$ - provocadas por diversos agentes fármaco-

HIPOFISARIA, diabetes, 128, 131. dinámicos, 87.

HIPOFISIS, influencia del extracto córticosuprarrenal sobre la, 143.

Histamina, hiperglucemia por, 90.

HoRDENINA, hiperglucemia por, 91.

HORMONA CORTICAL en sangre de la vena suprarrenal, 141.

INHIBICIón operatoria de las hiperglucemias, mecanismo de la, 78, 101, 108.

INSULINA, antagonismo con adrenalina, 113.

- hipersecreción de adrenalina provocada por la, 115.

- sensibilidad a la, 114.

LOBELINA, hiperglucemia, por, 91 .

MoRFina, hiperglucemia por, 91.

- sensibilidad a la, 135.

NaFtillamina, hiperglucemia por, 98.

Nicotina, hiperglucemia por, 97.

OPERACIón, inhibición de las hiperglucemias por la, 78, 108, 101.

PÁnCREAS, papel en hiperglucemia adrenalínica, 38.

Pancreatoprivos, acción del extracto córticosuprarrenal sobre los, 66 .

PARASINOMENINA, hiperglucemia por, 95.

Peptona, hiperglucemia por, 83.

Picadura del iV ventrículo, hiperglucemias por, 85.

Picrotoxina, hiperglucemia por, 93.

PILOCARPINA, hiperglucemia por, 93.

Pirofosfatos del músculo en la insuficiencia suprarrenal, 34.

Pituitrina, hiperglucemia por, 94.

Preparación del extracto córticosuprarrenal, 140.

QUININA, hiperglucemia por, 95 .

ReFLeJA, hiperglucemia, 80.

Sales CONCENTRAdas, hiperglucemia por, 95.

SANDMEYER, acción del extracto córticosuprarrenal sobre diabetes de, 70 . SENSIBILIDAD a la insulina, 114.

Sexuales, influencia del extracto córticosuprarrenal sobre las glándulas, 142.

SINOMENINA, hiperglucemia por, 90 .

Sulfato de sodio y de magnesia, hiperglucemia por, 96 . 
SUPRARRENALeS, papel en la hiperglucemia adrenalínica, 39.

- influencia del extracto córticosuprarrenal sobre las, 142.

TiRóides, influencia del extracto córticosuprarrenal sobre la, 142.

TiRoxina, hiperglucemia por, 96.

Titulación del extracto córticosuprarrenal, 135.

Tolerancia a la glucosa, 24.

- _ - - acción del extracto córticosuprarrenal sobre la, 67 .

TOXINA diftérica, hiperglucemia por, 96.

URETANo, hiperglucemia por, 87.

VACUNAS, hiperglucemia por, 97.

Vomicina, hiperglucemia por, 90. 

